\title{
Nachweis und Aufreinigung von Abscisinsäure- bindenden Proteinen aus dem Cytosol von Spinat- und Arabidopsis-Pflanzen
}

\author{
Dissertation \\ zur Erlangung des Doktorgrades \\ der Mathematisch-Naturwissenschaftlichen Fakultäten \\ der Georg-August-Universität zu Göttingen
}

\author{
vorgelegt von \\ Michaela Strauß \\ aus Stadtoldendorf
}

Göttingen 2002 
D 7

Referent: $\quad$ Priv.-Doz. Dr. D. Heineke

Korreferent: $\quad$ Prof. Dr. H.-W. Heldt

Tag der mündlichen Prüfung: 24.04.2002 


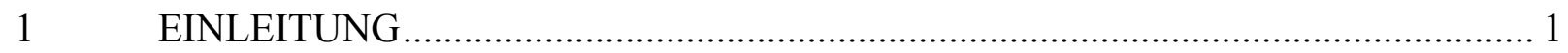

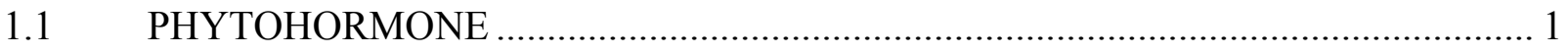

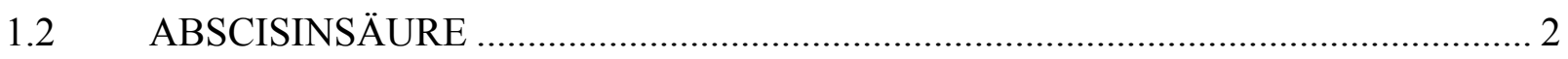

1.2.1 Synthese und Abbau von Abscisinsäure ................................................................ 3

1.3 WIRKUNGSWEISE VON ABSCISINSÄURE ..................................................... 6

1.3.1 Modell zur Abscisinsäue abhängigen Signaltransduktion in Stomata ......................... 6

1.3.2 ABA-Signaltransduktion und Pflanzenwachstum .................................................. 10

1.4 BISHERIGE ARBEITEN ZUM NACHWEIS VON ABA-BINDENDEN

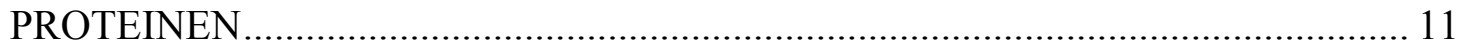

1.4.1 Membrangebundene ABA-Bindeproteine .......................................................... 12

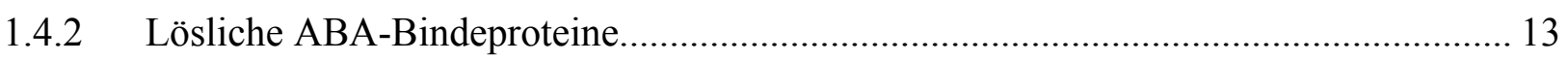

1.5 WEITERE LÖSLICHE PHYTOHORMONBINDENDE PROTEINE ....................... 14

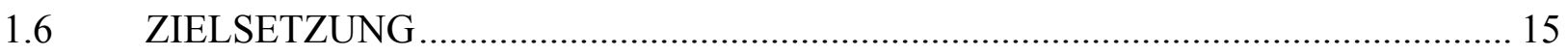

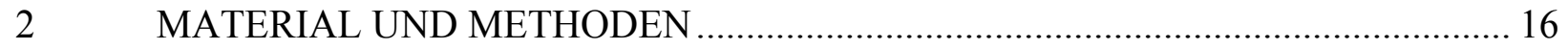

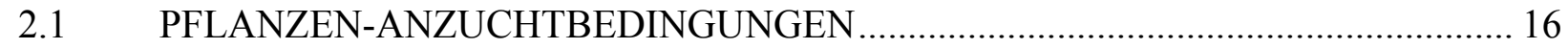

2.2 EXTRAKTION VON CYTOSOLISCHEN PROTEINEN ...................................... 16

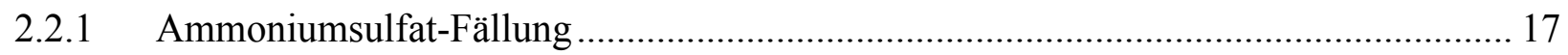

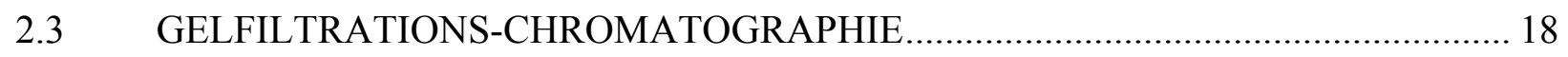

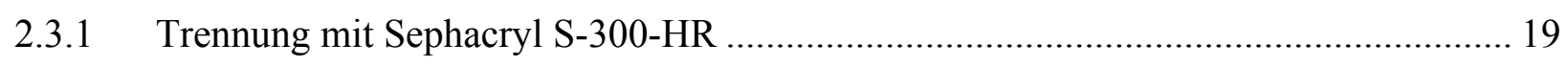

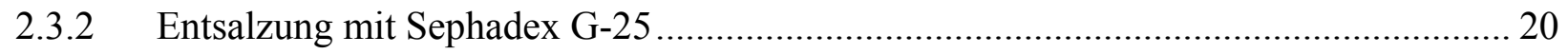

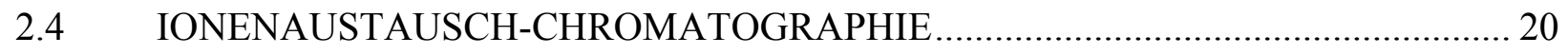

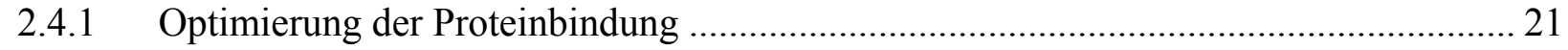

2.4.2 Trennung der Proteine durch Kationenaustausch-Chromatographie ............................ 21

2.5 ABA-AFFINITÄTS-CHROMATOGRAPHIE …................................................... 22

2.5.1 Kopplung von ABA an EAH-Sepharose 4 B ............................................................. 22

2.5.2 Proteinaufreinigung durch ABA-EAH-Sepharose 4 B ............................................ 24

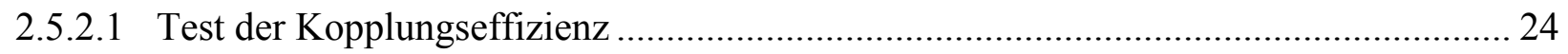

2.5.2.2 Aufreinigung ABA-bindender Proteine ................................................................... 24

2.6 TRYPSINVERDAU ABA-BINDENDER PROTEINE …....................................... 25

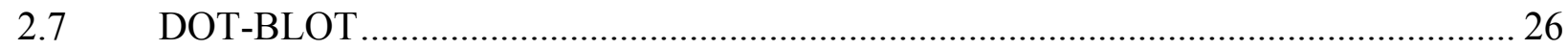

2.7.1 Peroxidase-Nachweis über „Enhanced Chemiluminescence“ (ECL) .......................... 27

2.8 ENTWICKLUNG EINES TESTS ZUM NACHWEIS ABA-BINDENDER

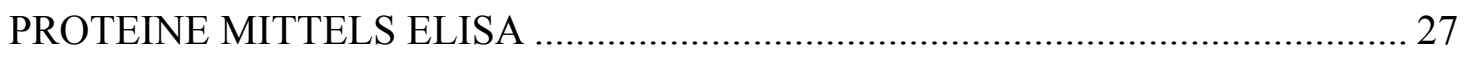

2.8.1 Kopplung von ABA an ein Trägerprotein......................................................... 27 
2.8.1.1 Bestimmung der Kopplung von ABA an BSA durch 3H-ABA ................................. 29

2.8.1.2 Bestimmung der Kopplung von ABA an BSA durch Massenspektrometrie................ 30

2.8.2 Gewinnung eines polyklonalen anti-ABA-BSA-Antikörpers 31

2.8.3 Bestimmung von Testbedingungen zum Nachweis von ABA-bindenden Proteinen durch nicht-kompetitiven ELISA ................................................................... 32

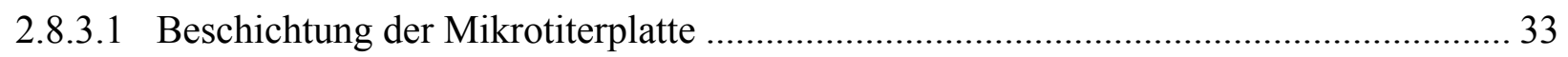

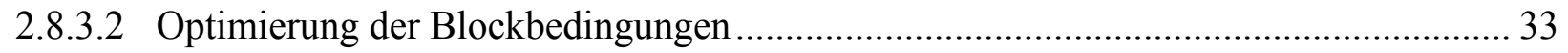

2.8.3.3 Optimierung der Bindung von anti-ABA-BSA-Antikörper an ABA-BSA-Konjugate . 34

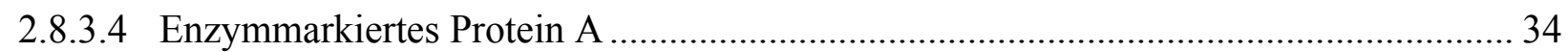

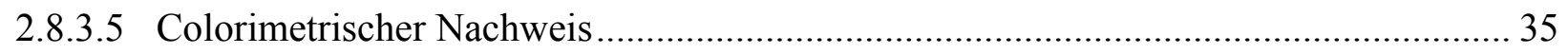

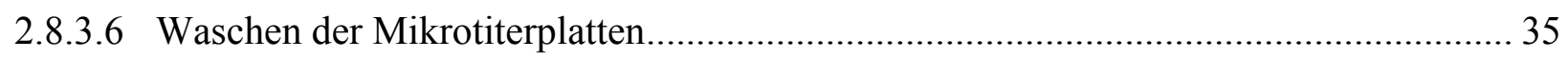

2.8.4 Nicht-kompetitiver ELISA zur Detektion ABA-bindender Proteine........................... 35

2.8.4.1 Testen der ABA-Bindung von RubisCO ..................................................................... 37

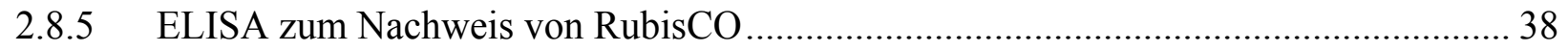

2.9 AUFREINIGUNG DES POLYKLONALEN ANTI-ABA-BSA-ANTIKÖRPERS ..... 38

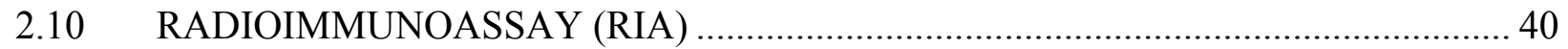

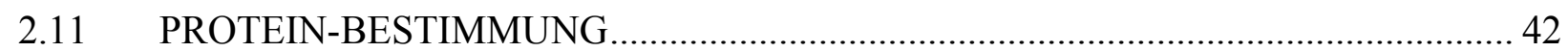

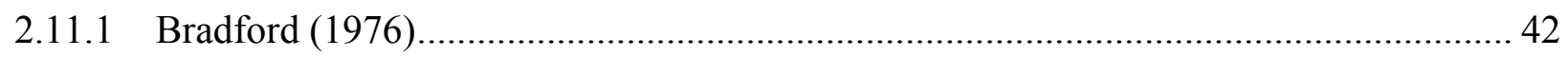

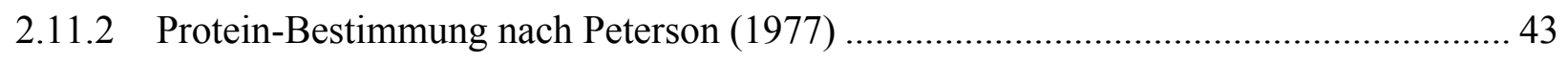

2.12 SDS-POLYACRYLAMID-GELELEKTROPHORESE (SDS-PAGE) ....................... 43

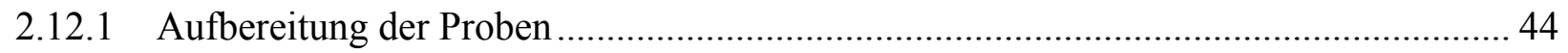

2.12.2 Zusammensetzung der Gele und Durchführung der Elektrophorese ........................... 44

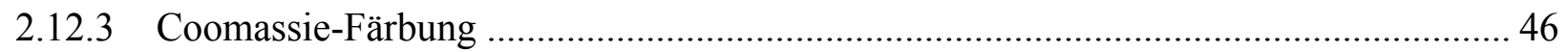

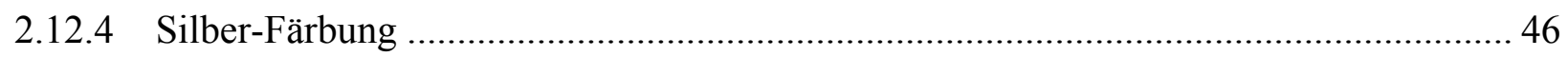

2.13 AUSWERTUNG DER DURCHGEFÜHRTEN EXPERIMENTE ............................. 48

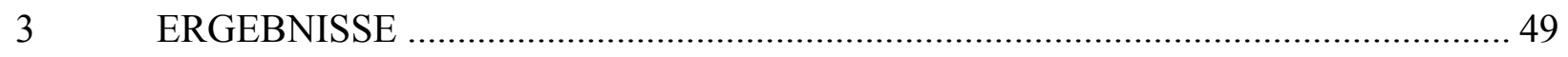

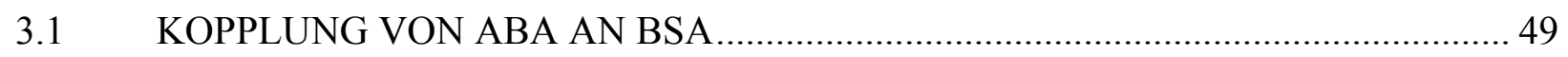

3.2 HERSTELLUNG EINES ANTI-ABA-BSA-ANTIKÖRPERS ................................ 56

3.2.1 Spezifität der anti-ABA-BSA-Antikörper................................................................. 56

3.2.2 Bestimmung der Dissoziationskonstante des anti-ABA-BSA-Antikörpers.................. 60

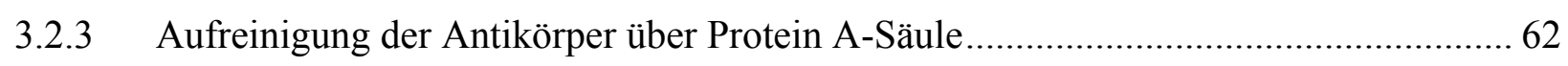

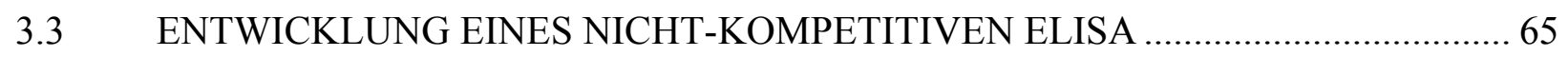

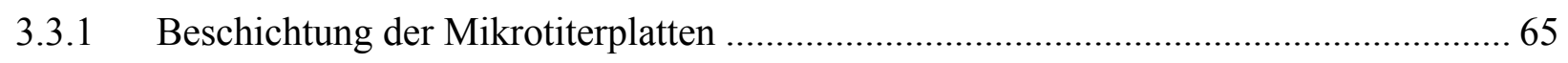

3.3.2 Optimierung der Bedingungen zum Blocken der Mikrotiterplatte .............................. 65 


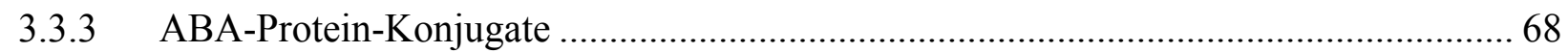

3.3.3.1 Bindung von ABA-Protein-Konjugaten an ABA-BSA-Antikörper ............................ 68

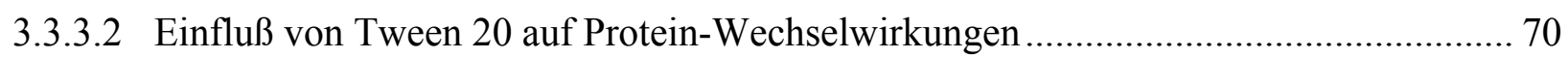

3.3.4 Optimierung der Bindung des anti-ABA-BSA-Antikörpers ...................................... 70

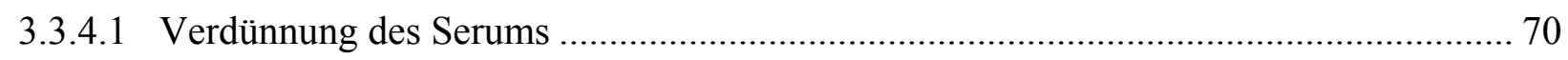

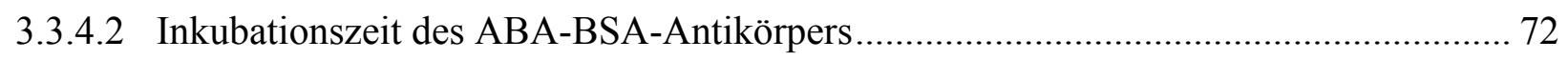

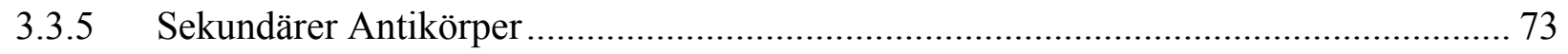

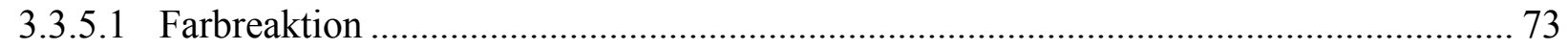

KOPPLUNG VON ABA AN EAH-SEPHAROSE ................................................. 74

3.5 AUFREINIGUNG VON CYTOSOLISCHEN PROTEINEN .................................... 77

3.6 AUFREINIGUNG ABA-BINDENDER PROTEINE AUS SPINATPFLANZEN....... 77

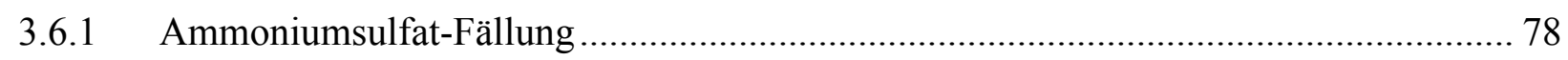

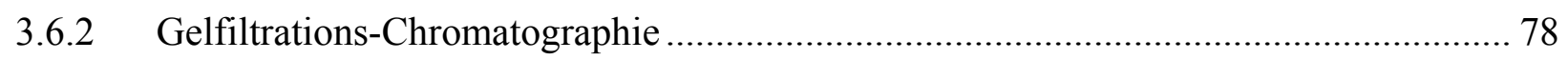

3.6.3 ELISA zur Detektion ABA-bindender Proteine aus Spinatextrakten .......................... 80

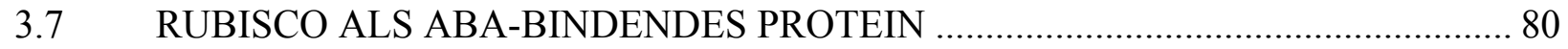

3.8 NACHWEIS UND AUFREINIGUNG ABA-BINDENDER PROTEINE AUS ARABIDOPSIS-EXTRAKTEN MITTELS GELFILTRATIONS-

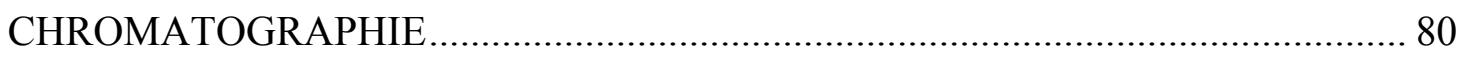

3.9 ABA-BINDENDE PROTEINE AUS ARABIDOPSIS-EXTRAKTEN ...................... 80

3.9.1 Optimierung der Bedingungen zur Bindung von ABA-bindenden Proteinen an

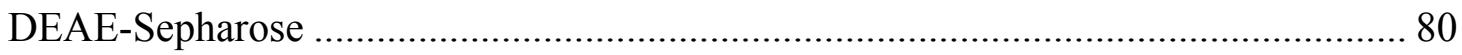

3.9.2 Aufreinigung ABA-bindender Proteine aus Arabidopsis-Extrakten mittels DEAE-

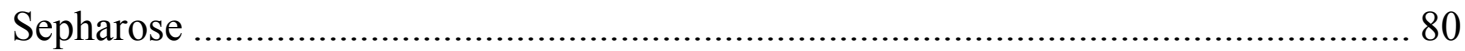

3.9.2.1 SDS-PAGE von Fraktionen des DEAE-Säulenlaufs ............................................... 80

3.9.2.2 Nachweis von RubisCO in Fraktionen des DEAE-Säulenlaufs................................... 80

3.9.3 Aufreinigung ABA-bindender Proteine mittels ABA-Affinitätssäule.......................... 80

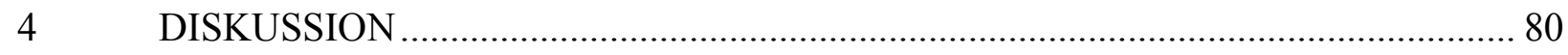

4.1 DIREKTE HINWEISE AUF CYTOSOLISCHE ABA-BINDENDE PROTEINE....... 80

4.2 ELISA ZUM NACHWEIS ABA-BINDENDER PROTEINE ................................... 80

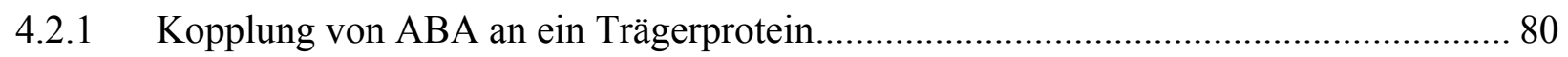

4.2.2 Herstellung und Charakterisierung von Anti-ABA-Antikörper................................. 80

4.2.3 Etablierung eines nicht-kompetitiven ELISA ........................................................ 80

4.2.3.1 Beschichtungs-Bedingungen der Mikrotiterplatten ............................................... 80

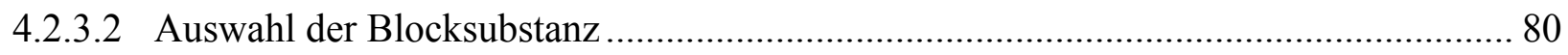


4.2.3.3 Untersuchungen zur Verwendbarkeit von ABA-Protein-Konjugaten im ELISA ......... 80

4.2.3.4 Untersuchungen zur Anwendung von Anti-ABA-BSA-Antikörper im ELISA ............ 80

4.3 GEWINNUNG CYTOSOLISCHER PROTEINE .................................................. 80

4.4 AUFREINIGUNG VON ABA-BINDENDEN PROTEINEN AUS

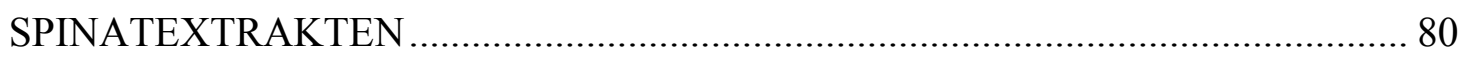

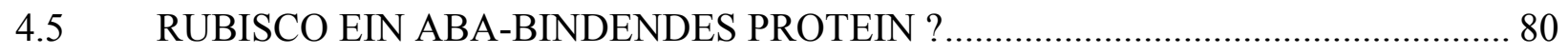

4.6 ABA-BINDENDE PROTEINE AUS ARABIDOPSIS-EXTRAKTEN...................... 80

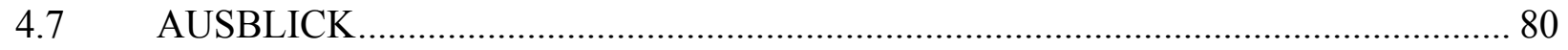

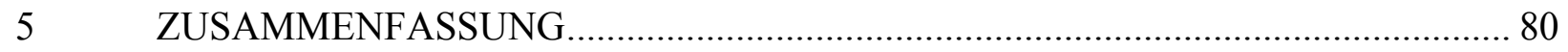

6 VERZEICHNIS DER ABBILDUNGEN UND TABELLEN …................................. 80

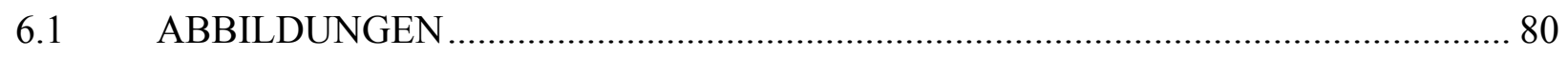

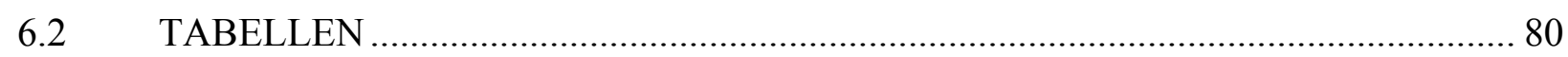

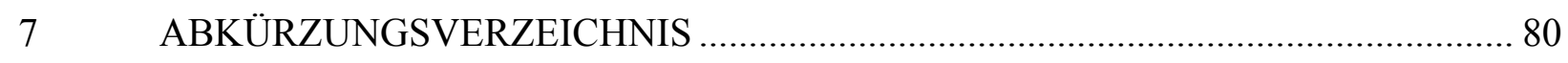

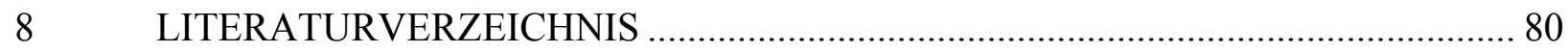




\section{Einleitung}

Vielzellige höhere Organismen bestehen aus einer großen Zahl spezialisierter Organe und Gewebe, welche zu einer funktionellen Einheit zusammengefügt sind. Zur Koordination der verschiedenen Teile des Organismus werden chemische Botenstoffe eingesetzt, für die der Begriff Hormon geprägt wurde. Im Tier werden Hormone in der Regel in speziellen Drüsen gebildet und über die Blutbahn im Organismus verteilt. Sie erreichen auf diese Weise das Zielgewebe und lösen dort Steuerungsprozesse aus. Dieses klassische, ursprünglich für tierische Organismen entwickelte Hormonkonzept wurde nach der Entdeckung des „Wuchsstoffes“ (Auxin) der Haferkoleoptile auch auf Botenstoffe der vielzelligen Pflanzen ausgeweitet. Diese als Phytohormone bezeichneten Substanzen unterscheiden sich jedoch chemisch grundlegend von den tierischen Hormonen. Zwischen pflanzlichen und tierischen Hormonen besteht keine Homologie, sondern es handelt sich vielmehr um funktionell analoge Substanzen.

\subsection{Phytohormone}

Phytohormone sind niedermolekulare Substanzen, die in der Pflanze gebildet werden und Einfluß auf Wachstum, Differenzierung und Entwicklung der verschiedenen Pflanzenorgane nehmen und deren Anpassung an unterschiedliche Umweltbedingungen steuern. Während der Metabolismus die Energie zum Wachstum der Pflanzen bereitstellt, regulieren Hormone dessen Geschwindigkeit. Die Beeinflussung physiologischer Prozesse erfolgt bereits durch äußerst niedrige Phytohormon-Konzentrationen. Phytohormone besitzen häufig die Funktion von autochtonen Signalüberträgern innerhalb eines Gewebes oder Organs. Bildungsort und Wirkort sind in diesem Fall nicht verschieden. Sie können aber auch als transportierbare Botenstoffe den Informationsaustausch zwischen Organen und Geweben vermitteln. Pflanzen besitzen keine morphologisch abgegrenzten Hormondrüsen. Vielmehr können Phytohormone in vielen Bereichen des Organismus gebildet werden. Das Hormon wird oftmals erst unter dem Einfluß eines Reizes gebildet und setzt regulatorische Prozesse in Gang, welche zu einer Reaktion auf den Umweltreiz führen. Alternativ zur Hormonsynthese kann auch eine Empfindlichkeitsänderung gegenüber dem Hormon der regulierte Schritt der Signalkette sein. 
In den meisten Fällen hängen Wachstums- und Entwicklungsprozesse nicht von nur einem Phytohormon ab, sondern sind das Ergebnis einer hormonellen Balance.

Eine Übersicht über die wichtigsten Phytohormonklassen und deren charakteristische Wirkung ist in Tabelle 1 zusammengefaßt.

Tabelle 1: Übersicht über die wichtigsten Klassen pflanzlicher Phytohormone und deren charakteristische Wirkung.

Phytohormonklasse Wirkung

Auxin

Gibberelline

Cytokinin

Abscisinsäure

Ethylen und Jasmonsäure
Stimulation des Streckungswachstums von Blättern und Stengeln

Förderung des Streckungswachtums und der Zellteilung

Stimulation der Zellteilung

Regulation des Wasserhaushalts

Förderung der Seneszenz

\subsection{Abscisinsäure}

Abscisinsäure (ABA) (Abbildung 1) wurde in den 50-iger Jahren entdeckt. Der Name dieser Verbindung geht auf die zuerst beobachtete Wirkung, den Blattabwurf (Abscission), zurück. Der systematische Name für ABA lautet 3-Methyl-5-(1'-hydroxy-4'-oxo-2',6',6'-trimethy-2'cyclohexen-1' -yl)-cis-2,4-pentadiensäure (Addicott et al. 1968).<smiles>CC1=CC(=O)CC(C)(C)[C@@]1(O)/C=C/C(C)=C\C(=O)O</smiles>

Abbildung 1: Struktur von S(+)-Abscisinsäure. 
Als Phytohormon ist ABA an der Regulation vieler physiologischer und entwicklungsabhängiger Prozesse während des gesamten Lebenszyklus einer Pflanze beteiligt. So reguliert ABA in der frühen Entwicklungsphase die Samenreifung und die embryonale Dormanz. Während der Ontogenese steuert ABA die Adapation der vegetativen Gewebe bei umweltbedingten Veränderungen, wie beispielsweise Trocken-, Kälte- und Salzstress, unter anderem durch Wachstumsreduzierung. Ein weiterer wichtiger durch ABA beeinflußter Prozeß ist die Veränderung der Öffnungsweite der Stomata als Anpassung auf Schwankungen im Wasserhaushalt.

\subsubsection{Synthese und Abbau von Abscisinsäure}

Die Konzentration eines Hormons im Gewebe hängt von seiner Syntheserate, seinem Metabolismus sowie von seinem Import und Export ab. Innerhalb eines Gewebes können somit ABA-Konzentrationen großen Änderungen unterliegen. Bei Wasserstreß kann der ABA-Gehalt innerhalb von 4 bis 8 Stunden auf das 10- bis 50-fache ansteigen (Daniel et al. 1995). Nach Beobachtungen von Pierce (1995) beruht die ABA-Akkumulation bei Wasserstreß auf einer Neusynthese. Der Ort der ABA-Synthese ist noch nicht sicher bestimmt. Die Wurzeln sind in der Lage, ABA zu synthetisieren, welche bei Bedarf über das Xylem in den Sproß transportiert wird (Jarvis und Davies 1997). Allerdings kann ABA auch im Mesophyll hergestellt werden (Davies und Zhang 1991).

Für die Biosynthese von ABA werden zwei Stoffwechselwege vorgeschlagen: einen direkten und einen indirekten. (1) Der direkte Syntheseweg ausgehend von Isopentenylpyrophosphat (IPP) $\left(\mathrm{C}_{5}\right)$ führt über Farnesylpyrophosphat $\left(\mathrm{C}_{15}\right)$ direkt zu ABA. Es gibt Hinweise darauf, daß dieser Stoffwechselweg in Pilzen abläuft (Zeevaart 1999). (2) Beim indirekten Syntheseweg, welcher in grünen Pflanzengeweben stattfindet, entsteht ABA durch die Spaltung von Carotinoiden $\left(\mathrm{C}_{40}\right)$. Erst kürzlich wurde bekannt, daß Carotinoide im Chloroplasten aus Isopentenylpyrophosphat (IPP) über den sogenannten 1-Deoxy-DXylulose-5-Phosphat (DOXP)-Stoffwechselweg synthetisiert werden (Lichtenthaler et al. 1997). Die Arbeitsgruppe konnte zeigen, daß neben dem seit 40 Jahren bekannten cytosolischen Acetat/Mevalonat-Weg auch der DOXP-Stoffwechselweg existiert. Isopentenylpyrophosphat wird dabei aus Glyceraldehydphosphat und Pyruvat innerhalb der Plastide synthetisiert. Aus dem DOXP-Stoffwechsel gehen unter anderem Phytole, Carotinoide und Plastochinone-9 hervor (Lichtenthaler 1999). Aus dem im Cytosol 
stattfindenden Acetat/Mevalonat-Stoffwechsel werden Sesquiterpene, Sterole und Polyterpene synthetisiert (Lichtenthaler 1999).

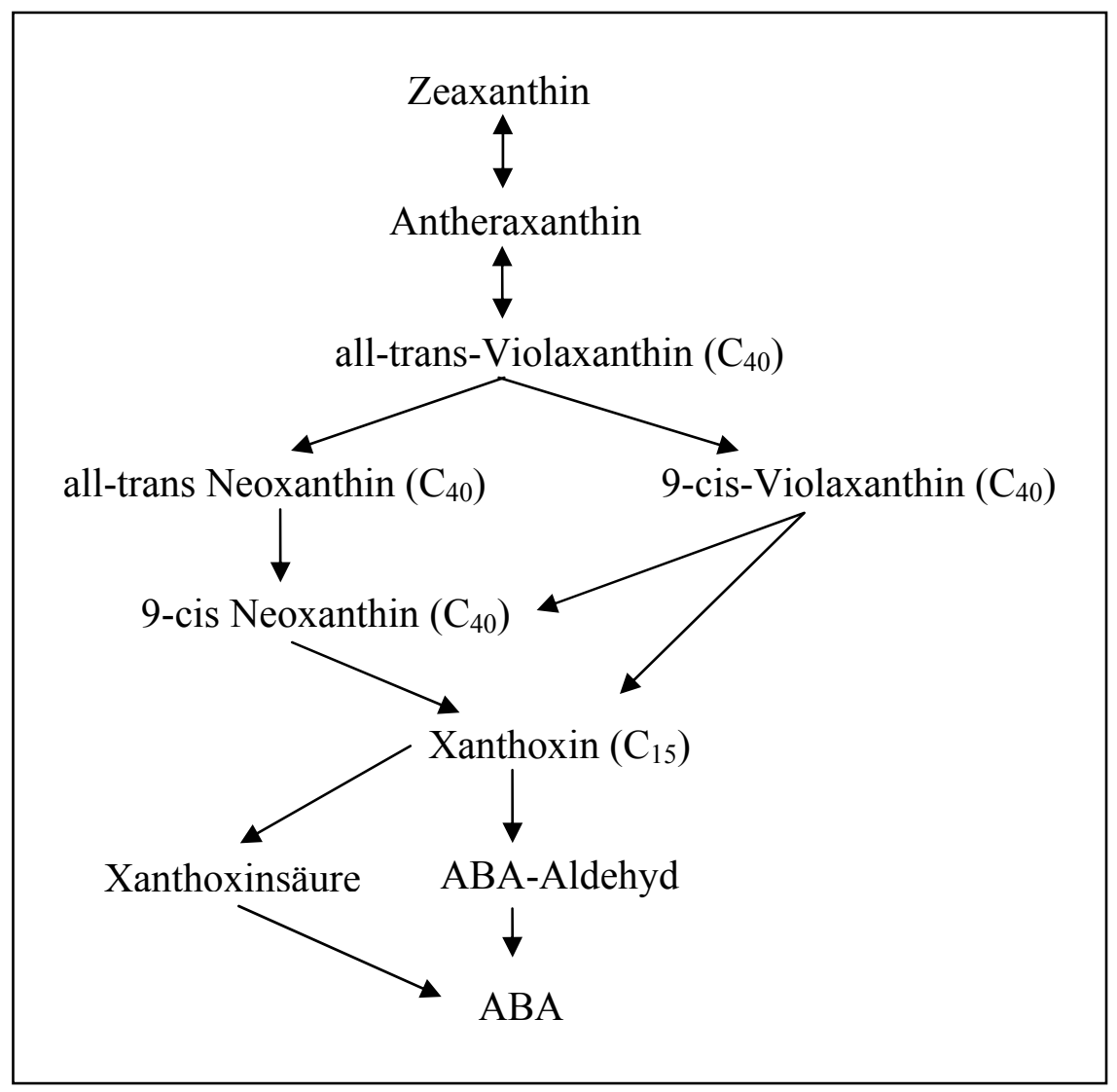

Abbildung 2: Mögliche Synthesewege von Abscisinsäure (nach Taylor et al. 2000, Seo und Koshiba 2002).

$\longleftrightarrow=$ Xanthophyll-Zyklus

Der von Carotinoiden ausgehende ABA-Syntheseweg, so wie er in Abbildung 2 dargestellt ist, wurde in erster Linie durch Untersuchungen von ABA-defizienten Mutanten aufgeklärt. Ausgangssubstanz für die ABA-Synthese ist das Carotinoid Violaxanthin (Taylor und Burdon 1972), das zusammen mit Zeaxanthin und Antheraxanthin den Xanthophyll-Zyklus bildet. Bislang nicht geklärt werden konnte allerdings, welche Isomerisierungen der $\mathrm{C}_{40}$-Moleküle ausgehend von all-trans-Violaxanthin auf dem Weg zur ABA-Synthese stattfinden: drei verschiedene Isomerisierungen könnten zur Bildung der letzten $\mathrm{C}_{40}$-Vorstufen (9-cisViolaxanthin und 9-cis-Neoxanthin) ablaufen. Aus all-trans-Violaxanthin könnte einerseits direkt 9-cis Violaxanthin gebildet werden oder andererseits über all-trans-Neoxanthin das 9cis-Neoxanthin hervorgehen. Weiterhin könnte 9-cis-Neoxanthin durch Isomerisierung aus 9cis-Violaxanthin entstehen. Sowohl 9-cis-Violaxanthin als auch 9-cis-Neoxanthin können 
durch die 9-cis-Epoxycarotinoid Dioxygenase (Qin und Zeevaart 1999) oxidativ in Xanthoxin $\left(C_{15}\right)$ gespalten werden. Vermutlich ist dies der geschwindigkeitsbestimmende Schritt der ABA-Synthese (Taylor et al. 2000). Xanthoxin wird zunächst zu ABA-Aldehyd umgewandelt. Der letzte Schritt der ABA-Biosynthese erfordert die Oxidation von ABAAldehyd zu ABA, dies erfolgt durch eine ABA-Aldehyd-Oxidase (Seo et al. 2000). In vivo kommt dabei ausschließlich das Enantiomer $(+)-\mathrm{S}-\mathrm{ABA}$ vor, und nur dieses ist auch biologisch wirksam (Zeevaart und Creelman 1988).

In vielen Experimenten konnte gezeigt werden, daß die Synthese von Abscisinsäure durch Oxidation von ABA-Aldehyd erfolgt (Seo et al. 2000). Neuere Untersuchungen zeigten jedoch, daß ABA auch durch die Oxidation von Xanthoxin zu Xanthoxinsäure synthetisiert werden kann (Seo und Koshiba 2002).

Über den Abbau von ABA liegen nur wenige Untersuchungen vor. Bekannt ist, daß ABA durch Umsetzung zu Phaseinsäure, Nigellinsäure, Dihydrophaseinsäure, ABA-ß-DGlukopyranosylester und weiteren ABA- und Phaseinsäureestern inaktiviert wird. ABAGlukoseester sind wahrscheinlich ausschließlich vakuolär lokalisiert und werden dort vermutlich irreversibel kompartimentiert (Lehmann und Glund 1986).

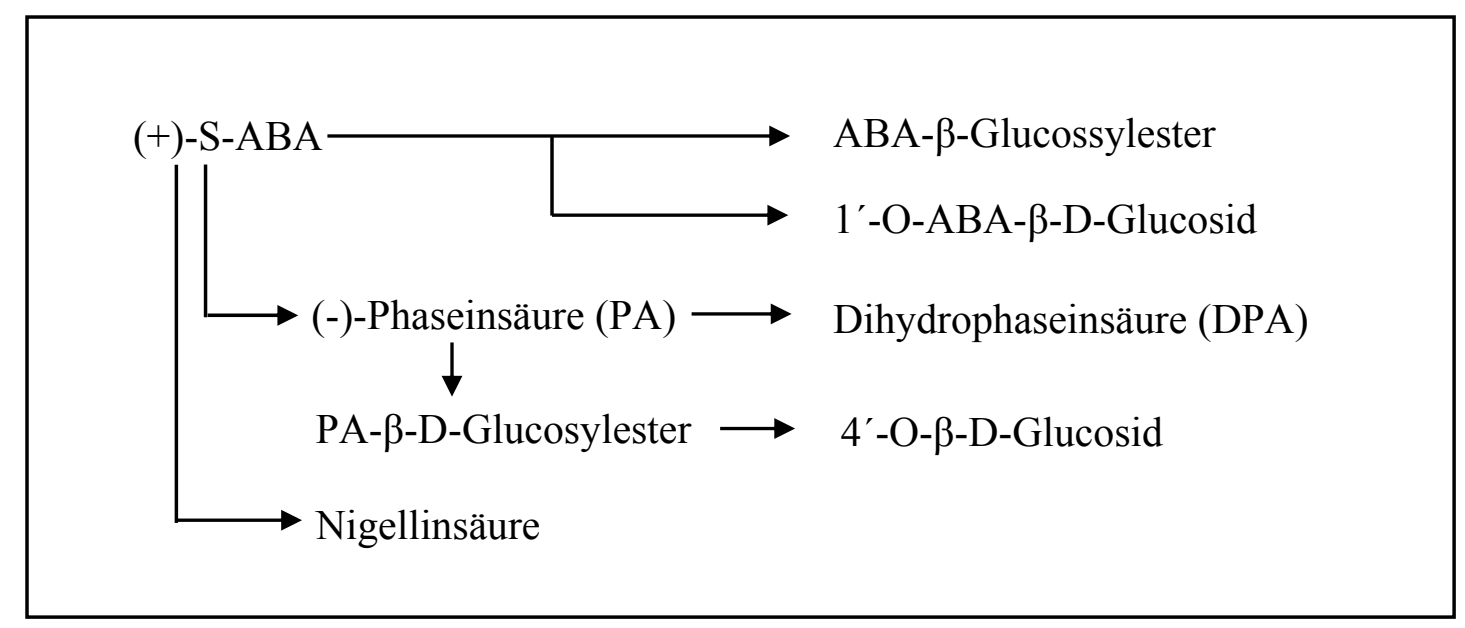

Abbildung 3: Abbauprodukte zur Inaktivierung von (+)-S-ABA. 


\subsection{Wirkungsweise von Abscisinsäure}

Es gibt viele Hinweise darauf, daß die Wirkung von ABA durch ABA-abhängige Signaltransduktionsketten vermittelt wird. Daran beteiligt zu sein scheinen unter anderem extrazelluläre und/oder intrazelluläre ABA-Rezeptoren, Membranproteine sowie Ionenkanäle, Glykoproteine, Second-Messenger wie Inositol-1,4,5-Triphosphat (Berridge 1993, Lee et al. 1996), zyklische ADP-Ribose (Wu et al. 1997), Calcium (Webb et al. 2001), Protein-Kinasen (Shen et al. 2001) und Protein-Phosphatasen (Xiong et al. 2001, Gosti et al. 1999). Die am besten untersuchten ABA-Signaltransduktionskaskaden sind die zum Schließen der Stomata (Hetherington und Quatrano, 1991; MacRobbie 1998) und zur Differenzierung des Pflanzenwachstums (Himmelbach et al. 1998). In beiden Systemen sind einige Gene, die an der ABA-Signaltransduktion beteiligt sind, identifiziert und kloniert worden (Leung und Giraudat 1998).

\subsubsection{Modell zur Abscisinsäure abhängigen Signaltransduktion in Stomata}

Stomata sind Öffnungen in der Blattoberfläche der Pflanzen, die durch zwei Schließzellen gebildet werden. Sie ermöglichen den Gasaustausch der Pflanzen mit ihrer Umgebung. Ein Öffnen der Stomata zur Aufnahme von $\mathrm{CO}_{2}$ ist immer mit einer Abgabe von Wasserdampf verbunden, was unter Umständen zu einem gefährlichen Wasserverlust für die Pflanzen führen kann. Bei einer Verschlechterung der Wasserverfügbarkeit reguliert ABA die Öffnungsweite der Stomata und bewirkt so eine Verringerung von Wasserverlusten durch Drosselung des Transpirationsstroms. Das Schließen der Stomata resultiert aus einer Verringerung des Turgor der Schließzellen, was durch den Ausstrom von Kaliumkationen und Anionen über das Plasmalemma sowie den Tonoplasten erreicht wird. ABA ist wahrscheinlich an der Regulation der Ionenströme beteiligt.

Die Signalkette für die Regulation der Stomataöffnung, einschließlich der ABASignalerkennung und Signalweiterleitung, ist jedoch in entscheidenden Abschnitten noch nicht aufgeklärt. In der Literatur finden sich Hinweise sowohl auf eine extrazelluläre als auch intrazelluläre Erkennung des ABA-Signals: ABA könnte an einen Rezeptor an der Außenseite der Plasmamembran oder an ein Transportprotein binden. Auf das Vorhandensein von ABABindeproteinen an der Außenseite des Plasmalemmas weisen Experimente von Hornberg und Weiler (1984) an Schließzellen-Protoplasten von Vicia faba hin. Darüber hinaus gibt es 
indirekte Hinweise auf einen intrazellulären ABA-Rezeptor. In Commelina konnte von Anderson et al. (1994) durch Mikroinjektion von ABA in das Cytosol von Schließzellen ein Schließen der Stomata beobachtet werden. Ein ABA-Rezeptor konnte bislang nicht identifiziert werden. Die Wirkungsweise von ABA auf das Schließen der Stomata konnte in verschiedenen Experimenten in Teilen aufgeklärt werden. Abbildung 4 gibt eine Übersicht zur ABA-indizierten Signaltransduktionskette in Schließzellen.

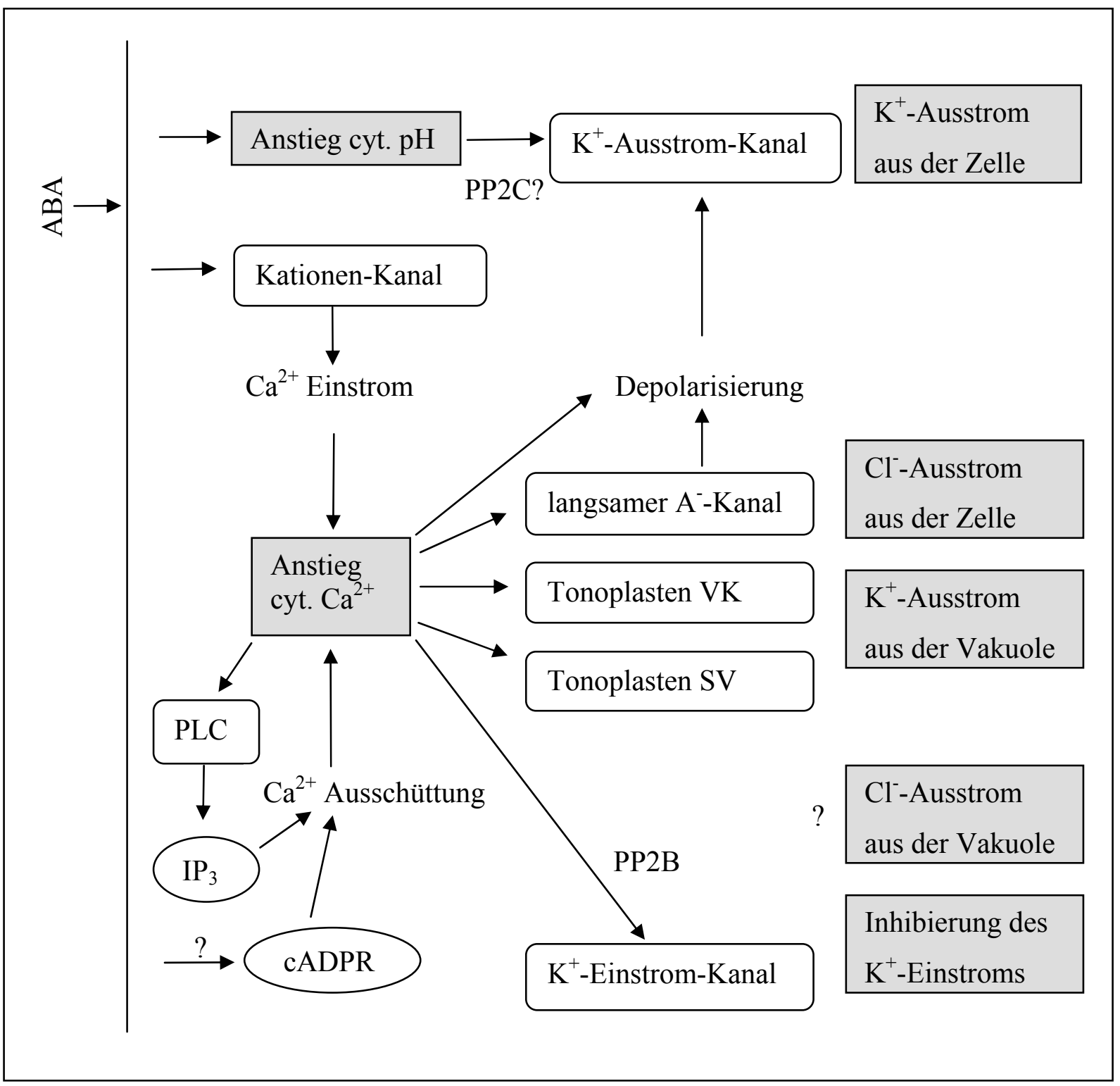

Abbildung 4: Modell zur ABA-induzierten Signaltransduktionskette in Schließzellen zum Schließen der Stomata (modifiziert nach MacRobbie 1998).

$\mathrm{A}^{-}=$Anionen, $\mathrm{cADPR}=$ zyklische ADP-Ribose, $\mathrm{IP}_{3}=$ Inositol-1,4,5-Triphosphat, $\mathrm{PLC}=$ Phospholipase C, PP2B = Protein-Phosphatase 2B, PP2C = Protein-Phosphatase 2C, SV = langsamer $\mathrm{K}^{+}$-Kanal, $\mathrm{VK}=$ spannungsunabhängiger $\mathrm{K}^{+}$-Kanal. 
Das Schließen der Stomata erfolgt über eine Verringerung des Tugors, verursacht durch den Austransport von Kaliumionen und Anionen aus den Schließzellen, sowie durch Blockierung des Einstroms von Kaliumionen in die Schließzellen. Nach Inkubation mit ABA können zwei grundlegende Veränderungen in den Zellen beobachtet werden: Einerseits steigt der cytosolische pH-Wert um 0,2 pH-Einheiten an (Irving et al. 1992), andererseits erhöht sich die cytosolische $\mathrm{Ca}^{2+}$-Konzentration (McAinsh et al. 1990, 1992).

Blatt und Armstrong (1993) zeigten, daß eine Aktivierung des $\mathrm{K}^{+}$-Ausstrom-Kanals durch Regulation des cytosolischen $\mathrm{pH}$-Werts ohne Veränderung des Membranpotentials und unabhängig von der Calcium-Konzentration erfolgt. Sie fanden heraus, daß nach Zugabe von ABA zu Schließzellen von Vicia faba der cytosolische $\mathrm{pH}$-Wert und die Leitfähigkeit des $\mathrm{K}^{+}$Ausstrom-Kanals anstiegen. Eine Ansäuerung des Cytosols durch Butyrate inhibiert den $\mathrm{K}^{+}$Ausstrom-Kanal, verhindert die ABA-induzierte Alkalisierung des Cytosols und blockiert die ABA-induzierte Aktivierung des $\mathrm{K}^{+}$-Ausstrom-Kanals. Weiterhin gibt es Hinweise darauf, daß an der Aktivierung des $\mathrm{K}^{+}$-Ausstrom-Kanals eine $\mathrm{pH}$-abhängige Protein-Phosphatase $2 \mathrm{C}$ (PP2C) beteiligt sein könnte (MacRobbie 1998).

MacRobbie beschrieb 1998, daß eine Erhöhung an Calcium im Cytosol von über 500 nM ein Schließen der Stomata bewirkt. Der Anstieg von cytosolischem $\mathrm{Ca}^{2+}$ verhindert einerseits einen Kaliumeinstrom über $\mathrm{K}^{+}$-Einstromkänale und somit ein Öffnen der Stomata (Schroeder und Hagiwara 1989). Es gibt Hinweise darauf, daß $\mathrm{K}^{+}$-Einstromkänale über eine $\mathrm{Ca}^{2+}$ aktivierte Protein-Phosphatase 2B (PP2B) reguliert werden (MacRobbie 1998). Andererseits bewirkt ein Anstieg an cytosolischem Calcium den Austransport von Kalium aus der Zelle: dies geschieht durch die Aktivierung von zwei Ionen-Kanälen des Tonoplasten, welche einen Kaliumstrom aus der Vakuole ins Cytosol leisten: der eine, ein spannungsunabhängiger $\mathrm{K}^{+}-$ Kanal (VK-Kanal), wird bereits bei geringen $\mathrm{Ca}^{2+}-$ Konzentrationen aktiviert (Ward und Schroeder 1994), der andere, ein langsamer $\mathrm{K}^{+}$-Kanal (SV-Kanal) kann durch Depolarisation der Tonoplastenmembran aktiviert werden (Hedrich und Neher 1987). Ein weiterer Ausstrom von Kalium aus dem Cytosol erfolgt über $\mathrm{K}^{+}$-Ausstromkanäle, welche sich bei Depolarisierung der Plasmamembran öffnen. Der ABA-induzierte Anstieg an cytosolischem Calcium und die Aktivierung eines Anionen-Kanals in der Plasmamembran, ein langsamer (S-Typ) Kanal, welcher einen Austransport von Chloridionen aus der Zelle gewährleistet und durch Calcium sowie Phosphorylierung aktiviert wird (Schmidt et al. 1995), könnten diese nötige Depolarisation zum Öffnen des $\mathrm{K}^{+}$-Ausstromkanals bewirken. Obwohl ein Anionen- 
Kanal in der Tonoplastenmembran noch nicht identifiziert werden konnte, zeigten Experimente mit Isotopen einen ABA-induzierten Transport von $\mathrm{Cl}^{-}$-Ionen aus der Vakuole ins Cytosol (MacRobbie 1998).

Bislang konnte nicht genau aufgeklärt werden, woher das $\mathrm{Ca}^{2+}$ für die $\mathrm{Ca}^{2+}$-abhängige Signaltransduktion stammt. Diskutiert wird, daß Calcium über die Plasmamembran durch einen unspezifischen Kationen- oder einen spezifischen $\mathrm{Ca}^{2+}$-Kanal ins Cytosol transportiert werden könnte (Schroeder und Hagiwara 1990) oder aus internen Speichern ausgeschüttet wird. Einige Membranen wie beispielsweise der Tonoplast oder das Endoplasmatische Retikulum (ER) verfügen über Inositol-1,4,5-Triphosphat $\left(\mathrm{IP}_{3}\right)$ sensitive Calcium-Kanäle (Alexandre et al. 1990; Muir und Sanders 1997). Einen direkten Hinweise darauf, daß ABA eine $\mathrm{Ca}^{+}$-Auschüttung bewirkt, wurde von MacRobbie (1998) aufgezeigt. Der Autor beschrieb, daß die Phospholipase C (PLC), welche an der Synthese von $\mathrm{IP}_{3}$ beteiligt ist, durch ABA und Calcium aktiviert werden kann. Weiterhin konnten Allen et al. (1995) zeigen, daß neben $\mathrm{IP}_{3}$-aktivierbaren Calcium-Kanälen auch durch cyklische ADP-Ribose (cADPR) induzierbare Calcium-Kanäle in der gleichen Tonoplastenmembran existieren.

Allen et al. (1994) zeigten im Gegensatz dazu, daß ein Schließen der Stomata auch ohne meßbaren Anstieg der $\mathrm{Ca}^{2+}$-Konzentration möglich ist. Dies deutet darauf hin, daß zwei Möglichkeiten einer Signalweiterleitung existieren: eine $\mathrm{Ca}^{2+}$-abhängige und eine $\mathrm{Ca}^{2+}$ unabhängige Signaltransduktion.

Erst kürzlich konnten Neill et al. (2002) zeigen, daß zum Schließen der Stomata die ABAinduzierte Synthese von Stickstoffmonoxid (NO) notwendig ist. Die Autoren fanden einen deutlichen Anstieg an NO innerhalb der Schließzellen von Pisum sativum nach Induktion mit $10 \mu \mathrm{M}$ ABA. In Gegenwart von $\mathrm{N}^{\mathrm{G}}$-Nitro-L-Arg-Methylester, einem Inhibitor der NOSynthese, führte die Inkubation von Epidermis-Streifen von Pisum sativum mit ABA nicht zum Schließen der Stomata Neill et al. (2002). Bei Zugabe von Stickstoffmonoxid konnte ein Schließen der Stomata ausgelöst werden. Diese Ergebnisse deuten darauf hin, daß Stickstoffmonoxid eine weitere Komponente der ABA-Signaltransduktionskette zum Schließen der Stomata darstellt. 


\subsubsection{ABA-Signaltransduktion und Pflanzenwachstum}

Bereits seit über 30 Jahren ist bekannt, daß ABA die DNA-Replikation in Wurzelspitzen inhibiert (van Overbeek et al. 1967). Seitdem wurde die inhibierende Wirkung von ABA auf das Wachstum von Sproß und Wurzel eingehend untersucht (van Volkenburgh und Davies 1983). Abscisinsäure tritt dabei als Antagonist von Auxin auf. ABA scheint das Wachstum über eine Regulierung der Zellelongation, möglicherweise über Tugorveränderungen und über einen Stop der Zellteilung zu beeinflussen (Himmelbach et al. 1998).

Der Mechanismus der ABA-vermittelten Regulation des Pflanzenwachstums und der Zellteilung ist allerdings noch weitestgehend ungeklärt. Die wichtigsten identifizierten Einflußfaktoren bei der ABA-Signalweiterleitung sind die Protein-Phosphatasen ABI1 und ABI2, cADP-Ribose, der pH-Wert und die cytosolische Calcium-Konzentration. Meskiene et al. (1998) fanden bei Arabidopsis, daß die Protein-Phosphatasen einer Aktivierung der MAPK-Kaskade entgegenwirken. MAPKs sind mitogenaktivierte Protein-Kinasen, welche bei Prozessen der Zellteilung mitwirken.

Himmelbach et al. (1998) stellten ein Modell vor, bei dem die Signaltransduktionskette für die Kontrolle des Pflanzenwachstums auf zwei Wegen erfolgt (siehe Abbildung 5). Nach diesem Modell reagiert ABA mit einem ABA-Rezeptor, wodurch einerseits der cytosolische pH-Wert ansteigt und andererseits cADP-Ribose gebildet wird. Die Synthese von cADPRibose bewirkt einen Anstieg der cytosolischen Calcium-Konzentration (Allen et al. 1995). Dieser Anstieg verstärkt das Signal und beeinflußt über noch unbekannte Schritte die Zellelongation und Zellteilung. Der Anstieg des pH-Werts aktiviert die Protein-Phosphatasen ABI1 und ABI2, welche einen potentiell vorhandenen aktiven Repressor $\left(R_{a}\right)$ der ABASignalkette dephosphorylieren und damit inaktivieren $\left(R_{\text {in }}\right)$, so daß eine ABASignalweiterleitung möglich wird.

Mit Hilfe von ABA-insensitiven Arabidopsis Mutanten konnten acht Gene identifiziert werden, welche das Pflanzenwachstum mittels ABA kontrollieren (GCA1 - GCA2). Die Arabidopsis Mutanten gca1 und gca2 ähneln in vielen Effekten, wie z. B. Stomata-Regulation und Samendormanz, den Arabidopsis Mutanten abi1 und abi2. Die Gene GCA3 - GCA8 dagegen kontrollieren scheinbar das ABA-regulierte Wachstum (Himmelbach et al. 1998). 


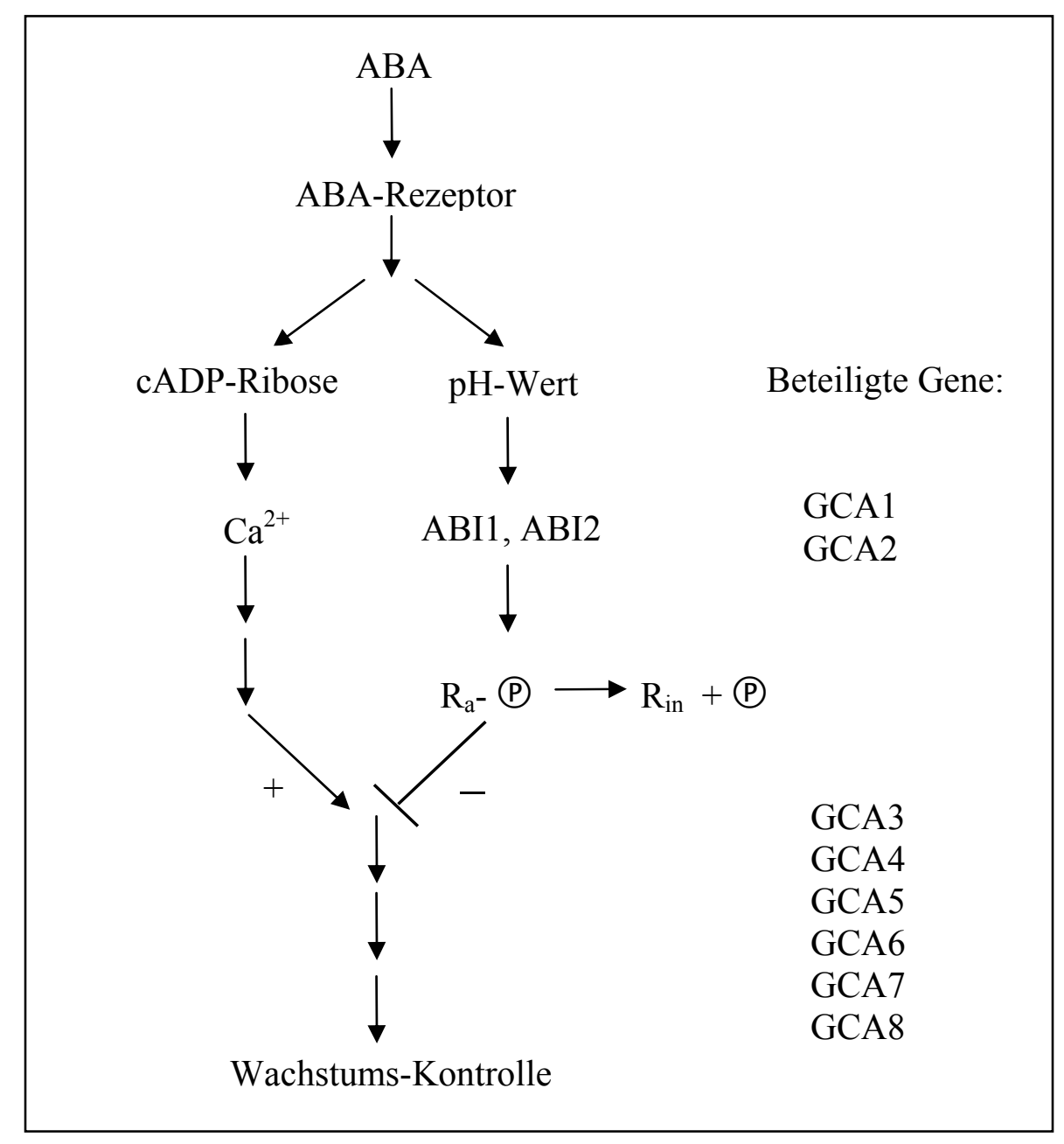

Abbildung 5: Schematische Darstellung eines zweiteiligen Modells der ABASignaltransduktionskette auf die Kontrolle des Pflanzenwachstums (Himmelbach et al. 1998). ABI1,2 = Protein Phosphatasen ABI1 und ABI2, cADPR = zyklische ADP-Ribose, GCA1 bis $8=$ ABA sensitive Gene aus Arabidopsis, welche Einfluß auf das Pflanzenwachstum nehmen, $\mathrm{R}_{\mathrm{a}}=$ aktiver Repressor, $\mathrm{R}_{\mathrm{in}}=$ inaktiver Repressor.

\subsection{Bisherige Arbeiten zum Nachweis von ABA-bindenden Proteinen}

In der Literatur wird die Lokalisation ABA-bindender Rezeptoren kontrovers diskutiert: So beschrieben verschiedene Arbeitsgruppen eine ABA-Bindung, die entweder intrazellulär oder extrazellulär lokalisiert wurde. Diskutiert werden weiterhin membrangebundene oder membranassoziierte sowie im Cytosol gelöste ABA-bindende Proteine. Eine Zusammenfassung der Literatur ist im Folgenden aufgeführt: Hocking et al. (1978) wiesen als erste eine ABA-Bindung an Mikrosomen aus Blättern nach. Wan und Hasenstein (1996) fanden eine ABA-Bindung an Proteine aus Mais-Wurzel-Membranen. Sie reinigten diese 
Proteine über ABA-BSA-Affinitäts-Säulen auf und wiesen über einen kompetitiven ELISABlocktest mit ABA-Ovalbumin deren ABA-Bindungsfähigkeit nach. Pédron et al. (1998) isolierten membranassoziierte Proteine aus Zellkulturen von Arabidopsis thaliana. Hierzu verwendeten sie ABA-Protein-Konjugate (BSA und Ovalbumin) als Sonden für ABAbindende Proteine, die sie mittels ELISA nachwiesen. Zhang et al. (1999) zeigten eine ABABindung an Mikrosomen aus dem Mesokarp von Weintrauben mittels ${ }^{3} \mathrm{H}-\mathrm{ABA}$. Den Proteincharakter des ABA-bindenden Proteins wiesen sie durch Trypsinverdau nach. Als Ergebnis der dargestellten Untersuchungen ergibt sich, daß membrangebundene Proteine existieren, die spezifisch ABA zu binden vermögen. Die verwendeten Methoden erlauben aber keine Differenzierung zwischen extra- und intrazellulärer Bindung.

\subsubsection{Membrangebundene ABA-Bindeproteine}

Für eine Bindung von ABA an der Außenseite des Plasmalemmas sprechen Befunde von Hornberg und Weiler (1984) an Schließzellen-Protoplasten von Vicia faba. Die Autoren fanden eine ABA-Bindung bei alkalischem $\mathrm{pH}$-Wert, bei dem ABA fast ausschließlich in der geladenen Form ( $\mathrm{ABA}^{-}$) vorliegt und daher nicht durch Membranen diffundieren kann (Kaiser und Hartung 1981). Diese ABA-Bindung verschwand nach Behandlung der Schließzellprotoplasten mit Trypsin. Weitere indirekte Hinweise auf einen extrazellulären ABA-Rezeptor lassen sich aus folgenden Studien ableiten: In Commelina wird das Öffnen der Stomata durch Mikroinjektion von ABA in das Cytosol der Schließzellen nicht verhindert (Anderson et al. 1994), extrazelluläre ABA-Applikation dagegen unterdrückt ein Öffnen der Stomata. Diese auf den ersten Blick klaren Ergebnisse werden dadurch relativiert, daß die Reaktion der Stomata bei einem hohen externen $\mathrm{pH}-$ Wert schwächer war als bei niedrigem. Dieser Befund weist somit eher auf einen intrazellulären ABA-Rezeptor hin (Anderson et al. 1994). Die Widersprüchlichkeit dieser Beobachtungen wird deutlich, wenn man sich vor Augen führt, daß Allan et al. (1994) durch Mikroinjektion von ABA direkt ins Cytosol von Commelina Schließzellen ein Schließen der Stomata auslösen konnten. Weiterhin konnte von Zhang et al. (2002) ein membranständiges ABA-bindendes Protein mit einem Molekulargewicht von $42 \mathrm{kDa}$ in der Epidermis von Vicia faba durch Bindung von ${ }^{3} \mathrm{H}-\mathrm{ABA}$ nachgewiesen werden. Für das Protein wurde ein $\mathrm{K}_{\mathrm{d}}$-Wert von $21 \mathrm{nM}$ für die Bindung von ABA bestimmt. Die Autoren vermuteten, daß es sich bei diesem Protein um einen Rezeptor handeln könnte, da die Inkubation eines monoklonalen Antikörper gegen das $42 \mathrm{kDa}$ große 
Protein mit Protoplasten-Schließzellen die ABA-abhängige Aktivierung der Phospholipase D verhinderte.

\subsubsection{Lösliche ABA-Bindeproteine}

Die Existenz löslicher ABA-Bindeproteine wurde sowohl aus direkten als auch aus indirekten Beobachtungen abgeleitet. Einen direkten Nachweis lieferte Veliev (1991), der eine ${ }^{3} \mathrm{H}-\mathrm{ABA}$ Bindung an cytosolischen Fraktionen aus etiolierten Weizensprößlingen fand, die er über ABA-Affinitäts-Chromatographie aufgereinigt hatte. Diese Fraktionen wurden im SDS-Gel aufgetrennt, aber nicht weiter aufgereinigt. Zhang et al. (2001) wiesen in cytosolischen Fraktionen von Äpfeln (Malus pumila L.) ebenfalls eine Bindung von ${ }^{3} \mathrm{H}-\mathrm{ABA}$ nach.

Indirekte Hinweise kommen aus Arbeiten unserer Arbeitsgruppe. Büssis et al. (1998) untersuchten die subzelluläre Kompartimentierung von ABA in Kartoffelblättern mit der Methode der nicht-wässrigen Fraktionierung. Dabei wurde eine Akkumulation von ABA im Cytosol von $6,9 \mu \mathrm{M}$ gefunden, während sich im Chloroplasten kein ABA nachweisen ließ. Diese Befunde widersprechen der von Solvik und Hartung (1992) vertretenen Hypothese über die subzelluläre Verteilung der ABA. Diese Arbeitsgruppe hatte Protoplasten mit ${ }^{3} \mathrm{H}-\mathrm{ABA}$ inkubiert und festgestellt, daß sich ein Diffusionsgleichgewicht für die undissoziierte Form von ABA zwischen den Kompartimenten einstellt. ABA kann als schwache Säure (pKs-Wert 4,75) in der ungeladenen Form, nicht dagegen in der anionischen Form, durch Membranen diffundieren (Kaiser und Hartung 1981). Daraus resultiert eine Akkumulation in dem alkalischen Kompartiment, dem Chloroplastenstroma. Die von Büssis et al. (1998) erhaltenen Ergebnisse deuten daher darauf hin, daß ABA im Cytoplasma nur akkumulieren kann, wenn sie nicht frei vorliegt. Daher ist die Existenz cytoplasmatischer Proteine mit ABABindungseigenschaft $\mathrm{zu}$ fordern.

Diese Hypothese wurde unterstützt durch die Ergebnisse von Strauß et al. (2001), die mit Hilfe der nicht-wässrigen Fraktionierung die subzelluläre Verteilung von ABA in Kartoffelpflanzen, welche einen Antikörper gegen ABA im endoplasmatischen Retikulum exprimieren (Artsaenko et al. 1995), untersuchten. Während der Gesamt-ABA-Gehalt in diesen Pflanzen anstieg, blieb die niedrige Konzentration in den Chloroplasten unverändert. Der Antikörper, der durch seine hohe Affinität ABA dem Diffusionsgleichgewicht entzieht, verhinderte eine verstärkte Diffusion des Hormons in den Chloroplasten. 
Um zu überprüfen, ob die von Slovik und Hartung (1992) in Protoplasten beobachtete freie Diffusion auch für intaktes Gewebe gilt, wurden Blattscheiben auf ABA-haltiger Lösung inkubiert. Durch nicht-wässrige Fraktionierung wurde nachgewiesen, daß dieses zusätzlich angebotene $\mathrm{ABA} z \mathrm{z}$ einer Konzentrationserhöhung von ABA in allen Kompartimenten führte (Strauß et al. 2001). Diese Ergebnis zeigt, daß eine Erhöhung der ABA-Konzentration über deren Bindungskapazität im Cytosol hinaus, eine Verteilung von ABA über den Kompartimenten entsprechend den $\mathrm{pH}-$ Gradienten erfolgte.

Obwohl viele Arbeiten eine ABA-Bindung an Membranen nachgewiesen haben und auch Anzeichen für cytoplasmatische ABA-Bindung existieren, ist bisher kein ABA-bindendes Protein aus grünen Pflanzenteile isoliert und auf seine Funktion hin untersucht worden. Diese Bindeproteine sind vermutlich wichtige Glieder der Signalperzeption und Signalweiterleitung.

\subsection{Weitere lösliche phytohormonbindende Proteine}

Während die Funktion von löslichen ABA-bindenden Proteinen aus grünen Pflanzenteilen noch nicht nachgewiesen wurde, konnten Libbenga und Mennes (1995) aus Tabakzellen ein lösliches Auxin-bindendes Protein isolieren, welches sich sowohl im Cytoplasma als auch im Zellkern befindet. Dieses Cytoplasma/Zellkern Auxin-bindende Protein ist offenbar nur in geringen Konzentrationen vorhanden und zeigt eine wesentlich höhere Affinität gegenüber Auxin als die in Tabak gefundenen membrangebundenen Auxin-bindenden Proteine. Die Autoren konnten eine direkte Beteiligung des Proteins an der Transkription zeigen. Sie fügten das partiell aufgereinigte Protein zu isolierten Zellkernen und zeigten eine Auxin-abhängige Stimulierung der RNA-Polymerase-II-Aktivität. 


\subsection{Zielsetzung}

Um die Ergebnisse von Büssis et al. (1998) sowie von Strauß et al. (2001) mit den Arbeiten von Slovik und Hartung (1992) in Einklang zu bringen, muß die Existenz cytoplasmatischer Proteine mit ABA-Bindungseigenschaft gefordert werden. In keiner der vorliegenden Untersuchungen über die Exsistenz löslicher ABA-Bindeproteine wurden cytosolische Fraktionen mit ABA-Bindung weiter aufgereinigt oder in grünen Blättern ABA-Bindung nachgewiesen.

Ziel der vorliegenden Arbeit war es lösliche ABA-bindende Proteine im Cytosol aus photosynthetisch aktiven Pflanzengeweben nachzuweisen. Dazu sollte eine Kopplungsmethode zur Synthese von ABA-Protein-Konjugaten etabliert werden, welche als Sonde für ABA-bindende Proteine dienen sollte. Die Herstellung und Charakterisierung von Antikörpern gegen ABA-Protein-Konjugate war weiterhin notwendig, um das Ziel der vorliegenden Arbeit zu erreichen. ABA-Protein-Konjugate und anti-ABA-Protein-Antikörper sollten zum Aufbau einer Reaktionskaskade für den Nachweis ABA-bindender Proteine mittels ELISA-Technik eingesetzt werden. Der ELISA bietet den Vorteil einer hohen Sensitivität und Spezifität zum Nachweis von Antigenen. Weiterhin sollte die Aufreinigung ABA-bindender Proteine aus cytosolischen Proteinextrakten in grünen Pflanzenteilen durchgeführt werden. In Hinblick darauf sollten verschiedene Proteinaufreinigungsverfahren zur Isolierung von ABA-bindenden Proteinen aus Spinat- und Arabidopsis-Pflanzen optimiert werden. Vorrangiges Ziel war dabei die Aufreinigung der cytosolischen Proteine über verschiedene Säulenmaterialien. 


\section{Material und Methoden}

\subsection{Pflanzen-Anzuchtbedingungen}

Für die Isolierung von cytosolischen Proteinen wurden im Rahmen dieser Arbeit 14 Tage alte Spinatpflanzen (Spinacia oleracea, Monopa) und Arabidopsis thaliana-Pflanzen Col-0 (Columbia) N1092 vewendet. Zur Anzucht der Spinatpflanzen wurde das Saatgut auf Vermiculite ausgebracht und anschließend eine Woche im Dunkeln bei $18^{\circ} \mathrm{C}$ gehalten. Die Dunkelphase diente dazu, die Keimungsrate zu erhöhen. Das weitere Wachstum der Pflanzen erfolgte bei $10 \mathrm{~h}$ Licht mit $160 \mu \mathrm{E}$. Die Temperatur lag tagsüber bei $22^{\circ} \mathrm{C}$ und nachts bei $18^{\circ} \mathrm{C}$. Das Saatgut von Arabidopsis thaliana wurde auf Erde (Minitray von Balster) ausgebracht. Die Pflanzen wurden bei einem Tag- / Nacht-Rhythmus von 12 h / 12 h bei $22^{\circ} \mathrm{C} / 18^{\circ} \mathrm{C}$ angezogen, wobei die Lichtintensität $160 \mu \mathrm{E}$ betrug.

\subsection{Extraktion von cytosolischen Proteinen}

Für die Extraktion von cytosolischen Proteinen wurden 14-Tage alte Spinat- bzw. Arabidopsis-Pflanzen verwendet. Die Ernte des Blattmaterials erfolgte spätestens eine Stunde nach Belichtungsbeginn, so daß die Pflanzen einen geringen Gehalt an Stärke aufwiesen. Etwa 20-30 g Spinat- und 40-50 g Arabidopsis-Pflanzen wurden sofort nach ihrer Ernte mit $50 \mathrm{ml}$ bzw. $80 \mathrm{ml}$ Homogenisationspuffer im Mörser auf Eis homogenisiert. Die dem Homogenisationspuffer zugegeben Proteinase-Inhibitoren sollten einen Abbau der Proteine durch die bei der Präparation aus der Vakuole freiwerdenden Proteinasen verhindern. Bei der Extraktion von cytosolischen Proteinen aus Arabidopsis wurde dem Homogenisationspuffer zusätzlich Sorbitol als Osmotikum zugesetzt. Ziel war es, Zellorganellen bei den Präparationsschritten möglichst intakt zu sedimentieren und vom Cytosol abzutrennen. 
Homogenisationspuffer:

$\begin{array}{rlll}100 & \mathrm{mM} & \text { Tris } & \mathrm{pH} \mathrm{7,5} \\ 300 & \mathrm{mM} & \text { Sorbitol } & \text { (nur bei Arabidopsis) } \\ 250 & \mathrm{mM} & \mathrm{NaCl} & \\ 2 & \mathrm{mM} & \text { EDTA } & \\ 1 & \mathrm{mM} & \text { DTT } & \end{array}$

Proteinase-Inhibitoren:

$1 \mu \mathrm{g} / \mathrm{ml}$ Pepstatin

$10 \mu \mathrm{g} / \mathrm{ml}$ Phenantrolin

$1 \mu \mathrm{g} / \mathrm{ml}$ Leupeptin

$0,5 \mu \mathrm{g} / \mathrm{ml}$ Aprotenin

Das Homogenat wurde über 2 Lagen Miracloth und 4 Lagen Mull filtriert. Zur Abtrennung von Stärke, größeren Zellbestandteilen und Chloroplasten wurde das Filtrat zunächst 10 min bei 650 x g zentrifugiert (HB4, Sorvall, Fa. Du Pont, Dreieich). Anschließend wurde der Überstand zur Separation von Zellorganellen, wie beispielsweise den Chloroplasten, Mitochondrien und Peroxisomen, $15 \mathrm{~min}$ bei 13.000 x g zentrifugiert (HB4, Sorvall, Fa. Du Pont, Dreieich). Die getrennte Sedimentation der Stärke und der Zellorganellen sollte eine höhere Ausbeute intakter Zellorganellen ermöglichen. Danach folgte eine einstündige Zentrifugation bei 150.000 x g (TFT 65.13, Ultrazentrifuge, Centrikon T-1065, Kontron Instruments) wobei Endomembranen sedimentiert wurden. Die Überstände wurden jeweils vorsichtig abgegossen und weiter verarbeitet. Alle Schritte wurden bei $4^{\circ} \mathrm{C}$ durchgeführt.

\subsubsection{Ammoniumsulfat-Fällung}

Eine Aufkonzentrierung der Proteine erfolgte durch Ammoniumsulfat-Fällung. Dazu wurde Ammoniumsulfat zu einer Endkonzentration von 80 \% (w/v) zum Proteinextrakt zugegeben und anschließend unter Rühren für 45 min bei $4{ }^{\circ} \mathrm{C}$ inkubiert. Die Proteine wurden pelletiert, indem der Extrakt $45 \mathrm{~min}$ bei $28800 \mathrm{x}$ g und $4^{\circ} \mathrm{C}$ zentrifugiert wurde (HB4, Sorvall, Fa. Du Pont, Dreieich). Das Pellet der sedimentierten cytosolischen Proteine aus Spinatpflanzenen bzw. Arabidopsis-Pflanzen wurde mit einem Pinsel in $5 \mathrm{ml}$ Tris-Puffer (50 mM Tris, pH 7,8, $200 \mathrm{mM} \mathrm{NaCl)} \mathrm{resuspendiert.} \mathrm{Die} \mathrm{Suspension} \mathrm{wurde} \mathrm{über} \mathrm{einen} \mathrm{Filter}$ mit einer Porengröße von 0,2 $\mu \mathrm{m}$ (Sarstedt, Nümbrecht) filtriert. Eine Auftrennung der 
Proteine erfolgte über die Gelfiltrations-Chromatographie (siehe Kapitel 2.3). Die Filtration der Proteine vor der Gelfiltration sollte die Lösung von noch vorhandenen größeren Bestandteilen befreien, um ein Verstopfen und eine Verunreinigung des Säulenmaterials zu vermeiden.

Für die Arabidopsis-Extraktion stellte es sich als günstiger heraus, die mit $80 \%(\mathrm{w} / \mathrm{v})$ Ammoniumsulfat gefällten Proteine, resuspendiert in $5 \mathrm{ml}$ MES-Puffer (50 mM MES, pH 5,4, $20 \mathrm{mM} \mathrm{NaCl}$ ), zunächst über eine Sephadex G-25 Säule (Amersham Pharmacia, Schweden) von Ammoniumsulfat wieder zu befreien (Kapitel 2.3.2). Eine weitere Auftrennung der Proteine erfolgte über eine Kationenaustauscher-Säule (DEAE-Sepharose, Amersham Pharmacia, Schweden) (siehe Kapitel 2.4).

\subsection{Gelfiltrations-Chromatographie}

Die Molekularsieb- oder Gelfiltrations-Chromatographie ist eine Methode zur Trennung von Makromolekülen aufgrund unterschiedlicher nativer Molekulargewichte. Die Materialien, die für diese Trennung eingesetzt werden, bestehen aus kleinen "Kügelchen” mit schwammartiger Struktur und Poren von einheitlicher Größe. Das Trennprinzip beruht darauf, daß kleinere Partikel durch die Poren in die Kugeln des Gelmaterial hineindiffundieren können und ihnen somit ein größeres Diffusionsvolumen zur Verfügung steht als größeren Partikeln, so daß sie langsamer von der Säule eluieren.

Bei der Gelfiltrations-Chromatographie wird die Trennung von Proteinen in erster Linie durch die Länge der Säule, die Partikelgröße des Gelmaterials, das Probenvolumen, sowie die Flußrate beeinflußt. Diese Parameter müssen im jeweiligen Experiment sorgfältig aufeinander abgestimmt werden, um eine optimale Auftrennung zu erreichen. Generell läßt sich die Auflösung der Gelfiltration durch längere Säulen, langsamere Durchflußgeschwindigkeit und feineres Matrixmaterial verbessern. Des Weiteren sollte das Volumen der gesamten Gelfiltrationssäule so gewählt werden, daß das Probenvolumen nicht mehr als 5 bis maximal $10 \%$ des Gesamtvolumens ausmacht. Der Reinigungsfaktor für die GelfiltrationsChromatographie liegt bei etwa $3-6$. 


\subsubsection{Trennung mit Sephacryl S-300-HR}

Zur Auftrennung der Proteinextrakte mittels Gelfiltrations-Chromatographie wurde das Säulenmaterial Sephacryl S-300-HR (Sigma) verwendet. Sephacryl S-300-HR hat eine Porengröße von $25-75 \mu \mathrm{m}$ und einen Trennbereich für globuläre Proteine mit einem Molekulargewicht von 10.000 bis $1.500 .000 \mathrm{~g} / \mathrm{mol}$. Dies ermöglicht eine optimale Trennung der meisten pflanzlichen Proteine.

Die Gelfiltrationssäule wies bei einem Durchmesser von $1,5 \mathrm{~cm}$ eine Länge von $95 \mathrm{~cm}$ auf. Das Gesamtvolumen betrug etwa $160 \mathrm{ml}$. Das Packen der Säule erfolgte bei $4^{\circ} \mathrm{C}$ in zwei Schritten. Um Schichtenbildung $\mathrm{zu}$ vermeiden, wurde das im Laufpuffer gequollene Matrixmaterial gleichmäßig in einem Zug in die Säule gegossen. Das Material konnte danach zunächst unter Ausnutzung der Gravitationskraft sedimentieren. Anschließend wurde das Säulenmaterial mit einer peristaltische Pumpe (Peristaltic Pump P-3, Pharmacia) bei einer Flußrate von $0,15 \mathrm{ml} / \mathrm{min}$ mit Laufpuffer weiter komprimiert. Der Vorteil dieser Methode bestand darin, daß eine Bildung von Luftblasen vermieden werden konnte. Die Säule mußte sowohl zum Gießen des Säulenmaterials, als auch bei der Gelfiltration selbst, absolut gerade stehen. Vor jeder Gelfiltration wurde die Säule mit mindestens zwei Säulenvolumina Laufpuffer equilibriert. Im Anschluß an die Proteinauftrennung wurde das Säulenmaterial mit Regenerationspuffer gereinigt.

$\begin{array}{lrrlr}\text { Laufpuffer: } & 50 & \mathrm{mM} & \text { Tris-HCl } & \mathrm{pH} \mathrm{7,8} \\ & 200 & \mathrm{mM} & \mathrm{NaCl} & \\ & & & & \\ & & & & \\ \text { Regenerationspuffer: } & 50 & \mathrm{mM} & \text { Tris-HCl } & \mathrm{pH} 7,8 \\ & 500 & \mathrm{mM} & \mathrm{NaCl} & \end{array}$

Für die Gelfiltration wurde das resuspendierte Sediment aus der Ammoniumsulfat-Fällung der Protein-Extraktion mit Hilfe einer Pumpe bei einer Flußrate von $0,15 \mathrm{ml} / \mathrm{min}$ auf die Säule geladen und bei einer Flußrate von $0,17 \mathrm{ml} / \mathrm{min}$ eluiert. Die Elution der Proteine wurde mittels UV-Detektion $(280 \mathrm{~nm})$ verfolgt. Fraktionen mit einem Volumen von jeweils etwa $3 \mathrm{ml}$ wurden während der Elution mittels eines Fraktionssammlers aufgenommen. Fraktionen mit Proteinen, welche zu einem Elutiongipfel gehörten, wurden entsprechend ihrem 
Elutionsmaximum zu einem Pool vereinigt. Die vereinigten Proteine wurden im ELISA (Kapitel 2.8.4) auf ihre ABA-Bindung getestet. Dazu wurden unterschiedliche Verdünnungsstufen der einzelnen Pools eingesetzt.

\subsubsection{Entsalzung mit Sephadex G-25}

Die resuspendierten Proteine der Ammoniumsulfat-Fällungen enthielten hohe Ammoniumsulfat-Konzentrationen, welche einer Bindung der Proteine an die Kationenaustauscher-Säule entgegenwirkten. Die Entsalzung der Proteine erfolgte über eine Sephadex G-25 Säule (Amersham Pharmacia).

Das Säulenmaterial wurde für vier Stunden bei Raumtemperatur in MES-Puffer $(50 \mathrm{mM}$ MES, pH 5,4, $20 \mathrm{mM} \mathrm{NaCl)}$ gequollen. Anschließend wurden defekte SäulenmaterialTeilchen durch dreimaliges Dekantieren entfernt. Das Material wurde in einem Zug in eine Glassäule gegossen.

Zur Abtrennung des Ammoniumsulfats wurde das Säulenmaterial mit fünf Säulenvolumen MES-Puffer (50 mM MES, pH 5,4, $20 \mathrm{mM} \mathrm{NaCl}$ ) equilibriert. Die resuspendierten Proteine wurden auf die Sephadex G-25-Säule geladen und nur unter Ausnutzung der Gravitationskraft eluiert. Eine Elution der Proteine wurde mittels UV-Detektion verfolgt. Fraktionen mit einem Volumen von jeweils ungefähr $2 \mathrm{ml}$ wurden mittels Fraktionssammler aufgefangen. Eine Bestimmung der Protein-Konzentration erfolgte nach der Bradford-Methode (Kapitel 2.11.1). Die Leitfähigkeit der Fraktionen wurde mittels eines Leitfähigkeitsmeßgerätes (Microprocessor Conductivity Meter LF 2000 WTW (Weilheim)) gemessen. Fraktionen mit hoher Protein-Konzentration und geringer Leitfähigkeit wurden vereinigt und durch Ionenaustauscher-Chromatographie weiter aufgereinigt.

\subsection{Ionenaustausch-Chromatographie}

Die Ionenaustausch-Chromatographie beruht auf einem reversiblen Austausch von in Lösung befindlichen Ionen mit elektrostatisch an einen unlöslichen Träger gebundenen Ionen. Im Falle eines Anionen-Austauschers sind an das inerte Trägermaterial kovalent positiv geladene und im Falle eines Kationen-Austauschers negativ geladene funktionelle Gruppen gebunden. Ausmaß und Stärke der Bindung eines Proteins an den Ionenaustauscher hängen vom pH- 
Wert und der Ionenstärke des Puffers, dem isoelektrischem Punkt des Proteins und der Dichte der Ladungen auf der Matrix ab. Die Reinigungsfaktoren bei der IonenaustauschChromatographie liegen zwischen 3 und 15. Durch Ionenaustauscher-Chromatographie kann eine Probe in der Regel aufkonzentriert werden. Die Auswahl eines bestimmten Austauschermaterials erfolgt empirisch.

\subsubsection{Optimierung der Proteinbindung}

Eine Auftrennung der Proteine aus Arabidopsis-Extrakten erfolgte über einen DEAESepharose-Kationenaustauscher (Pharmacia). Zunächst wurden geeignete Bedingungen zur Bindung der Proteine an die DEAE-Sepharose ermittelt. Dazu wurden $500 \mu \mathrm{l}$ des Säulenmaterials im Eppendorf-Reaktionsgefäß mit Arabidopsis-Extrakten bei unterschiedlichen pH-Werten von 4,5 bis 9 inkubiert. Das Säulenmaterial wurde mit dem jeweiligen Puffer durch mehrmaliges Waschen equilibriert. Für die pH-Werte von 4,5 bis 6 wurde als Puffer $50 \mathrm{mM}$ MES mit $50 \mathrm{mM} \mathrm{NaCl}$ und für die pH-Werte von 7 bis 9 als Puffersubstanz $50 \mathrm{mM}$ Tris mit $50 \mathrm{mM} \mathrm{NaCl}$ verwendet. Der Überstand vor und nach Inkubation mit dem Säulenmaterial wurde auf Bindung der ABA-Konjugate im ELISA untersucht. Als geeignete Bedingungen zur Bindung von ABA-bindenden Proteinen an das Säulenmaterial wurde die angesehen, bei denen nach Inkubation der Proteine mit DEAESepharose nur noch eine geringere Menge ABA-bindender Proteine im Überstand detektiert werden konnte.

\subsubsection{Trennung der Proteine durch Kationenaustausch-Chromatographie}

Nachdem die geeigneten Bindungsbedingungen empirisch ausgetestet waren, wurde das Matrixmaterial bei Raumtemperatur mit $50 \mathrm{mM}$ MES pH 5,4, $20 \mathrm{mM} \mathrm{NaCl}$ equilibriert und mit Hilfe einer Nutsche unter Vakuum entgast. Etwa $20 \mathrm{ml}$ des Säulenmaterials wurden bei $4^{\circ} \mathrm{C}$ in eine Säule mit einem Durchmesser von 1,5 cm gegossen und mit MES-Puffer bei einer Pumpengeschwindigkeit von $1 \mathrm{ml} / \mathrm{min}$ gepackt. Um ein Trockenlaufen der Säule zu verhindern, wurde die Pumpe hinter die Säule geschaltet.

Zur Auftrennung der Proteine durch Kationenaustauscher-Chromatographie wurden 10 $15 \mathrm{ml}$ der entsalzten Probe mit MES-Puffer bei einer Geschwindigkeit von $0,7 \mathrm{ml} / \mathrm{min}$ auf die Säule geladen. Proteine, die nicht an die Säule gebunden wurden, wurden solange mit MES- 
Puffer ausgewaschen bis keine Absorption mittels UV-Detektor $(280 \mathrm{~nm}) \mathrm{mehr}$ registriert werden konnte. Im Anschluß wurden die an die Säule gebundenen Proteine mit einem

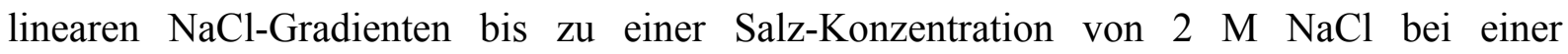
Geschwindigkeit von $1 \mathrm{ml} / \mathrm{min}$ eluiert. Das gesamte Elutionsvolumen betrug $60 \mathrm{ml}$. Fraktionen mit einem Volumen von jeweils etwa $3 \mathrm{ml}$ wurden mittels eines Fraktionssammlers aufgefangen. Regeneriert wurde die Säule durch längeres Waschen mit $2 \mathrm{M} \mathrm{NaCl}$. Bei starken Verunreingungen wurde die Säule kurzzeitig mit $1 \mathrm{M} \mathrm{NaOH}$ oder steigender Ethanol-Konzentration bis zu 70 \% gespült.

Aliquots der jeweiligen Fraktionen wurden sofort zur Protein-Bestimmung (siehe Kapitel 2.11.1) und zur Bestimmung der ABA-Bindung im ELISA (siehe Kapitel 2.8.4) entnommen. Das restliche Volumen der Fraktionen wurde zur Stabilisierung der Proteine mit $10 \%$ Glycerin versetzt und bei $-20^{\circ} \mathrm{C}$ eingefroren. Die Fraktionen mit hohem Protein-Gehalt und/oder hoher ABA-Bindung wurden durch $10 \%$ Trichloressigsäure (siehe Kapitel 2.12.1) gefällt und zur Auftrennung der Proteine auf ein SDS-Gel aufgetragen (siehe Kapitel 2.12). Protein-Fraktionen mit hoher ABA-Bindung wurden anschließend mittels ABA-AffinitätsChromatographie weiter aufgereinigt.

\subsection{ABA-Affinitäts-Chromatographie}

Bei der Affinitäts-Chromatographie wird ein spezifischer Ligand des gesuchten Proteins, der eine reaktive Gruppe besitzt, über einen Abstandshalter (Spacer) an eine Matrix gekoppelt. Bleiben dabei die Bindungseigenschaften des Liganden erhalten, bindet die derivatisierte Matrix selektiv das gesuchte Protein. Eine gute Affinitätssäule erreicht Reinigungsfaktoren von bis zu 1000 oder sogar darüber. Oftmals wird jedoch beobachtet, daß die derivatisierte Matrix das gesuchte Protein nicht bindet oder das Protein in der Säule seine Aktivität verliert. Weiterhin kommt es oft vor, daß das Protein zwar bindet, sich aber nicht eluieren läßt, weil die Bindung an den Liganden zu fest ist. Bei Liganden mit kleinem Molekulargewicht ist es notwendig, Säulenmaterialien mit langem Spacer zu verwenden.

\subsubsection{Kopplung von ABA an EAH-Sepharose 4 B}

Die Herstellung einer ABA-Affinitäts-Säule erfolgte nach der Carbodiimid-Methode. Dabei wurde die Carboxylgruppe der Abscisinsäure unter Verwendung des Carbodiimids 
$\mathrm{N}$-(3-Dimethylaminopropyl)-N'-ethylcarbodiimidhydrochlorid (EDC) an die Aminogruppe der EAH-Sepharose 4 B (Amersham Pharmacia) unter Ausbildung einer Peptidbindung gekoppelt. Dazu wurde das bereits vorgequollene Säulenmaterial mit Hilfe einer Nutsche über einen Glasfilter (G3) mit $80 \mathrm{ml}$ 0,5 M NaCl pro ml Säulenmaterial gewaschen. ABA wurde in $60 \%(\mathrm{v} / \mathrm{v})$ Ethanol und EDC in $\mathrm{H}_{2} \mathrm{O}$ gelöst. Der $\mathrm{pH}-$ Wert der Lösungen wurde mit $1 \mathrm{M}$ $\mathrm{NaOH}$ unter Verwendung von pH-Papier auf 5,2 - 5,4 eingestellt. Die Konzentrationen während der Kopplungsreaktion wurden so gewählt, daß eine 10-fach höhere ABA- und eine 20-fach höhere EDC-Menge als die Menge an vorhandener Bindungskapazität des Säulenmaterials vorlag.

Zur Kopplungsreaktion wurde das Säulenmaterial in ein Falkon-Röhrchen gegeben und der Überstand an Puffer bis auf $5 \mathrm{ml}$ abgenommen. Anschließend wurde das Gemisch aus ABA und EDC hinzupipettiert. Die Reaktion fand unter leichtem Schwenken für mindestens 20 Stunden bei Raumtemperatur statt. Während der ersten Stunde der Reaktionszeit wurde der pH-Wert der Lösung mit $1 \mathrm{M} \mathrm{NaOH}$ auf etwa 5,4 mit pH-Papier nachgestellt. Nach Beendigung der Kopplungsreaktion wurde die Matrix gründlich gewaschen, um alle nichtgebundenen Liganden zu entfernen. Bei jedem Waschschritt wurden $40 \mathrm{ml}$ der jeweiligen Lösung verwendet, das Säulenmaterial wurde kurz geschwenkt und zur Sedimentation $3 \mathrm{~min}$ bei $30 \mathrm{x}$ g in der Megafuge 1.0 (Heraeus, Sepatech) zentrifugiert. Die Matrix wurde zunächst $5 \mathrm{x}$ mit $50 \%$ (v/v) Ethanol gewaschen. Es folgten vier Waschzyklen mit jeweiligem Wechsel des pH-Werts unter Verwendung von Na-Acetat-Puffer $(0,1 \mathrm{M} \mathrm{Na}$ Acetat, $0,5 \mathrm{M} \mathrm{NaCl}, \mathrm{pH} 4,0)$ und Tris-Puffer (0,1 M Tris-HCl, 0,5 M NaCl, pH 8,0). Zum Schluß wurde das Material 3 x mit $\mathrm{H}_{2} \mathrm{O}$ gewaschen und bei $4^{\circ} \mathrm{C}$ gelagert.

Der Erfolg der Kopplungsreaktion wurde mittels Dot-Blot-Analyse (Kapitel 2.7) überprüft. Dazu wurde das substituierte Matrixmaterial in eine Plexiglassäule gegossen und mit einem polyklonalen Antikörper gegen ABA (Sigma) inkubiert. Eine starke Bindung des Antikörpers an das Säulenmaterial war ein Maß für den Erfolg der Kopplungsreaktion. 


\subsubsection{Proteinaufreinigung durch ABA-EAH-Sepharose 4 B}

\subsubsection{Test der Kopplungseffizienz}

Zur Überprüfung der Kopplungseffizienz von ABA an das Säulenmaterial wurden $5 \mathrm{ml}$ der ABA-EAH-Sepharose $4 \mathrm{~B}$ in eine Säule mit einem Durchmesser von 0,7 cm gegossen und mit vier Säulenvolumina 0,2 M Na-Acetat-Puffer $\mathrm{pH}$ 4,5 bei einer Flußgeschwindigkeit von 0,5 $\mathrm{ml} / \mathrm{min}$ equilibriert. $200 \mu \mathrm{l}$ des polyklonalen ABA-Antikörpers (Sigma) wurden in $10 \mathrm{ml}$ Na-Acetat-Puffer verdünnt und bei einer Flußgeschwindigkeit von $0,3 \mathrm{ml} / \mathrm{min}$ an die Säule gebunden. Der Antikörper wurde insgesamt drei mal über die ABA-EAH-Sepharose $4 \mathrm{~B}$ Säule gegeben. Nicht gebundener Antikörper und Proteine wurden durch Waschen mit 0,2 M Na-Acetat $\mathrm{pH} 4,5$ bei einer Flußrate von $0,5 \mathrm{ml} / \mathrm{min}$ entfernt. Anschließend folgte eine Elution der ABA-Antikörper mit ABA. Dazu wurden $60 \mu \mathrm{mol} \mathrm{ABA}$ in $1 \mathrm{ml} 95 \%$ Ethanol gelöst und danach mit $10 \mathrm{ml} \mathrm{Na-Acetat-Puffer} \mathrm{verdünnt.} \mathrm{Die} \mathrm{Elution} \mathrm{erfolgte} \mathrm{bei} \mathrm{einer}$ Flußgeschwindigkeit von $0,2 \mathrm{ml} / \mathrm{min}$. Regeneriert wurde die Säule durch Waschen mit $\mathrm{H}_{2} \mathrm{O}$ und im Anschluß daran durch dreimaliges Waschen mit jeweils zwei Säulenvolumen wechselnden $\mathrm{pH}$-Werts mit Tris-Puffer $(0,1 \mathrm{M}$ Tris-HCl, 0,5 M NaCl, $\mathrm{pH} 8,5)$ und NaAcetat-Puffer (0,1 M Na-Acetat, 0,5 M NaCl, pH 4,5). Das Waschen des Säulenmaterials mit wechselndem $\mathrm{pH}-$ Wert diente zur Entfernung fest gebundener Antikörper. Am Schluß erfolgte ein Waschen der Säule mit $20 \%$ (v/v) Ethanol. Die eluierten Lösungen wurden jeweils zu $2 \mathrm{ml}$ fraktioniert. Jeweils $300 \mu \mathrm{d}$ der Fraktionen wurden zur Dot-Blot-Analyse (siehe Kapitel 2.7) eingesetzt.

\subsubsection{Aufreinigung ABA-bindender Proteine}

Fraktionen der Kationenaustauscher-Chromatographie mit hoher ABA-Bindungsaffinität wurden zur weiteren Separation mittels ABA-Affinitäts-Chromatographie aufgereinigt. Aufgrund des geringen Proteingehalts dieser Fraktionen erfolgte eine Aufreinigung im $2 \mathrm{ml}$ Eppendorf-Reaktionsgefäß mit $500 \mu 1$ des Säulenmaterials. Es wurde ein neutraler pH-Wert eingestellt, der für cytosolische Proteine die Bindung an ABA unter diesen Bedingungen ermöglichen sollte. Dazu wurden die ABA-Bindeprotein-haltigen Fraktionen der DEAE-Säule mit Hilfe von Vivaspin-Röhrchen (5,000 MWCO PES, Sartorius, Göttingen) umgepuffert.

Dies erfolgte dadurch, daß die Proteinlösungen auf die Membran der Röhrchen pipettiert und mit $50 \mathrm{mM}$ Tris, $200 \mathrm{mM} \mathrm{NaCl}$ pH 7,5 auf $6 \mathrm{ml}$ aufgefüllt wurde. Anschließend wurden die Röhrchen in der Megafuge für $21 \mathrm{~min}$ bei 3200 x g zentrifugiert und erneut mit Tris-Puffer 
auf ein Volumen von $6 \mathrm{ml}$ aufgefüllt. Die Proteine wurden auf diese Weise insgesamt dreimal gewaschen. Nach dem letzten Waschschritt wurden die Proteine in einem Volumen von 1,2 ml Tris-Puffer aufgenommen. Ein Volumen von $1 \mathrm{ml}$ der umgepufferten Fraktionen des DEAE-Säulenlaufs wurden über Nacht unter leichtem Schwenken an das Säulenmaterial gebunden.

Nach der Sedimentation des Säulenmaterials wurde der Überstand abgenommen und zur späteren Verwendung im ELISA und SDS-Gel auf Eis aufbewahrt. Um unspezifisch gebundene Proteine zu entfernen, wurde das Säulenmaterial viermal mit $50 \mathrm{mM}$ Tris, $200 \mathrm{mM}$ NaCl-Puffer, pH 7,5 gewaschen. Die Elution spezifisch gebundener Proteine erfolgte nacheinander durch Waschen des Säulenmaterials mit $750 \mathrm{mM} \mathrm{NaCl}$ in $50 \mathrm{mM}$ Tris, pH 7,5 und 1,5 M NaCl in $50 \mathrm{mM}$ Tris, $\mathrm{pH} 7,5$ und anschließend mit $2 \mathrm{M}$ Harnstoff in $50 \mathrm{mM}$ Tris, pH 7,5. Die Puffer der einzelnen Wasch- und Elutionsschritte wurden jeweils für 30 bis 45 Minuten mit dem Säulenmaterial inkubiert. Anschließend wurde das Säulenmaterial durch vier-minütige Zentrifugation (Megafuge 30 x g) sedimentiert. Alle Schritte wurden im Kühlraum bei $4^{\circ} \mathrm{C}$ durchgeführt.

Zum Nachweis der Proteine mittels SDS-Gelelektrophorese wurden $700 \mu$ oder $5 \mu \mathrm{g}$ Gesamtproteingehalt der Überstände mit TCA behandelt, wodurch die Proteine gefällt wurden (Kapitel 2.12.1). Anschließend wurden die Sedimente in SDS-Probenpuffer resuspendiert, auf ein 12,5 \% SDS-Gel aufgetragen (Kapitel 2.12.2) und mittels Silber-Färbung (Kapitel 2.12.4) nachgewiesen. Der Test auf ABA-Bindung erfolgte, indem 2 x $100 \mu 1$ der Überstände im ELISA auf ABA-Bindung getestet wurden. Zur Bindung der Proteine an die Mikrotiterplatten mußten diese erneut umgepuffert werden. Die Proben wurden in Eppendorf-Reaktionsgefäße überführt und mit einer Dialyse-Membran (Medicell, MWCO 12-14 kDa, Kleinfeld) verschlossen. Die Proteine wurden fünfmal für jeweils 20 min gegen 2 Liter $50 \mathrm{mM}$ MES, $20 \mathrm{mM} \mathrm{NaCl}, \mathrm{pH}$ 5,4 dialysiert.

\subsection{Trypsinverdau ABA-bindender Proteine}

Um den Proteincharakter der gefundenen ABA-bindenden Proteine nachzuweisen, wurde eine Fraktion des DEAE-Säulenlaufs mit hoher ABA-Bindung im ELISA mit Trypsin behandelt und damit die vorhandenen Proteine verdaut. Dadurch sollte eine Bindung der ABA-BSAKonjugate im ELISA nicht mehr möglich sein. $200 \mu \mathrm{l}$ der Fraktion wurden mit $100 \mu 1$ 
Trypsin $(1 \mathrm{mg} / \mathrm{ml})$ (Sigma) für $30 \mathrm{~min}$ bei $37^{\circ} \mathrm{C}$ inkubiert. Im Anschluß daran wurden $100 \mu 1$ eines Trypsin-Inhibitors $(0,5 \mathrm{mg} / \mathrm{ml})$ (Sigma) hinzugegeben. Zur Kontrolle wurde die Fraktion nur mit $200 \mu 1$ Puffer behandelt. Weiterhin wurde die Fraktion mit Trypsin inkubiert, welches zuvor für 5 min mit Trypsin-Inhibitor behandelt wurde. Die Fraktionen wurden im ELISA auf ABA-Bindung hin untersucht.

\subsection{Dot-Blot}

Mit der Dot-Blot-Analyse kann man schnell und einfach ein Antigen an NitrocelluloseMembranen adsorbieren und nachweisen. Im Rahmen dieser Arbeit wurde der Dot-Blot zum Nachweis von anti-ABA-Antikörpern verwendet werden, welche an die ABA-Affinitätssäule gebunden und wieder eluiert wurden. Dies diente dem Nachweis der Kopplungseffizienz von ABA an das Säulenmaterial.

Um mittels Dot-Blot-Analyse die Kopplungseffizienz von ABA an das Säulenmaterial zu bestimmen, wurden $300 \mu 1$ der Fraktionen des ABA-Affinitätssäulenlaufs (Kapitel 2.5.2.1) mit anti-ABA-HSA-Antikörper (Sigma) auf die Dot-Blot-Apparatur aufgetragen. Durch Anlegen von Unterdruck wurden die Proteine an eine Nitrocellulose-Membran (Sartorius, Göttingen) adsorbiert. Die Membran wurde zur Absättigung überschüssiger Bindungskapazitäten für eine Stunde mit $5 \%$ Milchpulver (Naturaflor, Töpfer) in TBSBlockpuffer inkubiert und anschließend 2 x 5 min mit TBST gewaschen. Ein Nachweis des gebundenen Antikörpers erfolgte durch anti-Kaninchen IgG-Peroxidase-Konjugat (Sekundärantikörper), welche den ABA-HSA-Antikörper erkennt. Der Sekundärantikörper wurde bei einer Verdünnung von 1:10.000 in TBS-Blockpuffer eingesetzt. Anschließend wurde die Membran 3 x kurz und 3 x 5 min mit TBST gewaschen. Die Bindung des Sekundärantikörpers wurde über die Methode der „Enhanced Chemiluminescence“ (ECL) nachgewiesen.

\begin{tabular}{|c|c|c|c|}
\hline TBST: & 50 & $\mathrm{mM}$ & Tris $\quad \mathrm{pH} 7,5$ \\
\hline & 155 & $\mathrm{mM}$ & $\mathrm{NaCl}$ \\
\hline & 0,05 & $\%$ & Tween 2 \\
\hline
\end{tabular}

Blockpuffer: $\quad 5 \%$ Milchpulver (Naturaflor, Töpfer) in TBST 


\subsubsection{Peroxidase-Nachweis über „Enhanced Chemiluminescence“6 (ECL)}

Die „Enhanced Chemiluminescence“ wurde als sehr sensitiver Nachweis der an Antikörper gekoppelten Peroxidase entwickelt. Unter alkalischen Bedingungen katalisiert die Peroxidase die Oxidation von Luminol durch $\mathrm{H}_{2} \mathrm{O}_{2}$, wodurch Luminol kurzzeitig zur Lichtemission (Chemilumineszenz) veranlaßt wird. Die Lichtemission wird durch Phenole verstärkt und erreicht 5-20 Minuten nach Reaktionsstart ihr Maximum. Die Halbwertszeit beträgt etwa eine Stunde.

Die Nitrocellulose-Membran wurde in einer Lösung aus 1:1 „ECL Western blotting detection reagents 1“ und „2“ (Amersham Pharmacia Biotech) für eine Minute inkubiert und luftblasenfrei in Frischhaltefolie verpackt. Im Anschluß wurde die Membran auf einen photographischen Film (X-OMAT XAR-5, Fa. Kodak) gelegt und dieser für zunächst eine und dann fünf Minuten und wenn nötig nochmals für eine Stunde exponiert und die Filme entwickelt (Entwickler und Fixierer, Kodak).

\subsection{Entwicklung eines Tests zum Nachweis ABA-bindender Proteine mittels ELISA}

Zum Nachweis von ABA-bindenden Proteinen besteht die Möglichkeit, Proteinextrakte an Mikrotiterplatten zu binden und ABA-bindende Proteine über ABA-Protein-Konjugate als Sonden nachzuweisen. Für dieses Testverfahren müssen zunächst ABA-Protein-Konjugate hergestellt werden. Zur Detektion dieser Konjugate waren weiterhin geeignete Antikörper notwendig.

\subsubsection{Kopplung von ABA an ein Trägerprotein}

Die Kopplung von ABA an ein Trägerprotein erfolgte unter Modifikation einer Methode von Pédron et al. (1996). Dazu wurde die Carboxylguppe von ABA zunächst durch NHydroxysuccinimid (NHSC) und N-(3-Dimethylaminopropyl)-N'-ethylcarbodiimidhydrochlorid (EDC) aktiviert und anschließend unter Abspaltung eines Harnstoff-Derivats mit einer der freien Aminogruppen des Trägerproteins unter Ausbildung einer Peptidbindung zum ABA-Protein-Konjugat gekoppelt. 
Zur Aktivierung von ABA wurden $100 \mu \mathrm{mol}$ ABA mit $200 \mu \mathrm{mol}$ NHSC in 1,8 ml N,N Dimethylformamid gelöst. Danach wurden $200 \mu$ mol EDC in $200 \mu 1 \mathrm{H}_{2} \mathrm{O}$ gelöst und zur ersten Lösung hinzugegeben. Die Reaktionszeit zur Aktivierung von ABA betrug 3 Stunden und wurde bei Raumtemperatur unter leichtem Schwenken der Lösung durchgeführt. Anschließend erfolgte die eigentliche Kopplung an das Trägerprotein. Dazu wurde die Aktivierungslösung mit $2 \mathrm{~N} \mathrm{NaOH}$ auf einen pH-Wert von 8,7 eingestellt. Im Anschluß wurde die Lösung zu $1 \mu \mathrm{mol}$ Rinderserumalbumin (BSA), gelöst in $5 \mathrm{ml} \mathrm{H}_{2} \mathrm{O}$ gegeben und der $\mathrm{pH}$-Wert der Lösung auf 8,7 nachgestellt. Die Reaktion erfolgte für 20 Stunden bei $4^{\circ} \mathrm{C}$ unter leichtem Schwenken. Anschließend wurden die Konjugate für 5 Tage gegen $\mathrm{H}_{2} \mathrm{O}$ dialysiert. Dabei wurden 2 x täglich $51 \mathrm{H}_{2} \mathrm{O}$ ersetzt. Alle Reaktionen wurden bei Dämmerlicht durchgeführt. Die Konjugate wurden bei $-20^{\circ} \mathrm{C}$ gelagert.

Die optimalen Kopplungsbedingungen wurden durch Variationen des BSA:ABAKonzentrationsverhältnisses ermittelt. Es wurden Reaktionen mit BSA:ABAKonzentrationsverhältnissen von 1:10, 1:100, 1:200 durchgeführt. Eine Anpassung der Konzentrationen von EDC und NHSC erfolgte entsprechend. Zur Bestimmung der Kopplung von ABA an BSA wurden verschiedene Tests durchgeführt:

1) Radioaktive Bestimmung der Kopplung durch Zugabe von ${ }^{3} \mathrm{H}$-ABA während der Kopplungsreaktion. Durch Ammoniumsulfat-Fällung wurde nicht gebundenes ABA entfernt.

2) Massenspektrometrische Bestimmung des Molekulargewichts der Konjugate.

3) SDS-PAGE

Zur Kontrolle der Ergebnisse wurden Reaktionen durchgeführt, bei denen einer der Kopplungspartner (NHSC, EDC oder ABA) während der Aktivierungsreaktion fehlte. Damit sollte festgestellt werden, ob EDC oder NHSC mit BSA reagierten. Wird EDC oder NHSC an BSA gekoppelt, so muß dies bei der massenspektrometrischen Bestimmung des Molekulargewichts der Konjugate mit berücksichtigt werden. 


\subsubsection{Bestimmung der Kopplung von $A B A$ an $B S A$ durch ${ }^{3} H-A B A$}

Dem Reaktionsansatz zur Kopplung von ABA an BSA wurden $1 \mu \mathrm{Ci}^{3} \mathrm{H}-\mathrm{ABA}$ zugesetzt und die Reaktion wie oben beschrieben durchgeführt. Für die Messung der spezifischen Radioaktivität wurden aus dem Aktivierungsansatz $3 \times 10 \mu 1$ und $3 \times 50 \mu l$ Aliquots entnommen und mit jeweils $3 \mathrm{ml}$ Szintillationslösung (Emulsifier-Safe ${ }^{\mathrm{TM}}$, Packard) versetzt. Anschließend wurde die Intensität der $\beta$-Strahlung im Szintillationszähler (Liquid Scintillation Analyzer, 1900 TR, Packard) gemessen.

Nach der Kopplungsreaktion von ABA an das Trägerprotein mußten nicht gebundene ABA und Kofaktoren entfernt werden. Dazu wurden die Konjugate auf 6 Aliquots zu je $1 \mathrm{ml}$ aufgeteilt und mit jeweils $1 \mathrm{ml}$ gesättigter Ammoniumsulfat-Lösung für $30 \mathrm{~min}$ bei Raumtemperatur inkubiert. Die Proben wurden anschließend 15 min bei $4^{\circ} \mathrm{C}$ und $16.000 \mathrm{x} \mathrm{g}$ zentrifigiert (Tischzentrifuge, Eppendorf). Die Überstände wurden vorsichtig abgenommen und verworfen oder zur Bestimmung der Radioaktivität im Szintillationszähler mit $10 \mathrm{ml}$ Szintillations-Lösung versetzt. Die Sedimente wurden in $200 \mu 1 \mathrm{H}_{2} \mathrm{O}$ aufgenommen und durch 10-minütige Behandlung im Ultraschallbad (Sonorex RK 510S, Bandelin) wieder in Lösung gebracht. Die gelösten Sedimente wurden mehrmals gewaschen, indem sie mit $1 \mathrm{ml} 60$ \%iger (w/v) Ammoniumsulfat-Lösung $15 \mathrm{~min}$ bei RT inkubiert und anschließend 15 min bei $4^{\circ} \mathrm{C}$ und $14.000 \mathrm{x}$ g zentrifugiert (Tischzentrifuge, Eppendorf, Hamburg) wurden. Die Sedimente wurden erneut durch 10-minütige Behandlung im Ultraschallbad in $200 \mu 1 \mathrm{H}_{2} \mathrm{O}$ gelöst. Dieser Waschschritt wurde solange wiederholt, bis die Strahlungsintensität im Überstand konstant blieb. Dies trat in der Regel nach drei Waschzyklen ein. Im Anschluß daran wurden die in $200 \mu \mathrm{l} \mathrm{H}_{2} \mathrm{O}$ gelösten Sedimente mit $3 \mathrm{ml}$ Szintillations-Lösung versetzt und ihre Radioaktivität gemessen.

Gesättigte Ammoniumsulfat-Lösung:

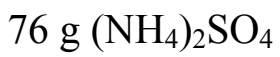

in $100 \mathrm{ml} 10 \mathrm{mM}$ Hepes $\mathrm{pH}$ 7,5

60 \%ige Ammoniumsulfat-Lösung

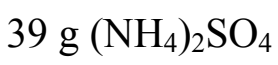

in $100 \mathrm{ml} 10 \mathrm{mM}$ Hepes pH 7,5 
Die Berechnung der Kopplungseffizienz erfolgte nach folgenden Formeln:

$[\mathrm{ABA}]=\frac{\text { Radioaktivität der Pr obe }[\mathrm{dpm} / \mu \mathrm{l}]}{\text { spezifische Radioaktiv ität }[\mathrm{dpm} / \mu \mathrm{mol}]} \cdot$ Gesamtvolumen $[\mu \mathrm{l}]$

spez. Radioaktiv ität $[\mathrm{dpm} / \mu \mathrm{mol}]=\frac{\text { Radioaktivität der Probe }[\mathrm{dpm} / \mu \mathrm{l}]}{\mathrm{ABA}-\text { Konzentrat ion }[\mu \mathrm{mol} / \mu \mathrm{l}]}$

\subsubsection{Bestimmung der Kopplung von ABA an BSA durch Massenspektrometrie}

Die Massenspektrometrie ist eine Technik zur Massenbestimmung und Strukturaufklärung von Molekülen und Molekülbruchstücken. Bei Pepiden, Proteinen und DNA versagt die herkömmliche Massenspektrometrie, da große und dazu noch geladene Moleküle nicht flüchtig sind. Durch „,matrix-assisted laser-desorption ionization (MALDI) gelingt es dennoch, hochmolekulare Ionen ins Vakuum springen zu lassen. Die Proteine werden in Kristalle von UV-absorbierenden Molekülen eingebaut. Dabei übertragen die sauren UVabsorbierenden Moleküle Protonen auf die Proteine und laden sie positiv auf. Diese Kristalle werden dann im Hochvakuum des Massenspektrometers mit einem UV-Laser Puls bestrahlt. Der setzt explosionsartig die UV-absorbierenden Moleküle und damit auch die eingebauten Proteinionen frei. Moleküle mit solchen Eigenschaften der Kokristallbildung, dem Protonentransfer und der UV-Absorption nennt man Matrix. Die positiv geladenen Proteine gehen ohne Hydratwasser und Gegenion in die Gasphase. Diese Ionen beschleunigt ein elektrisches Feld auf einer Blende zu. Die Geschwindigkeit ist proportional zu eins dividiert durch die Wurzel aus Masse und Ladung. Alle Ionen fliegen durch die Blende in eine feldfreie Vakuum-Flugröhre, den Flugzeitanalysator oder TOF (time of flight). Die Flugstrecke ist für alle Ionen gleich. Anschließend treffen die Ionen auf den Detektor. Weil sie aber unterschiedliche Masse/Ladungsverhältnisse und daher Geschwindigkeiten haben, erreichen sie den Detektor zu unterschiedlichen Zeiten. Diese Flugzeiten werden gemessen. Die Genauigkeit der Proteinbestimmung durch MALDI-TOF-Analyse liegt bei 0,1 Promille.

Mit Hilfe der Massenspektrometrie lassen sich die Molekulargewichte der ABA-BSAKonjugate bestimmen. Aufgrund dieser Ergebnisse können Rückschlüsse auf die Anzahl der an BSA gekoppelten ABA-Moleküle gezogen werden. Die Experimente zur Bestimmung der 
Molekulargewichte der ABA-BSA-Konjugate wurden in der Abteilung Biochemie II der Universität Göttingen in der Arbeitsgruppe von Dr. Bernhard Schmidt durchgeführt.

$1 \mathrm{mg} / \mathrm{ml}$ der Konjugate wurden 1:2 mit der Matrix verdünnt.

Die Matrix wurde folgendermaßen angesetzt: $5 \mathrm{mg}$ Sinapinsäure

$$
\begin{aligned}
& 1 \mathrm{ml} \quad 30 \quad \%(\mathrm{v} / \mathrm{v}) \text { Acetonitril } \\
& 0,1 \%(\mathrm{v} / \mathrm{v}) \quad \text { Trifluoressigsäure } \\
& \text { ad. } \mathrm{H}_{2} \mathrm{O}_{\text {dest. }} \text {. }
\end{aligned}
$$

Das Gemisch wurde kurz im Ultraschallbad gelöst und unlösliche Bestandteile in einer Eppendorftischzentrifuge bei maximaler Geschwindigkeit für 3 min sedimentiert. Etwa $1 \mu 1$ des Überstands wurde auf einen Probenteller aufgetragen und mit einem MALDI-TOFMassenspektrometer (REFLEX III, Brucker/Daltonics, Bremen) im linearen Modus gemessen.

Berechnung der Anzahl gekoppelter ABA-Moleküle pro BSA:

Moleküle ABA / Molekül BSA $=\frac{\text { MG Produkt }(\mathrm{g} / \mathrm{mol})-\mathrm{MG} \text { unspezifis che Kopplung }(\mathrm{g} / \mathrm{mol})}{\operatorname{MG}(\mathrm{ABA})(\mathrm{g} / \mathrm{mol})}$

\subsubsection{Gewinnung eines polyklonalen anti-ABA-BSA-Antikörpers}

Die hergestellten ABA-BSA-Konjugate (siehe Kapitel 2.8.1) wurden zur Gewinnung eines polyklonalen anti-ABA-BSA-Antikörper verwendet. Dieser Schritt erwies sich als notwendig, da die bisher käuflich erhältlichen anti-ABA-HSA-Antikörper (Sigma) nicht mehr hergestellt wurden und wir nur noch über Restbestände dieses Antikörpers verfügten.

Die Immunisierung von zwei Kaninchen und die Rohserengewinnung wurden von der Firma Bioscience (Göttingen) vorgenommen. $1 \mathrm{mg} / \mathrm{ml}$ ABA-BSA-Konjugat wurden 1:2 mit Freunds Adjuvans versetzt. Zwei Kaninchen (423 und 426) wurden viermal mit den Konjugaten immunisiert. Unmittelbar vor der ersten Immunisierung wurde den Kaninchen Blut abgenommen und daraus Präimmunserum für spätere Kontrollexperimente gewonnen. Der 
zeitliche Verlauf der Immunisierung und Serengewinnung läßt sich aus folgender Tabelle 2 entnehmen:

Tabelle 2: Übersicht zur Immunisierung und Serengewinnung von zwei Kaninchen (423 und 426) nach Injektion von ABA-BSA-Konjugaten.

\begin{tabular}{clcc}
\hline Wochen & \multicolumn{1}{c}{ Vorgang } & \multicolumn{2}{c}{ Serum (ml) } \\
& & 423 & 426 \\
0 & Blutabnahme, Injektion & 6 & 6 \\
3 & Injektion & & \\
5 & Blutabnahme & 25 & 30 \\
7 & Injektion & & \\
9 & Blutabnahme & 23 & 40 \\
11 & Injektion & & 47 \\
13 & Blutabnahme & 35 & \\
\hline
\end{tabular}

Die Injektionen erfolgten intradermal, wobei für die erste Injektion 10 und für alle weiteren je 5 Injektionspunkte gewählt wurden. Die so hergestellten Seren wurden nach weiteren Aufreinigungsschritten (Kapitel 2.9) für die im Rahmen dieser Arbeit durchgeführten immunologischen Analysen verwendet.

\subsubsection{Bestimmung von Testbedingungen zum Nachweis von ABA-bindenden Proteinen durch nicht-kompetitiven ELISA}

Der nicht-kompetitive ELISA sollte die Detektion ABA-bindender Proteine im Pflanzenextrakt über ABA-Protein-Konjugate als Affinitätssonden ermöglichen. Der Einsatz dieses Testverfahrens setzte voraus, daß zunächst geeignete Versuchsbedingungen festgelegt wurden. Dazu wurden ABA-Protein-Konjugate an die Mikrotiterplatten gebunden und die weiteren Reaktionsbedingungen zum Nachweis der Konjugate in verschiedenen Testserien 
experimentell bestimmt. Die dazu durchgeführten Experimente sind in diesem Kapitel zusammenfassend beschrieben. Im Ergebnisteil werden die jeweils für den ELISA verwendeten Versuchsbedingungen kurz aufgelistet.

\subsubsection{Beschichtung der Mikrotiterplatte}

Da eine Polystyrolmatrix proteinähnliche Substanzen adsorbiert, können Mikrotiterplatten (Roth, Karlsruhe) mit Proteinextrakten bzw. Protein-Konjugaten beschichtet werden. Der Mechanismus, durch den Proteine an Polystyrol haften, ist nicht völlig aufgeklärt. Vermutlich spielen Ladung und Hydrophobie eine wichtige Rolle. Der Bereich der Proteinkonzentrationen, bei denen es keine Beeinträchtigung der Bindung an Plastik gibt, liegt in der Praxis üblicherweise zwischen 1 und $10 \mu \mathrm{g} / \mathrm{ml}$.

Für den Nachweis von ABA-Protein-Konjugaten wurden 0,1 bis $10 \mu \mathrm{g} / \mathrm{ml}$ der Konjugate in Natrium-Carbonat-Puffer ( $50 \mathrm{mM} \mathrm{Na}_{2} \mathrm{CO}_{3} \mathrm{pH} 9,6 ; 180 \mathrm{mM} \mathrm{NaCl}$ ) gelöst und für eine Stunde bei $37^{\circ} \mathrm{C}$ oder über Nacht bei $4^{\circ} \mathrm{C}$ an die Mikrotiterplatte gebunden.

\subsubsection{Optimierung der Blockbedingungen}

Um die nicht besetzten Bindungsstellen der Mikrotiterplatte abzusättigen, ist die Zugabe eines geeigneten Blockmittels nötig. Dazu bieten sich verschiedene Reagenzien an, die jedoch zunächst auf ihre Eignung hin ausgetestet werden müssen. Es können sowohl zunehmende als auch abnehmende Hintergrundaktivitäten als Ergebnis der Blockade beobachtet werden. Die Größe des zur Blockade verwendeten Proteins hat in der Regel einen starken Einfluß. Allgemein gilt, daß kleine Proteine wirksamer sind als große.

Als Blocksubstanzen wurden Fischhautgelantine, KLH (Keyhole limpet hemocyanin) und Ovalbumin getestet. Dazu wurden die Mikrotiterplatten mit $10 \mu \mathrm{g} / \mathrm{ml}$ ABA-BSA-Konjugaten beschichtet und durch $250 \mu 1$ dieser Proteine, gelöst in PBS $+0,1 \%$ (v/v) Tween 20, 1,5 h bei Raumtemperatur abgesättigt. Weiterhin wurde überprüft, ob die Konjugate oder verwendeten Antikörper eine unspezifische Bindungen mit den Blockproteinen eingehen. Dazu wurden $250 \mu 1$ der Blockproteine, gelöst in PBS $+0,1 \%(\mathrm{v} / \mathrm{v})$ Tween 20, an die Mikrotiterplatte gebunden. Der Nachweis gebundener ABA-BSA-Konjugate erfolgte jeweils durch ABABSA-Antikörper und Protein A-HRP-Konjugat. 


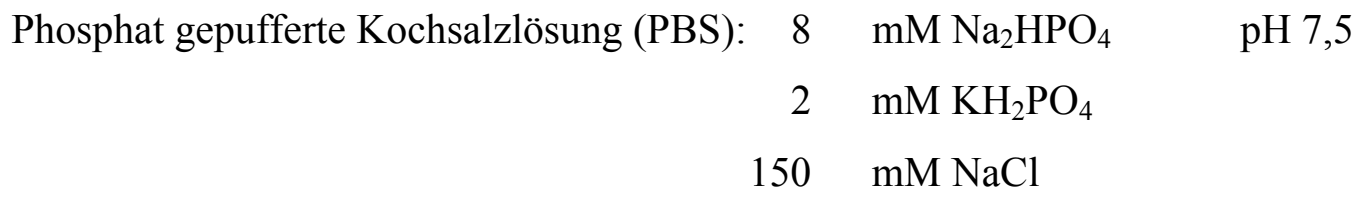

\subsubsection{Optimierung der Bindung von anti-ABA-BSA-Antikörper an ABA-BSA-Konjugate}

Zunächst wurde in einer Testreihe die Spezifität der aus den immunisierten Kaninchen gewonnenen Seren bestimmt. Dazu wurden Verdünnungsreihen von 1:100 bis 1:10.000 vom Präimmunserum und den einzelnen Blutungen der beiden Kaninchen (423 und 426) angefertigt. Es wurde die Bindung der Seren an ABA-BSA-Konjugate $(10 \mu \mathrm{g} / \mathrm{ml})$ getestet. Die Seren wurden in Tris-HCl-Puffer (50 mM Tris pH 7,5; $180 \mathrm{mM} \mathrm{NaCl}$ ) gelöst und mit je $100 \mu \mathrm{l}$ pro Ansatz $2 \mathrm{~h}$ bei Raumtemperatur inkubiert. Der Nachweis gebundener Antikörper erfolgte mittels Protein A-HRP-Konjugat.

In einer weiteren Testreihe sollte von dem Serum mit der höchsten ABA-Konjugat-Bindung dessen Bindung an BSA, sowie an BSA-Kopplungsprodukte, in Abwesenheit einzelner Cofaktoren (ABA, EDC und/oder NHSC) ermittelt werden (siehe Kapitel 2.8.1).

Für das im ELISA verwendete Serum sollten unspezifische Bindungen an das Trägerprotein BSA möglichst gering sein. Hingegen sollte eine Bindungen des Serums an die ABA-BSAKonjugate möglichst hoch sein. Dazu wurden die Seren der Kaninchen 423 und 426 mit höchster ABA-Konjugat-Bindung in unterschiedlichen Verdünnungen (1:100 bis 1:10.000) auf ihre Bindung an BSA und ABA-BSA-Konjugaten verglichen. Die Verdünnung, bei der die Differenz zwischen der Detektion von BSA und der von ABA-BSA-Konjugaten am größten war, wies die geringsten unspezifischen Bindungen an das Trägerprotein auf. Weiterhin wurde die optimale Inkubationszeit von eine, zwei oder drei Stunden für den antiABA-BSA-Antikörper bestimmt.

\subsubsection{Enzymmarkiertes Protein A}

Protein A ist ein Protein der Zelloberfläche von Bakterien und bindet Antikörper reversibel über ihre Effektoren-Domäne. Protein A kann dadurch, wenn es mit einem Enzym gekoppelt wurde, für immunolgische Test als Detektor zum Nachweis von Antikörpern verwendet werden. Protein A-HRP-Konjugat (Sigma) ist ein Kopplungsprodukt der Meerettich- 
Peroxidase (HRP) mit Protein A. In der hier vorliegenden Arbeit wurden Protein A-HRPKonjugate zum Nachweis der gebundenen anti-ABA-BSA-Antikörper im ELISA verwendet. Das enzymmarkierte Protein A wurde mit PBS 1:3000 verdünnt und je $100 \mu 1$ pro Ansatz eine Stunde bei Raumtemperatur inkubiert.

\subsubsection{Colorimetrischer Nachweis}

Als Substrat für die Peroxidase-Reaktion wurde ABTS [2,2`-Azino-di (3-ethylbenthiazolin) sulfonsäure-6] verwendet. ABTS wird von der Peroxidase $\mathrm{zu}$ einem dunkelgrünen Endprodukt umgesetzt, welches bei einer Wellenlänge von $405 \mathrm{~nm}$ detektiert werden kann. Die Messung der Farbstoffbildung erfolgte nach genau 30 min im Mikrotiterplatten-Lesegerät (Dynex).

ABTS-Substat-Lösung:

$10 \mathrm{mg}$ ABTS [2,2`-Azino-di (3-ethylbenthiazolin) sulfonsäure-6]

$7 \mu \mathrm{l}$ Wasserstoffperoxid $\left(\mathrm{H}_{2} \mathrm{O}_{2}\right)$

$10 \mathrm{ml}$ Substratpuffer

39,8 mM Zitronensäure-Monohydrat $\quad \mathrm{pH} 4,5$

$60 \quad \mathrm{mM} \mathrm{Na}_{2} \mathrm{HPO}_{4}$

\subsubsection{Waschen der Mikrotiterplatten}

Zur Entfernung nicht gebundener Substanzen und zur Reduzierung unspezifisch gebundener Substrate wurden die Platten zwischen den einzelnen Beschichtungsschritten nach folgendem Schema gewaschen:

$1 \times \mathrm{H}_{2} \mathrm{O}$ dest.

$2 \times \mathrm{PBS} / 0,1 \%(\mathrm{v} / \mathrm{v})$ Tween 20

$1 \mathrm{x} \mathrm{H}_{2} \mathrm{O}$ dest.

$1 \times$ PBS

\subsubsection{Nicht-kompetitiver ELISA zur Detektion ABA-bindender Proteine}

In diesem Kapitel wird beschrieben, wie der entwickelte nicht-kompetitive ELISA (siehe Kapitel 2.8.3) zur Detektion ABA-bindender Proteine verwendet wurde. Im ersten Schritt wurden die Mikrotiterplatten hierbei mit cytosolischen Proteinextrakten beschichtet. Die 
durchgeführten Beschichtungsschritte des ELISAs zum Nachweis ABA-bindender Proteine sind in Abbildung 6 dargestellt.

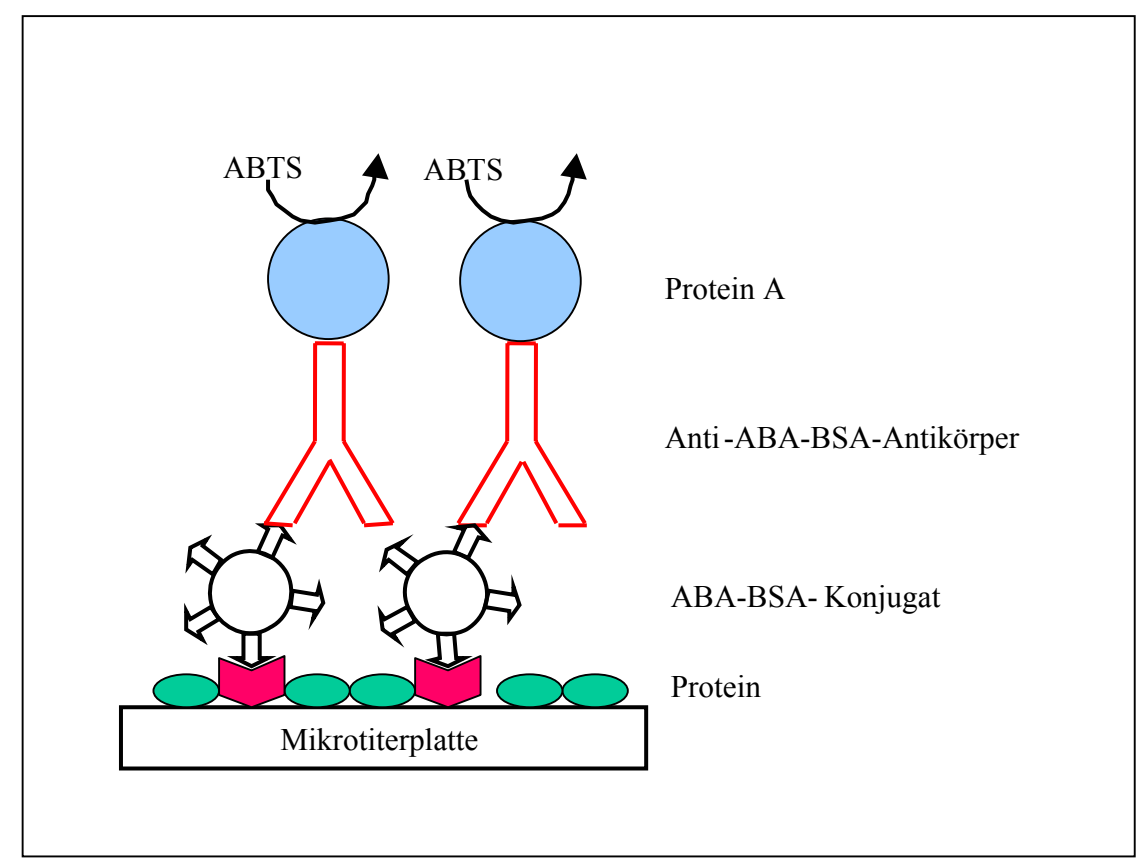

Abbildung 6: Schematische Darstellung der Bindungs-Reaktionskaskade zum Nachweis von ABA-bindenden Proteinen.

Zunächst wurden die Mikrotiterplatten mit aufgereinigten cytosolischen Proteinextrakten beschichtet. Dazu wurden Protein-Fraktionen der Gelfiltrationssäule mit Tris-HCl-Puffer $(50 \mathrm{mM}$ Tris $\mathrm{pH} 7,8 ; 200 \mathrm{mM} \mathrm{NaCl})$ so verdünnt, daß $100 \mu 1$ Probe mit ProteinKonzentrationen von $100 \mu \mathrm{g} / \mathrm{ml}$ bis $0,16 \mu \mathrm{g} / \mathrm{ml}$ aufgetragen werden konnten. ProteinFraktionen der Kationenaustauscher-Säule wurden unverdünnt zu je $100 \mu$ l aufgetragen. Die Beschichtung erfolgte über Nacht bei $4^{\circ} \mathrm{C}$.

Nach dreimaligem Waschen der Platten mit $\mathrm{H}_{2} \mathrm{O}$ wurden nicht besetzte Bindungsstellen mit $250 \mu 11 \%(\mathrm{w} / \mathrm{v})$ Ovalbumin in PBS / 0,1\% (v/v) Tween 20 eine Stunde bei Raumtemperatur abgesättigt.

Der Nachweis der Bindung von ABA-bindenden Proteinen erfolgte über ABA-BSAKonjugate als Sonden. Dafür wurden pro Vertiefung $100 \mu 1$ Konjugat in einer Konzentration von $50 \mu \mathrm{g} / \mathrm{ml}$ in Tris/MES-Puffer (50 mM Tris-HCl pH 7,2; $100 \mathrm{mM}$ MES; $125 \mathrm{mM} \mathrm{NaCl}$; 
$0,1$ bis $0,5 \%(\mathrm{v} / \mathrm{v})$ Tween 20$) 1,5 \mathrm{~h}$ bei RT inkubiert. Die Inkubation erfolgte bei Dämmerlicht. Zum Nachweis ABA-bindender Proteine aus cytosolischen Extrakten wurde ein pH-Wert von 7,2 gewählt, da dieser pH-Wert auch im Cytosol vorliegt. Der pH-Wert bei der Bindung von ABA-BSA-Konjugaten an ABA-bindenden Proteinen spielt ebenfalls eine wichtige Rolle. Unterschiede im $\mathrm{pH}-$ Wert führen $\mathrm{zu}$ unterschiedlichen Bindungsaffinitäten der Abscisinsäure an verschiedene Proteine. In Kontrollexperimenten wurde anstelle der ABA-BSA-Konjugate das Trägerprotein BSA mit Proteinextrakten inkubiert. Die Proteinextrakte wurden dazu mit $100 \mu \mathrm{l}$ BSA $(50 \mu \mathrm{g} / \mathrm{ml})$ beschichtet. Damit sollte gezeigt werden, ob das Trägerprotein BSA unspezifisch an die Proteinextrakte bindet.

Gebundene ABA-BSA-Konjugate und BSA wurden mittels aufgereinigtem polyklonalen antiABA-BSA-Antikörper (siehe Kapitel 2.9) nachgewiesen. Dazu wurden die Mikrotiterplatten mit $100 \mu \mathrm{l}$ des 1:200 mit Tris-HCl-Puffer (50 mM Tris pH 7,5; $180 \mathrm{mM} \mathrm{NaCl;} \mathrm{0,1 \%} \mathrm{(v/v)}$ Tween 20) verdünnten Antikörpers $1 \mathrm{~h}$ bei RT inkubiert. Der Nachweis gebundener Antikörper erfolgte wie unter 2.8.3.4 und 2.8.3.5 beschrieben über Peroxidase-markiertes Protein A und ABTS.

Die Platten wurden nach jeder Beschichtung mit 1 x $\mathrm{H}_{2} \mathrm{O}$ dest., 2 x PBS / 0,1 \% (v/v) Tween 20, $1 \times \mathrm{H}_{2} \mathrm{O}$ dest. und $1 \times$ PBS gewaschen, mit Ausnahme der Beschichtung durch Proteinextrakte, wobei ein dreimaliges Waschen mit $\mathrm{H}_{2} \mathrm{O}$ ausreichend war.

\subsubsection{Testen $\operatorname{der} A B A-B i n d u n g$ von RubisCO}

Zur Aufklärung der ABA-Bindung durch Ribulosebisphosphat-Carboxylase/Oxygenase (RubisCO), wurde RubisCO (Sigma) in unterschiedlichen Versuchsreihen an die Mikrotiterplatten gebunden und wie unter 2.8.4 aufgeführt auf ABA-Bindung getestet.

Zur Durchführung eines kompetitiven ELISAs wurden $100 \mu \mathrm{g} / \mathrm{ml}$ RubisCO gelöst in $50 \mathrm{mM}$ Tris, $200 \mathrm{mM} \mathrm{NaCl} \mathrm{pH} \mathrm{7,8} \mathrm{an} \mathrm{die} \mathrm{Mikrotiterplatten} \mathrm{gebunden} \mathrm{und} \mathrm{mit} 50 \mu \mathrm{g} / \mathrm{ml} \mathrm{ABA-BSA-}$ Konjugaten, welche jeweils vorher mit 5000, 1000, 200, 40 und $0 \mu \mathrm{g} / \mathrm{ml} \mathrm{ABA}$ versetzt wurden waren, inkubiert. Der Nachweis gebundener ABA-BSA-Konjugate erfolgte mittels aufgereinigtem Antikörper gegen ABA-BSA (siehe Kapitel 2.9) in einer Verdünnung von 1:200 in $50 \mathrm{mM}$ Tris, $180 \mathrm{mM} \mathrm{NaCl}, 0,1 \%$ (v/v) Tween 20. Gebundene Antikörper wurden durch enzymmarkiertes Protein A detektiert. 


\subsubsection{ELISA zum Nachweis von RubisCO}

In diesem Kapitel wird der Nachweis von RubisCO mittels ELISA-Technik beschrieben. Dieser Test diente zur Bestimmung der quantitativen Bindung von RubisCO (Sigma, Steinsheim, Deutschland) an die Mikrotiterplatten. Weiterhin wurde mit Hilfe dieses Detektionsverfahrens die RubisCO in Fraktionen des DEAE-Säulenlaufs nachgewiesen. Dazu wurden unterschiedliche Konzentrationen des Proteins $(100 \mu \mathrm{g} / \mathrm{ml}$ bis $0,16 \mu \mathrm{g} / \mathrm{ml})$ bzw. $100 \mu 1$ der Protein-Fraktionen eine Stunde bei Raumtemperatur oder über Nacht bei $4^{\circ} \mathrm{C}$ an die Mikrotiterplatten gebunden. Freie Bindungsstellen der Platten wurden mit 0,6 \% (w/v) Ovalbumin in PBST-Puffer für 1,5 Stunden geblockt. Der Nachweis gebundener RubisCO erfolgte mittels eines polyklonalen Antikörpers gegen die RubisCO (1:300) in TBST-Puffer, welcher durch Protein A Peroxidase-Konjugat (1:3000) in TBST nachgewiesen wurde. Die Farbreaktion der Peroxidase erfolgte wie unter 2.8.3.5 beschrieben.

Der Antikörper gegen RubisCO wurde von Prof. Eckhard Neuhaus, Osnabrück zur Verfügung gestellt. Zur Herstellung des Antiserums wurde die RubisCO aus Erbsen verwendet und zur Immunisierung Kaninchen injiziert.

\subsection{Aufreinigung des polyklonalen anti-ABA-BSA-Antikörpers}

Die gewonnen Antikörper aus dem Serum 426 (s. Kapitel 2.8.2) wurden über eine Protein ASepharose CL-4B-Säule (Sigma) aufgereinigt. Dabei wurden die Immunglobuline vom Restserum getrennt, da die Effektorregion von Immunglobulinen aus Kaninchen Epitop für Protein A ist.

Um unlösliche Zellbestandteile aus dem Serum zu entfernen, wurde das Serum 10 min bei $4^{\circ} \mathrm{C}$ und $10.000 \times \mathrm{g}$ (Tischzentrifuge, Eppendorf) zentrifugiert. Zur Einstellung des pH-Werts wurden dem Überstand 1/10 des Volumens $1 \mathrm{M}$ Tris- $\mathrm{HCl}$ pH 8,0 zugegeben.

Die Protein A-Säule wurde vorbereitet, indem 1 g Säulenmaterial mit 10 ml 100 mM Tris$\mathrm{HCl}$ pH 8,0 für 30 min bei RT zur Quellung gebracht und in eine Säule gegossen wurde. Das Säulenmaterial wurde bei einer Flußrate von $1 \mathrm{ml} / \mathrm{min}$ mit 10 Säulenvolumina $100 \mathrm{mM}$ Tris$\mathrm{HCl} \mathrm{pH}$ 8,0 gewaschen. Das Serum wurde mit einer Flußrate von $0,1 \mathrm{ml} / \mathrm{min}$ über die Protein A-Säule aufgereinigt. Um andere Proteine aus dem Serum zu entfernen und den 
Antikörper möglichst quantitativ an die Säule zu binden, wurde nacheinander mit folgenden Flußraten und Volumina gespült:

Tabelle 3: Übersicht zu den Versuchsbedingungen zur Aufreinigung von polyklonalen Antikörpern über Protein A-Säulen.

\begin{tabular}{ccc}
\hline Puffer & Flußrate & Säulenvolumina \\
\hline $100 \mathrm{mM}$ Tris-HCl pH 8,0 & $0,1 \mathrm{ml} / \mathrm{min}$ & 1 \\
& $0,3 \mathrm{ml} / \mathrm{min}$ & 1 \\
$10 \mathrm{mM}$ Tris- $\mathrm{HCl} \mathrm{pH} 8,0$ & $0,5 \mathrm{ml} / \mathrm{min}$ & 10 \\
\hline
\end{tabular}

Die Elution erfolgte durch insgesamt 10 Säulenvolumina $50 \mathrm{mM}$ Glycin $\mathrm{pH}$ 3,0. Das Eluat wurde fraktionsweise zur Neutralisierung des $\mathrm{pH}-$ Werts in $1 / 10$ seines Volumens $1 \mathrm{M}$ Tris $\mathrm{pH}$ 8,0 aufgefangen. Der Proteingehalt der Fraktionen wurde durch die Bradford-Methode (Kapitel 2.11.1) bestimmt und eine Auswahl an Proben der Fraktionen mit hohem Proteingehalt durch TCA-Fällung (Kapitel 2.12) aufkonzentriert und mittels SDS-PAGE (Kapitel 2.12) aufgetrennt. Fraktionen, welche nach Begutachtung des SDS-Gels über den aufgereinigten Antikörper verfügten, wurden vereinigt und in Aliquots bei $-20^{\circ} \mathrm{C}$ gelagert. Die kurzfristige Lagerung von Aliquots erfolgte bei $4{ }^{\circ} \mathrm{C}$ mit $0,02 \%(v / v)$ Natrium-Azid. Die Reinigung und Regeneration des Säulenmaterials erfolgte mit 5 Säulenvolumina $100 \mathrm{mM}$ Glycin pH 2,5. 


\subsection{Radioimmunoassay (RIA)}

(nach Weiler 1979)

Der Radioimmunoassay beruht auf der Grundlage, daß radioaktiv markierte ABA $\left({ }^{3} \mathrm{H}-\mathrm{ABA}\right)$ mit nicht markierter Abscisinsäure um die Bindung an einen anti-ABA-Antikörper konkurriert. Dazu wurden unterschiedliche Mengen von ABA (0 - 40 ng ) zu den Antikörpern gegeben. Freibleibende Antikörper-Bindungsstellen wurden mit ${ }^{3} \mathrm{H}-\mathrm{ABA}$ (Amersham, Braunschweig) abgesättigt. Viel nicht markiertes ABA in der Probe führte daher zu wenig an den Antikörper gebundener Radioaktivität. Freie und an den Antikörper gebundene ${ }^{3} \mathrm{H}-\mathrm{ABA}$ wurden durch eine Ammoniumsulfat-Fällung des Antikörpers voneinander getrennt.

Der in diesem Experiment durchgeführte Radioimmunoassay wurde zur Bestimmung der Dissoziationskonskonstante $\left(\mathrm{K}_{\mathrm{d}}\right.$-Wert) des von der Firma Bioscience gelieferten anti-ABABSA-Antikörpers und des anti-ABA-HSA-Antikörpers von der Firma Sigma eingesetzt. Des weiteren wurde die Methode dazu verwendet, beide Antikörper in ihrem Bindungsvermögen von Abscisinsäure aus pflanzlichen Extrakten zu vergleichen.

Beide anti-ABA-Antikörper wurden in Na-Acetat-Puffer $(0,2 \mathrm{M}$ Na-Acetat, $\mathrm{pH} 4,0)$ aufgenommen. Der Antikörper der Firma Sigma lag in lyophilisierter Form vor und wurde in 10 ml Na-Acetat-Puffer gelöst. Im Gegensatz dazu wurde der Antikörper der Firma Bioscience mit Na-Acetat 1:50 verdünnt eingesetzt. $100 \mu \mathrm{l}$ der Antikörper-Lösungen wurden zu folgendem Ansatz pipettiert:

$100 \mu \mathrm{l}$ ABA-Standard $(0-40.000$ pg ABA)

$500 \mu 1$ 0,2 M Na-Acetat-Puffer $\mathrm{pH}$ 4,0

$100 \mu 11 \%$ Rinderserumalbumin (BSA)

Dann wurden $20 \mathrm{nCi}{ }^{3} \mathrm{H}-\mathrm{ABA}$ in $100 \mu 1 \mathrm{H}_{2} \mathrm{O}$ zugegeben, kräftig gemischt und 90 min bei $4^{\circ} \mathrm{C}$ im Dunkeln inkubiert. Für die Antikörper-Fällung wurde $1 \mathrm{ml}$ gesättigte AmmoniumsulfatLösung zugegeben, gemischt und $30 \mathrm{~min}$ bei RT inkubiert. Anschließend wurden die Antikörper durch 15-minütige Zentrifugation (Tischzentrifuge, Eppendorf) bei $2000 \mathrm{x} \mathrm{g}$ sedimentiert. Der Überstand wurde vorsichtig abgenommen und verworfen. Zum Sediment wurde $1 \mathrm{ml} 50 \%$ (w/v) Ammoniumsufat-Lösung zugegeben. Auf kräftiges Mischen folgte eine 15-minütige Inkubation bei RT. Wiederum wurde 15 Minuten bei $2000 \mathrm{x}$ g und $4^{\circ} \mathrm{C}$ 
zentrifugiert und der Überstand verworfen. Das Sediment wurde in $150 \mu 1 \mathrm{H}_{2} \mathrm{O}$ resuspendiert und in ein $5 \mathrm{ml}$ Szintillationsgefäß überführt. Nach Zugabe von $3 \mathrm{ml}$ Szintillationslösung (Emulsifier-Safe $^{\mathrm{TM}}$, Packard, Dreieich) wurde die gebundene Radioaktivität in einem Szintillationszähler (Liquid Scintillation Analyzer 1900 TR, Packard) ermittelt.

Die Gründlichkeit der Waschschritte und die unspezifische Bindung von ${ }^{3} \mathrm{H}-\mathrm{ABA}$ wurden ermittelt, indem 4 Ansätze mit $\mathrm{H}_{2} \mathrm{O}$ anstatt der Probe und Präimmunserum anstatt des Antikörpers getestet wurden.

Die Abwesenheit von ABA (0 pg) in der Probe führte zu vollständiger Absättigung der Antikörper-Bindungsstellen durch ${ }^{3} \mathrm{H}$-ABA. Die Bindungskapazität der vorgelegten Menge des Antikörpers ließ sich daher in Relation zur steigenden Menge an ABA ermitteln.

Die Affinität des Antikörpers konnte ermittelt werden, indem das Bindeverhalten des Antikörpers gegen definierte ABA-Konzentrationen ausgewertet wurde. Die Auswertung erfolgte mit Hilfe einer logit-Transformation auf Basis der Bindung der ${ }^{3} \mathrm{H}-\mathrm{ABA}$ an den Antikörper.

Bindung $[\%]=\frac{\text { Meßwert }[\mathrm{dpm}]-\text { unspezifische Bindung }[\mathrm{dpm}]}{\text { Nullwert }[\mathrm{dpm}]-\text { unspezifische Bindung[dpm }]}$

Die Eichkurve, eine Auftragung der Bindung [\%] gegen den dekadischen Logarithmus der eingesetzten Menge ABA [pg], wird durch eine logit-Transformation linearisiert (siehe Abbildung 7):

Logit $=\ln \frac{\text { Bindung }[\%]}{100-\text { Bindung[\%] }}$

Aus der linearisierten Darstellung läßt sich der Wert, an dem 50 \% ABA gebunden vorliegt, anhand der Geradengleichung ermitteln. Dieser wird auf pmol ABA/ $\mu 1$ zurückgerechnet und so der $\mathrm{K}_{\mathrm{d}}$-Wert bestimmt. 

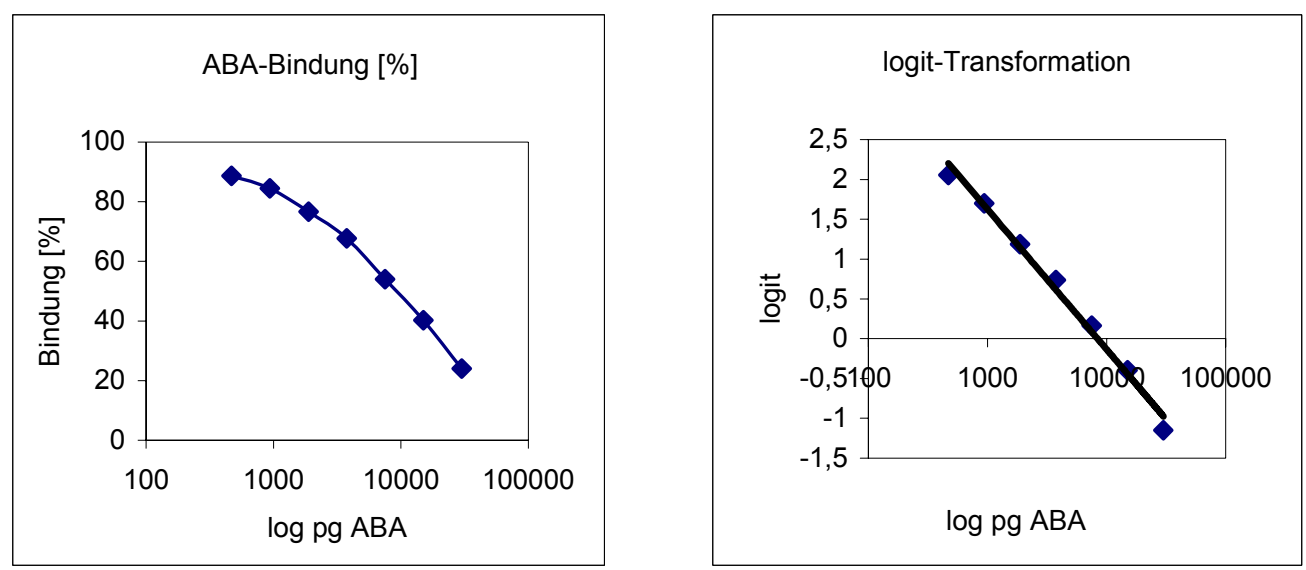

Abbildung 7: Beispiel einer logit-Transformation zur Linearisierung des Verhältnisses zwischen der prozentualen ABA-Bindung am Antikörper in Abhängigkeit von der ABAMenge.

\subsection{Protein-Bestimmung}

\subsubsection{Bradford (1976)}

Die Bestimmung des Proteingehalts der jeweiligen Probe erfolgte mit Hilfe einer Eichkurve, die unter den gleichen Bedingungen mit BSA-Eichlösung zwischen 0 und $15 \mu \mathrm{g}$ BSA in $50 \mu 1$ aufgenommen wurde. Eich- und Probenlösung wurden mit $1 \mathrm{ml}$ Bradford-Lösung versetzt. Nach zwei Minuten wurde der gebildete Farbkomplex bei einer Extinktion von $595 \mathrm{~nm}$ an einem Photometer (Uvikon 922, Kontron) gemessen.

Herstellung der Bradford-Lösung

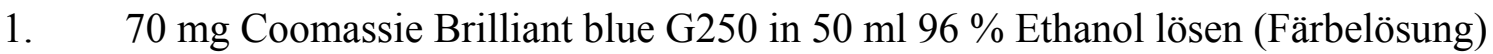

2. $600 \mathrm{ml} \mathrm{H}_{2} \mathrm{O}$ mit $100 \mathrm{ml} 85$ \%iger Phosphorsäure versetzen

3. Färbelösung in die wässrige Phosphorsäure geben, längere Zeit rühren lassen und filtrieren.

Vorteil dieser Methode ist, daß die Bradford-Lösung für lange Zeit stabil bleibt. Außerdem muß nicht bei jeder Protein-Bestimmung eine eigene Eichkurve aufgenommen werden. 


\subsubsection{Protein-Bestimmung nach Peterson (1977)}

Die Protein-Bestimmung nach Peterson ist eine sehr zeitaufwendige, aber dafür sensitivere Methode als die Protein-Bestimmung nach Bradford. Die Proteine werden zunächst in Desoxycholat (DOC) solubilisiert und dann mit Trichloressigsäure (TCA) ausgefällt. Anschließend werden die Proteine vom Medium abgetrennt und wieder in NatriumDodecylsulfat (SDS) gelöst.

Stammlösungen:
A) $\quad 0,15 \%(\mathrm{w} / \mathrm{v}) \quad \mathrm{DOC}$
B) $72 \%(\mathrm{w} / \mathrm{v})$ TCA
C) $\quad 0,5 \mathrm{mg} / \mathrm{ml} \quad \mathrm{BSA}$
D) $\quad 1: 6 \quad$ Folin-Ciocalteus Phenolreagenz mit $\mathrm{H}_{2} \mathrm{O}$ verdünnt
E) Reagenz I: Mischungen aus den Lösungen 1, 2, 3 und 4 im Verhältnis 1:1:1:1
1. Kupfer-Tartrat-Carbonat-Mischung:
$10 \% \mathrm{Na}_{2} \mathrm{CO}_{3}, 0,1 \%$ Kupfersulfat, 0,2\% Kaliumtartrat
2. $10 \%(\mathrm{w} / \mathrm{v})$ SDS
3. $0,8 \mathrm{~N} \mathrm{NaOH}$
4. $\mathrm{H}_{2} \mathrm{O}$

Bei dieser Protein-Bestimmung wurde eine BSA-Eichkurve für den Bereich zwischen 0 und $20 \mu \mathrm{g}$ Protein für jeden Ansatz erstellt. Die Proben wurden zunächst mit $\mathrm{H}_{2} \mathrm{O}$ auf ein Gesamtvolumen von $1 \mathrm{ml}$ gebracht. Eine Fällung der Proteine erfolgte unter Zugabe von je $100 \mu 1$ DOC und TCA. Nach 30-minütiger Inkubation bei Raumtemperatur wurde das Protein 15 min bei 15.8000 x g (Eppendorf Tischzentrifuge) zentrifugiert. Die Sedimente wurden in $480 \mu 1 \mathrm{H}_{2} \mathrm{O}$ und $500 \mu 1$ Reagenz I solubilisiert. Nach 10-minütiger Inkubation wurden $250 \mu 1$ Folin-Reagenz zugegeben und die Extinktion der Proben bei $578 \mathrm{~nm}$ am Photometer (Uvikon 922, Kontron) gemessen.

\subsection{SDS-Polyacrylamid-Gelelektrophorese (SDS-PAGE)}

Die Natrium-Dodecylsulfat (SDS)- Polyacrylamid-Gelelektrophorese wurde angewandt, um qualitativ die Aufreinigung der Proteine nach Gelfiltrations- und KationenaustauscherSäulenläufen sowie die des über Protein A aufgereinigten Antikörpers zu überprüfen und den 
Grad der Aufreinigung aufzuzeigen. Des weiteren wurde der Kopplungserfolg von ABA an BSA mittels SDS-Gelelektrophorese dokumentiert.

\subsubsection{Aufbereitung der Proben}

Die proteinhaltigen Fraktionen der Säulenchromatographie aus den Pflanzenextrakten und Antikörperaufreinigungen wurden mit Trichloressigsäure (TCA) gefällt. Dazu wurden die Proben, wenn nötig, auf ein Gesamtvolumen von $200 \mu$ gebracht. Die Fällung der Proteine erfolgte mit $30 \mu 172 \%$ (v/v) Trichloressigsäure für eine Stunde bei $4^{\circ} \mathrm{C}$. Sedimentiert wurden die Proteine durch 20-minütige Zentrifugation (Eppendorf Tischzentrifuge) bei $15.800 \times \mathrm{g}$ und $4{ }^{\circ} \mathrm{C}$. Anschließend wurden die Sedimente mit Aceton gewaschen, um die restliche Trichloressigsäure zu entfernen. Dazu wurden die Sedimente mit $500 \mu 1$ Aceton versetzt, kurz solubilisiert und durch 5-minütige Zentrifugation (Eppendorf Tischzentrifuge) bei $15.800 \mathrm{x} \mathrm{g}$ und RT wieder sedimentiert. Anstelle von Aceton konnte für das Waschen der Sedimente ebenso $96 \%$ Ethanol verwendet werden.

Die Sedimente der TCA-Fällung oder $5 \mu \mathrm{g}$ der ABA-BSA-Konjugate wurden in $15 \mu 1$ SDSProbenpuffer aufgenommen und zur Solubilisierung für $30 \mathrm{~min}$ bei RT inkubiert. Anschließend wurden die Proben 3 min bei $95^{\circ} \mathrm{C}$ denaturiert. Analog wurde mit einem Molekulargewichts-Standard (Amersham Pharmacia Biotech, USA) verfahren, der zur Bestimmung des Molekulargewichts von Proteinen auf den SDS-Gelen mitgeführt wurde.

\begin{tabular}{|c|c|c|c|}
\hline SDS-Probenpuffer: & 10 & $\mathrm{mM}$ & Tris-HCl \\
\hline & 5 & $\%(\mathrm{w} / \mathrm{v})$ & SDS \\
\hline & 2 & $\%(\mathrm{v} / \mathrm{v})$ & 2-Mercaptoethanol \\
\hline & 20 & $\%(\mathrm{v} / \mathrm{v})$ & Glycerin \\
\hline & 0 & $\%(\mathrm{v} / \mathrm{v})$ & Bromphenolblau \\
\hline
\end{tabular}

\subsubsection{Zusammensetzung der Gele und Durchführung der Elektrophorese}

(nach Laemmli 1970)

Zur Gelelektrophorese wurden 5-10 $\mu$ g Protein für Coomassie-gefärbte Gele (Kapitel 2.12.3) und $2 \mu \mathrm{g}$ Protein für Silver Stain-markierte Gele (Kapitel 2.12.4) verwendet. Die Auftrennung der Proteine aufgrund ihrer Größe erfolgte bei $25 \mathrm{~mA}$ in $10 \%$ bzw. 12,5\% 
SDS-Polyacrylamidgelen solange, bis die durch Bromphenol-Blau markierte Lauffront das Gelende erreichte. Das Gel setzte sich aus einem Trenn- und Sammelgel zusammen, die nacheinander gegossen wurden. Die Geldicke betrug $1 \mathrm{~mm}$, die Sammelgel-Länge $7 \mathrm{~mm}$ und die Trenngel-Länge $6 \mathrm{~cm}$. Beachtet werden mußte, daß bei Gelen unter 12,5\% Acrylamid Proteine mit einem Molekulargewicht von unter $14 \mathrm{kDa}$ innerhalb der Lauffront wandern.

Tabelle 4: Benötigte Volumina zur Herstellung von zwei Minigelen zur Protein-Analyse.

\begin{tabular}{lccc}
\hline & Sammelgel & \multicolumn{2}{c}{ Trenngel } \\
& & $10 \%$ & $12,5 \%$ \\
\hline Acrylamid-Lösung & $0,77 \mathrm{ml}$ & $4 \mathrm{ml}$ & $5 \mathrm{ml}$ \\
Trenngel-Puffer-Lösung & - & $3 \mathrm{ml}$ & $3 \mathrm{ml}$ \\
Sammelgel-Puffer-Lösung & $1,3 \mathrm{ml}$ & - & - \\
$\mathrm{H}_{2} \mathrm{O}$ & $3 \mathrm{ml}$ & $5 \mathrm{ml}$ & $4 \mathrm{ml}$ \\
TEMED & $20 \mu \mathrm{l}$ & $10 \mu \mathrm{l}$ & $10 \mu \mathrm{l}$ \\
$10 \%$ (w/v) Ammoniumpersulfat & $60 \mu \mathrm{l}$ & $30 \mu \mathrm{l}$ & $30 \mu \mathrm{l}$ \\
\hline
\end{tabular}

TEMED $=\mathrm{N}, \mathrm{N}, \mathrm{N}^{\prime}, \mathrm{N}^{\prime}-$ Tetramethylethylendiamin

Acrylamid-Lösung: $\quad 30 \quad \%(w / v)$ Acrylamid

$0,8 \%(\mathrm{w} / \mathrm{v}) \mathrm{N}, \mathrm{N}-$ Methylenbisacrylamid

Trenngel-Puffer-Lösung: $\quad 1,5 \quad \mathrm{M} \quad$ Tris- $\mathrm{HCl} \quad \mathrm{pH} 8,8$

$0,4 \%(w / v)$ SDS

Sammelgel-Puffer-Lösung $\quad 0,5 \quad \mathrm{M} \quad$ Tris-HCl pH 6,8

$0,4 \%(w / v)$ SDS

Elektrophorese-Puffer: $\quad 25 \quad \mathrm{mM} \quad$ Tris- $\mathrm{HCl} \mathrm{pH} 8,3$

0,25 M Glycin

$0,1 \quad \%(\mathrm{w} / \mathrm{v}) \mathrm{SDS}$ 


\subsubsection{Coomassie-Färbung}

Um die Proteinbanden auf den Minigelen einzufärben, wurden die Gele für 30 min in einer Färbelösung fixiert und angefärbt. Die sich anschließende Inkubation in einer Entfärbelösung erfolgte solange, bis der Gelhintergrund nahezu farblos war. Die beiden Lösungen hatten folgende Zusammensetzung:

Färbelösung: $\quad 0,25 \%(v / v)$ Coomassie Blue (Serva Blau R)

$40 \%(\mathrm{v} / \mathrm{v})$ Methanol

$10 \%(\mathrm{v} / \mathrm{v})$ Essigsäure

Entfärber: $\quad 50 \quad \%(\mathrm{v} / \mathrm{v})$ Methanol

$10 \%(\mathrm{v} / \mathrm{v})$ Essigsäure

\subsubsection{Silber-Färbung}

(nach Blum et al. 1987)

Verglichen mit der Coomassie-Färbung zeichnet sich die Silberfärbung von Proteinen im SDS-Gel durch ihre 10 bis 100-fach höhere Sensitivität aus.

Silberionen reagieren unter sauren Bedingungen mit Proteinseitengruppen (nicht stöchiometrisch) und werden nachfolgend durch Formaldehyd unter alkalischen Bedingungen $\left(\mathrm{Na}_{2} \mathrm{CO}_{3}\right)$ zu metallischem Silber reduziert. Die bei der Silberfärbung reaktiven Gruppen der Proteine sind freie Amino- und Sulfhydrylgruppen (Deutscher 1990). Folglich hängt die Intensität der Färbung von der Primärstruktur des Proteins ab und ist bei basischen Proteinen höher als bei sauren. Das SDS-Gel wurde nacheinander in folgenden Lösungen inkubiert: 


\begin{tabular}{|c|c|c|c|c|}
\hline \multirow{2}{*}{$\begin{array}{l}\text { Arbeitsschritt } \\
\text { Fixierung }\end{array}$} & \multicolumn{3}{|c|}{ Lösung } & \multirow{2}{*}{$\begin{array}{l}\text { Zeit } \\
90 \mathrm{~min}\end{array}$} \\
\hline & 50 & $\%(\mathrm{v} / \mathrm{v})$ & Ethanol & \\
\hline & 12 & $\%(\mathrm{v} / \mathrm{v})$ & Essigsäure & \\
\hline & 0,05 & $\%(\mathrm{v} / \mathrm{v})$ & $37 \%$ iges Formaldehyd & \\
\hline Waschen & 50 & $\%(\mathrm{v} / \mathrm{v})$ & Ethanol & $3 \times 20 \mathrm{~min}$ \\
\hline Imprägnierung & 0,01 & $\%(\mathrm{v} / \mathrm{v})$ & $\mathrm{Na}_{2} \mathrm{~S}_{2} \mathrm{O}_{3} \cdot 5 \mathrm{H}_{2} \mathrm{O}$ & $1 \mathrm{~min}$ \\
\hline Waschen & \multicolumn{3}{|c|}{$\mathrm{H}_{2} \mathrm{O}$ bidest } & $3 \times 20 \mathrm{sec}$ \\
\hline \multirow[t]{3}{*}{ Entwicklung } & 3 & $\%(\mathrm{w} / \mathrm{v})$ & $\mathrm{Na}_{2} \mathrm{CO}_{3}$ & $2-10 \mathrm{~min}$ \\
\hline & 0,05 & $\%(\mathrm{v} / \mathrm{v})$ & $37 \%$ iges Formaldehyd & \\
\hline & 0,5 & $\%$ (w/v) & $\mathrm{Na}_{2} \mathrm{~S}_{2} \mathrm{O}_{3} \cdot 5 \mathrm{H}_{2} \mathrm{O}$ & \\
\hline Stop & 10 & $\mathrm{mM}$ & $\mathrm{Na}_{2}$ EDTA & ca. $10 \mathrm{~min}$ \\
\hline Aufbewahrung & \multicolumn{3}{|c|}{$\mathrm{H}_{2} \mathrm{O}_{\text {bidest }}$} & \\
\hline
\end{tabular}

Die Bestimmung der Molekulargewichte von Proteinen im SDS-Gel erfolgte mittels linearer Regression. Dazu wurde in jedem Gel neben den Proben ein Molekulargewichts-Standard mit Proteinen von unterschiedlicher Größe aufgetragen. Die Laufstrecken der Markerproteine des jeweiligen Gels wurden für Proteine mit einem Molekulargewicht von 66 bis 20,1 kDa ausgemessen. 


\subsection{Auswertung der durchgeführten Experimente}

Die in dieser Arbeit dargestellen Ergebnisse sind entweder Einzelergebnisse, die einen typischen Verlauf der durchgeführten Experimente widerspiegeln, oder gemittelte Ergebnisse. Einzelexperimente wurden in der Regel durch weitere Versuche unter nur leicht veränderten Bedingungen mehrmals wiederholt. Bei der Zusammenfassung von Experimenten sind der arithmetische Mittelwert und die Standardabweichung als mittlerer Fehler der Einzelmessungen angegeben.

Mittelwert:

$$
x_{m}=\frac{\sum_{i=1}^{n} x_{i}}{n}
$$

Standardabweichung:

$$
S D=\sqrt{\frac{\sum_{(i=1)}^{n}\left(x_{i}-x_{m}\right)^{2}}{n-1}}
$$

$$
\begin{aligned}
& \mathrm{n}=\text { Anzahl der Einzelmessungen } \\
& \mathrm{x}_{\mathrm{i}}=\text { Meßwert einer Einzelmessung }
\end{aligned}
$$




\section{Ergebnisse}

Den experimentellen Untersuchungen der vorliegenden Arbeit lag die Fragestellung zu Grunde, ob sich im Cytosol ABA-bindende Proteine nachweisen lassen.

Mehrere Arbeitsgruppen konnten die Existenz membran-gebundener ABA-bindender Proteine zeigen (Hornberg und Weiler 1984, Pédron et al. 1998, Zhang et al. 1999). Allerdings wurde in nur zwei Artikeln bislang direkt über eine Bindung von $\mathrm{ABA}$ an lösliche cytosolische Fraktionen aus Mais-Wurzeln (Veliev 1991) und reifenden Äpfeln (Zhang et al. 2001) berichtet. Keine Untersuchungen auf lösliche ABA-bindende Proteine erfolgten bisher an cytosolischen Fraktionen aus grünen Pflanzenorganen. Die Arbeiten von Büssis et al. (1998) geben indirekte Hinweise auf das Vorhandensein von ABA-bindenden Proteinen im Cytosol von grünen Pflanzen. Entgegen der Hypothese, ABA würde im Chloroplasten akkumulieren (Solvik und Hartung 1992), wurde von Büssis et al. (1998) eine Anreicherung von ABA im Cytoplasma nachgewiesen, während sich im Chloroplasten kein ABA befand. Diese Befunde können durch die Existenz ABA-bindender Proteine im Cytoplasma erklärt werden.

Der Nachweis von cytosolischen Proteinen, welche ABA binden, erforderte im wesentlichen zwei Schritte, für die in dieser Arbeit neue Verfahren entwickelt wurden. Zunächst wurde ein sensitiver Nachweis für ABA-bindende Proteine etabliert. Parallel dazu wurden geeignete Aufreinigungsmethoden zur Anreicherung ABA-bindender Proteine aus Spinat- und Arabidopsis-Pflanzen entwickelt.

\subsection{Kopplung von ABA an BSA}

Eine nichtradioaktive und sehr sensitive Methode zum Nachweis von Antigenen bietet der ELISA. Um dieses Testverfahren auf ABA-bindende Proteine anwenden zu können, ist es notwendig, ABA an ein Trägerprotein zu koppeln. Die so erhaltenen Konjugate lassen sich als „Verbindungsglieder“ sog. Linker zum Nachweis ABA-bindender Proteine verwenden. Die Kopplungsreaktion erfolgte nach einer Methode von Pédron et al. (1996), mit BSA als Trägerprotein. Dazu wurde die Carboxylguppe von ABA zunächst durch N-Hydroxysuccinimid (NHSC) und N-(3-Dimethylaminopropyl)-N'-ethylcarbodiimidhydrochlorid (EDC) aktiviert und anschließend mit einer der freien Aminogruppen des Trägerproteins unter Ausbildung einer Peptidbindung zum ABA-Protein-Konjugat gekoppelt. 
Theoretisch stehen $59 \varepsilon-\mathrm{NH}_{2}$-Gruppen des BSA-Moleküls für diese Reaktion zur Verfügung. Wie viele Gruppen davon tatsächlich eine Reaktion eingehen können, ist nicht genau bekannt, da durch die Faltung des Proteins nicht alle Aminogruppen zugänglich sind. Nach Dayhoff (1976) könnte die Anzahl reagierender Aminogruppen zwischen 30 - 35 liegen.

Der Nachweis des Erfolgs der Kopplungsreaktion und die Bestimmung des optimalen Verhältnisses der Konzentration von ABA zu BSA in den Reaktionsansätzen erfolgten durch die Bestimmung der Kopplungsrate bei verschiedenen ABA-Konzentrationen. Dazu wurde einerseits dem Reaktionsansatz ${ }^{3} \mathrm{H}-\mathrm{ABA}$ (Tabelle 5) zugegeben und so der Einbau von ABA an BSA gemessen und andererseits massenspektrometrisch das Molekulargewicht der Konjugate (Tabelle 6) ermittelt.

Tabelle 5: Kopplungseffizienz von ABA an BSA gemessen durch den Einbau von ${ }^{3} \mathrm{H}-\mathrm{ABA}$.

ABA wurde mit BSA in einem stöchiometrischen Verhältnis von 1:10, 1:100 und 1:200 nach der unter 2.8.1 beschriebenen Methode inkubiert. Die Kopplung wurde durch Nachweis des Einbaus von ${ }^{3} \mathrm{H}-\mathrm{ABA}$ bestimmt.

Verhältnis BSA:ABA im Reaktionsansatz
$1: 10$
$1: 100$
$1: 200$

Anzahl der gekoppelten ABA- $\quad$ kein Einbau

$10,4 \pm 4,6$

$24,1 \pm 8,8$

Moleküle pro BSA-Molekül

$\mathrm{N}$

1

5

3

Durch die Verwendung von ${ }^{3} \mathrm{H}-\mathrm{ABA}$ konnte bei einem Verhältnis BSA:ABA von 1:10 keine meßbare Kopplung von ABA an BSA bestimmt werden. Bei einem stöchiometrischen Verhältnis BSA:ABA von 1:100 wurden im Durchschnitt etwa 10 und bei einem Verhältnis von 1:200 etwa 24 ABA-Moleküle pro BSA-Molekül bestimmt.

Bei der Betrachtung der Ergebnisse muß allerdings folgendes Problem berücksichtigt werden. Ein Nachteil bei der Bestimmung der Kopplung von ${ }^{3} \mathrm{H}-\mathrm{ABA}$ an BSA besteht darin, daß die Proteinfällung der ABA-BSA-Konjugate mit Ammoniumsulfat zum Entfernen nicht 
gebundener ${ }^{3} \mathrm{H}-\mathrm{ABA}$ wahrscheinlich nicht quantitativ ist und somit ein Teil der Konjugate im Überstand bleibt und somit verloren geht.

Um dieses Problem zu verdeutlichen, wurden ABA-BSA-Konjugate bei einem Verhältnis BSA:ABA von 1:100 und 1:200 mittels ${ }^{3} \mathrm{H}$-ABA hergestellt und wie unter Kapitel 2.8.1.1 beschrieben zunächst mit $50 \%$ (w/v) Ammoniumsulfat und im Anschluß daran dreimal mit jeweils $60 \%(\mathrm{w} / \mathrm{v})$ Ammoniumsulfat gefällt, um nicht gebundenes ${ }^{3} \mathrm{H}-\mathrm{ABA} \mathrm{zu}$ entfernen. Anschließend wurden die Konjugate mit unterschiedlichen AmmoniumsulfatKonzentrationen von 30 bis $80 \%$ (w/v) gefällt und die Radioaktivität im Überstand und Sediment gemessen. Die Ergebnisse sind in Abbildung 8 dargestellt.

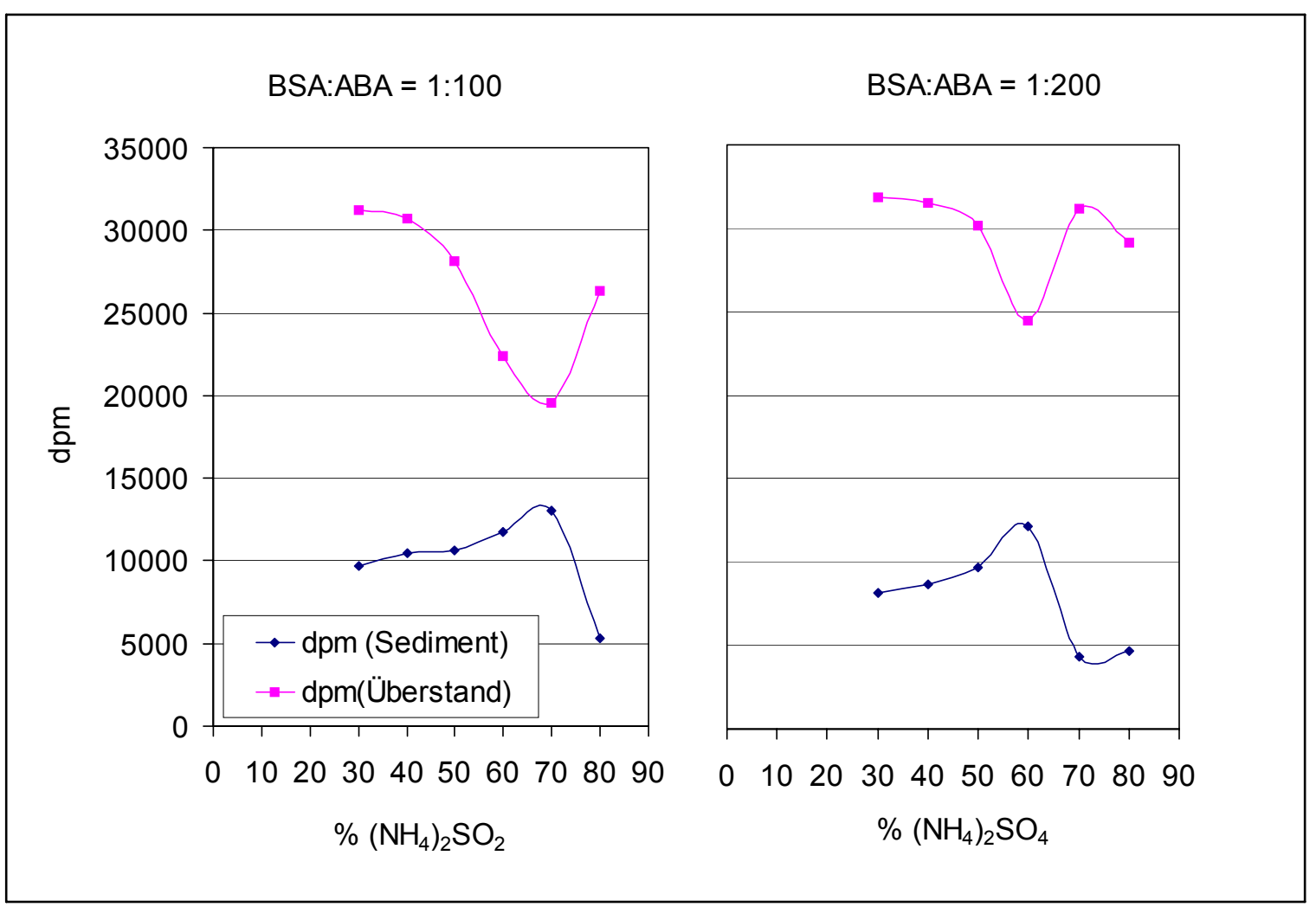

Abbildung 8: Ammoniumsulfat-Fällung der ABA-BSA-Konjugate bei unterschiedlichen Ammoniumsulfat-Konzentrationen. Gemessen wurde die Radioaktivität im Überstand und in den Sedimenten. 
Aus Abbildung 8 läßt sich erkennen, daß während der Ammoniumsulfat-Fällung ein großer Teil der Radioaktivität im Überstand bleibt. Die Konjugate wurden im Experiment zur Bestimmung der Kopplungseffizienz bei 50 und 60 \% (w/v) Ammoniumsulfat gefällt. Eine optimale Konzentration zur Fällung der Konjugate, welche bei einem Verhältnis BSA:ABA von 1:100 hergestellt wurden, wäre bei $70 \%(\mathrm{w} / \mathrm{v})$ Ammoniumsulfat und für die Konjugate, welche bei einem Verhältnis von 1:200 gekoppelt wurden, bei $60 \%$ (w/v) Ammoniumsulfat gewesen. Doch auch bei den jeweils optimalen Ammoniumsulfat-Konzentrationen blieb noch ein großer Teil der Radioaktivität im Überstand. Dies zeigt, daß die Konjugate durch diese Methode nicht vollständig sedimentiert werden konnten. Daher wurde zur Bestimmung der Einbaurate von ABA an BSA das Molekulargewicht der Konjugate mit Hilfe der Massenspektrometrie bestimmt.

Tabelle 6: Massenspektrometrische Bestimmung des Molekulargewichts (g/mol) der ABABSA-Konjugate.

Die Kopplungsreaktion von ABA an BSA erfolgte bei einem Verhältnis von 1:100 und 1:200 nach der unter 2.8.1 beschriebenen Methode. In einem weiteren Versuchsansatz wurde der $\mathrm{pH}-$ Wert der Aktivierungslösung nicht auf 8,7 eingestellt.

Verhältnis BSA:ABA im Reaktionsansatz

\begin{tabular}{|c|c|c|}
\hline $\begin{array}{c}\text { Kontrolle 1:0 } \\
\text { (nur BSA) }\end{array}$ & $1: 100$ & $1: 200$ \\
\hline
\end{tabular}

$\begin{array}{lllll}\text { Konjugat }(\mathrm{g} / \mathrm{mol}) & 66340 \pm 243 & 76980 \pm 1527 & 79799 \pm 507 & 69532 \pm 179\end{array}$

$\begin{array}{lllll}\mathrm{N} & 5 & 6 & 2 & 2\end{array}$

Durch die Kopplung von ABA an BSA bei einem stöchiometrischen Verhältnis BSA:ABA von 1:100 und 1:200 erhöhte sich das Molekulargewicht der Kopplungsprodukte von durchschnittlich $66340 \mathrm{~g} / \mathrm{mol}$ (BSA) auf $76980 \mathrm{~g} / \mathrm{mol} \mathrm{bzw.} 79799 \mathrm{~g} / \mathrm{mol}$.

Trotz des höheren Einbaus von ABA an BSA bei einem Reaktionsverhältnis von 1:200 wurden alle weiteren Kopplungsreaktionen bei einem Verhältnis von 1:100 durchgeführt, da 
bei einer Konzentration von 1:200 der Versuchsansatz am Ende der Reaktion ungewöhnlich trüb wurde und diese Trübung nicht erklärt werden konnte.

Wird der pH-Wert im Anschluß an die Aktivierungsreaktion nicht auf 8,7 eingestellt, so führt dies nur zu einer geringen Erhöhung des Molekulargewichts $(69532 \mathrm{~g} / \mathrm{mol})$ im Vergleich zu dem von BSA (66340 g/mol). Dies zeigt, daß der pH-Wert zur Kopplung der aktivierten ABA-Lösung an ein Trägerprotein entscheidend für den Erfolg der Kopplungsrate war.

Werden zur Bestimmung der Kopplungsrate von ABA an BSA die gemessenen Molekulargewichte zu Grunde gelegt, so ergeben sich bei einem Molekulargewicht für ABA von $264 \mathrm{~g} / \mathrm{mol}$ Einbauwerte von 40 bzw. 51 ABA-Molekülen pro BSA für eine Kopplungsreaktion bei einem Verhältnis BSA:ABA von 1:100 bzw. 1:200. Diese Werte liegen weit über den erwarteten Einbauraten von 30 - 35 Molekülen (Dayhoff 1976). Um mit Hilfe der Massenspektrometrie zu berechnen, wie viele ABA-Moleküle pro BSA tatsächlich eingebaut wurden, war es daher notwendig Kontrollexperimente durchzuführen. Diese dienten zur Bestimmung, ob die bei der Kopplungsreaktion verwendeten Kofaktoren (EDC und NHSC) ebenfalls an BSA gekoppelt wurden.

Tabelle 7: Massenspektrometrische Bestimmung des Molekulargewichts der Kopplungsprodukte von ABA an BSA in An- oder Abwesenheit von Kofaktoren (NHSC sowie EDC) und ABA.

Die Reaktion wurde bei einem Verhältnis BSA:ABA von 1:100 durchgeführt. Es werden jeweils Einzelexperimente dargestellt.

Während der Kopplungsreaktion verwendete Kofaktoren

ABA

ABA

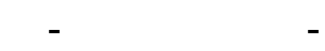

ABA

NHSC

NHSC

- $\quad$ NHSC

EDC

EDC

EDC

Konjugat (g/mol) $\quad 7738$

66462

71738

66938

66441 
Die Kopplungsreaktion von ABA an BSA wurde unter Verwendung der Kofaktoren EDC und NHSC durchgeführt. Dazu wurde während einer Aktivierungsreaktion zunächst die Carboxylgruppe von ABA durch EDC und NHSC aktiviert. Im Anschluß an die Aktivierungsreaktion wurde der Ansatz zu BSA zugegeben. Um zu überprüfen, ob einer der Kofaktoren eine Reaktion mit BSA eingeht, wurde die Aktivierungsreaktion und anschließende Kopplungsreaktion durchgeführt, wobei jeweils einer der Kofaktoren oder ABA weggelassen wurde. Eine Durchführung der Kopplungsreaktion von BSA nur mit ABA (2), EDC (4) bzw. ABA mit NHSC (5) führt zu keiner bzw. nur zu einer geringen Erhöhung der Molekulargewichte im Vergleich zu dem von BSA (66340 g/mol) (Tabelle 6 und Tabelle 7). Daraus kann geschlossen werden, daß ABA ohne Aktivierung durch EDC und NHSC (2) nicht an BSA gekoppelt wird. Weiterhin konnte gezeigt werden, daß eine Aktivierung von ABA nur durch NHSC (5) nicht ausreichte, um ABA an BSA zu koppeln. Eine Kopplung von EDC an BSA (4) führte zu einer geringen Erhöhung des Molekulargewichts um knapp $600 \mathrm{~g} / \mathrm{mol}$. Eine Reaktion von BSA mit EDC und NHSC ohne ABA (3) führte zu Produkten, deren Molekulargewicht mit $71738 \mathrm{~g} / \mathrm{mol}$ gegenüber dem von BSA $(66340 \mathrm{~g} / \mathrm{mol})$ deutlich erhöht waren. Daraus läßt sich schließen, daß auch die Kofaktoren EDC und NHSC eine Reaktion mit BSA eingehen. Erfolgte diese Kopplungsreaktion von ABA an BSA mit EDC und NHSC (1), ergaben die Produkte ein Molekulargewicht von 77381 g/mol. Berücksichtigt man den unspezifischen Einbau der von EDC und NHSC an BSA (3) so kann eine Zunahme des Molekulargewichts, welche nur auf ABA zurück zuführen ist, von $5643 \mathrm{~g} / \mathrm{mol}$ errechnet werden. Bei einem Molekulargewicht von $264 \mathrm{~g} / \mathrm{mol}$ für ABA kann somit eine Kopplung von 21 ABA-Molekülen pro BSA ermittelt werden.

Zur routinemäßigen Überprüfung des Kopplungserfolgs wurden die Konjugate auf ein SDSGel aufgetragen oder im ELISA getestet, indem verschiedene Konzentrationen der Konjugate direkt an die Platte gebunden wurden und mittels Antikörper gegen ABA-BSA-Konjugate nachgewiesen wurden. Bei einer Auftrennung der Kopplungsprodukte in An- oder Abwesenheit von ABA und/oder einem der Kofaktoren im SDS-Gel findet man eine deutliche Veränderung der Laufstrecke im elektromagnetischen Feld (Abbildung 9): 


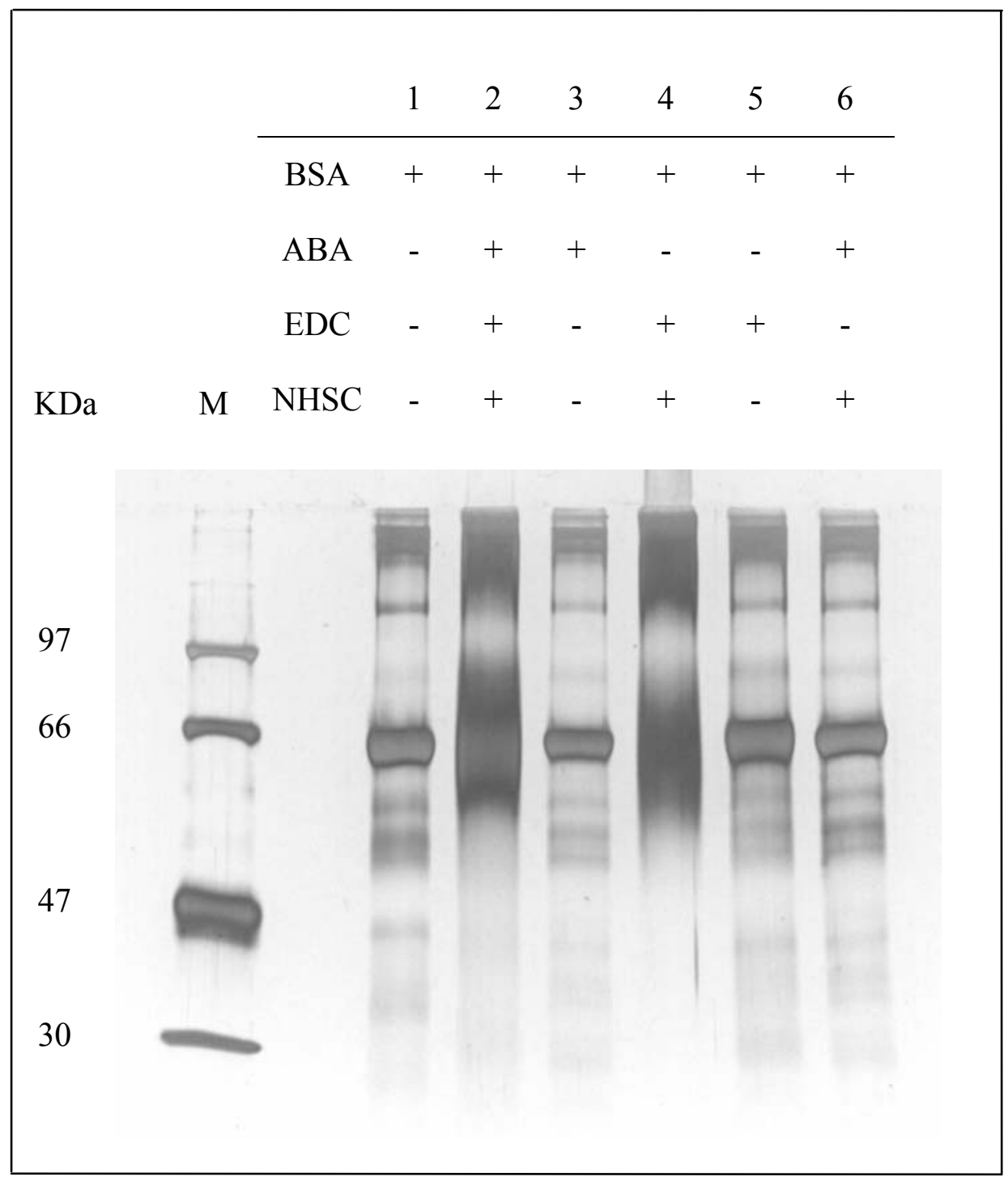

Abbildung 9: SDS-PAGE der Kopplungsprodukte von ABA an BSA, welche in An- oder Abwesenheit der Kofaktoren EDC bzw. NHSC gekoppelt wurden.

Auf dem $10 \%$ igen SDS-Gel wurden jeweils $5 \mu \mathrm{g}$ Kopplungsprodukt aufgetragen. In der Tabelle über dem SDS-Gel sind die während der Kopplungsreaktion verwendeten Faktoren angegeben.

Im Vergleich zur BSA-Bande (1) treten signifikante Unterschiede in der Bandenstruktur bei den Kopplungsprodukten aus den Reaktionen von BSA mit ABA, EDC, NHSC (2) und von BSA mit EDC und NHSC hervor. Bei diesen beiden Proben ist eine Verbreiterung der Bande zu erkennen. Eine Erhöhung der Molekulargewichte dieser Kopplungsprodukte ist im SDSGel nicht so deutlich abzulesen wie bei den massenspektrometrischen Untersuchungen. Diese Banden der Kopplungsprodukte von BSA mit ABA, EDC, NHSC (2) und von BSA mit EDC und NHSC (4) ließen sich nur durch Silber Färbung und nicht durch Coomassie-Färbung 
nachweisen. Vermutlich kann dies auf die nach der Kopplungsreaktion nicht mehr für eine Anfärbung zur Verfügung stehenden Aminogruppen zurückgeführt werden.

\subsection{Herstellung eines anti-ABA-BSA-Antikörpers}

Für Experimente stand in der Vergangenheit zum Nachweis von ABA ein polyklonaler antiABA-HSA-Antikörper der Firma Sigma zur Verfügung. Dieser wurde jedoch seit etwa 1999 nicht mehr von dem Unternehmen vertrieben. Daher wurde für die vorliegende Arbeit die Produktion eines anti-ABA-BSA-Antikörpers bei der Firma BioScience, Göttingen in Auftrag gegeben. Die Produktion des Antikörpers erfolgte in zwei Kaninchen, denen die hergestellten ABA-BSA-Konjugate (siehe Kapitel 3.1) injiziert wurden. Die aus den Tieren gewonnenen Antikörperseren wurden auf ihre Spezifität gegenüber ABA-BSA-Konjugaten hin getestet (siehe Kapitel 3.2.1). Des Weiteren wurde mittels ${ }^{3} \mathrm{H}$-ABA-Bindung der $\mathrm{K}_{\mathrm{d}}$-Wert des Antiserums bestimmt (siehe Kapitel 3.2.2). Nachdem sich die Eignung des Antikörpers herausgestellt hatte, wurde das Serum über eine Protein A-Säule aufgereinigt (siehe Kapitel 3.2.3) und im ELISA zum Nachweis von ABA-bindenden Proteinen eingesetzt.

\subsubsection{Spezifität der anti-ABA-BSA-Antikörper}

Den von der Firma Bioscience (Göttingen) immunisierten Kaninchen (426 und 423) wurde insgesamt dreimal Blut zur Serumgewinnung abgenommen (siehe Versuchsdurchführung 2.8.2). Die einzelnen Seren und die Präimmunseren wurden im ELISA auf ihre Bindung von ABA-BSA-Konjugaten hin untersucht. Dadurch sollte einerseits gezeigt werden, daß die Präimmunseren keine Reaktion mit den ABA-BSA-Antikörpern eingehen und die nach Immunisierung gebildeten Antikörper spezifisch gegen die ABA-BSA-Konjugate gebildet wurden. Andererseits sollte das Serum mit der höchsten Bindung an ABA-BSA-Konjugate ermittelt werden. 


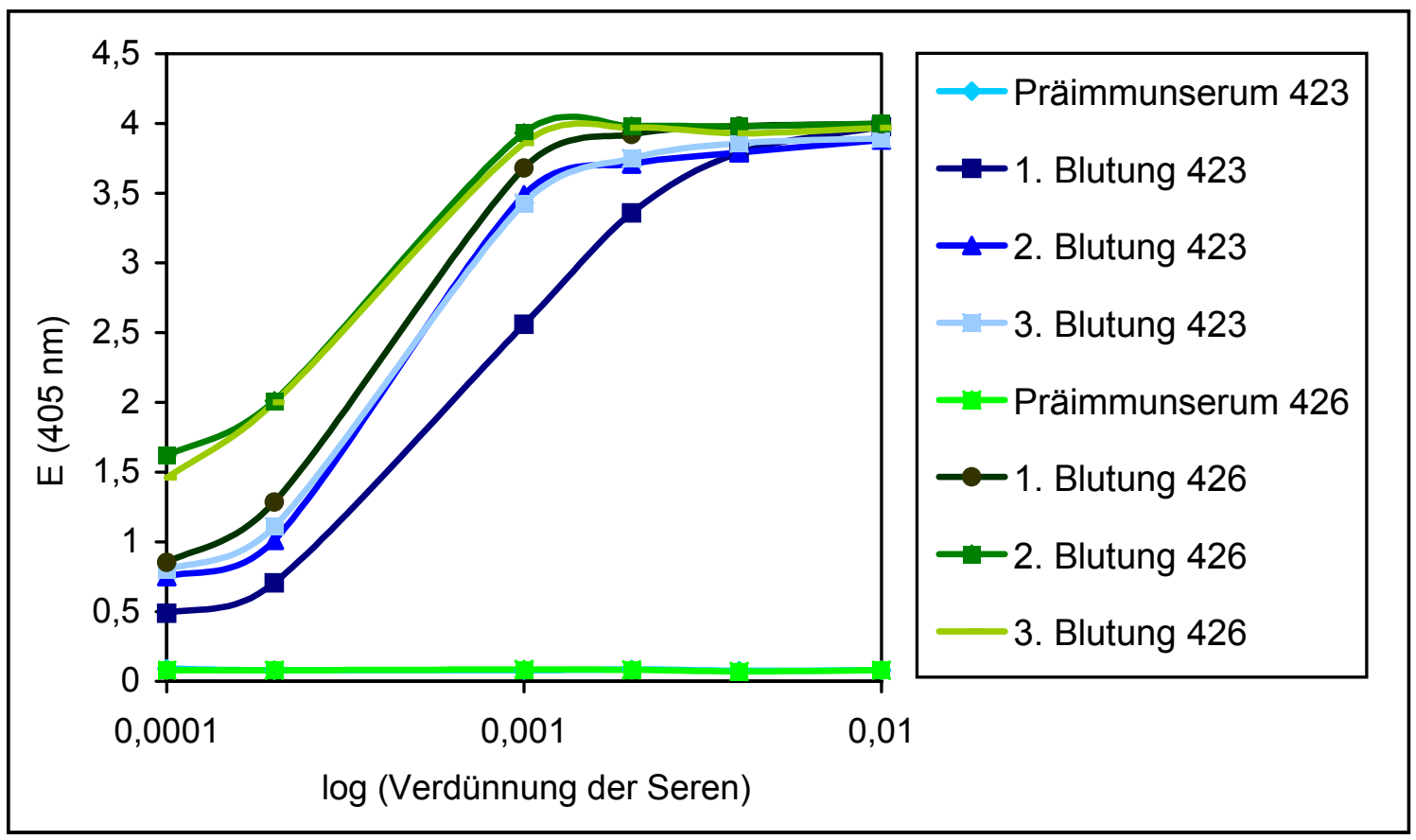

Abbildung 10: Bestimmung der Bindung der Präimmunseren und der polyklonalen Antikörperseren aus den Kaninchen 423 und 426 (jeweils 3 Blutabnahmen) an ABA-BSAKonjugate durch ELISA.

Die Mikrotiterplatten wurden mit ABA-BSA-Konjugaten $(10 \mu \mathrm{g} / \mathrm{ml})$ beschichtet und anschließend mit den Präimmunseren sowie den Seren von drei Blutabnahmen der Kaninchen 423 und 426 in unterschiedlichen Verdünnungsstufen (1:100 bis 1:10000) inkubiert. Der Nachweis der gebundenen Antikörper erfolgte über Protein A-HRP-Konjugat (1:3000).

Aus Abbildung 10 ist zu erkennen, daß die Seren der einzelnen Blutabnahmen von Kaninchen 426 im Vergleich zu denen von Kaninchen 423 gegenüber ABA-BSA-Konjugaten eine höhere Bindung aufwiesen. Die Seren der zweiten und dritten Blutabnahme des Kaninchens 426 wiesen ein höheres Bindungsvermögen gegenüber ABA-BSA-Konjugaten auf als das Serum der ersten Blutabnahme. Daher wurde das Serum der zweiten Blutabnahme des Kaninchens 426 für die Durchführung der weiteren Experimente verwendet. Für die Präimmunseren wurde keine Bindung von ABA-BSA beobachtet.

Weiterhin wurde überprüft, ob das Präimmunserum mit Proteinen aus Pflanzenextrakten eine Kreuzreaktion eingeht. Dazu wurde ein ELISA durchgeführt, wobei 0,16 bis $100 \mu \mathrm{g} / \mathrm{ml}$ der Proteinextrakte aus Spinatblättern an die Mikrotiterplatte gebunden wurden. Die Proteine wurden mit $50 \mu \mathrm{g} / \mathrm{ml}$ ABA-BSA-Konjugaten inkubiert. Das Präimmunserum wurde in einer 
Verdünnung von 1:200 eingesetzt. Gebundene Antikörper wurden mit Protein A-HRPKonjugaten nachgewiesen. Bei diesem Test konnte keine Bindung des Präimmunserums an Proteine aus Spinatextrakten gemessen werden. Daraus läßt sich schließen, daß bis zum Zeitpunkt der Immunisierung keine Antikörper von den Kaninchen gegen Proteine aus Spinatpflanzen gebildet wurden.

Tabelle 8: Bestimmung von Kreuzreaktionen des Präimmunserums mit Proteinen aus Spinatextrakten, durch ELISA.

$\begin{array}{cccccr}\text { Proteingehalt }(\mu \mathrm{g} / \mathrm{ml}) & 100 & 20 & 4 & 0,8 & 0,16 \\ \text { E }(405 \mathrm{~nm}) & 0,025 & 0,017 & 0,007 & 0,009 & 0,006\end{array}$

Um herauszufinden, ob der gegen die ABA-BSA-Konjugate gebildete Antikörper spezifisch gegen das ABA-Molekül gerichtet war oder auch die bei der Kopplungsreaktion verwendeten Kofaktoren (EDC und NHSC) detektieren konnte, wurde ein entsprechender ELISA durchgeführt. Dazu wurden ABA-BSA-Konjugate, BSA und BSA-Kopplungsprodukte, bei denen während der Kopplungsreaktion einige der Kofaktoren oder ABA weggelassen wurden (siehe Kapitel 3.1), an die Mikrotiterplatten gebunden und mit dem ABA-BSA-Antikörper inkubiert. 


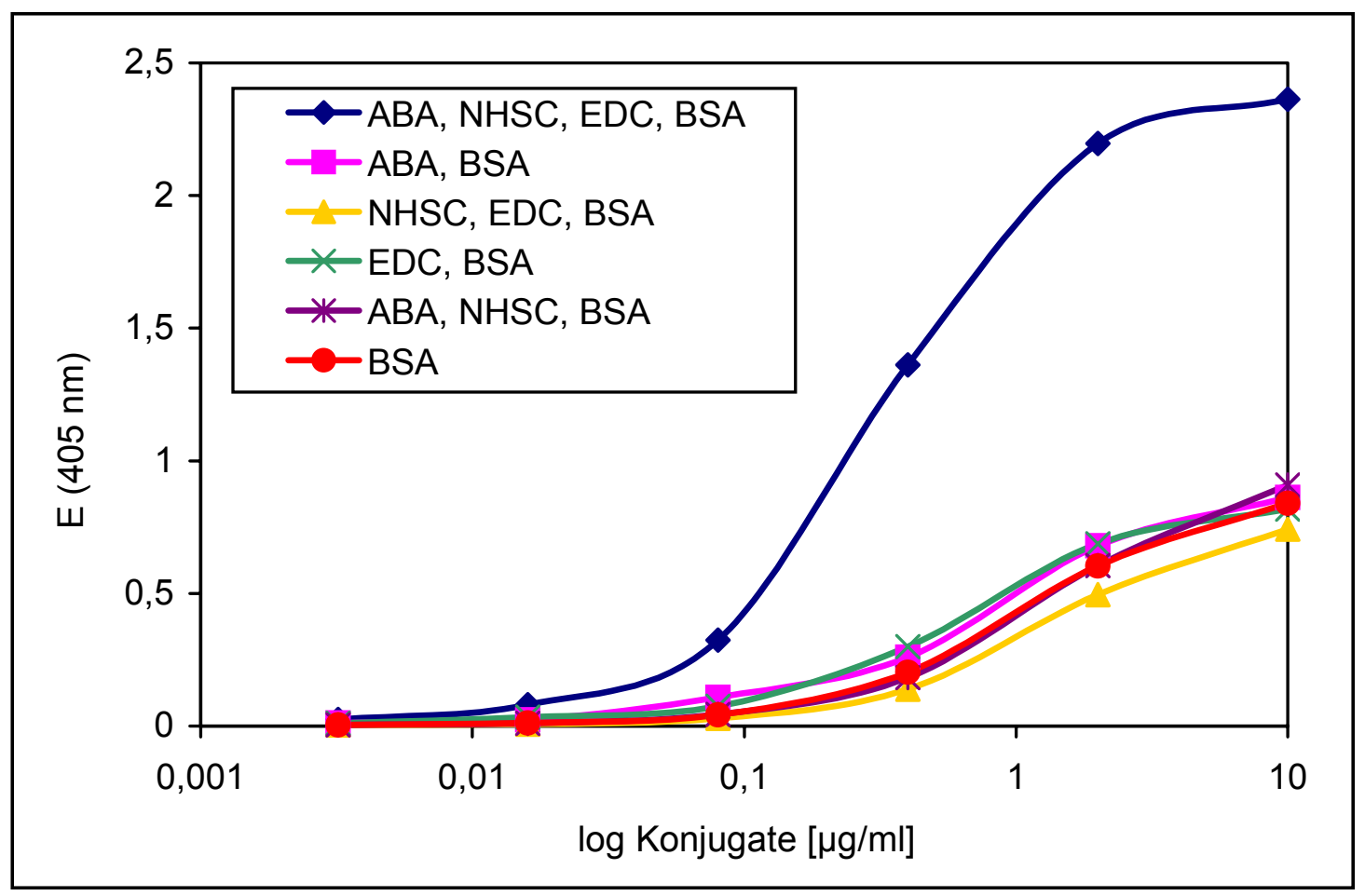

Abbildung 11: Untersuchung der spezifischen Bindung des anti-ABA-BSA-Antikörpers gegenüber ABA-BSA-Konjugat, BSA bzw. BSA-Kopplungsprodukten, die mit oder ohne Zusatz von ABA, EDC und/oder NHSC hergestellt wurden.

Die Mikrotiterplatten wurden jeweils mit Konzentrationen von 0,0032 bis $10 \mu \mathrm{g} / \mathrm{ml}$ der Konjugat-Lösungen beschichtet und mit ABA-BSA-Antikörper (1:500) inkubiert. In der Legende aufgeführt sind jeweils die Substanzen, die während der Kopplungsreaktion vorhanden waren. Der Nachweis der gebundenen ABA-BSA-Antikörper erfolgte über Protein A-HRP-Konjugat.

Aus Abbildung 11 geht hervor, daß eine bei weitem stärkere Bindung des Antikörpers an ABA-BSA-Konjugate gegenüber allen anderen BSA-Kopplungsprodukten und BSA erfolgte. Dies läßt darauf schließen, daß der ABA-BSA-Antikörper das ABA-Molekül mit relativ hoher Spezifität erkennt. Weiterhin zeigt dieser ELISA, daß der Antikörper auch Domänen des BSA-Moleküls bindet. Der Antikörper wies etwa das gleiche niedrige Bindungsvermögen gegenüber den BSA-Kopplungsprodukten, die mit oder ohne Zusatz von ABA, EDC und/oder NHSC und BSA hergestellt wurden auf. Dies zeigt, daß keine Bindung des Antikörpers an EDC oder NHSC erfolgte. 


\subsubsection{Bestimmung der Dissoziationskonstante des anti-ABA-BSA-Antikörpers}

Die Dissoziationskonstante $\left(\mathrm{K}_{\mathrm{d}}\right.$-Wert) erfaßt quantitativ die Affinität zwischen Ligand und Bindungsstelle. Je kleiner der $\mathrm{K}_{\mathrm{d}^{-}}$Wert ist, desto höher affin ist die Bindung. Hochaffin heißt eine Bindung, deren $\mathrm{K}_{\mathrm{d}}$-Wert kleiner als $10 \mathrm{nM}$ ist. Allerdings muß erwähnt werden, daß der $\mathrm{K}_{\mathrm{d}}$-Wert keine Auskunft über die Spezifität des Antikörpers gibt.

Der $\mathrm{K}_{\mathrm{d}}$-Wert des anti-ABA-BSA-Antikörpers aus der zweiten Blutung von Kaninchen 426 gegenüber ABA wurde mittels Radioimmunoassay durch Bindung von ${ }^{3} \mathrm{H}-\mathrm{ABA}$ über die logit-Transformation (Abbildung 13) bestimmt (siehe Kapitel 2.10). Auch der $\mathrm{K}_{\mathrm{d}}$-Wert des anti-ABA-HSA-Antikörpers (Sigma) gegenüber ABA wurde nach dieser Methode bestimmt. Dies war möglich, da Restbestände des ABA-HSA-Antikörpers noch vorrätig waren. Aus den Daten der Szintillationsmessungen wurde die Bindung der beiden anti-ABA-Antikörper gegen aufsteigende Konzentrationen ABA dargestellt.

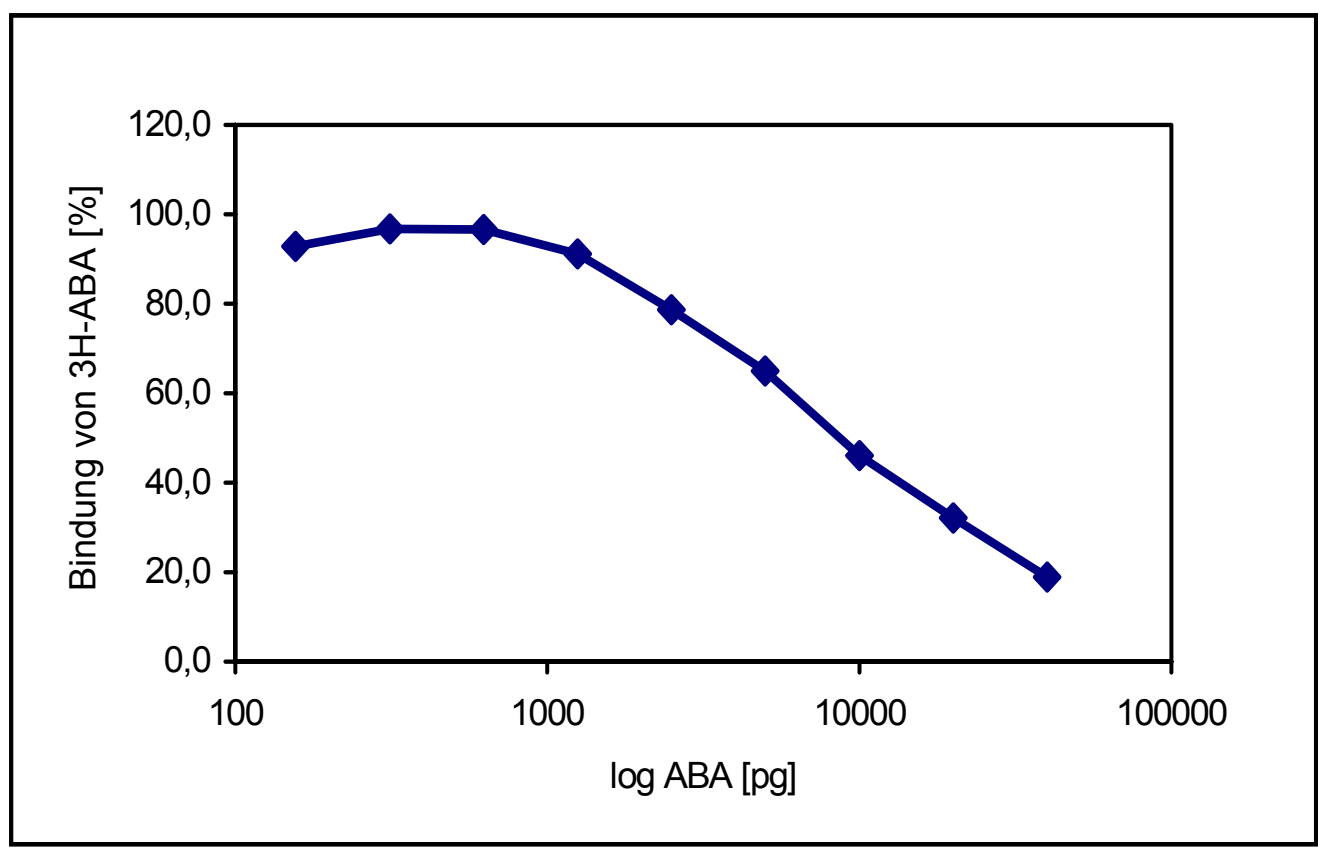

Abbildung 12: Prozentuale Bindung des anti-ABA-BSA-Antikörpers an ${ }^{3} \mathrm{H}-\mathrm{ABA}$ bei unterschiedlichen ABA-Konzentrationen $(n=4)$. 


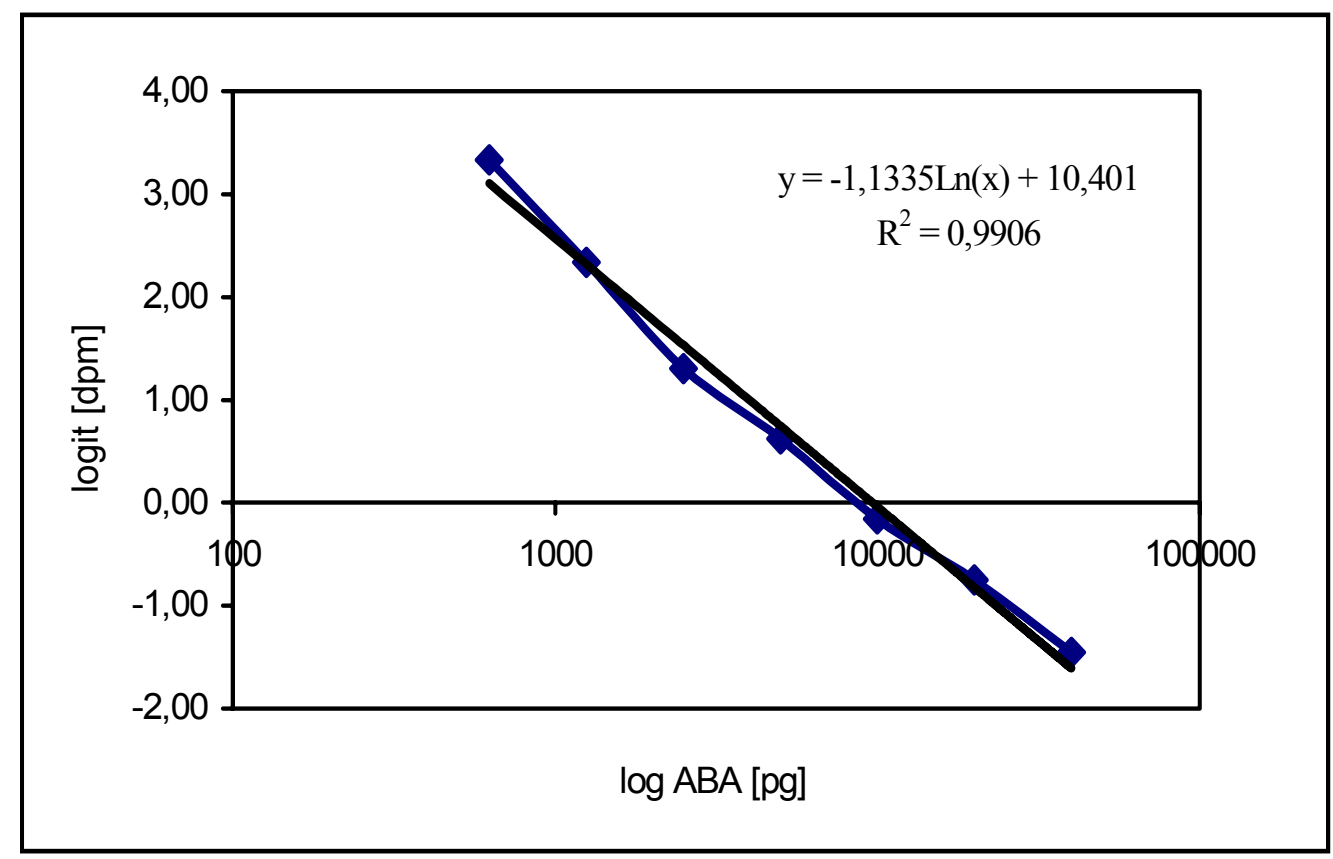

Abbildung 13: Logit-Transformation für die prozentuale Bindung des anti-ABA-BSAAntikörpers in Abhängigkeit von den ABA-Konzentrationen.

Aus der Kurve für die Bindung von ${ }^{3} \mathrm{H}-\mathrm{ABA}$ an den Antikörper (Abbildung 12) wurde die sogenannte logit-Auftragung abgeleitet (Abbildung 13) (siehe Kapitel 2.10). Für die Auswertung wurde der Bereich gewählt, in dem die ABA-Bindung an den Antikörper nahezu linear verläuft (625 - 40.000 pg ABA). Die Berechnung des $\mathrm{K}_{\mathrm{d}}$-Werts erfolgte bei halbmaximaler Bindung des Antikörpers an ABA.

Berechnung des $\mathrm{K}_{\mathrm{d}}$-Wertes für den anti-ABA-BSA-Antikörper/ABA-Komplex: $\mathrm{m}_{50 \%}$ wird aus der Geradengleichung (Abbildung 13) ermittelt: $\mathrm{y}=\mathrm{a} \ln (\mathrm{x})+\mathrm{b}$

$$
\begin{array}{llll}
\mathrm{a} & = & -1,1335 \\
\mathrm{~b} & = & 10,4 \\
\mathrm{~m}_{50 \%} & = & 8,74 * 10^{-9} \mathrm{~g} \mathrm{ABA} \\
\mathrm{M}_{\mathrm{ABA}} & = & 264,32 \mathrm{~g} / \mathrm{mol} \\
\mathrm{n}=\mathrm{m}_{50 \%} / \mathrm{M}_{\mathrm{ABA}} & = & 3,31 * 10^{-11} \mathrm{~mol} \mathrm{ABA} \\
\mathrm{V}_{\text {Probe }} & =900 \mu 1 \\
\mathbf{K}_{\mathbf{d}}=\mathbf{n} / \mathbf{M}_{\mathbf{A B A}} & = & \mathbf{3 , 6 8} * \mathbf{1 0}^{-\mathbf{8}} \mathbf{m o l ~ A B A} / \mathbf{l}=\mathbf{3 6 , 8} \mathbf{~ n M}
\end{array}
$$


Auch für den anti-ABA-HSA-Antikörper der Firma Sigma wurde der $\mathrm{K}_{\mathrm{d}}$-Wert nach dieser Methode ermittelt:

$$
\begin{array}{lll}
\mathrm{a} & = & -0,913 \\
\mathrm{~b} & = & 7,56 \\
\mathrm{~m}_{50 \%} & = & 1,00 * 10^{-9} \mathrm{~g} \mathrm{ABA} \\
\mathrm{M}_{\mathrm{ABA}} & = & 264,32 \mathrm{~g} / \mathrm{mol} \\
\mathrm{n}=\mathrm{m}_{50 \%} / \mathrm{M}_{\mathrm{ABA}} & = & 3,79 * 10^{-12} \mathrm{~mol} \mathrm{ABA} \\
\mathrm{V}_{\text {Probe }} & = & 900 \mu 1 \\
\mathbf{K}_{\mathbf{d}}=\mathbf{n} / \mathbf{M}_{\mathbf{A B A}} & = & \mathbf{4 , 2} * \mathbf{1 0}^{-\mathbf{9}} \mathbf{m o l ~ A B A} / \mathbf{l}
\end{array}
$$

Im direkten Vergleich hat der von der Firma BioScience mit den von uns hergestellten ABABSA-Konjugaten gewonnene anti-ABA-BSA-Antikörper eine etwas größere Dissoziationskonstante als der anti-ABA-HSA-Antikörper der Firma Sigma. Der gefundene $\mathrm{K}_{\mathrm{d}}$-Wert von 36,8 nM für den ABA-BSA-Antikörper läßt eine Klassifikation des Antikörpers als affin zu.

\subsubsection{Aufreinigung der Antikörper über Protein A-Säule}

Nach einer Immunisierung sind nur ein kleiner Teil der Serumproteine Antikörper. Eine Verbesserung der Spezifität des Serums kann durch Aufreinigung mittels einer Protein ASepharosesäule erreicht werden. Dabei werden die Antikörper über ihre Effektorendomäne (Fc-Domäne) spezifisch an Protein A der Säule gebunden und dadurch von den Serumproteinen abgetrennt. Das Serum des Kaninchens 426 aus der zweiten Blutabnahme wurde so über eine Protein A-Sepharose-Säule (Sigma) aufgereinigt. 


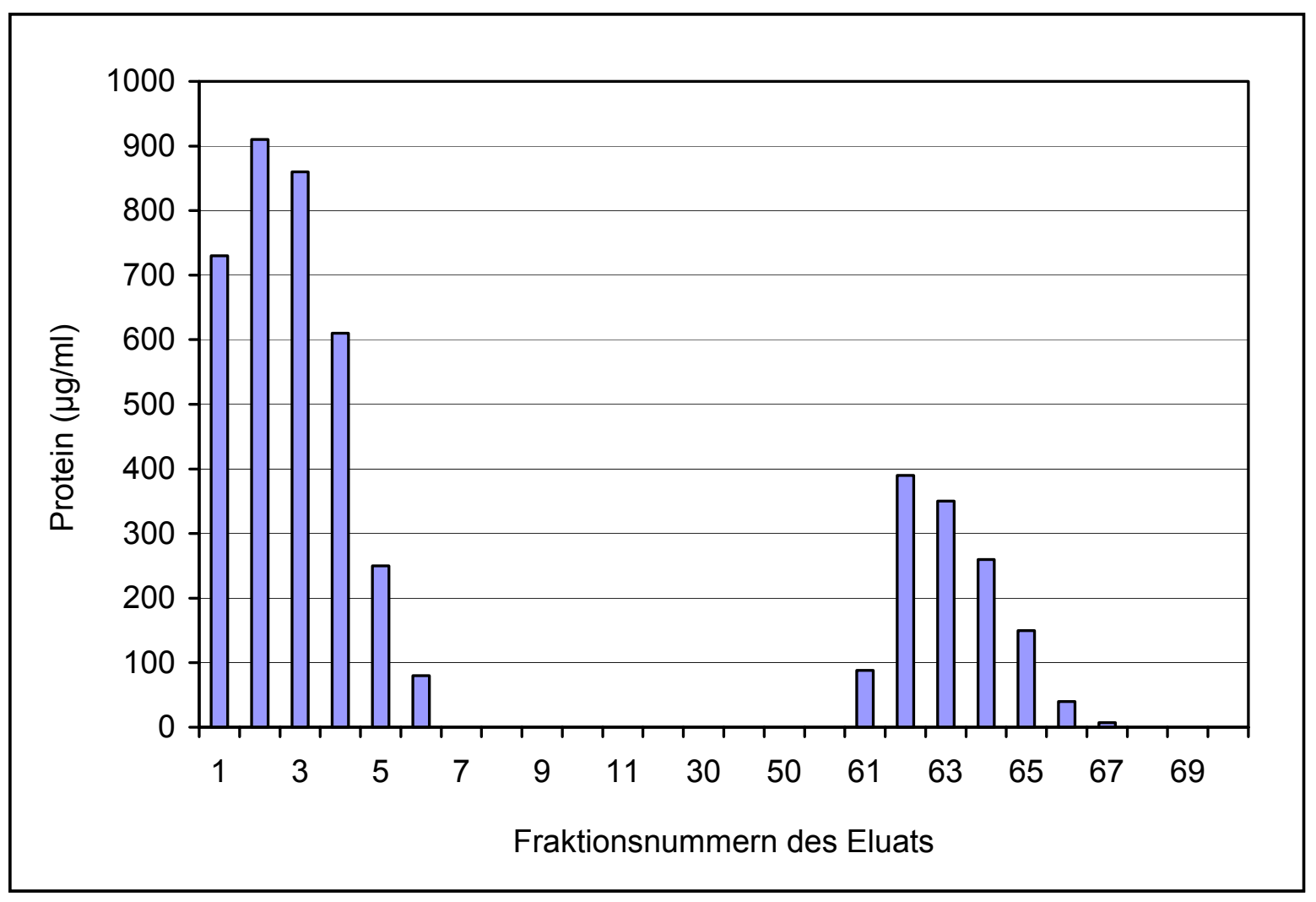

Abbildung 14: Proteingehalte der Fraktionen des Protein A-Sepharose-Säulenlaufs für die Antikörper-Aufreinigung.

Die Antikörper wurden mit $100 \mathrm{mM}$ Tris pH 8,0 an das Säulenmaterial gebunden, wobei der Großteil der Serumproteine von der Säule gewaschen wurden. Eluiert wurden die Antikörper ab Fraktion 50 mit 50 mM Glycin pH 3,0. Die Proteinbestimmung erfolgte nach Bradford.

Anhand eines SDS-Gels konnten die Fraktionen mit gereinigten Immunglobulinen mittels der erwarteten Untereinheiten der leichten $(25 \mathrm{kDa})$ und schweren $(50 \mathrm{kDa})$ Polypeptidketten von Antikörpern identifiziert werden. Die Größe der Proteinbanden wurde mit Hilfe eines Molekulargewichts-Standards durch lineare Regression von der Laufstrecke gegen den Logarithmus des Molekulargewichts bestimmt. Die Fraktionen, welche den aufgereinigten Antikörper enthielten, wurden zu einem Pool vereinigt und bei $-80^{\circ} \mathrm{C}$ gelagert. 


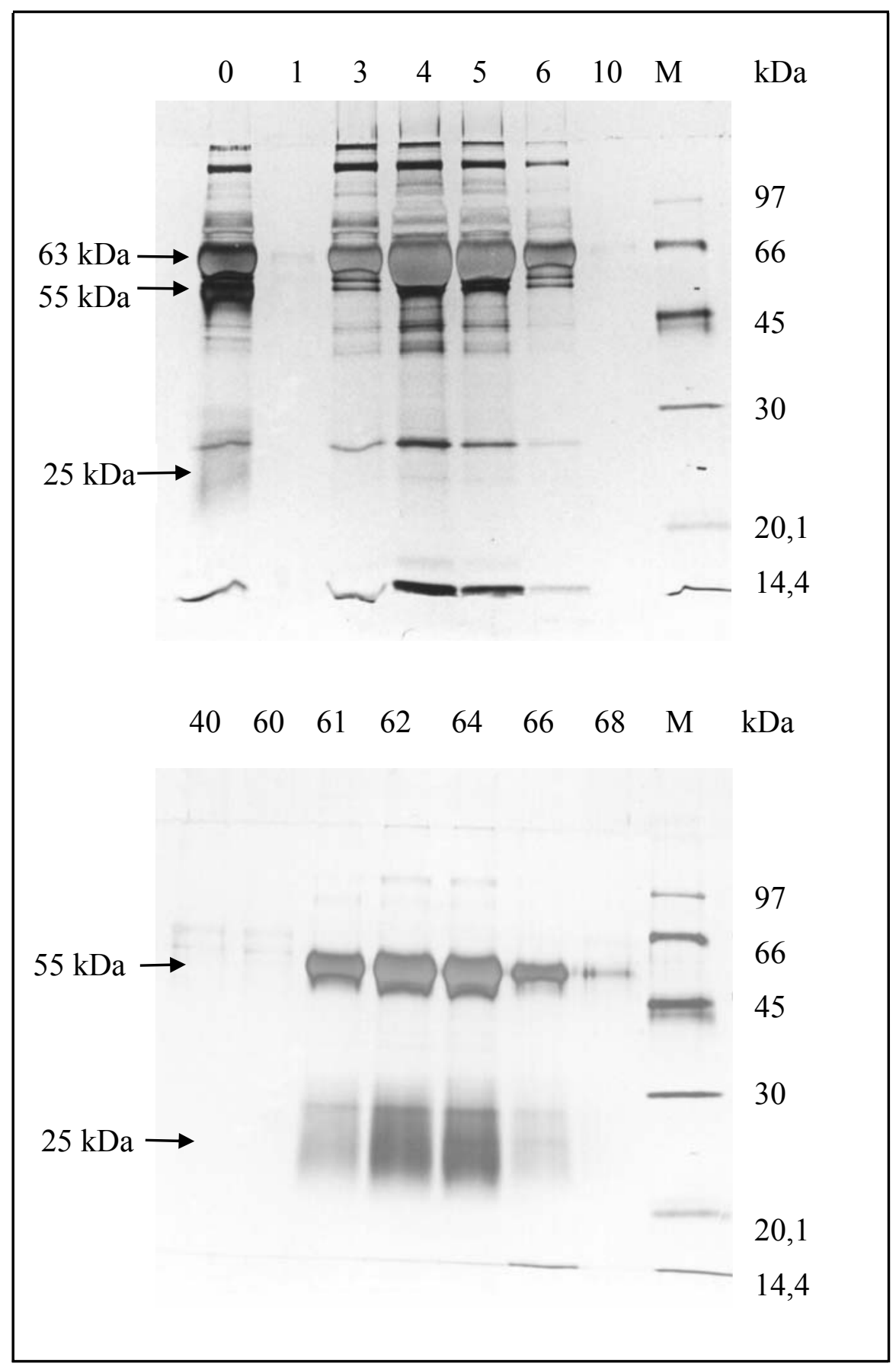

Abbildung 15: Analyse von Fraktionen der Antikörper-Aufreinigung über Protein ASepharose durch SDS-PAGE.

Spur $0=$ Serum vor der Aufreinigung, alle weiteren Nummern entsprechen den Fraktionen des Säulenlaufs, $M=$ Molekulargewichts-Standard. Es wurde pro Spur eine Proteinmenge von $2 \mu \mathrm{g}$ aufgetragen. Von Fraktionen, bei denen sich nach der Bradford-Methode kein Protein nachweisen lies, wurden $200 \mu \mathrm{l}$ aufgetragen. Die Proteine wurden mit TCA gefällt und in $12 \mu 1$ SDS-Probenpuffer solubilisiert. Die im Gel aufgetrennten Proteine wurden mittels Silber-Färbung nachgewiesen. Die Molekulargewichte der Proteine wurden durch lineare Regression bestimmt. 


\subsection{Entwicklung eines nicht-kompetitiven ELISA}

Ein wichtiges Ziel im Rahmen dieser Arbeit bestand darin, einen immunologischen Test zur Detektion ABA-bindender Proteine $\mathrm{zu}$ entwickeln. Dazu wurde der ELISA als Nachweisverfahren gewählt. Zur Erhöhung der Sensitivität dieses Verfahrens war es notwendig, das Verhältnis von spezifischer ABA-Bindung an das entsprechende Protein zu unspezifischer Bindung zu optimieren. Die dazu geeigneten Konzentrationsverhältnisse der einzelnen Komponenten und Testbedingungen wie Puffer, Inkubationszeiten, Waschschritte, etc. wurden in Vorexperimenten bestimmt. Dazu wurden Mikrotiterplatten mit ABA-ProteinKonjugaten beschichtet und eine Reaktionskaskade zum Nachweis des Antigens durch ABABSA-Antikörper und Protein A-HRP-Konjugat aufgebaut. Die jeweiligen Schritte dieses Detektionsverfahrens wurden in einzelnen Experimenten bestimmt.

\subsubsection{Beschichtung der Mikrotiterplatten}

Die Kapazität von Plastik-Mikrotiterplatten zur Bindeung von Proteinen ist begrenzt. Bei hohen Konzentrationen tendieren Proteinmoleküle stärker dazu, sich gegenseitig zu binden, wodurch eine Bindung an die Mikrotiterplatten verschlechtert werden kann. Zudem kann eine hohe Antigendichte die Detektion durch Antikörper sterisch erschweren. Aus diesem Grund wurde ein Konzentrationsbereich von 0,1 bis $10 \mu \mathrm{g} / \mathrm{ml}$ ABA-Protein-Konjugat gewählt (Kemeny, 1994). Die Beschichtung mit ABA-BSA-Konjugaten als Antigen erfolgte bei $37^{\circ} \mathrm{C}$ für eine Stunde.

Hinzu kommt, daß die Bindung der Proteine an die Mikrotiterplatten von $\mathrm{pH}-$ Wert und der Ionenstärke des Puffers, in dem sich die Proteine befinden, abhängt. Eine optimale Bindung eines Proteins an die Mikrotiterplatten muß für jedes Protein individuell bestimmt werden.

\subsubsection{Optimierung der Bedingungen zum Blocken der Mikrotiterplatte}

Freie Bindungsstellen auf der Mikrotiterplatte müssen durch ein geeignetes Protein als Blocksubstanz besetzt werden. Das Blockmittel durfte kein Antigen der anti-ABA-BSAAntikörper oder des sekundären Antikörpers sein. Als mögliche Blockmittel kamen Fischhautgelantine (Sigma, Steinheim, Deutschland), KLH (Keyhole limpet hemocyanin) (ICN, Aurora, USA) und Ovalbumin (ICN, Aurora, USA) in Betracht. 
Die Blockmittel wurden jeweils in Hinblick auf ihre unspezifische Bindung gegenüber den ABA-BSA-Konjugaten und BSA, sowie auf ihre Antigenizität gegenüber den anti-ABABSA-Antikörpern und Protein A untersucht.

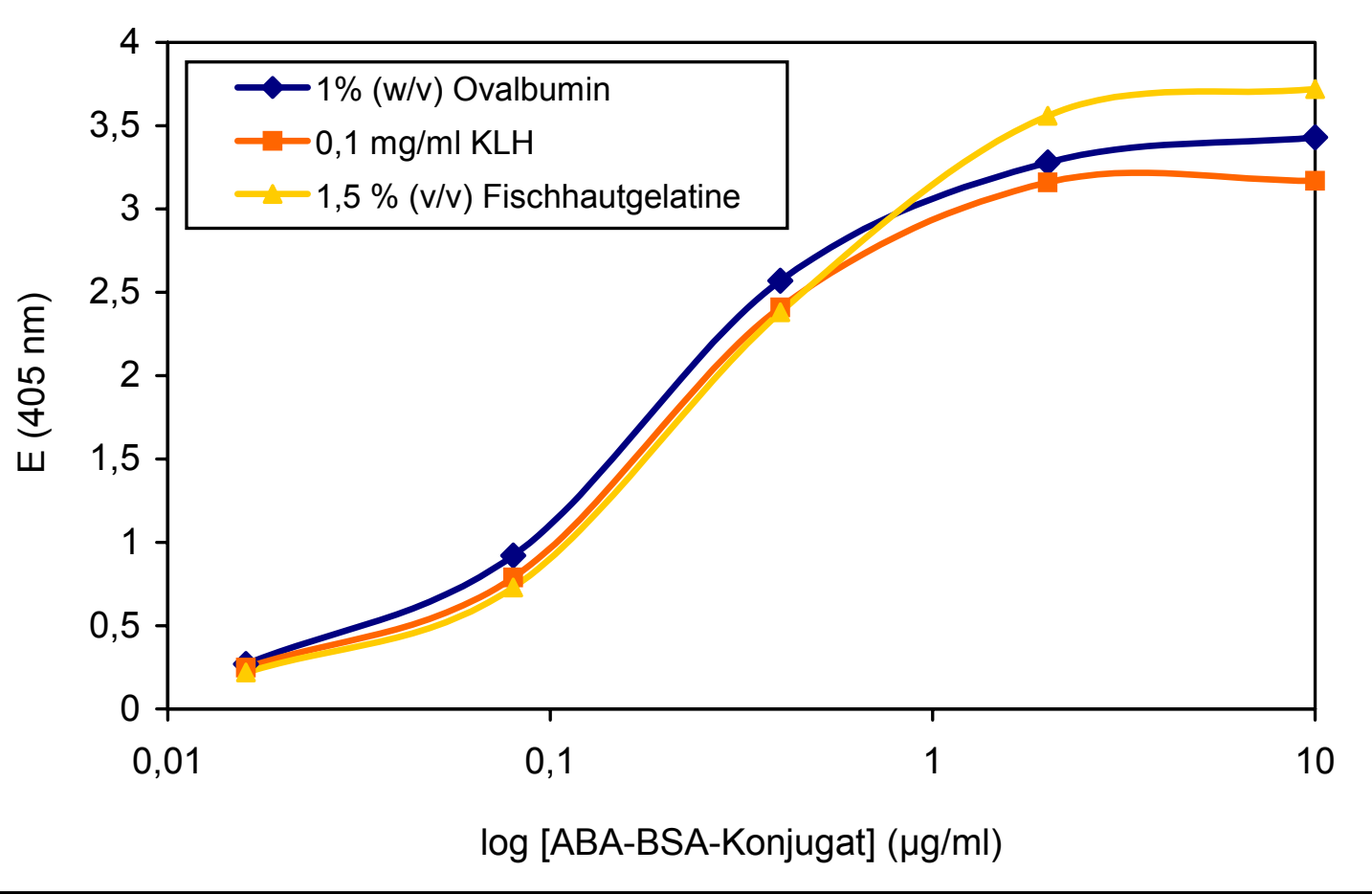

Abbildung 16: Optimierung der Wahl des Blockmittels durch ELISA.

Die Mikrotiterplatten wurden mit unterschiedlichen Konzentrationen $(0,016$ bis $10 \mu \mathrm{g} / \mathrm{ml})$ ABA-BSA-Konjugat beschichtet. Freie Bindungsstellen wurden mit verschiedenen Blockmitteln abgesättigt. Der Nachweis der ABA-BSA-Konjugate erfolgte wie im Kapitel 2.8.4 beschrieben.

Zum Blocken verwendete Proteine könnten folgende Probleme beim Nachweis des Antigens verursachen: Einerseits könnten große Proteine kleinere Antigene verdecken und dadurch ihre Detektion durch den Antikörper erschweren. Weiterhin können als Blocksubstanzen verwendete Proteine an Antigene binden und somit ebenfalls eine Detektion verhindern. Aus Abbildung 16 ist $\mathrm{zu}$ erkennen, daß keines der verwendeten Blocksubstanzen die Detektionsfähigkeit der ABA-BSA-Konjugate wesentlich verschlechtert.

Wechselwirkungen der Konjugate mit den verwendeten Blocksubstanzen wurden durch den in Abbildung 17 dargestellten ELISA bestimmt. Dazu wurden die Mikrotiterplatten mit 
verschiedenen Blockmitteln beschichtet und mit ABA-BSA-Konjugaten inkubiert. Weiterhin wurden unspezifische Bindungen des anti-ABA-Antikörpers und von Protein A an die Blocksubstanzen untersucht. Konnte kein Substratumsatz durch die Peroxidasereaktion gemessen werden, so zeigte dies, daß auch keine unspezifische Bindungen der ABA-BSAKonjugate, des Antikörpers und von Protein A an die Blockproteine vorlagen.

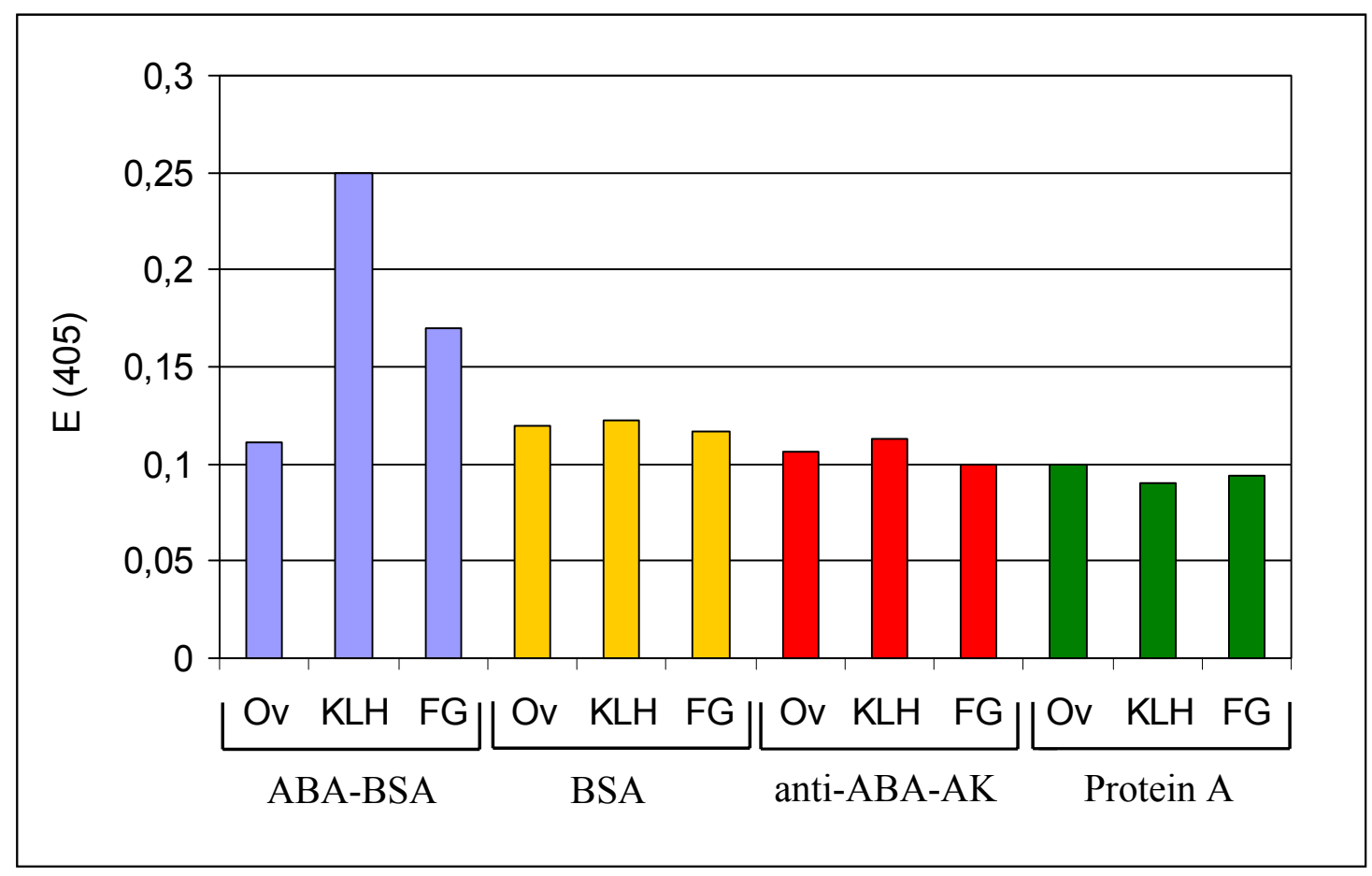

Abbildung 17: Untersuchung von unspezifischen Bindungen zwischen ABA-BSAKonjugaten, BSA, anti-ABA-Antikörper und Protein A an Ovalbumin (Ov), KLH und Fischhautgelatine (FG).

Die Mikrotiterplatten wurden mit jeweils $1 \%$ Ovalbumin, $0,1 \mathrm{mg} / \mathrm{ml} \mathrm{KLH}$ oder 1,5\% Fischhautgelatine beschichtet und mit $10 \mu \mathrm{g} / \mathrm{ml}$ ABA-BSA-Konjugaten, $10 \mu \mathrm{g} / \mathrm{ml}$ BSA, dem aufgereinigten Antikörper gegen ABA (1:500) und Protein A-HRP-Konjugat (1:3000) inkubiert. Der Bindungsnachweis wurde entsprechend der Reaktionskaskade in 2.8 .4 durchgeführt.

Aus Abbildung 17 ist zu erkennen, daß ABA-BSA-Konjugate mit KLH und geringfügig mit Fischhautgelantine unspezifische Bindungen eingehen. Ovalbumin erwies sich somit als das am besten geeignete Blockmittel. Keine nennenswerten Wechselwirkungen konnten für BSA, den anti-ABA-Antikörper und Protein A mit den Blocksubstanzen gemessen werden. 


\subsubsection{ABA-Protein-Konjugate}

Um das Bindungsvermögen des ABA-BSA-Antikörpers an verschiedene ABA-ProteinKonjugate zu untersuchen, wurde ABA nicht nur an BSA, sondern auch an Ovalbumin und KLH gekoppelt. Diese Protein-Konjugate wurden auf ihre Verwendbarkeit im ELISA getestet. Eine Kopplungseffizienz wurde nur für ABA-BSA-Konjugate ermittelt. Weiterhin wurde der Einfluß von Tween 20 auf unspezifische Wechselwirkungen der Konjugate mit Proteinen gemessen.

\subsubsection{Bindung von ABA-Protein-Konjugaten an ABA-BSA-Antikörper}

Geeignete ABA-Protein-Konjugate wurden im ELISA in Hinblick auf spezifische Bindung an ABA-BSA-Antikörper untersucht. Hierfür wurden Konjugate verwendet, bei denen ABA mit BSA, Ovalbumin und KLH gekoppelt wurde. Um optimale Konzentrationsverhältnisse zwischen Antigen und Antikörper herauszufinden, wurden unterschiedliche Konzentrationen der Konjugate an die Mikrotiterplatten gebunden und mit dem Antikörper inkubiert.

Der Vergleich der Bindung des ABA-BSA-Antikörpers an unterschiedliche ABA-ProteinKonjugate zeigt einen deutlichen Unterschied in seinem Bindungsverhalten (Abbildung 18). Eine starke Bindung des ABA-Antikörpers konnte an ABA-BSA-Konjugate und ABA-KLHKonjugate nachgewiesen werden. Bei ABA-Ovalbumin-Konjugaten wurde darüber hinaus beobachtet, daß eine Erhöhung der Konjugat-Konzentration über $2 \mu \mathrm{g} / \mathrm{ml}$ zu einer verringerten Bildung von Antikörper-Konjugat-Komplexen führte. Die Ergebnisse zeigen, daß ABA-BSA und ABA-KLH-Konjugate durch den ABA-Antikörper gleichermaßen detektiert werden. 


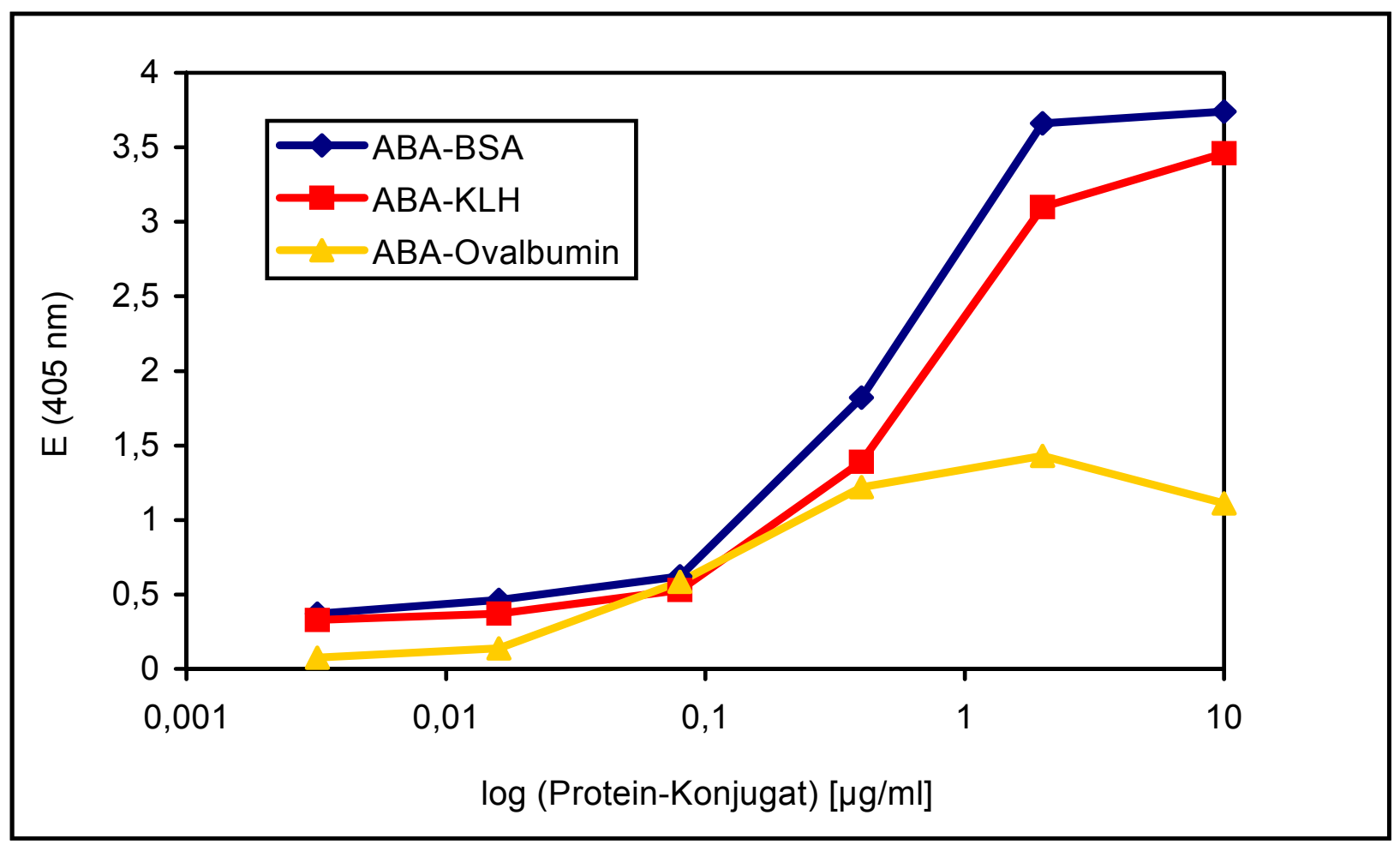

Abbildung 18: Bestimmung der Konzentrationsabhängigkeit der Bindung des ABA-BSAAntikörpers an diverse ABA-Protein-Konjugate durch ELISA.

Die Mikrotiterplatte wurde mit ABA-Protein-Konjugaten (ABA-BSA, ABA-KLH und ABAOvalbumin) in Konzentrationen von 0,0032 bis $10 \mu \mathrm{g} / \mathrm{ml}$ beschichtet. Anschließend wurden die Konjugate mit dem aufgereinigten ABA-BSA-Antikörper (1:500) inkubiert. Ein Nachweis der gebundenen Antikörper erfolgte über Protein A-HRP-Konjugat.

Für den ELISA zum Nachweis von ABA-bindenden Proteinen wurden im Folgenden die ABA-BSA-Konjugate verwendet. Die ABA-BSA-Konjugate boten den Vorteil, daß unspezifische Wechselwirkungen des Trägerproteins BSA mit den Proteinen aus Pflanzenextrakten gemessen werden können. Dies ergibt sich daraus, daß der verwendete ABA-Antikörper sowohl die ABA-BSA-Konjugate als auch BSA detektieren kann. Der ELISA wurde so durchgeführt, daß Extrakte oder Fraktionen immer in Kontrollexperimenten mit BSA anstelle von ABA-BSA-Konjugaten inkubiert wurden. Eine unspezifische Bindung des Trägerproteins BSA an Proteine der Extrakte konnte durch die Bindung der ABA-BSAAntikörper nachgewiesen werden. Einen analogen Vorteil boten KLH und Ovalbumin nicht, da für diese Proteine keine Antikörper erhältlich waren. Unspezifische Bindungen dieser Trägerproteine mit Proteinextrakten konnten dadurch nicht gemessen werden. 


\subsubsection{Einfluß von Tween 20 auf Protein-Wechselwirkungen}

Bei einigen Experimenten wurde Tween 20 in unterschiedlichen Konzentrationen zu den Proben gegeben. Damit wurde untersucht, ob sich unspezifische Protein-ProteinWechselwirkungen reduzieren lassen und welche Tween-Konzentration dazu notwendig ist. Dazu wurde ein ELISA durchgeführt, wobei die Mikrotiterplatten mit Ovalbumin beschichtet und abgesättigt wurden. Anschließend wurden die Platten mit BSA unter Zugabe von verschiedenen Tween 20-Konzentrationen inkubiert. Dadurch konnte gezeigt werden, daß durch Zugabe von 0,05\% Tween 20 unspezifische Bindungen bereits deutlich reduziert wurden. Wurde kein Tween 20 dazugegeben, zeigte sich eine hohe unspezifische Bindung zwischen BSA und Ovalbumin (Daten nicht gezeigt). Dies verdeutlicht, daß sich unspezifische Wechselwirkungen zwischen Proteinen durch die Zugabe von Tween 20 deutlich reduzieren. Der ELISA zum Nachweis von ABA-bindenden Proteinen wurde daher mit ABA-BSA-Konjugaten, BSA, anti-ABA-BSA-Antikörper und Protein A unter Zugabe von $0,1 \%$ Tween 20 durchgeführt.

\subsubsection{Optimierung der Bindung des anti-ABA-BSA-Antikörpers}

Die Seren aus der zweiten Blutabnahme der Kaninchen 426 und 423 wiesen die höchste Bindung an ABA-BSA-Konjugate auf. Diese Seren sollten für eine Verwendung im ELISA getestet und optimiert werden.

\subsubsection{Verdünnung des Serums}

Zur Durchführung des ELISAs war es notwendig, eine optimale Verdünnung der anti-ABABSA-Seren zu ermitteln. Optimal ist ein hohes Verhältnis von spezifischen zu unspezifischen Bindungen (Signal-zu-Rausch-Verhältnis) des Antikörpers. Dazu wurden die Seren der Kaninchen 423 und 426 in unterschiedlichen Verdünnungen zur Bindung an ABA-BSAKonjugate bzw. BSA eingesetzt. Anschießend wurde das Verhältnis von ABA-BSA-Konjugat und BSA-Bindung an den Antikörper ermittelt. 


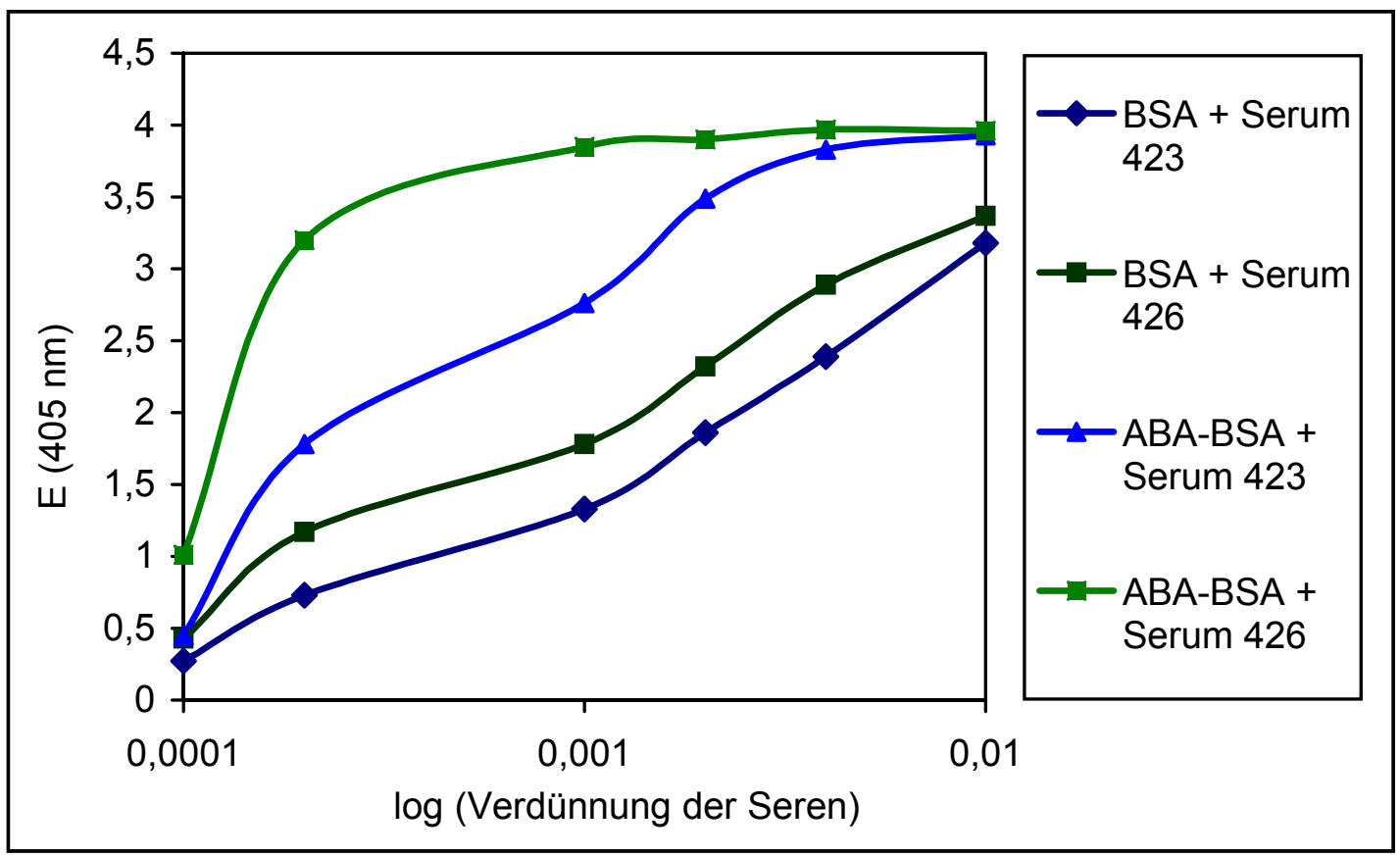

Abbildung 19: Untersuchung des polyklonalen anti-ABA-BSA-Serums aus der zweiten Blutung auf Bindung an ABA-BSA-Konjugate und BSA im ELISA.

Die Mikrotiterplatten wurden mit ABA-BSA bzw. BSA $(10 \mu \mathrm{g} / \mathrm{ml})$ beschichtet und mit den Seren der Kaninchen 423 sowie 426 in unterschiedlichen Verdünnungsstufen inkubiert. Der Nachweis der gebundenen Antikörper erfolgte über Protein A-HRP-Konjugat.

Tabelle 9: Differenz der gemessenen Extinktionen bei der Bindung zwischen ABA-BSAKonjugat und BSA der anti-ABA-BSA-Seren aus der zweiten Blutung aus Kaninchen 423 und 426.

Die Daten wurden aus Abbildung 19 berechnet.

Verdünnung

$1: 100$

$1: 250$

$1: 500$

$1: 1000$

$1: 5000$

$1: 10000$
Serum 423

0,75

0,59

1,44

1,08

1,63

1,58

1,43

2,07

1,05

2,03

0,18

0,58 
Bei einer Verdünnung des Serums von Kaninchen 426 von 1:1000 bis 1:5000 ist das Verhältnis der Bindung von ABA-BSA-Konjugat zu BSA an höchsten. Die im ELISA ermittelte Differenz beträgt bei beiden Verdünnungsstufen etwa 2 Extinktionseinheiten. Für diesen Bereich liegt somit ein optimales Signal-zu-Rausch-Verhältnis vor. Daher wurde für alle weiteren Experimente das Serum des Kaninchens 426 mit einer Verdünnung von 1:3000 eingesetzt.

Bei der Aufreinigung der ABA-BSA-Antiseren über Protein A-Säulen (siehe Kapitel 2.9) wird die Lösung um einen Faktor von ungefähr 10 bis 12 verdünnt. Daher wurde der aufgereinigte Antikörper abhängig vom Experiment in einer Verdünnung zwischen 1:200 und 1:500 eingesetzt.

\subsubsection{Inkubationszeit des ABA-BSA-Antikörpers}

Zur Ermittlung optimaler Inkubationszeiten des Antikörpers wurden Experimente mittels ELISA durchgeführt. Dazu wurden ABA-BSA-Konjugate für eine, zwei oder drei Stunden mit den Antikörper inkubiert. Die Konzentrationen der ABA-BSA-Konjugate wurden bei diesem Experiment im Bereich von 0,016 bis $10 \mu \mathrm{g} / \mathrm{ml}$ variiert.

Aus Abbildung 20 ist zu erkennen, daß bereits eine Inkubationszeit von zwei Stunden genügte, um eine maximale Bindung des Antikörpers an die ABA-BSA-Konjugate zu gewährleisten. Weiterhin ist aus der Abbildung zu entnehmen, daß auch nach drei Stunden Inkubationszeit keine signifikante Abnahme der Menge gebundener Antikörper auftrat. Daraus läßt sich schließen, daß die Bindung der Antikörper an ABA-BSA-Konjugate längere Zeit stabil blieb. Für die Durchführung des ELISAs zum Nachweis ABA-bindender Proteine wurde daher eine Inkubationszeit von zwei Stunden gewählt.

Analoge ELISA-Experimente wurden auch zur Ermittlung optimaler Inkubationszeiten für die Bindung des Antikörpers an ABA-Ovalbumin- und ABA-KLH-Konjugaten durchgeführt (Daten nicht gezeigt). Für ABA-Ovalbumin-Konjugate zeigte sich eine maximale Bindung an den Antikörper bereits nach einer Stunde. Auffällig war, daß bei einer KonjugatKonzentration von $10 \mu \mathrm{g} / \mathrm{ml}$ die Bindung der Antikörper wieder schwächer wurde. ABAKLH-Konjugate zeigten eine maximale Bindung nach zwei Stunden. Die Bindung der Antikörper blieb für alle Konjugate bei einer Inkubationszeit von drei Stunden stabil. 


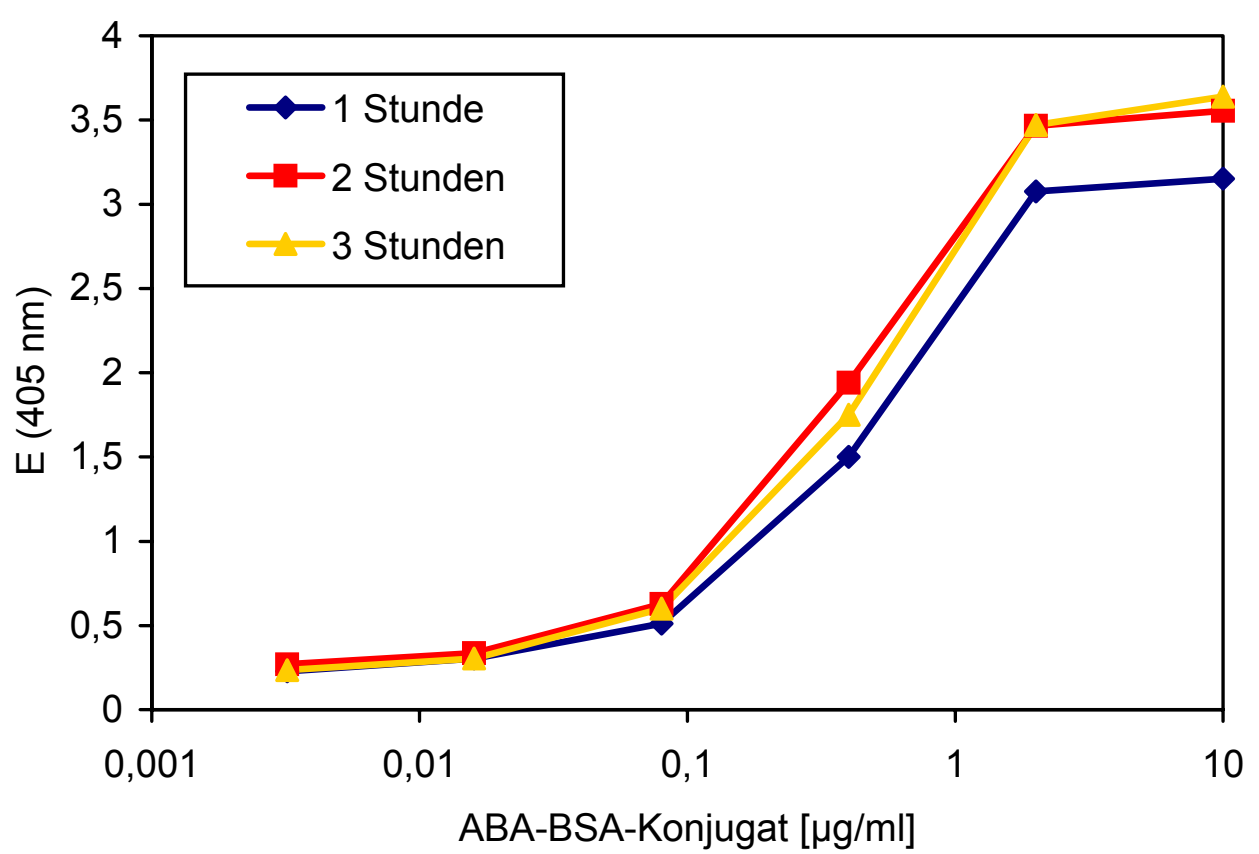

Abbildung 20: Bestimmung der optimalen Inkubationszeit zur Bindung des anti-ABA-BSAAntikörpers an unterschiedliche ABA-BSA-Konjugat-Konzentrationen durch ELISA $(\mathrm{n}=2)$.

Die Mikrotiterplatten wurden mit ABA-BSA $(0,0032$ bis $10 \mu \mathrm{g} / \mathrm{ml})$ beschichtet und mit dem ABA-BSA-Antikörper (1:500) 1, 2 und 3 Stunden inkubiert. Der Nachweis der gebundenen Antikörper erfolgte über Protein A-HRP-Konjugat.

\subsubsection{Sekundärer Antikörper}

Protein A bindet Kaninchen-Antikörper sehr gut, daher wurde zum Nachweis der ABA-BSAAntikörper aus Kaninchen die Protein A-Meerrettichperoxidase (HRP) gewählt. Nach Aussage des Herstellers (BioRad) liegt die optimale Verdünnung von Protein A-HRPKonjugat im ELISA bei 1:3000. Für die Durchführung des ABA-BSA-ELISAs wurde das Konjugat dazu in der genannten Konzentration verwendet.

\subsubsection{Farbreaktion}

Als Substrat der Meerrettichperoxidase wurde 2,2`-Azino-bis (3-Ethylbenz-Thiazolin-6sulfonsäure) (ABTS) verwendet. Die Peroxidase setzt bei saurem pH-Wert und in Gegenwart von Wasserstoffperoxid ABTS zu einem grün gefärbtes, deutlich sichtbares Produkt um, welches bei einer Wellenlänge von $405 \mathrm{~nm}$ Licht absorbiert. 


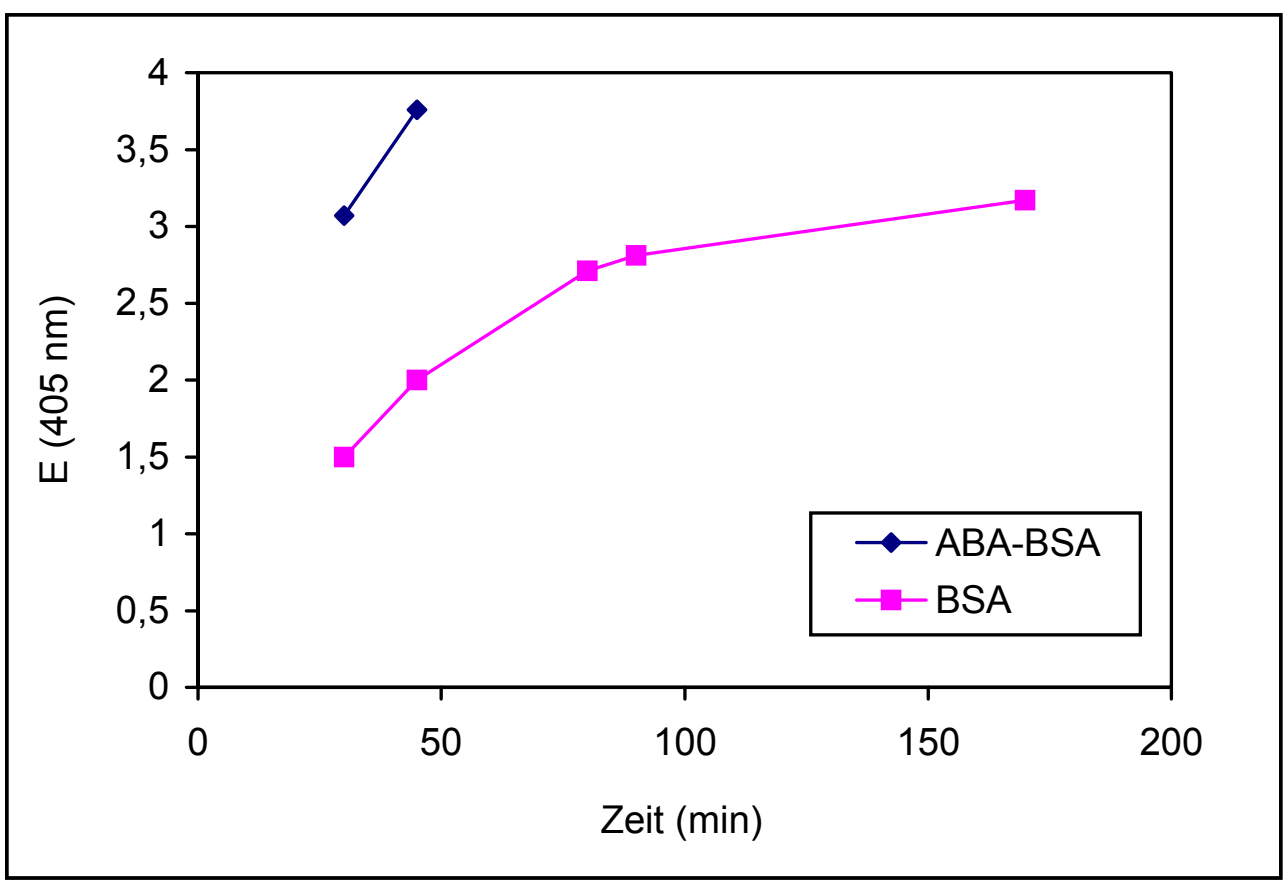

Abbildung 21: ELISA zur Bestimmung der optimalen Reaktionszeit der Peroxidase-HRPKonjugat mit ABTS.

Die Mikrotiterplatten wurden mit $10 \mu \mathrm{g} / \mathrm{ml}$ ABA-BSA-Konjugat bzw. BSA beschichtet und mit $1 \%$ Ovalbumin abgesättigt. Der Nachweis gebundener Konjugate bzw. BSA-Moleküle erfolgte über aufgereinigten Antikörper gegen ABA-BSA-Konjugate (1:500) (vier Meßwerte wurden aufgezeichnet).

Die Farbreaktion der Peroxidase mit ABTS zeigte einen exponentiellen Verlauf der Extinktion als Funktion der Zeit. Auch nach einer Reaktionszeit von fast drei Stunden stieg die Extinktion weiter an (Abbildung 21). Bei den Experimenten mit ABA-BSA-Konjugaten in einer Konzentration von $10 \mu \mathrm{g} / \mathrm{ml}$ stieg die Extinktion nach etwa 80 Minuten über den Wert von 4 und verließ damit den Meßbereich. Sollten mehrere ELISA-Platten miteinander verglichen werden, wurde eine Reaktionszeit der Peroxidase von genau 30 min eingehalten.

\subsection{Kopplung von ABA an EAH-Sepharose}

Für die Aufreinigung von ABA-bindenden Proteinen mittels Affinitäts-Chromatographie mußte ABA als Ligant an ein Säulenmaterial gekoppelt werden. In der vorliegenden Arbeit wurde die Effizienz verschiedener Kopplungsreaktionen von ABA an unterschiedliche Säulenmaterialien untersucht. Zur Überprüfung der Kopplungseffizienz wurde den Reaktionsansätzen entweder ${ }^{3} \mathrm{H}-\mathrm{ABA}$ zugegeben, oder der Erfolg der Kopplungsreaktion 
wurde durch die Bindung von anti-ABA-Antikörper an das Säulenmaterial überprüft. Dazu wurde das fertige Säulenmaterial mit dem Antikörper inkubiert. Eine hohe Bindung des Antikörpers an das Säulenmaterial spiegelte eine hohe Kopplungseffizienz wieder. Die folgende Tabelle gibt eine Übersicht über die untersuchten Kopplungsreaktionen und die dabei verwendeten Säulenmaterialien.

Tabelle 10: Übersicht über die verwendeten Kopplungsmethoden von ABA über deren Ketound Carboxylgruppe an ein Säulenmaterial.

A) Kopplung von ABA über die Ketogruppe:

Säulenmaterial

Reaktive Gruppe

Reaktion

Thiopropyl-Sepharose 6 B

Thiol (R-SH)

Kondensation

EAH-Sepharose 4 B

Aminogruppe $\left(\mathrm{R}-\mathrm{NH}_{2}\right)$

Reaktion zu einem instabilen

Imin und anschließende

Reduktion zu einem stabilen

Amin

a) $\mathrm{BH}^{-}$

b) $\mathrm{BH}_{3} \mathrm{CN}^{-}$

B) Kopplung von ABA über die Carboxylgruppe

EAH-Sepharose 4 B

Aminogruppe

Nukleophile Substitution

Katalysator: EDC

Die Kopplung von ABA über deren Carboxylgruppe an die Aminogruppe der EAHSepharose 4 B nach der Carbodiimid-Methode ergab die besten Kopplungsergebnisse. Um zu überprüfen, ob das so hergestellte ABA-Sepharose-Säulenmaterial für die reversible Bindung von ABA-bindenden Proteinen geeignet ist, wurden Säulenläufe mit einem polyklonalen antiABA-Antikörper (Sigma) durchgeführt. Es zeigte sich, daß dieser mit hoher Affinität an das 
Säulenmaterial gebunden wurde. Der Antikörper konnte nicht durch Elution mit 5 mM ABA sondern erst durch anschließendes Waschen bei unterschiedlichen pH-Werten von der Säule eluiert werden. Für den Nachweis des anti-ABA-Antikörpers wurden die Fraktionen auf eine Dot-Blot-Apperatur aufgetragen und der ABA-Antikörper durch Peroxidase-markiertes Protein A nachgewiesen (Abbildung 22).

Die Säule wurde mit Na-Acetat-Puffer $\mathrm{pH}$ 4,5 äquilibiert und nach dem Auftragen des Antikörpers mit Na-Acetat-Puffer pH 4,5 gewaschen. In den ersten Fraktionen wurde nur wenig Antikörper mit Puffer ausgewaschen. Bei diesem pH-Wert sollte der Antikörper an ABA binden (Weiler, 1979). Ab Fraktion 25 wurde versucht, den Antikörper durch $5 \mathrm{mM}$ ABA von der Säule zu eluieren. Wegen der hohen Affinität des Antikörpers zu ABA gelang die Ablösung erst durch Veränderung des pH-Wertes (ab Fraktion 39). Dieses Experiment zeigt, daß die Kopplung von ABA an die EAH-Sepharose $4 \mathrm{~B}$ erfolgreich verlaufen ist und daß das Säulenmaterial für eine reversible Bindung ABA-bindender Proteine geeignet ist.

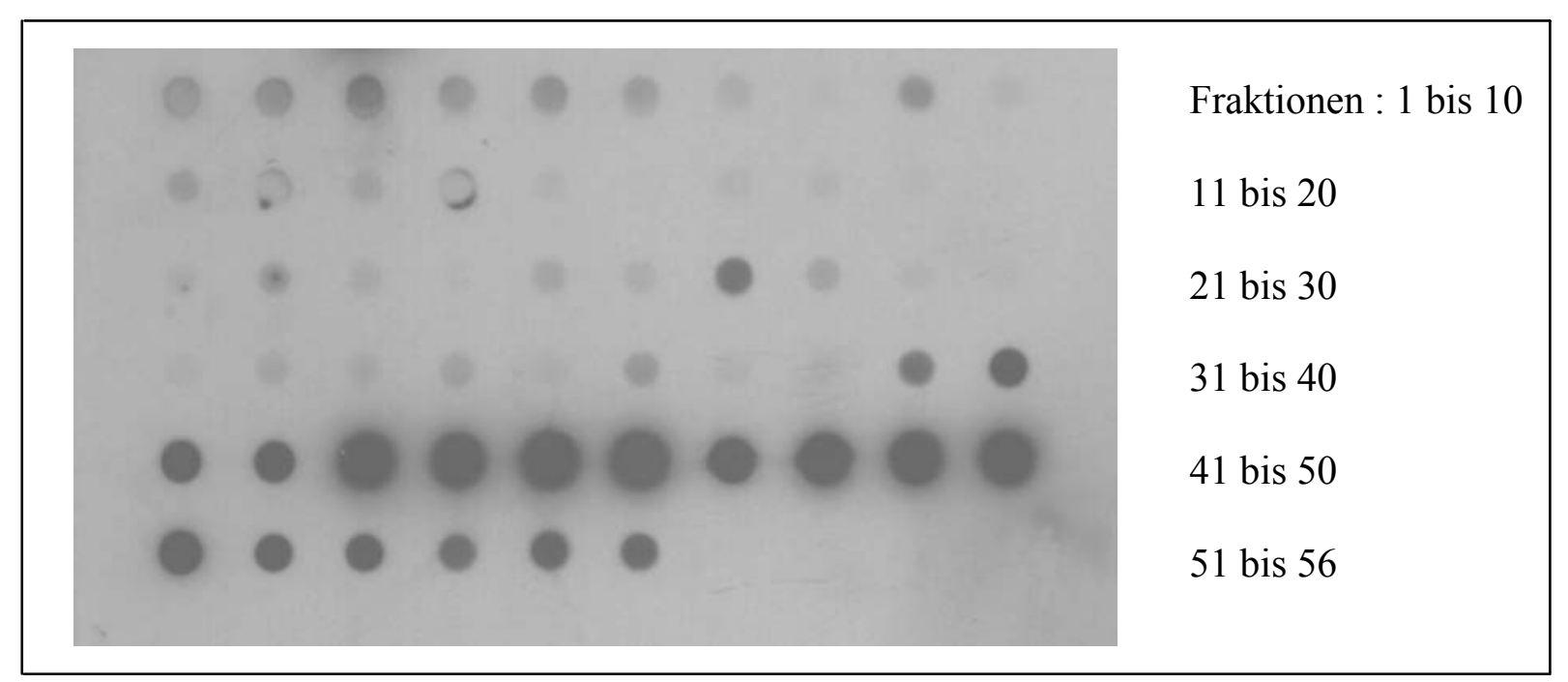

Abbildung 22: Dot-Blot-Analyse der Bindung eines anti-ABA-BSA-Antikörpers an ABAEAH-Sepharose 4 B-Säule zum Nachweis der Kopplungseffizienz von ABA an EAHSepharose 4 B.

Nachdem der Antikörper auf die mit ABA gekoppelte EAH-Sepharose 4 B-Säule aufgetragen wurde folgte ab Fraktion 1 bis 25 ein Waschen der Säule mit Na-Acetat-Puffer $\mathrm{pH}$ 4,5. Ab Fraktion 25 folgte die Elution mit $5 \mathrm{mM}$ ABA. Anschließend wurde die Säule ab Fraktion 39 im Wechsel mit Na-Acetat-Puffer $\mathrm{pH}$ 4,5 und Tris-Puffer $\mathrm{pH}$ 8,5 gewaschen. Pro Fraktion wurden $300 \mu \mathrm{l}$ auf die Dot-Blot-Apperatur aufgetragen und die Antikörper durch Peroxidasemarkiertes Protein A nachgewiesen. 


\subsection{Aufreinigung von cytosolischen Proteinen}

Entsprechend der Zielsetzung der vorliegenden Arbeit wurde für die Aufreinigung ABAbindender Proteine eine Extraktionsmethode gewählt, bei der hauptsächlich lösliche cytosolische Proteine erhalten werden. Dazu wurden 14 Tage alte Spinat- oder ArabidopsisPflanzen im Mörser auf Eis homogenisiert. Die dem Homogenisationspuffer zugegebenen Proteinase-Inhibitoren sollten einen Verdau der Proteine durch die bei der Präparation aus der Vakuole freiwerdenden Proteinasen verhindern. Im Anschluß daran wurde das Homogenat filtiert und die cytosolischen Proteine über mehrere Zentrifugationsschritte angereichert. Die erste Zentrifugation erfolgte bei einer relativ niedrigen Geschwindigkeit (650 x g), so daß zunächst nur größere Zelltrümmer und Stärkekörner sedimentiert wurden. Diese Abtrennung der Stärke von den Organellen sollte bewirken, daß ein höherer Anteil der Organellen intakt blieb. Die zweite Zentrifugation erfolgte bei 13.000 x g, dabei wurden Zellbruchstücke, Zellkerne, und intakte Chloroplasten und andere Organellen sedimentiert. Die anschließende Zentrifugation in der Ultrazentrifuge bei $150.000 \mathrm{x} \mathrm{g}$ diente der Sedimentation von Endomembranen. Bei der Extraktion von Proteinen aus Arabidopsis wurde dem Puffer zusätzlich Sorbitol als Osmotikum zugesetzt. Ein generelles Ziel bestand darin, bei den Präperationsschritten Zellorganellen möglichst intakt zu sedimentieren.

Zur Volumenreduktion der proteinhaltigen Überstände wurden die löslichen Proteine mit $80 \%$ (w/v) Ammoniumsulfat gefällt und erneut in Puffer gelöst. Für die weitere Aufreinigung der Arabidopsis-Extrakte mittels Kationenaustauschersäule-(DEAE)-Säule wurden die gelösten Proteine über eine Sephadex G-25 Säule entsalzt. Die weitere Auftrennung der

Proteine aus Spinatextrakten wurde hingegen mittels Gelfiltrations-Chromatographie vorgenommen (Kapitel 3.6). Die Fraktionen des Eluats der DEAE-Säule bzw. der Gelfiltrationssäule wurden im ELISA auf ABA-Bindung getestet. Fraktionen der DEAESäule mit hoher ABA-Konjugat-Bindung im ELISA wurden mittels ABA-Affinitätssäule (ABA-EAH-Sepharose) weiter aufgereinigt (Kapitel 3.9).

\subsection{Aufreinigung ABA-bindender Proteine aus Spinatpflanzen}

Für den Nachweis ABA-bindender Proteine aus Spinatpflanzen mittels ELISA wurden die Proteine der cytosolischen Extrakte zunächst durch Ammoniumsulfat-Fällung aufkonzentriert. Anschließend wurden die Proteine mittels Gelfiltrations-Chromatographie aufgetrennt. 


\subsubsection{Ammoniumsulfat-Fällung}

Die cytosolischen Proteine der Spinatpflanzen wurden zur Reduktion des Volumens mit 80 \% Ammoniumsulfat sedimentiert. Eine Kontrolle, ob der Großteil der Proteine bei dieser Ammoniumslufat-Konzentration gefällt werden konnte, erfolgte durch SDSGelelektrophorese. In Abbildung 24 sind die durch SDS-PAGE aufgetrennten Proteine des Extrakts vor Ammoniumsulfat-Fällung (E) und des Überstands nach AmmoniumsulfatFällung (Ü) dargestellt. Zu erkennen ist, daß im Überstand nach Ammoniumsulfat-Fällung kaum noch Proteine vorhanden sind. Als einzige Bande konnte ein $51 \mathrm{kDa}$ großes Protein identifiziert werden.

\subsubsection{Gelfiltrations-Chromatographie}

Die proteinhaltigen Sedimente der Ammoniumsulfat-Fällung wurden in $5 \mathrm{ml} \mathrm{Tris} / \mathrm{NaCl}$ Puffer resuspendiert und auf eine Sephacryl S-300-HR-Säule mit einem Trennbereich von 10 bis $1.500 \mathrm{kDa}$ geladen. Die Proteine wurden dadurch ihrer Größe entsprechend separiert. Ihre Elution wurde mittels UV-Detektion verfolgt. Abhängig von der Güte der Trennung konnten die Proteine in drei bis vier Elutionsgipfel unterteilt werden. Die Protein-Fraktionen eines Elutionsgipfels wurden vereinigt und im ELISA auf ihre Fähigkeit, ABA zu binden untersucht.

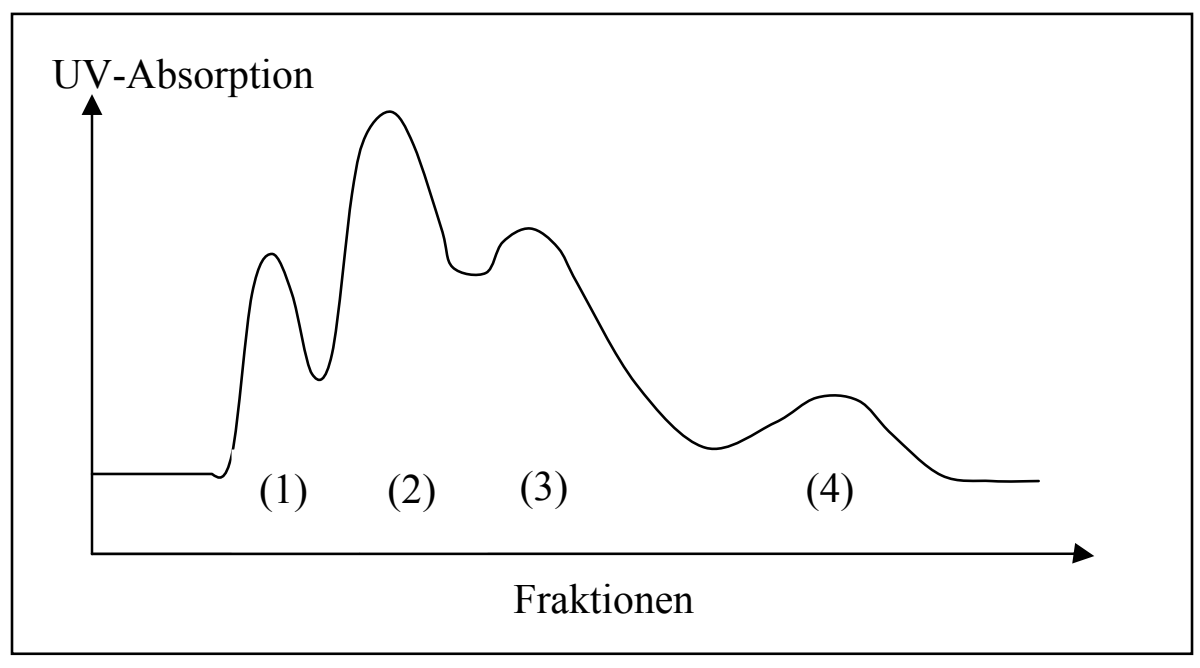

Abbildung 23: Schematische Darstellung der UV-Detektion des Protein-Elutionsprofils mittels Sephacryl S-300-HR. Die Elutionsgipfel (1) bis (4) stellen die zu einem Pool vereinigten Fraktionen dar. 
Die Güte der Trennung hing in erster Linie von der Länge der Säule, aber auch von der Qualität der Proteinase-Inhibitoren ab. Um eine bessere Auftrennung der Proteine zu erhalten, wurde die Länge der Säule von anfänglich $60 \mathrm{~cm}$ auf später $95 \mathrm{~cm}$ erhöht. Bei der Equilibrierung der Säule und der Elution der Proteine wurden dem Laufpuffer ProteinaseInhibitoren zugesetzt. Waren die Proteinase-Inhibitoren älter als etwa $1 / 2$ Jahr oder wurden bereits mehrfach aufgetaute und wieder eingefrorene Proteinase-Inhibitoren verwendet, so konnte deutlich eine Zunahme der Protein-Menge des vierten Protein-Pools festgestellt werden. Da in dieser Fraktion die kleinsten Proteine bzw. Peptide eluiert wurden, deutet dies darauf hin, daß im Experiment vorhandene Proteinasen Proteine bereits zu Peptiden verdaut haben könnten. Im SDS-Gel wurden die Proteine weiter aufgetrennt (Abbildung 24).

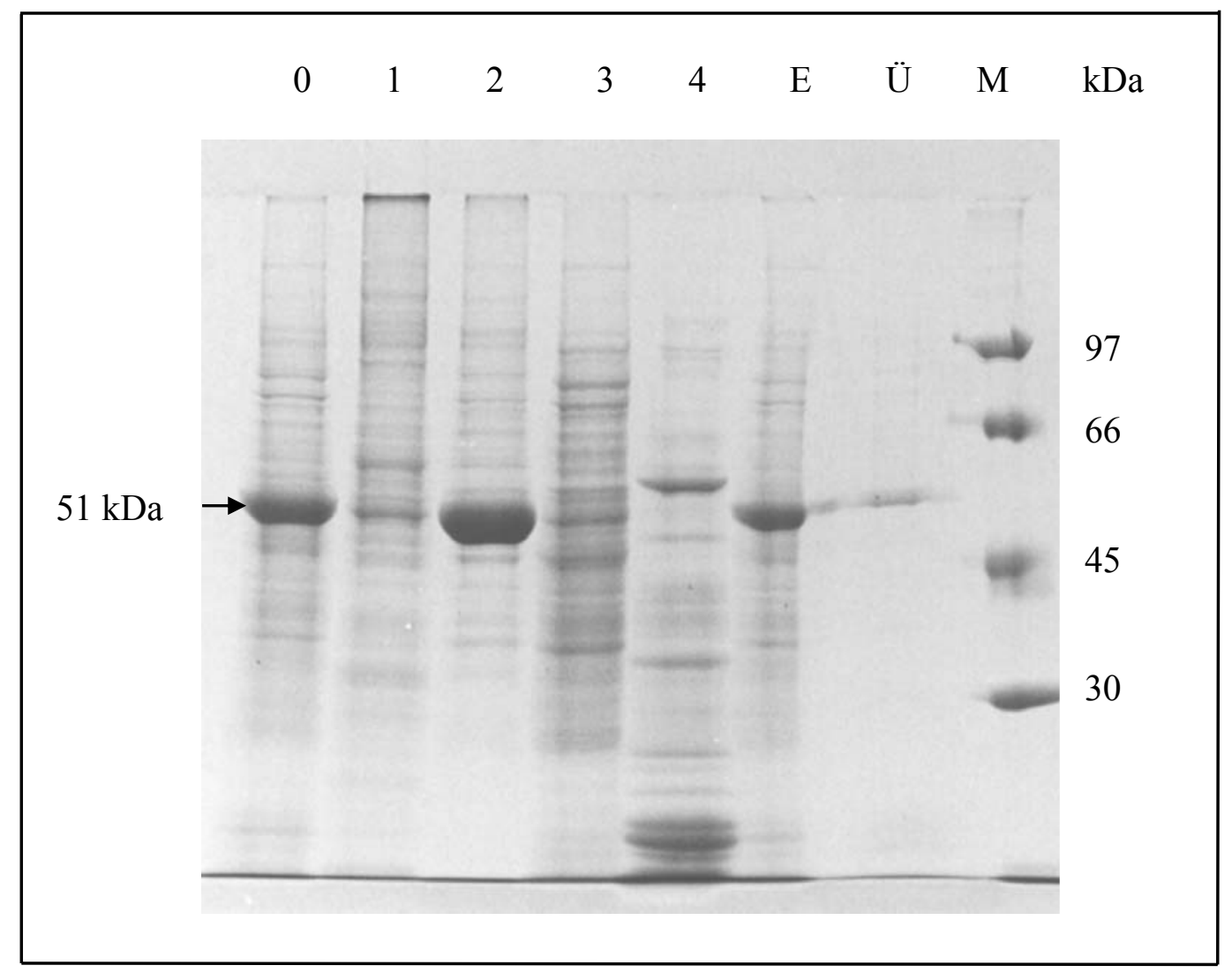

Abbildung 24: Auftrennung der zu einem Pool vereinigten Elutionsgipfel der mittels Gelfiltrations-Chromatographie aufgetrennten cytosolischen Spinat-Extrakte, des Extraktes vor und des Überstands nach Ammoniumsulfat-Fällung durch ein 10 \%iges SDS-Gel.

Aufgetragen wurden je Gelspur $30 \mu \mathrm{g}$ Protein bzw. $200 \mu \mathrm{l}$ für die Spur (Ü), welche nach erfolgter Elektrophorese mit Coomassie angefärbt wurde. (0) Fraktion vor Gelfiltration, (1) bis (4) Proteinelutionsgipfel der Gelfiltration, (E) Extrakt vor Ammoniumsulfat-Fällung, (Ü) Überstand der AS-Fällung, (M) Molekulargewichtsmarker. Das MG wurde durch lineare Regression bestimmt. 


\subsubsection{ELISA zur Detektion ABA-bindender Proteine aus Spinatextrakten}

Der ELISA wurde wie in Kapitel 2.8.4 beschrieben durchgeführt. In Vorversuchen wurden die optimalen Konzentrationen von ABA-BSA-Konjugaten und Antikörpern ermittelt. Die Beschichtung der Mikrotiterplatten erfolgte mit unterschiedlichen Konzentrationen von $0,16 \mu \mathrm{g} / \mathrm{ml}$ bis $100 \mu \mathrm{g} / \mathrm{ml}$ aufgereinigten Proteinen aus Spinatextrakten, um einen möglichst weiten Protein-Bereich auf ABA-Bindung zu testen.

Als Kontrolle von unspezifischen Bindungen wurden im ELISA anstelle der ABA-BSAKonjugate BSA bzw. Puffer verwendet. Die Differenz der Signale für ABA-BSA-KonjugatBindung und BSA-Bindung erlaubte eine quantitative Abschätzung der spezifischen ABABindung an ABA-bindende Proteine ohne Beteiligung des Trägerproteins BSA an der Bindung. Die Signalstärke bei Verwendung des Puffers anstelle von Konjugaten diente zur Quantifizierung des durch unspezifische Bindung der Antikörper an Proteine aus dem Spinatextrakt verursachten Hintergrunds.

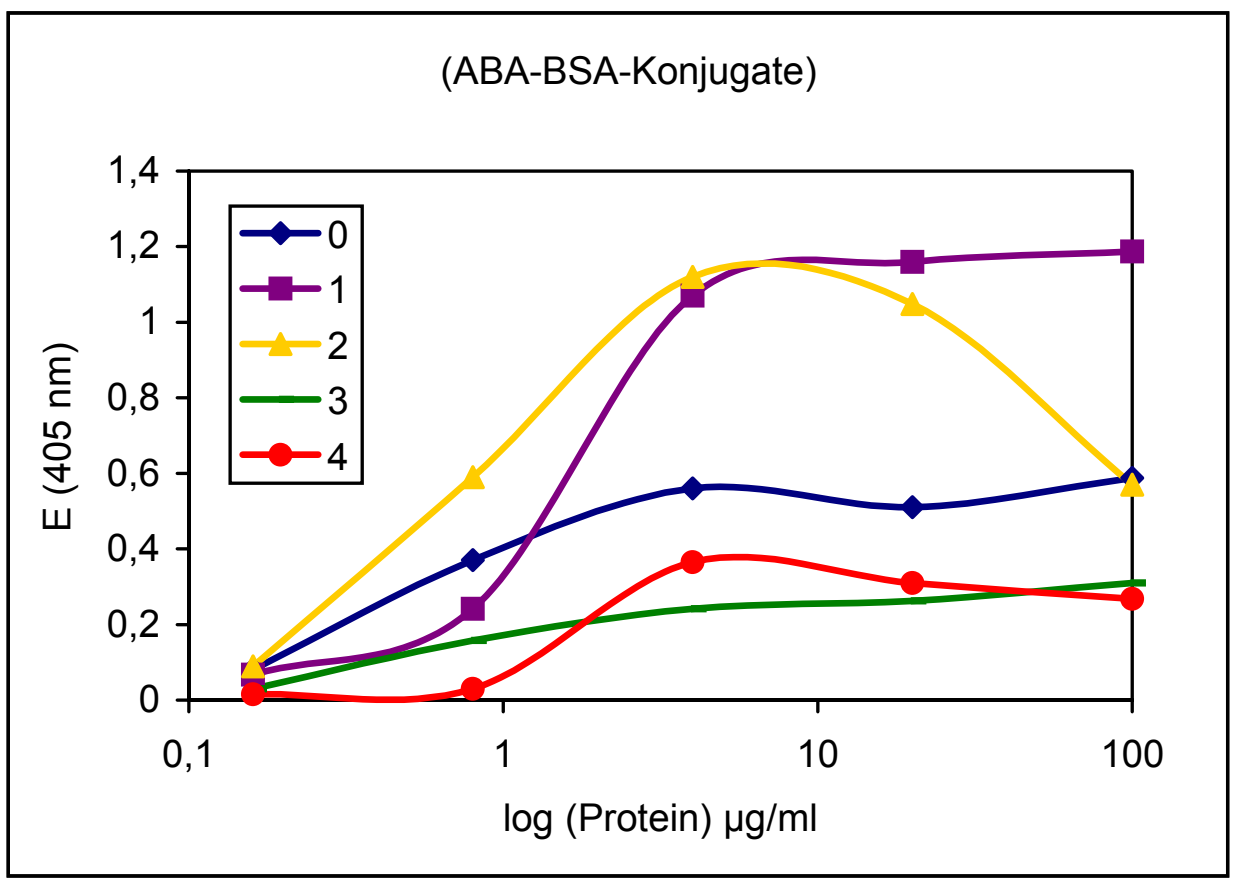

Abbildung 25, A): Nachweis ABA-bindender Proteine aus Spinatextrakten, welche mittels Gelfiltration aufgereinigt wurden, durch ELISA $(n=5)$.

Die Mikrotiterplatten wurden jeweils mit 0,16 bis $100 \mu \mathrm{g} / \mathrm{ml}$ Proteinen der einzelnen Fraktionen beschichtet. (0) Fraktion vor Gelfiltration, (1) bis (4) Elutionsgipfel der Gelfiltration. Gemessen wurde die Bindung von ABA-BSA-Konjugaten $(50 \mu \mathrm{g} / \mathrm{ml})$. 


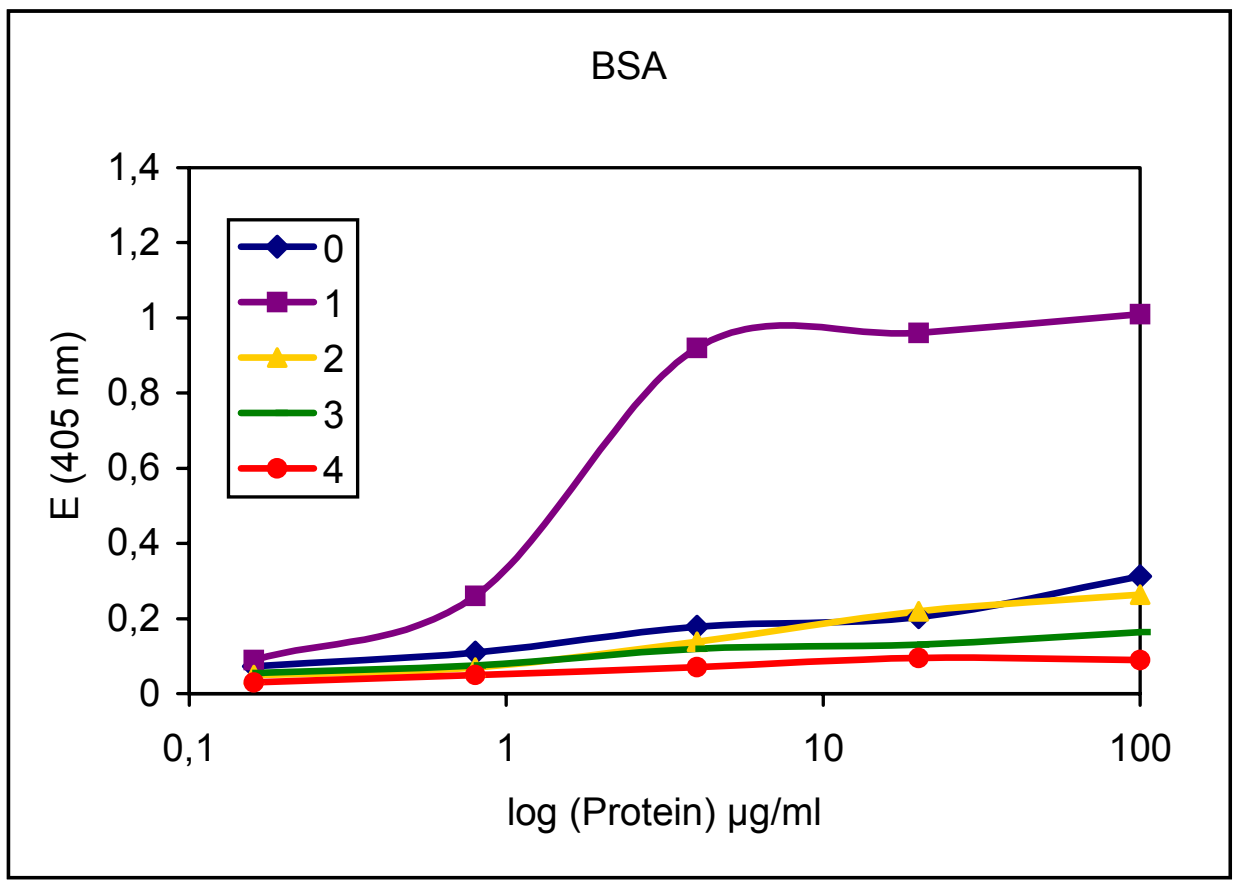

Abbildung 25, B): Nachweis unspezifischer Bindungen des Trägerproteins BSA an Proteine aus Spinatextrakten, durch ELISA $(\mathrm{n}=5)$.

Die Mikrotiterplatten wurden wie in Abbildung 25, A) beschrieben beschichtet. Anstelle der ABA-BSA-Konjugate wurden die Platten mit $50 \mu \mathrm{g} / \mathrm{ml}$ BSA inkubiert.

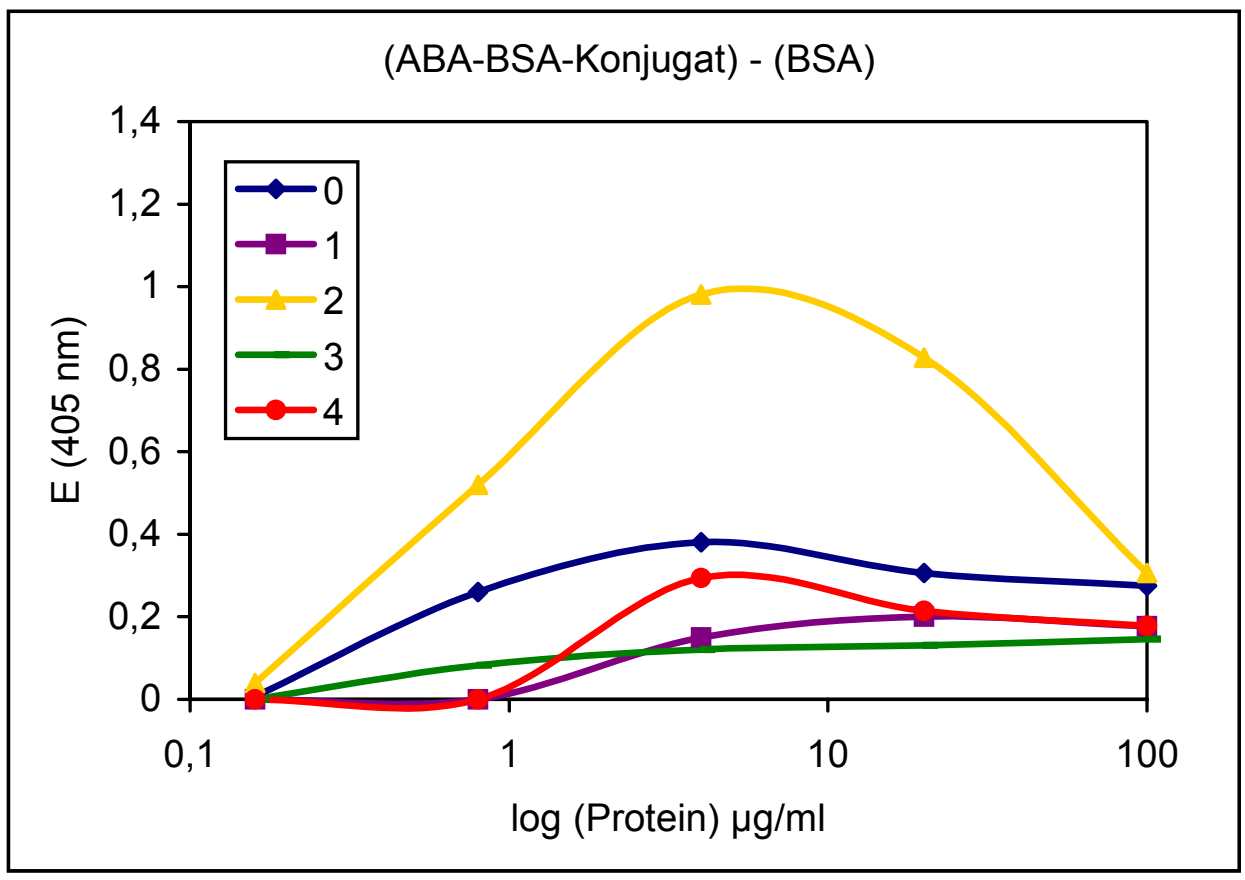

Abbildung 25, C): Die gemessene Extinktion der Bindung von ABA-BSA-Konjugaten (Abbildung 25, A) wurde von der Extinktion, welche durch Bindung von BSA (Abbildung 25, B) detektiert wurde, subtrahiert. 


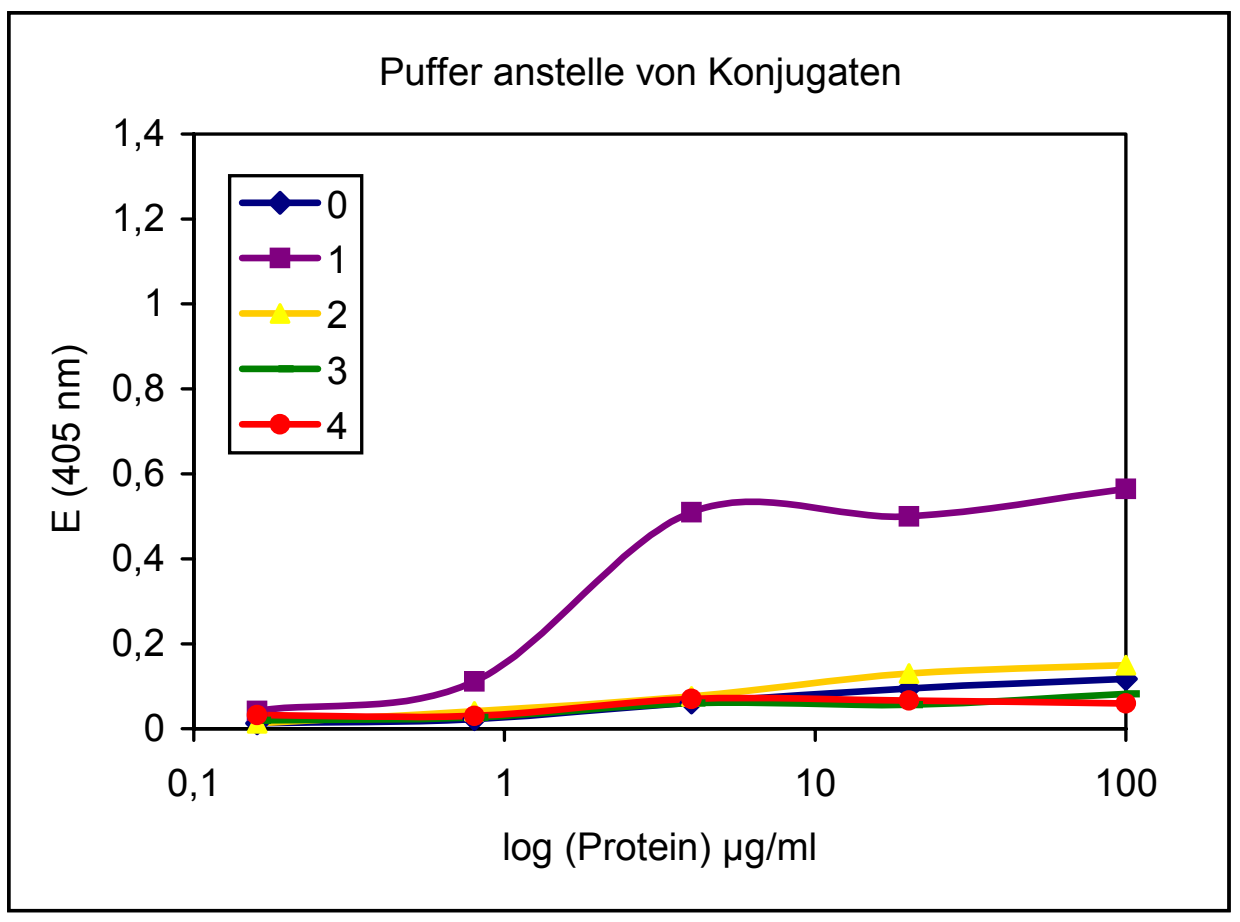

Abbildung 25, D): Nachweis von unspezifischer Bindung des ABA-Antikörpers und Protein A an Proteine aus Spinatextrakten, durch ELISA $(n=5)$.

Die Mikrotiterplatten wurden wie in Abbildung 25, A beschrieben beschichtet. Gemessen wurde eine unspezifische Bindung des primären und sekundären Antikörpers, indem anstelle der Konjugate die Platten mit Puffer inkubiert wurden.

Aus Abbildung 25, A) läßt sich erkennen, daß im Vergleich zum unfraktionierten Extrakt (0) ABA-BSA-Konjugate an die Proteine aus der ersten und zweiten Fraktion signifikant stärker binden. In Abhängigkeit von der Proteinkonzentration ist in der ersten Fraktion eine Zunahme der Signalintensität zu erkennen. In der zweiten Fraktion steigt zunächst die Extinktion mit zunehmender Protein-Konzentration an, nimmt dann allerdings bei einer Konzentration von $50 \mu \mathrm{g} / \mathrm{ml}$ wieder ab. In der ersten Fraktion lag eine hohe unspezifische Bindung des BSAMoleküls (Abbildung 25, B) und Antikörpers (Abbildung 25, D) an diese Proteine vor. Bei der Auftrennung der Proteine mittels SDS-PAGE (Abbildung 24) zeigte sich, daß in der ersten Fraktion vorwiegend größere Proteine mit einem Molekulargewicht von über $60 \mathrm{kDa}$ angereichert sind. Eine oder mehrere Proteinbanden befanden sich noch im Sammelgel, da sie aufgrund ihrer Größe nicht im 10 \%igen SDS-Gel aufgetrennt werden konnten. Die Ergebnisse aus der Gelfiltration und der SDS-Gelelektrophorese scheinen konsistent, da insbesondere größere Proteine stärkere unspezifische Wechselwirkungen mit anderen Proteinen eingehen. Nach Abzug des Signals der unspezifischen Bindung des Trägerproteins (Abbildung 25, C) von der Bindung durch ABA-BSA-Konjugate (Abbildung 25, A) erhält 
man Signale, die ausschließlich die spezifische Bindung wiederspiegeln sollten (Abbildung 25, C). Es zeigte sich, daß ein deutliches Signal nur für die zweite Fraktion erhalten blieb. In dieser Fraktion befand sich hauptsächlich ein 51 kDa großes Protein. Das Molekulargewicht der großen Untereinheit der RubisCO beträgt zwischen 51 bis $58 \mathrm{kDa}$. Es ist deshalb wahrscheinlich, daß es sich bei diesem Protein um die große Untereinheit der RubisCO handelt. Dies läßt den Schluß zu, daß eine Bindung von ABA-BSA-Konjugaten an Proteine der zweiten Fraktion vermutlich auf RubicsCO-ABA-BSA-Komplexe zurückgeführt werden kann.

\subsection{RubisCO als ABA-bindendes Protein}

Um herauszufinden, ob ABA durch RubisCO gebunden wird, wurden Bindungs-Experimente mit käuflicher RubisCO (Sigma), welche aus Spinat aufgereinigt wurde, im ELISA durchgeführt. Dabei wurde die Konzentration des RubisCO variiert. Aus den mit RubisCO beschichteten Mikrotiterplatten ergab sich folgendes Signal:

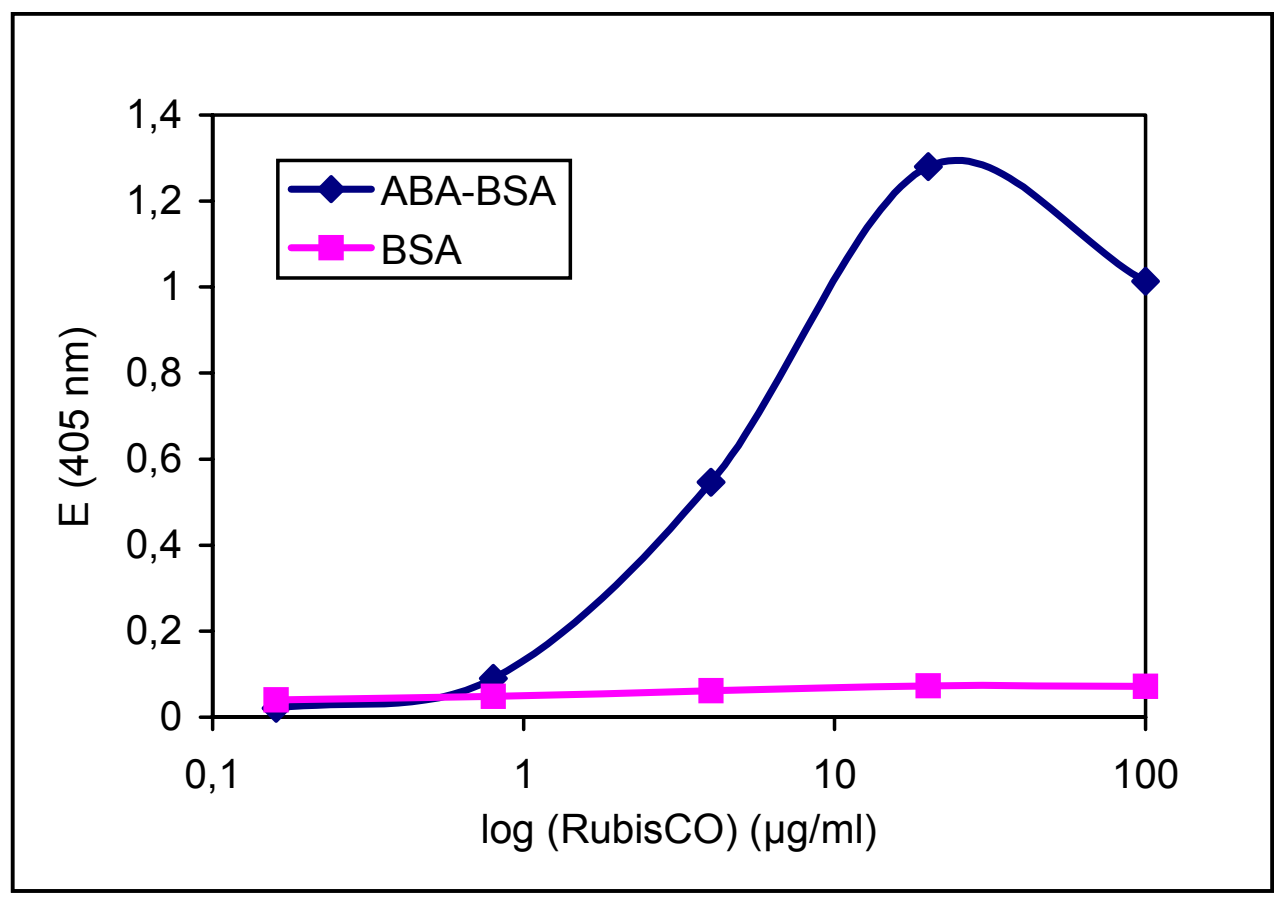

Abbildung 26: Untersuchung der ABA-BSA-Konjugat-Bindung an RubisCO durch ELISA.

Die Mikrotiterplatten wurden mit $0,16 \mu \mathrm{g} / \mathrm{ml}$ bis $100 \mu \mathrm{g} / \mathrm{ml}$ RubisCO (Sigma) beschichtet. Freie Bindungsstellen der Platten wurden mit 0,5\% Ovalbumin in PBST abgesättigt. Die Inkubation erfolgte mit $50 \mu \mathrm{g} / \mathrm{ml}$ ABA-BSA-Konjugaten bzw. BSA für 90 Minuten. 
Aus Abbildung 26 ist zu erkennen, daß ABA-BSA-Konjugate an RubisCO (Sigma) binden. Die Bindung von ABA-BSA-Konjugaten an RubisCO in Abhängigkeit von der ProteinKonzentration ähnelt sehr stark der Bindung der Konjugate an Proteine aus der zweiten Fraktion der Gelfiltration (Abbildung 25, A). Auch hier konnte eine Abnahme der Extinktion bei höheren Protein-Konzentrationen gemessen werden. Diese Beobachtungen lassen den Schluß zu, daß die ABA-Bindung an Proteine aus der zweiten Fraktion der Gelfiltration überwiegend auf eine Bindung der Konjugate an RubisCO zurückzuführen ist. BSA zeigt keine unspezifische Bindung an RubisCO. Auffällig ist, daß bei sehr hohen ProteinKonzentrationen $(100 \mu \mathrm{g} / \mathrm{ml})$ die gemessene Extinktion wieder abnimmt. Dies könnte darauf zurückzuführen sein, daß RubisCO ihrerseits unter diesen Bedingungen als Inhibitor für die Bindung an die Mikrotiterplatten auftritt. Ein ELISA, bei dem nur die Bindung der RubisCO an die Platte bestimmt wurde, wurde zur Überprüfung dieser Hypothese ausgeführt (Abbildung 27):

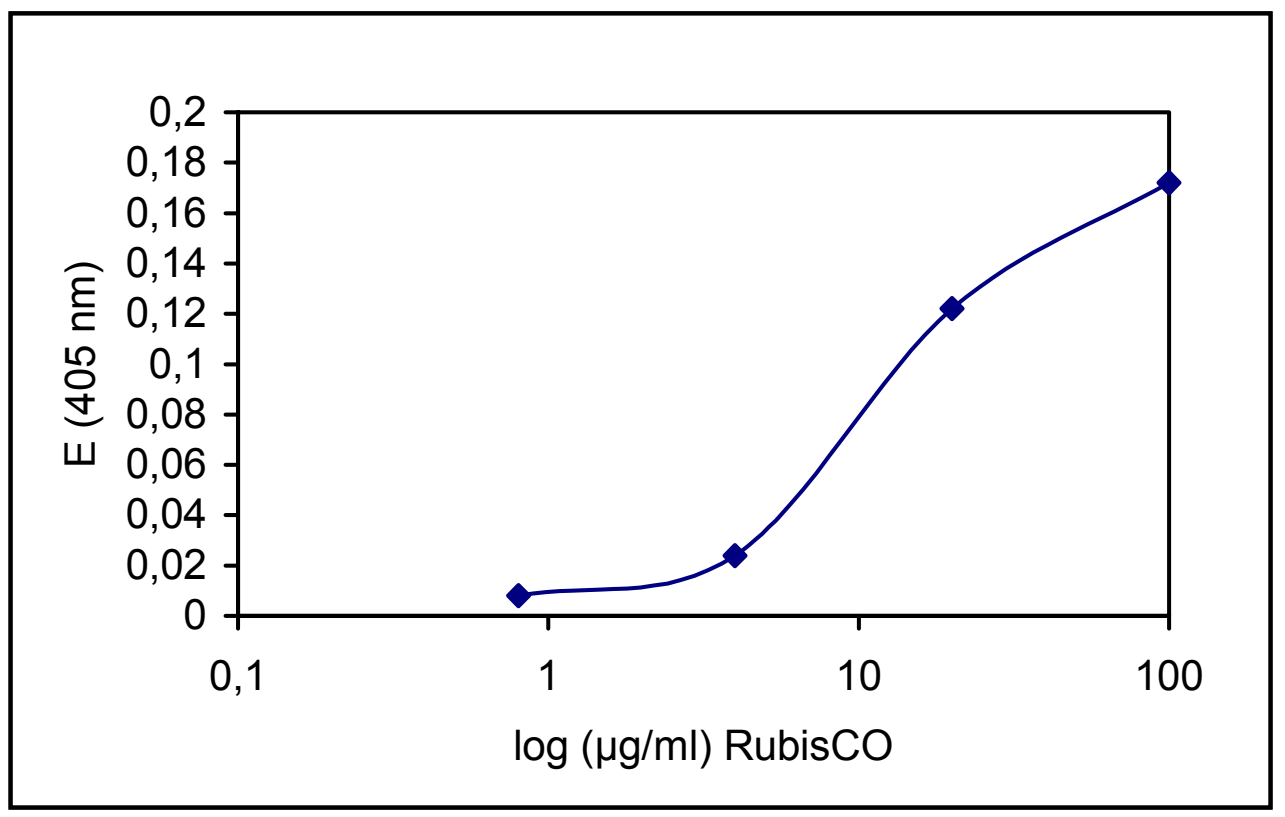

Abbildung 27: Bestimmung der Bindung von RubisCO (Sigma) an die Mikrotiterplatte durch ELISA.

Die Platte wurde mit Konzentrationen von $0,8 \mu \mathrm{g} / \mathrm{ml}$ bis $100 \mu \mathrm{g} / \mathrm{ml}$ RubisCO in Tris/NaClPuffer $\mathrm{pH} 7,8$ beschichtet. Freie Bindungsstellen wurden mit $0,6 \%$ Ovalbumin in PBST abgesättigt. Der Nachweis gebundener RubisCO erfolgte mittels Antikörper gegen RubisCO (1:300) in TBS. Gebundene Antikörper wurden mit Protein A-Peroxidase (1:3000) in TBS nachgewiesen. Die Peroxidase setzte ABTS zu einem grünen Produkt um, welches bei einer Wellenlänge von $405 \mathrm{~nm}$ gemessen wurde. 
Mit diesem ELISA konnte gezeigt werden, daß RubisCO auch bei Konzentrationen von $100 \mu \mathrm{g} / \mathrm{ml}$ noch an die Mikrotiterplatte binden. Eine gegenseitige Behinderung der RubisCO bei der Bindung an die Platte erfolgt offensichtlich nicht. Als Erklärung für die Abnahme der Signalintensität bei hohen RubisCO-Konzentrationen im ELISA zum Nachweis der Bindung von ABA-BSA-Konjugaten an RubisCO (Abbildung 26) müssen somit andere Effekte in Betracht gezogen werden. Möglicherweise verringern sterische Bedingungen, die ihre Ursache in den hohen ABA-BSA-Konjugate- oder Antikörper-Konzentrationen haben, die Antikörper-Bindung.

Eine Bestimmung der Dissoziationskonstante der ABA-Bindung an die RubisCO sollte durch einen kompetitiven ELISA erfolgen. Dazu wurden die an die Mikrotiterplatte gebundene RubisCO mit ABA-BSA-Konjugaten bzw. BSA, welche mit ABA in unterschiedliche Konzentrationen versetzt waren, inkubiert (Abbildung 28). Die Bindung von nicht gekoppelter ABA sollte die detektierbaren ABA-BSA-Konjugate von den Bindungsstellen der RubisCO verdrängen.

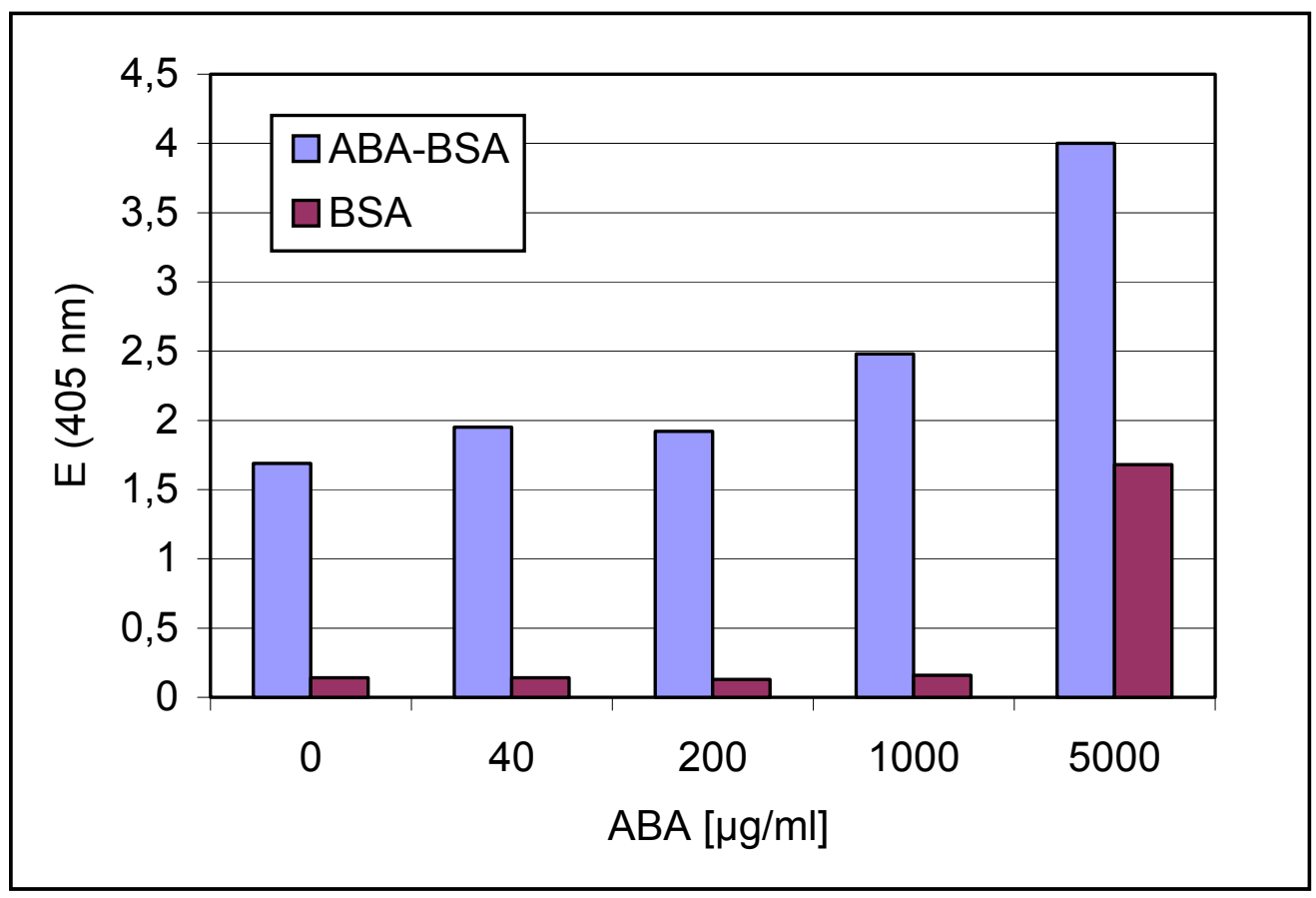

Abbildung 28: Kompetitiver ELISA zur Bestimmung der ABA-Bindung an RubisCO.

Die Mikrotiterplatten wurden mit $20 \mu \mathrm{g} / \mathrm{ml}$ RubisCO (Sigma) in Tris/NaCl-Puffer $\mathrm{pH} 7,8$ beschichtet. Freie Bindungsstellen wurden mit $1 \%$ Ovalbumin in PBST abgesättigt. $0 \mu \mathrm{g} / \mathrm{ml}$ ABA bis $5000 \mu \mathrm{g} / \mathrm{ml}$ ABA wurden mit jeweils $50 \mu \mathrm{g} / \mathrm{ml}$ ABA-BSA-Konjugaten bzw. BSA für 1,5 Stunden inkubiert. Der Nachweis gebundener ABA-BSA-Konjugate erfolgte mittels aufgereinigtem ABA-BSA-Antikörper (1:200). 
Aus Abbildung 28 geht hervor, daß bei einer Erhöhung der ABA-Konzentration auch eine stärkere Bindung des Antikörpers an ABA erfolgt. Bei einer ABA-Konzentration von $5000 \mu \mathrm{g} / \mathrm{ml}$ ergibt sich auch bei der negativen Kontrolle mit BSA anstelle von ABA-BSAKonjugat eine deutliche Bindung des Antikörpers. Dies deutet darauf hin, daß der Antikörper ABA detektiert, welches an die RubisCO bindet, ohne über einen Linker gekoppelt zu sein. Um diese Hypothese zu überprüfen, wurde ein ELISA durchgeführt, bei dem reines ABA anstelle von ABA-BSA-Konjugaten verwendet wurde (Abbildung 29).

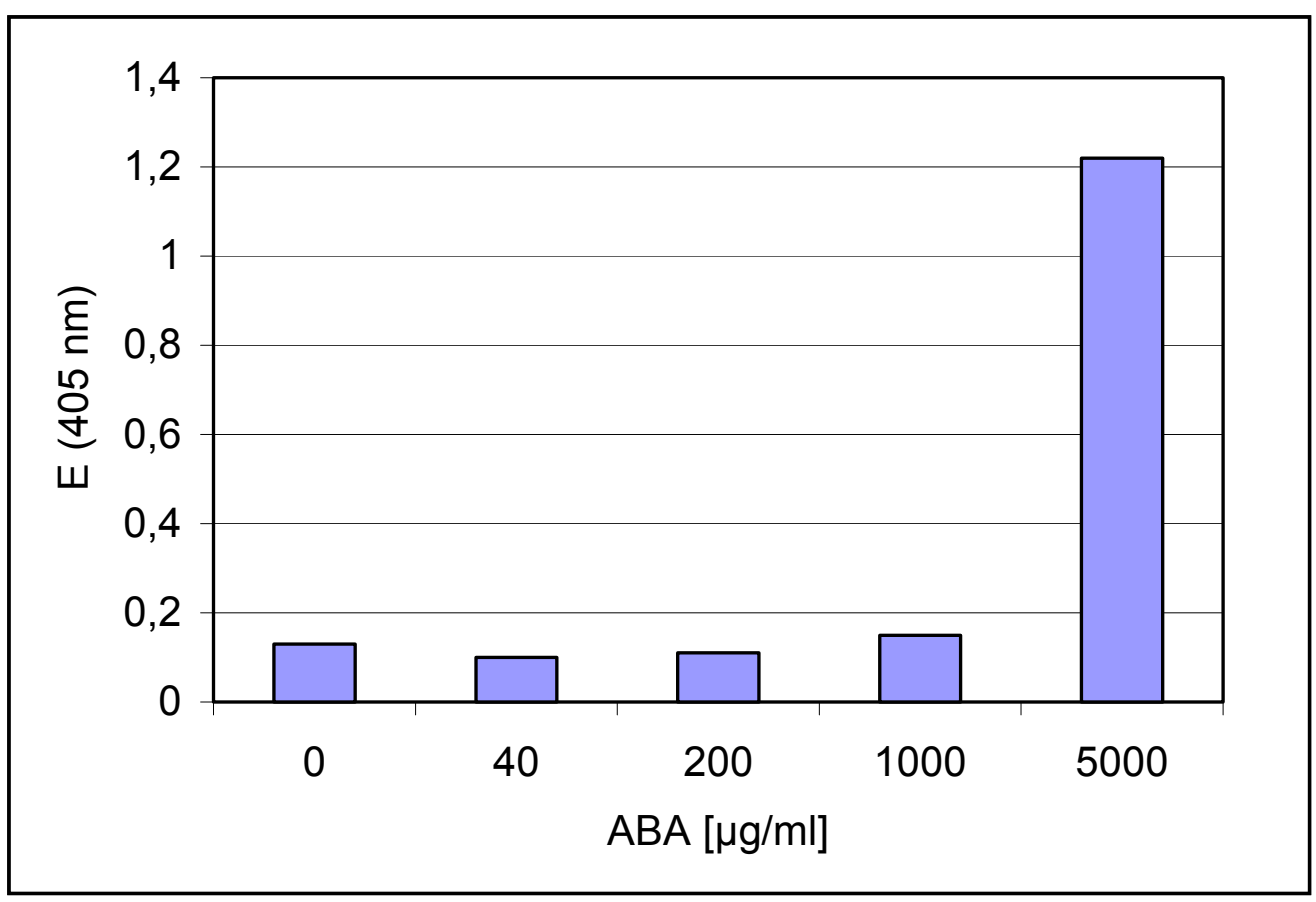

Abbildung 29: Bestimmung der Bindung von freier, nicht an ein Trägerprotein gebundener, ABA an RubisCO durch ELISA.

Die Mikrotiterplatte wurde mit $20 \mu \mathrm{g} / \mathrm{ml}$ RubisCO (Sigma) beschichtet. Freie Bindungsstellen wurden mit $1 \%$ Ovalbumin in PBST abgesättigt. Die gebundene RubisCO wurde mit 0 bis $5000 \mu \mathrm{g} / \mathrm{ml}$ ABA inkubiert. Gebundene ABA wurde mit aufgereinigtem ABA-BSAAntikörper (1:200) nachgewiesen.

Aus Abbildung 29 geht deutlich hervor, daß bei ABA-Konzentrationen von $5 \mathrm{mg} / \mathrm{ml}$ an RubisCO gebundenes ABA durch den ABA-BSA-Antikörper nachgewiesen wird. Der ABAAntikörper selbst bindet nicht an RubisCO, wie aus dem Experiment ohne Zugabe von ABA $(0 \mu \mathrm{g} / \mathrm{ml})$ ersichtlich ist (Abbildung 29). Somit war es nicht möglich, mittels kompetitivem ELISA den $\mathrm{K}_{\mathrm{d}}$-Wert der ABA-Bindung an RubisCO zu bestimmen. 
Um zu überprüfen, in wie weit eine Bindung von $\mathrm{ABA}$ an RubisCO unter physiologischen Bedingungen relevat ist, wurde eine Abhängigkeit der ABA-Bindung an RubisCO vom $\mathrm{pH}$ Wert in folgendem Experiment durchgeführt. ABA-BSA-Konjugate wurden bei unterschiedlichen $\mathrm{pH}-$ Werten mit RubisCO inkubiert (Abbildung 30). Bei einem pH-Wert von 7 wurden die meisten Konjugate an die RubisCO gebunden. Hingegen konnte keine Bindung von ABA-BSA-Konjugaten an die RubisCO bei einem $\mathrm{pH}-$ Wert von 9 und nur eine geringe Bindung bei einem pH-Wert von 8 nachgewiesen werden. Eine noch relativ hohe Bindung der Konjugate erfolgte bei $\mathrm{pH}-$ Werten von 5,5, 6,5 und 7,5. Das ChloroplastenStroma weist einen $\mathrm{pH}-\mathrm{Wert}$ von etwa 8 auf. Bei diesem $\mathrm{pH}-$ Wert konnte nur eine geringe Bindung von ABA-BSA-Konjugaten an die RubisCO gefunden werden. Dies zeigt, daß unter physiologischen Bedingungen die RubisCO als ABA-bindendes Protein keine Rolle spielt.

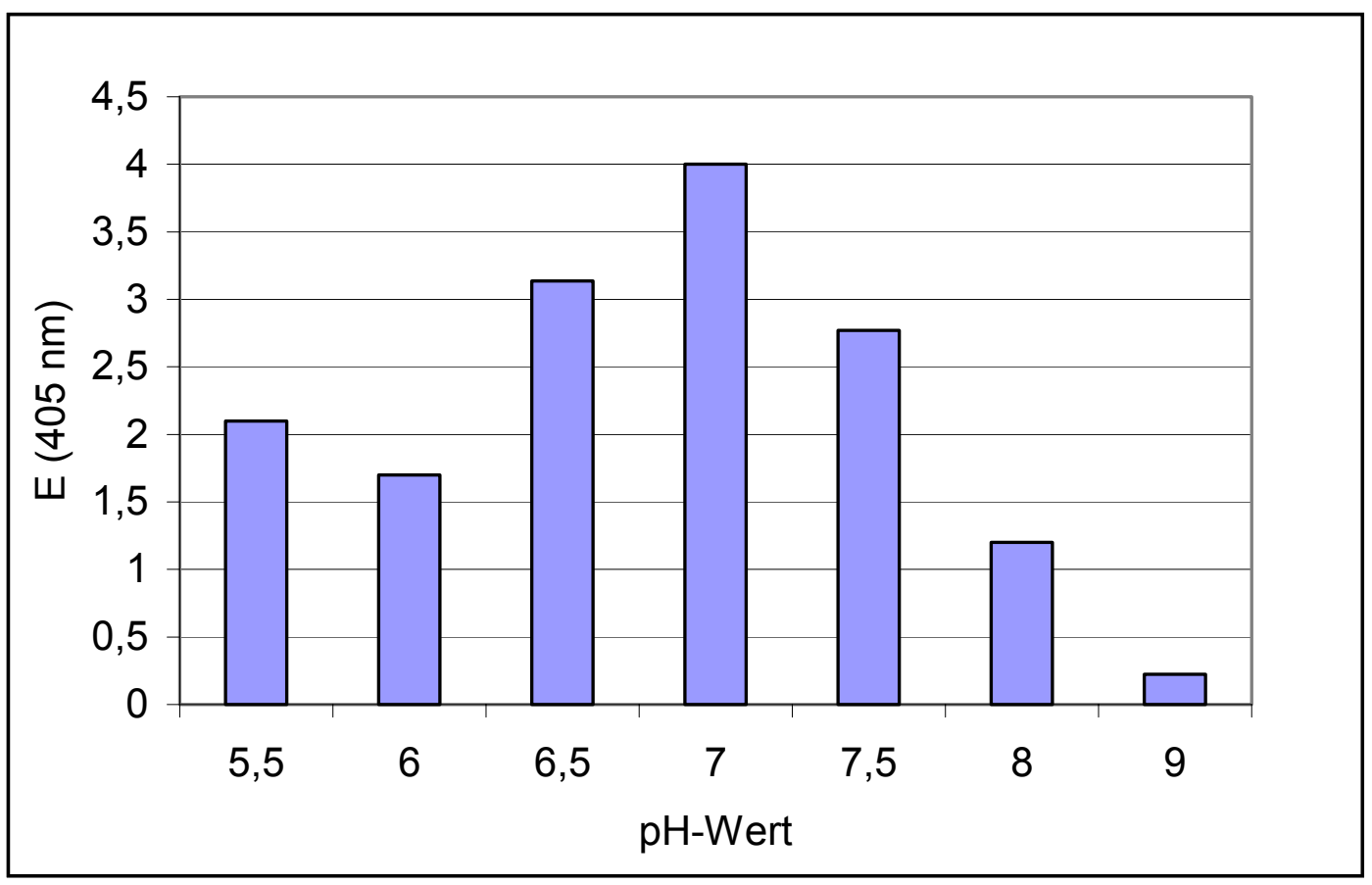

Abbildung 30: Untersuchung der Bindung von ABA-BSA-Konjugaten an RubisCO in Abhängigkeit vom pH-Wert durch ELISA.

Die Mikrotiterplatten wurden mit $100 \mu \mathrm{g} / \mathrm{ml}$ RubisCO (Sigma) gelöst in Tris/NaCl-Puffer $\mathrm{pH}$ 9 beschichtet. Freie Bindungsstellen wurden mit $1 \%$ Ovalbumin in PBST abgesättigt. ABABSA-Konjugate sowie BSA als Negativkontrolle wurden in Puffern mit unterschiedlichen $\mathrm{pH}-$ Werten gelöst und für 1,5 Stunden mit der an die Platte gebundenen RubisCO inkubiert. Der Nachweis gebundener ABA-BSA-Konjugate und BSA erfolgte durch Antikörper gegen ABA-BSA und Protein A-Peroxidase-Konjugat. Die Signale, die sich aus der unspezifischen Bindung von BSA ergaben, wurden von dem zugehörigen ABA-BSA-Signal subtrahiert. 


\subsection{Nachweis und Aufreinigung ABA-bindender Proteine aus Arabidopsis- Extrakten mittels Gelfiltrations-Chromatographie}

Aus Spinatextrakten konnte durch die gewählte Methode der Gelfiltrations-Chromatographie nur die RubisCO als ABA-bindendes Protein identifiziert werden. Wahrscheinlich ist, daß durch die Bindung von ABA-BSA-Konjugaten an RubisCO eine Detektion anderer ABAbindender Proteine erschwert wurde. Um herauszufinden, ob eine Aufreinigung ABAbindender Proteine aus anderen Pflanzen durch Gelfiltrations-Chromatographie erfolgreicher verlaufen könnte, wurden Proteine aus Arabidopsis-Pflanzen auf eine ABA-Bindung hin untersucht.

Für den Nachweis ABA-bindender Proteine in Arabidopsis-Pflanzen mittels ELISA wurden die cytosolischen Proteinextrakte zunächst durch eine Ammoniumsulfat-Fällung aufkonzentriert. Anschließend wurden die Proteine mittels Gelfiltrations-Chromatographie aufgetrennt. Die Auftrennung der Proteine nach ihrer Molekülgröße ergab wie bei den Spinatextrakten vier Protein-Größenklassen, welche jeweils zu einem Pool vereinigt und im ELISA auf ihre Fähigkeit ABA zu binden, getestet wurden (Abbildung 31, A).

Durch die Gelfiltrations-Chromatographie konnten wie bei Spinatpflanzen auch in Arabidopsis-Pflanzen ABA-BSA-bindende Proteine in der ersten und zweiten Fraktion (Abbildung 31, A) nachgewiesen werden. Eine unspezifische Bindung von BSA an Arabidopsis-Proteine trat für die erste Fraktion in geringem Umfang auf (Abbildung 31, B). Aus den Ergebnissen der SDS-Gelelektrophorese und dem typischen Kurvenverlauf für die Bindung von ABA-BSA-Konjugaten an die RubisCO wurde geschlossen, daß die Bindung an Proteine aus der zweiten Fraktion auf eine ABA-Bindung an RubisCO zurückgeführt werden kann. In der ersten Fraktion wurden neben dem Protein mit $51 \mathrm{kDa}$ (RubisCO) weitere Proteine nachgewiesen (Abbildung 32). Der im Vergleich zur ABA-Bindung an RubisCO abweichende Kurvenverlauf der ABA-Bindung dieser Fraktion deutet darauf hin, daß weitere Proteine in dieser Fraktion ABA zu binden vermögen. 


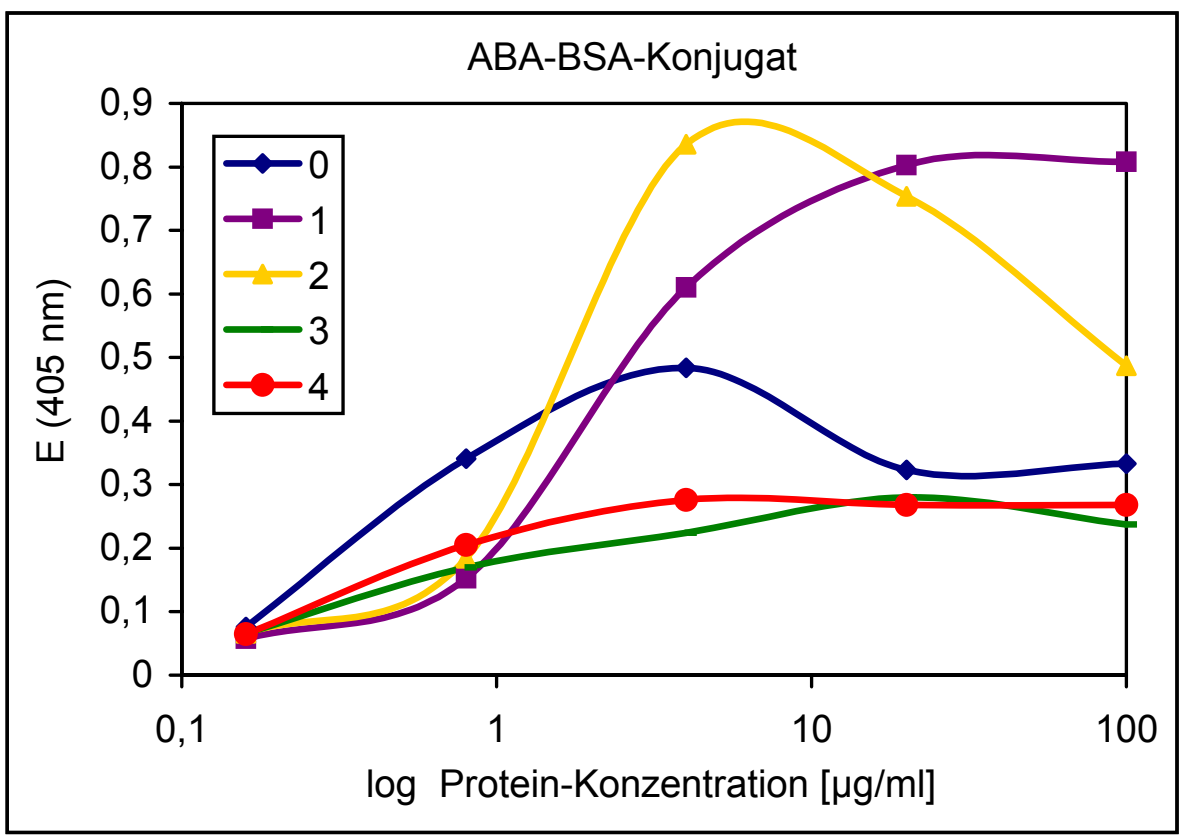

Abbildung 31, A): Nachweis von ABA-bindenden Proteinen aus Arabidopsis-Extrakten durch ELISA. Die Proteine wurden zuvor mittels Gelfiltration aufgereinigt.

Die Mikrotiterplatten wurden mit 0,16 bis $100 \mu \mathrm{g} / \mathrm{ml}$ Protein der einzelnen Fraktionen beschichtet. (0) Fraktion vor Gelfiltration, (1) bis (4) vereinigte Fraktionen der Gelfiltration. Untersucht wurde die Bindung von ABA-BSA-Konjugaten $(50 \mu \mathrm{g} / \mathrm{ml})$.

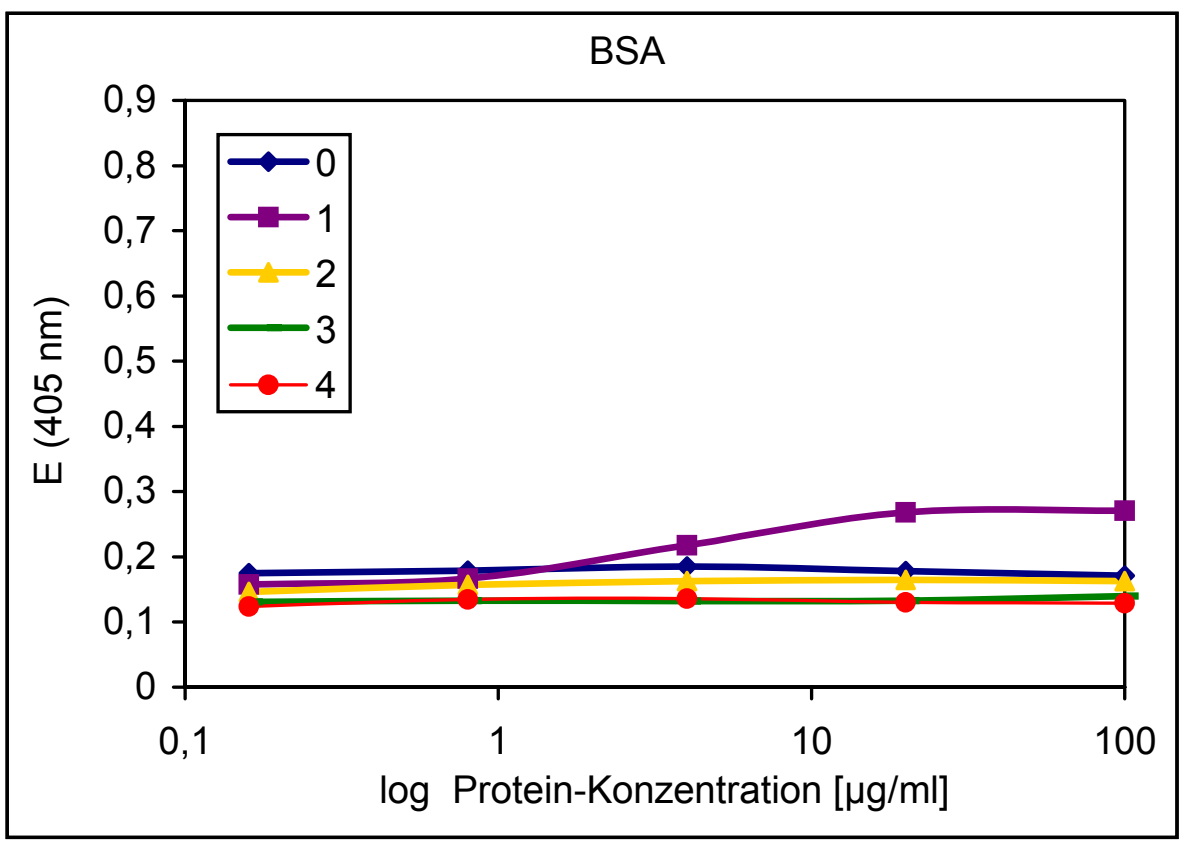

Abbildung 31, B): Untersuchung der unspezifischen Bindung des Trägerproteins BSA an Proteine aus Arabidopsis-Extrakten.

Die Mikrotiterplatten wurden wie in Abbildung 31, A) beschrieben beschichtet. Anstelle der ABA-BSA-Konjugate wurden die Proteine mit $50 \mu \mathrm{g} / \mathrm{ml}$ BSA inkubiert. 


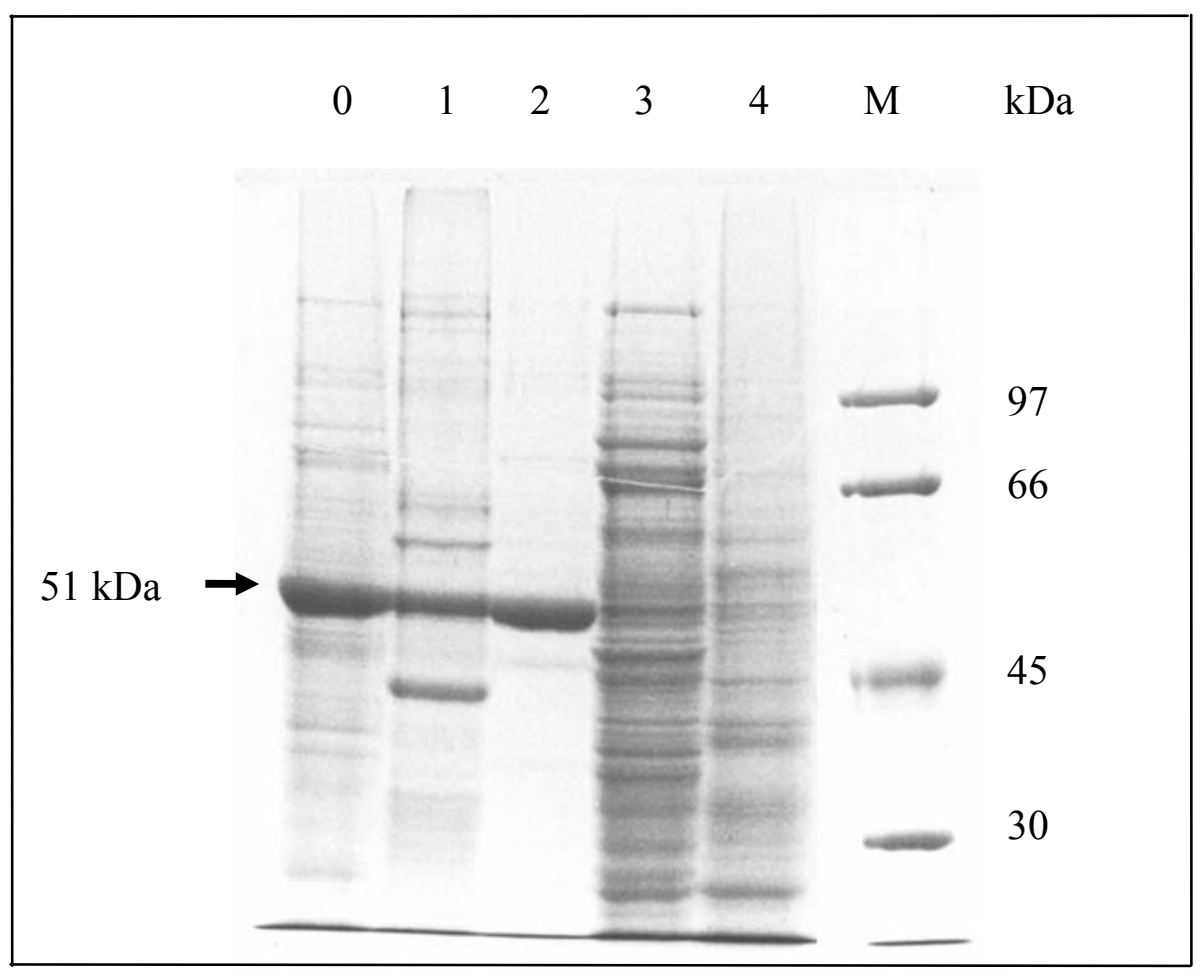

Abbildung 32: SDS-PAGE von aus Gelfiltration resultierenden Fraktionen von Proteinen aus Arabidopsis-Extrakten, durch ein $10 \%$ iges SDS-Gel.

Aufgetragen wurden je Gelspur $30 \mu \mathrm{g}$ Protein, welches nach erfolgter Elektrophorese mit Coomassie angefärbt wurde. (0) Fraktion vor Gelfiltration, (1) bis (4) Elutionsgipfel der Gelfiltration, (M) Molekulargewichtsmarker. Das Molekulargewicht wurde durch lineare Regression ermittelt.

Bei einer weiteren Aufreinigung der ersten Fraktion über eine ABA-Affinitätssäule konnten zwar Fraktionen mit hoher ABA-Bindung nachgewiesen werden, doch als hauptsächliches Protein konnte mittels SDS-Gelelektrophorese in diesen Fraktionen überwiegend die RubisCO nachgewiesen werden (Daten nicht gezeigt). Die RubisCO erwies sich als äußerst störend bei dem Versuch, weitere ABA-bindende Proteine aufzureinigen. Daher mußte ein Verfahren entwickelt werden, das es ermöglichte, die Aufreinigung so zu optimieren, daß die RubisCO von anderen ABA-bindenden Proteinen separiert wurde. Um dies zu erreichen, wurde dem Extraktionspuffer Sorbitol als Osmotikum zugesetzt, damit bei der Proteinextraktion möglichst viele Chloroplasten intakt sedimentiert wurden. Weiterhin sollten Proteine aus Arabidopsis-Extrakten durch andere Aufreinigungsverfahren als die Gelchromatographie besser aufgetrennt werden, so daß ABA-bindende Proteine deutlich von der RubisCO getrennt vorlagen. Dies erfolgte mittels Ionenaustauscher-Säule. 


\subsection{ABA-bindende Proteine aus Arabidopsis-Extrakten}

Um RubisCO von anderen ABA-bindenden Proteinen abzutrennen, wurde die Kationenaustauscher-Chromatographie zur Aufreinigung von Arabidopsis-Proteinen eingesetzt. Zunächst wurden geeignete Bedingungen für die Bindung von ABA-bindenden Proteinen an ein Kationenaustauscher-Material getestet. Als Säulenmaterial wurde die DEAESepharose gewählt, da dieses Säulenmaterial für eine schnelle Aufreinigung von Proteinen aus nur wenig vorgereinigten Extrakten geeignet ist.

\subsubsection{Optimierung der Bedingungen zur Bindung von ABA-bindenden Proteinen an DEAE-Sepharose}

Die Proteinextrakte von Arabidopsis-Pflanzen wurden mittels einer Ammoniumsulfat-Fällung aufkonzentriert. Anschließend wurden die Sedimente in Puffern unterschiedlichen pH-Werts gelöst und über eine Sephadex G-25-Säule vom restlichen Ammoniumsulfat befreit. Dieser Schritt war notwendig, da eine Bindung der Proteine an DEAE-Sepharose nur bei einer niedrigen Salzkonzentration in ausreichendem Maße erfolgte.

Die entsalzten Proteinextrakte wurden über Nacht bei unterschiedlichen pH-Werten an $500 \mu 1$ DEAE-Sepharose gebunden. Zur qualitativen Ermittlung der Bindung der Proteine an das Säulenmaterial wurden im ELISA die Gehalte an ABA-bindenden Proteinen in den Extrakten vor der Inkubation und den Überständen nach der Inkubation bestimmt. Um eine Bindung der Proteine an die Mikrotiterplatten unter gleichen Bedingungen $\mathrm{zu}$ ermöglichen, wurden die Proben mit Tris/NaCl-Puffer $\mathrm{pH}$ 7,8 verdünnt und eine Protein-Konzentration von $100 \mu \mathrm{g} / \mathrm{ml}$ im Versuch eingesetzt. 


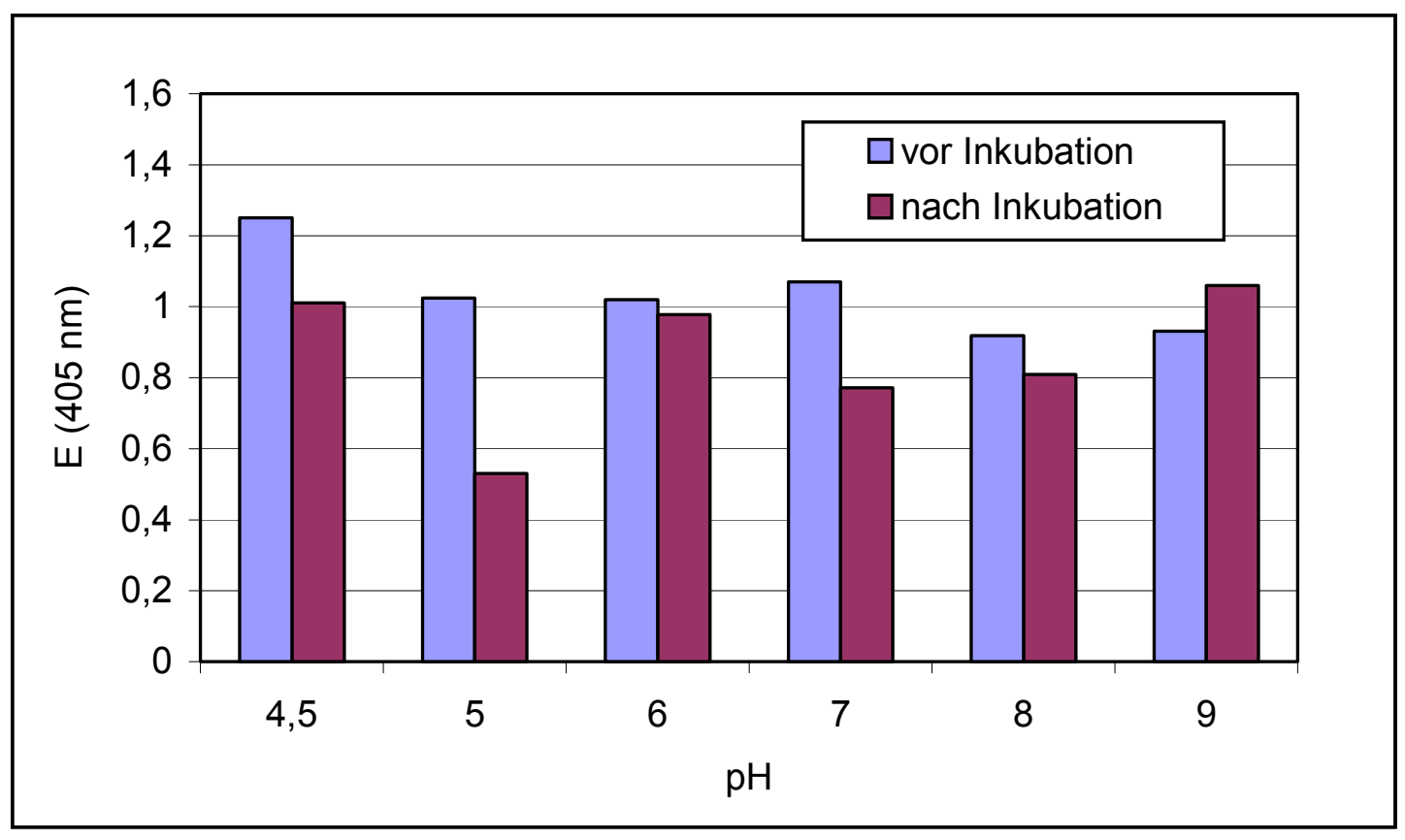

Abbildung 33: Optimierung des $\mathrm{pH}-$ Wertes für die Bindung von ABA-bindenden Proteinen aus Arabidopsis-Extrakten an einen DEAE-Sepharose-Kationenaustauscher (Pharmacia).

Der Nachweis ABA-bindender Proteine erfolgte durch ELISA. Dazu wurden die Mikrotiterplatten mit $100 \mu \mathrm{g} / \mathrm{ml}$ Protein vom Arabidopis-Extrakt vor und nach der Inkubation mit DEAE-Sepharose beschichtet.

Aus Abbildung 33 ist ersichtlich, daß bei pH 5 eine $50 \%$ ige Reduktion der Menge ABAbindender Proteine im Überstand nach der Inkubation mit dem Säulenmaterial auftrat. Unter diesen Bedingungen fand somit eine Bindung von ABA-bindenden Proteinen an den Kationenaustauscher statt. Bei allen anderen untersuchten $\mathrm{pH}-$ Werten wurden weit weniger ABA-bindende Proteine vom Säulenmaterial gebunden. Die Durchführung des ELISAs mit BSA anstelle von ABA-BSA-Konjugaten ergab bei allen $\mathrm{pH}-$ Werten einen sehr geringen Hintergrund von etwa 0,2 Extinktionseinheiten. Dies zeigte, daß keine unspezifischen Bindungen des Trägerproteins BSA im ELISA stattfanden.

Für eine effiziente Bindung eines Proteins an das DEAE-Säulenmaterial sollte der pH-Wert der Pufferlösung um etwa eine Einheit vom isoelektrischen Punkt des zu bindenden Proteins abweichen (Amersham Pharmacia Biotech). Der isoelektrische Punkt der RubisCO aus Arabidopsis liegt bei 6,24. Um weitere ABA-bindende Proteine aus Arabidopsis-Extrakten isolieren zu können, wurde vor der Weiterverarbeitung der Extrakte ein DEAE-Säulenlauf bei pH 5,2 mit dem Ziel der Abtrennung von RubisCO durchgeführt. 


\subsubsection{Aufreinigung ABA-bindender Proteine aus Arabidopsis-Extrakten mittels DEAE- Sepharose}

Cytosolische Extrakte aus Arabidopsis-Pflanzen wurden mit 80\% Ammoniumsulfat versetzt, wodurch die enthaltenen Proteine gefällt wurden. Die Sedimente wurden in $5 \mathrm{ml}$ MES-Puffer gelöst. Anschließend wurden die Proteine durch eine Sephadex G-25 Säule von noch vorhandenem Ammoniumsulfat befreit. Eine gute Aufreinigung der Proteine vom Ammoniumsulfat konnte bei einer Länge der Sephadex G-25-Säule von 9,5 cm und einem Durchmesser von 2,3 cm erreicht werden. Die Ergebnisse sind in Abbildung 34 dargestellt.

Fraktionen der Sephadex G-25-Säule mit einem hohen Proteingehalt und niedriger Ionenleitfähigkeit wurden zu einem Pool vereinigt und auf die DEAE-Sepharose-Säule aufgetragen. Bei dem in Abbildung 34 dargestellten Experiment wurden die Fraktionen 2 bis 6 vereinigt.

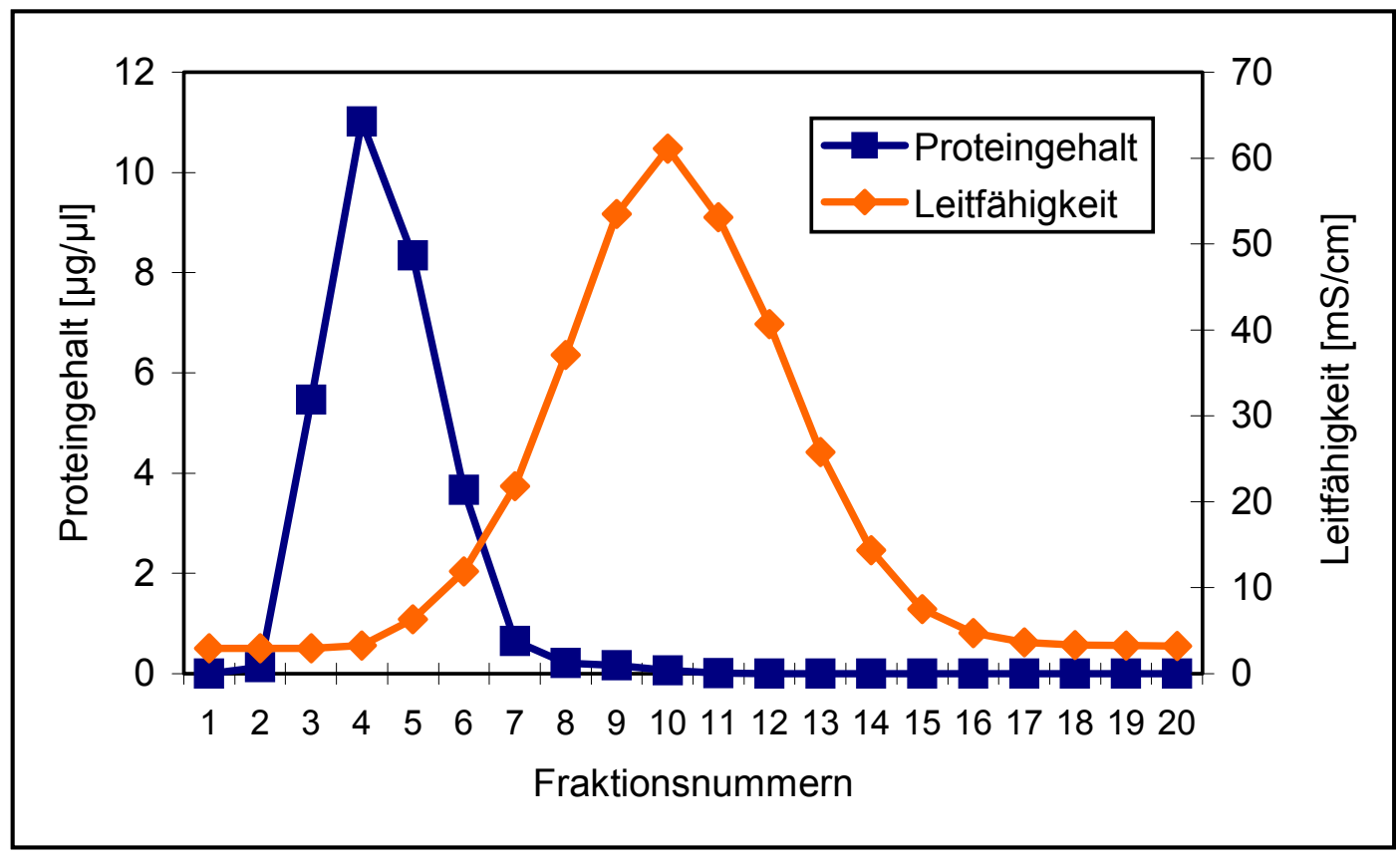

Abbildung 34: Proteinkonzentration und Ionenleitfähigkeit von Fraktionen einer Sephadex G-25-Säule zum Entsalzen der Proteine aus Arabidopsis-Extrakten.

Eine Bindung der Proteine an die DEAE-Säule erfolgte in den ersten Experimenten bei einem $\mathrm{pH}-$ Wert von 5,2. Die Auftrennung und Anfärbung der Proteine mittels SDSGelelektrophorese zeigte, daß ein Großteil der RubisCO an das Säulenmaterial gebunden wurde (Daten nicht gezeigt). Zur Aufreinigung ABA-bindender Proteine wurden daraufhin 
die Versuchsbedingungen soweit optimiert, bis eine vollständige Bindung der RubisCO an das Säulenmaterial erreicht wurde. Dadurch konnte die RubisCO von anderen ABAbindenden Proteinen abgetrennt werden. Als optimal für die Bindung erwiesen sich eine $\mathrm{NaCl}-$ Konzentration von $20 \mathrm{mM}$ und ein $\mathrm{pH}$-Wert von 5,4. Eine Bindung der Proteine an die DEAE-Säule erfolgte somit unter Verwendung von MES/NaCl-Puffer pH 5,4. Die Säule wurde solange mit Puffer gespült, bis keine Proteine mehr von der Säule gewaschen wurden. Eine Protein-Detektion erfolgte durch ein UV-Meßgerät (UVICORD II, LKB, Schweden) bei $280 \mathrm{~nm}$ sowie durch Protein-Bestimmung mittels Bradford-Methode. An die Säule gebundene Proteine wurden mit steigendem NaCl-Gradienten von $20 \mathrm{mM}$ bis $2 \mathrm{M}$ eluiert. Die Proteine der Fraktionen des DEAE-Säulenlaufs wurden im ELISA auf ihre ABA-Bindung untersucht (Abbildung 35) und im SDS-Gel (Abbildung 38) aufgetrennt.

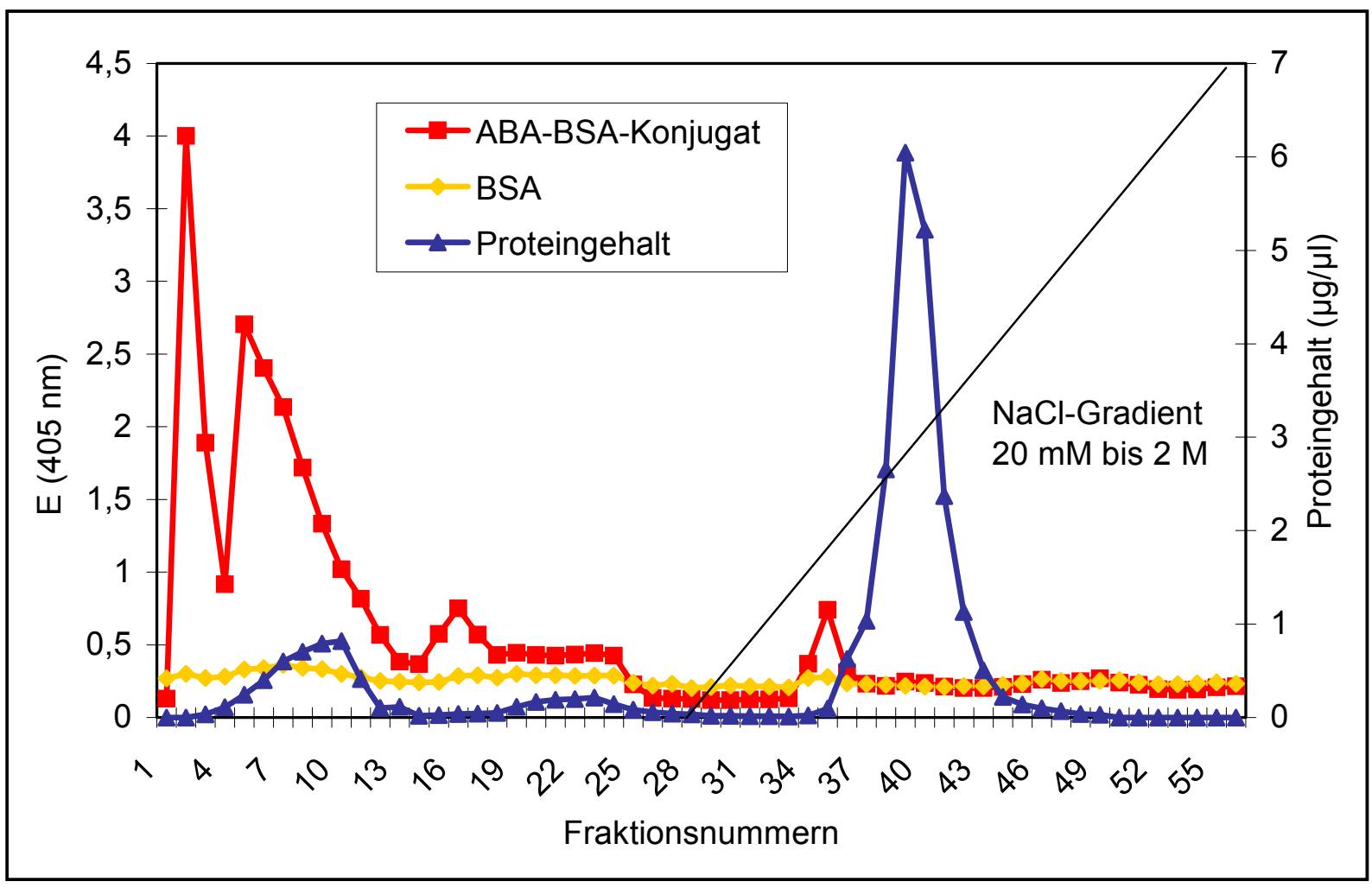

Abbildung 35: Elutionsprofil ABA-bindender Proteine aus Arabidopsis-Extrakten, welche mittels der DEAE-Sepharose fraktioniert wurden.

Die Proteinkonzentration der Fraktionen wurde nach der Bradford-Methode bestimmt. Der Nachweis ABA-bindender Proteine erfolgte mittels ELISA. Dazu wurden die Mikrotiterplatten mit jeweils $100 \mu$ pro Fraktion bei einem pH-Wert von 5,4 beschichtet. Die Inkubation mit ABA-BSA-Konjugat bzw. BSA $(50 \mu \mathrm{g} / \mathrm{ml})$ als Negativkontrolle erfolgte für 1,5 Stunden. Der aufgereinigte Antikörper gegen ABA wurde 1:200 verdünnt eingesetzt und durch Protein A-Peroxidase-Konjugat nachgewiesen. 
Aus Abbildung 35 ist anhand der Proteinbestimmung zu erkennen, daß nur ein geringer Teil vom Gesamtprotein ohne an die Säule zu binden wieder ausgewaschen wurde. Ein Großteil der Proteine band an das Säulenmaterial. Diese Proteine wurden bei dem in Abbildung 35

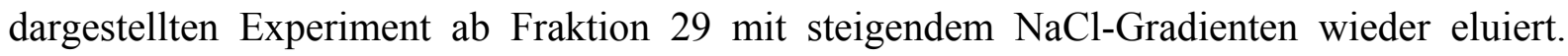
Dabei konnten die Proteine bei einer NaCl-Konzentration von etwa 0,8 - 1,0 M eluiert werden.

Um zu überprüfen, ob die eluierten Proteine unspezifische Bindungen mit dem Trägerprotein der ABA-BSA-Konjugate eingehen, wurde der ELISA mit BSA anstelle der ABA-BSAKonjugate durchgeführt. Eine signifikante Reaktion mit BSA im ELISA konnte nicht gemessen werden (Abbildung 35).

In einzelnen Fraktionen wurden Proteine mit Bindungsaffinität zu ABA-BSA-Konjugaten gefunden. Das stärkste Signal trat bei der zweiten Fraktion auf (Abbildung 35). Eine genaue Bestimmung der Extinktion war für diese Fraktion nicht möglich. Die Färbung lag oberhalb des meßbaren Bereichs und wurde daher mit dem maximal meßbaren Wert von 4 Extinktionseinheiten angegeben. Auch in den Fraktionen 5 bis 8, 15 bis 17 sowie 34 bis 36 befanden sich Proteine, mit hoher Affinität zu den ABA-BSA-Konjugaten (Abbildung 35). Die ABA-bindenden Proteine der Fraktionen 34 und 36 konnten bereits bei geringen NaClKonzentrationen eluiert werden. Für die Fraktionen 37 bis 43, bei denen die meisten der gebundenen Proteine mit $\mathrm{NaCl}$ eluiert wurden, konnte keine ABA-Bindung nachgewiesen werden, obwohl sich in diesen Fraktionen auch die RubisCO, für die eine ABA-Bindung gezeigt wurde, befand. Ein Nachweis der RubisCO in diesen Fraktionen wurde durch SDSGelelektrophorese (Abbildung 38) und mittels Antikörper gegen RubisCO durch ELISATechnik (Abbildung 39) erbracht. Die Tatsache, daß im ELISA für diese Fraktionen keine ABA-Bindung gefunden wurde, steht auch im Widerspruch zu den Vorversuchen (Kapitel 3.9.1). Bei denen gezeigt wurde, daß etwa $50 \%$ der ABA-bindenden Proteine bei einem pHWert von 5 an das Säulenmaterial banden. Das bedeutet, daß eine höhrere Aktivität der ABABindung an Proteine in den Fraktionen 37 bis 40 (Abbildung 35) zu erwarten gewesen wäre. Diese Diskrepanz ist wahrscheinlich darauf zurückzuführen, daß der hohe Proteingehalt, die hohe NaCl-Konzentration und/oder der niedrige $\mathrm{pH}-$ Wert der Lösung von 5,4 in diesen Fraktionen eine Bindung der RubisCO und möglicherweise auch anderer ABAbindender Proteine an die Mikrotiterplatte verhinderte und somit eine Detektion der ABA- 
Bindungs-Aktivität nicht möglich war. Um dies zu überprüfen, wurden alle Fraktionen des DEAE-Säulenlaufs gegen 50 mM Tris, 200 mM NaCl-Puffer pH 7,5 dialysiert. Anschließend wurden die Proteine der Fraktionen bei dem höheren pH-Wert mittels ELISA untersucht.

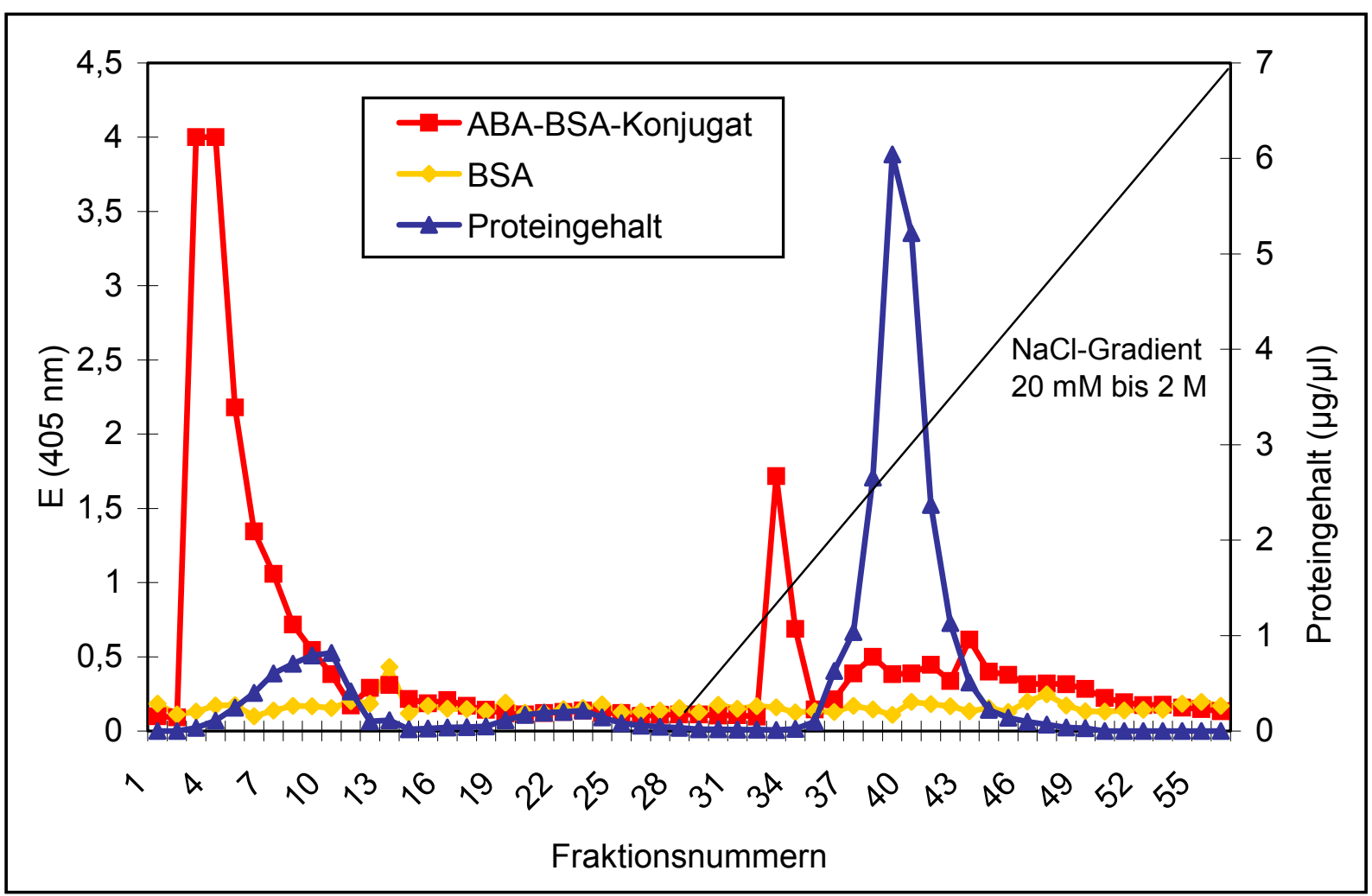

Abbildung 36: Elutionsprofil ABA-bindender Proteine aus Arabidopsis-Extrakten, welche mittels der DEAE-Sepharose fraktioniert wurden.

Die Fraktionen des DEAE-Säulenlaufs wurden gegen Tris/NaCl-Puffer $\mathrm{pH}$ 7,5 dialysiert und die Proteine auf ABA-Bindung untersucht. Beschichtet wurden die Mikrotiterplatten mit jeweils $100 \mu \mathrm{l}$ der dialysierten Fraktion bei einem pH-Wert von 7,5. Die Bindung der ABABSA-Konjugate bzw. BSA $(50 \mu \mathrm{g} / \mathrm{ml})$ als Negativkontrolle erfolgte für 1,5 Stunden. Der aufgereinigte Antikörper gegen ABA wurde 1:200 verdünnt eingesetzt und durch Protein APeroxidase-Konjugat nachgewiesen. Der Proteingehalt der Fraktionen wurde nach Bradford bestimmt.

Aus Abbildung 36 ist ersichtlich, daß nach der Dialyse der Fraktionen gegen Tris/NaCl-Puffer $\mathrm{pH}$ 7,5 und Bindung der Proteine an die Mikrotiterplatten bei diesem pH-Wert sich ein anderes Bild der ABA-BSA-Konjugat-Bindung ergab als bei der Bindung der Proteine an die Platten bei pH 5,4 (Abbildung 35). Eine Erklärung der pH-Wert-Abhängigkeit beim Nachweis ABA-bindender Proteine liefert die Eigenschaft der Mikrotiterplatten. Die Bindung von 
Proteinen an eine Polystyrolmatrix ist abhängig vom $\mathrm{pH}-$ Wert und Puffer, in dem sich das Protein befindet (siehe Kapitel 3.3.1).

Eine ABA-BSA-Bindung konnte in Abbildung 36 für die Proteine aus den Fraktionen 3 und 4 sowie 33 und 34 und in den Fraktionen 37 bis 43 nachgewiesen werden. Auch bei einer Bindung der Fraktionen bei pH 7,5 erfolgt die stärkste ABA-Bindung bei niedrigen ProteinKonzentrationen (Fraktionen 3 und 4).

In den Fraktionen 37 bis 40 konnte somit gezeigt werden, daß nach der Dialyse der Proteine eine ABA-Bindung nachgewiesen werden konnte. Allerdings ist die gemessene Aktivität der ABA-bindenden Proteine, immer noch niedriger als aus den Vorversuchen zu erwarten gewesen wäre. Eine weitere Erklärung dafür könnte eine hohe Protein-Konzentration in diesen Fraktionen sein (Vergleich Kapitel 3.3.1). Aus diesem Grund wurde ein ELISA mit fünffach verdünnten Proben der Fraktionen 37 bis 40 durchgeführt.

Tabelle 11: Bestimmung der ABA-BSA-Bindung an Proteine der Fraktionen 37 bis 40 des DEAE-Säulenlaufs bei $\mathrm{pH} 7,5$.

Aufgetragen wurden $100 \mu 1$ der 1:5 verdünnten und unverdünnten Fraktionen bei einem pHWert von 7,5.

\begin{tabular}{ccccc}
\hline Fraktion & 37 & 38 & 39 & 40 \\
\hline unverdünnt & 0,499 & 0,383 & 0,388 & 0,446 \\
$1: 5$ & 0,498 & 0,53 & 0,41 & 0,38 \\
\hline
\end{tabular}

Aus Tabelle 11 geht hervor, daß bei Verdünnung der Fraktionen 38 und 39 eine höhere Extinktion im ELISA gemessen wurde als bei den unverdünnten Fraktionen. Dies zeigt, daß eine hohe Protein-Konzentration teilweise der Grund für eine Verschlechterung der ProteinBindung an die Mikrotiterplatten war. Die gewählten Bedingungen zur Bindung von Proteinen an die Mikrotiterplatten waren somit nicht für alle ABA-bindende Proteine optimal. 
Abbildung 37 zeigt im Vergleich die für die jeweiligen Fraktionen im ELISA erhaltenen Signal-Intensitäten bei Puffer-pH-Werten von 5,4 und 7,5. Es wird deutlich, daß der Nachweis ABA-bindender Proteine bei den gewählten Verfahren stark pH-Wert abhängig ist. Für die Fraktionen 37 bis 43, in denen sich unter anderem auch die RubisCO befindet (Abbildung 38 und Abbildung 39), konnte bei einem pH-Wert von 7,5 eine ABA-Bindung nachgewiesen werden.

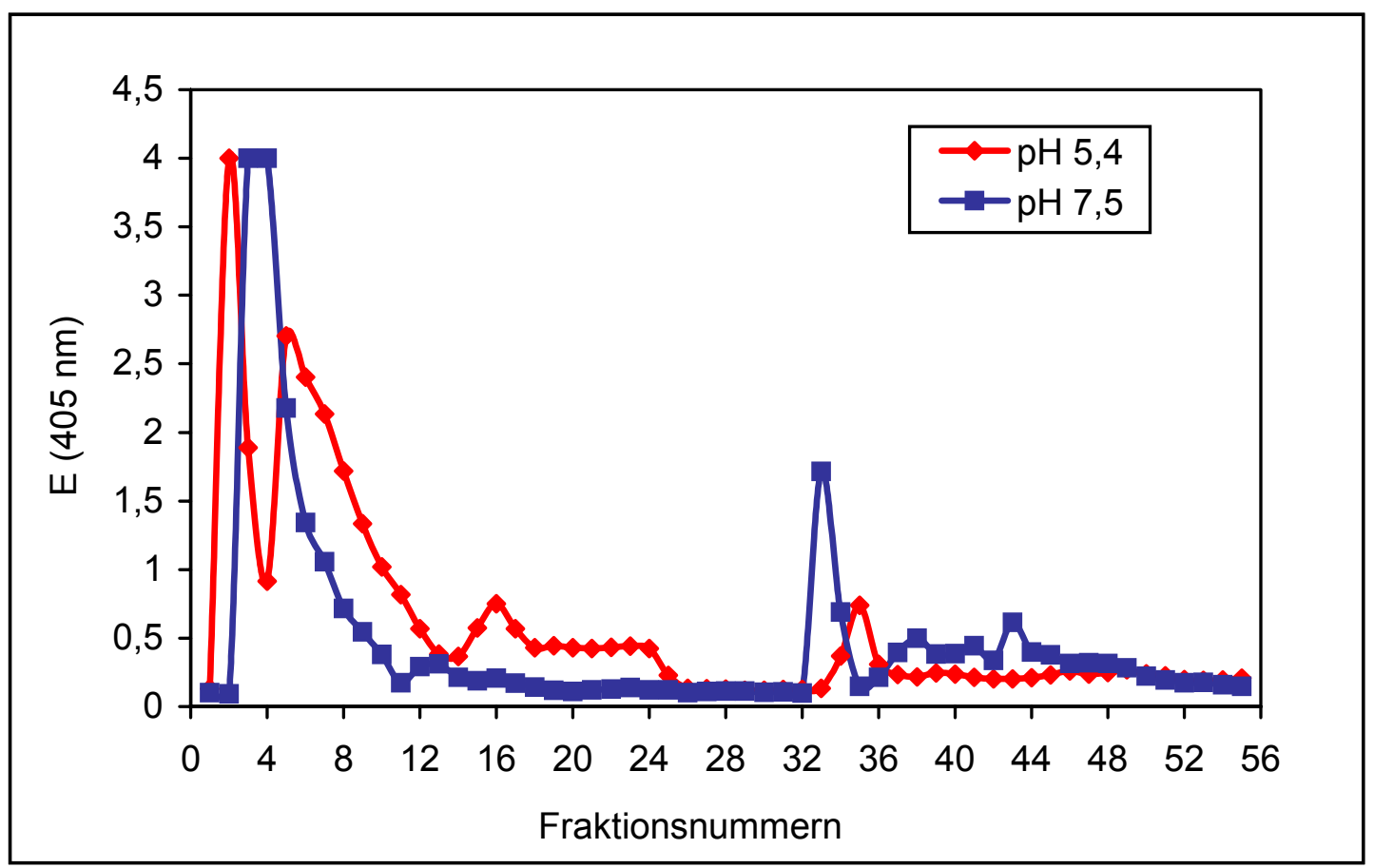

Abbildung 37: Untersuchung der Abhängigkeit vom pH-Wert bei der Bindung der Proteine an die Mikrotiterplatten durch ELISA. Die Ergebisse der ABA-BSA-Bindung an Proteinfraktionen des DEAE-Säulenlaufs aus Abbildung 35 und Abbildung 36 wurden hier miteinander verglichen.

Um den Proteincharakter der ABA-Bindung zu zeigen, wurde eine Fraktion des DEAESäulenlaufs mit hoher ABA-BSA-Konjugat-Bindung mittels Trypsin verdaut und im ELISA die ABA-Bindung untersucht. Dazu wurde die Fraktion für 30 min mit Trypsin inkubiert und im Anschluß daran das Trypsin inaktiviert. Die Ergebnisse sind in Tabelle 12 dargestellt. Zur Kontrolle wurde die nur mit gleichen Volumina an Puffer behandelte Fraktion (Kontrolle) und die Fraktion, welche mit inaktiviertem Trypsin behandelt wurde, im ELISA auf ABABindung hin untersucht. 
Tabelle 12: Bestimmung der ABA-BSA-Konjugat Bindung an ABA-bindende Proteine des DEAE-Säulenlaufs, welche mit Trypsin behandelt wurden, durch ELISA.

Die Mikrotiterplatten wurden mit jeweils $100 \mu$ l einer Fraktion des DEAE-Säulenlaufs mit hoher ABA-Bindung beschichtet, welche mit Puffer (Kontrolle), mit Trypsin und mit inaktiviertem Trypsin behandelt wurde.

\begin{tabular}{llll}
\hline & Kontrolle & Trypsin & Inaktivertes Trypsin \\
\hline E (405) & 2,073 & 0,215 & 0,848 \\
\hline
\end{tabular}

Aus Tabelle 12 ist zu erkennen, daß die mit Trypsin behandelte Fraktion des DEAESäulenlaufs im Vergleich zu unbehandelten Fraktion eine deutliche Reduktion der ABABSA-Konjugat-Bindung aufwies. Dies zeigt, daß die Bindung der ABA-BSA-Konjugate an Proteine und nicht an andere Strukturen erfolgte. Die mit inaktiviertem Trypsin behandelte Fraktion weist ebenfalls eine geringere ABA-Bindung auf, dies könnte darauf zurückzuführen sein, daß die Inaktivierung von Trypsin nicht vollständig stattgefunden hatte.

\subsubsection{SDS-PAGE von Fraktionen des DEAE-Säulenlaufs}

Fraktionen mit hohen Protein-Konzentrationen oder höherer Signalintensität im ELISA des DEAE-Säulenlaufs wurden mittels SDS-Gelelektrophorese aufgetrennt und angefärbt. In Abbildung 38 sind die entsprechenden Gele dargestellt. Deutlich erkennen läßt sich das Elutionsprofil von verschiedenen Proteinen. In den Fraktionen 0, G-25 sowie 37 bis 43 wurde ein Protein mit $51 \mathrm{kDa}$ nachgewiesen, hierbei handelt es sich vermutlich um die große Untereinheit der RubisCO. 


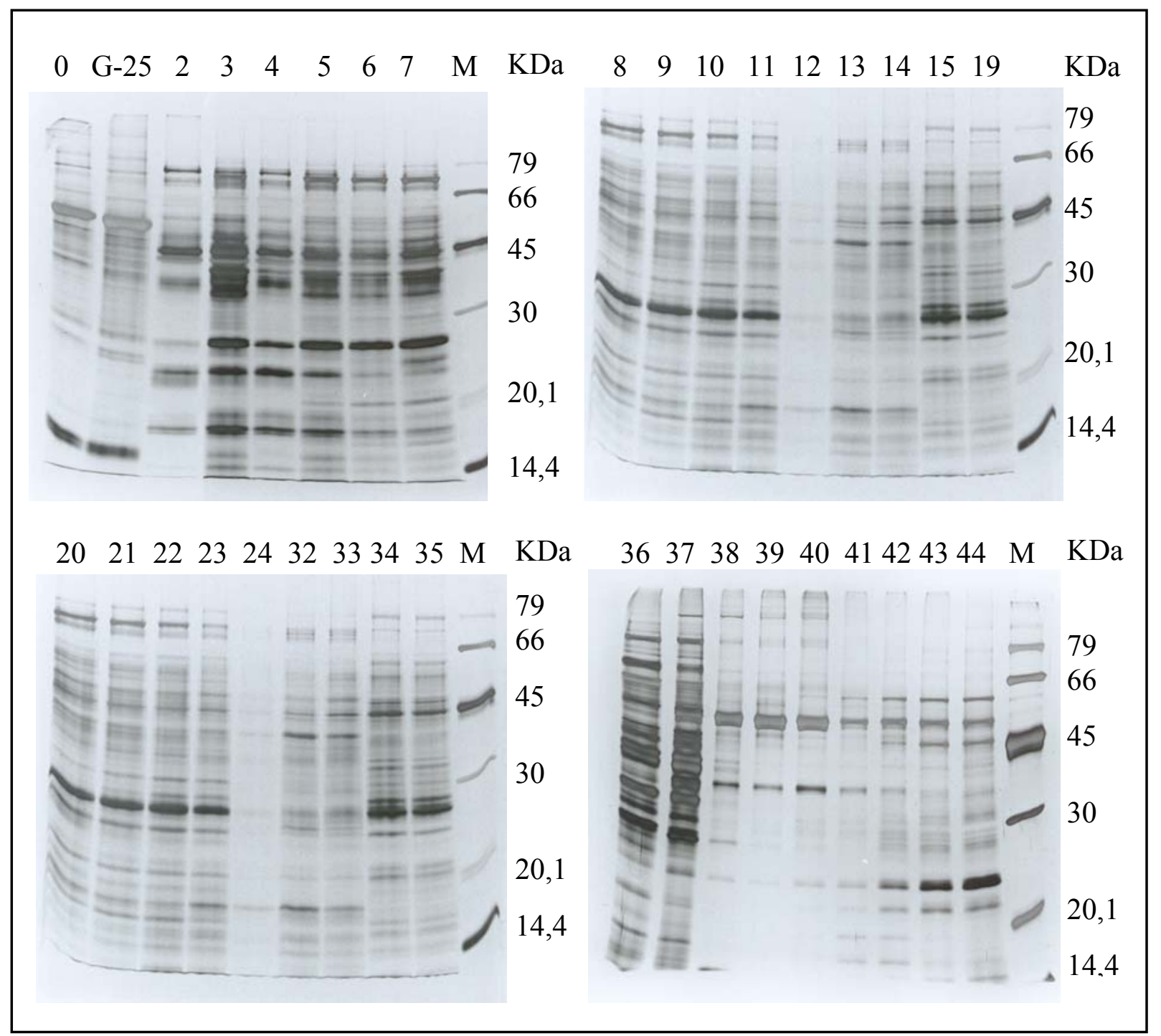

Abbildung 38: SDS-PAGE der Fraktionen des DEAE-Säulenlaufs durch 12,5 \% SDS-Gel.

Je Gelspur wurden $5 \mu \mathrm{g}$ Protein der Fraktion aufgetragen. Für Fraktionen, in denen sich durch Bradford kein Protein nachweisen ließ, wurden $200 \mu \mathrm{l}$ der Probe aufgetragen. Untersucht wurden nur Proben aus Fraktionen, in denen sich Protein detektieren ließ oder ein Signal im ELISA gemessen werden konnte. Nach erfolgter Elektrophorese wurden die Proteine mit Silver Stain angefärbt. (0) Fraktion vor Gelfiltration, (G25) Fraktion nach der G25 Entsalzungssäule, (1) bis (44) Fraktionen aus dem DEAE-Säulenlauf, (M) Molekulargewichtsmarker.

Aus dem SDS-Gel (Abbildung 38) läßt sich erkennen, daß sich in der zweiten Fraktion, in der im ELISA das stärkste Signal der ABA-Bindung gemessen wurde, nur wenige ProteinBanden nachwiesen ließen. Eine weitere Aufreinigung von ABA-bindenden Proteinen aus dieser Fraktion erscheint aufgrund der geringen Menge verschiedener Proteine besonders 
geeignet. Die weitere Aufreinigung dieser Protein-Fraktion sollte mittels ABA-AffinitätsChromatographie erfolgen.

\subsubsection{Nachweis von RubisCO in Fraktionen des DEAE-Säulenlaufs}

Aufgrund der Vielzahl von Proteinen ist die RubisCO im SDS-Gel nicht immer eindeutig zu identifizieren. Um einen deutlichen Beweis zu erbringen, in welchen Fraktionen die RubisCO vorhanden war, wurde ein ELISA zum Nachweis der RubisCO durchgeführt. Dadurch sollte gezeigt werden, daß die RubisCO von anderen ABA-bindenden Proteinen abgetrennt wurde. Die Fraktionen des DEAE-Säulenlaufs wurden dazu gegen Tris/NaCl-Puffer dialysiert. Der Nachweis der RubisCO erfolgte anschließend im ELISA durch einen polyklonalen Antikörper gegen RubisCO aus Erbse, welcher freundlicherweise von Prof. Eckhard Neuhaus, Osnabrück zur Verfügung gestellt wurde.

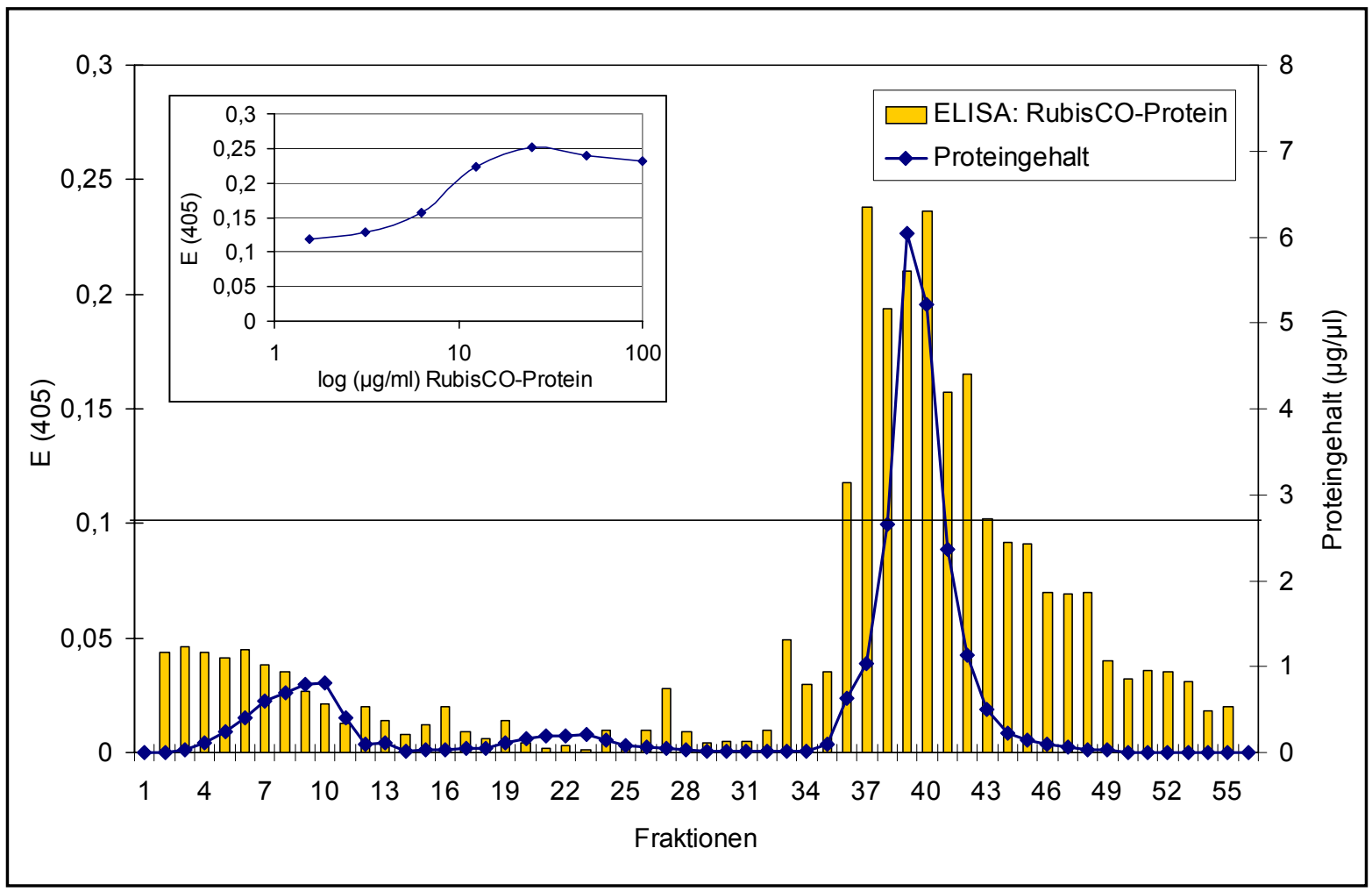

Abbildung 39: Detektion der RubisCO in den Fraktionen des DEAE-Säulenlaufs.

Beschichtet wurden die Mikrotiterplatten mit jeweils $100 \mu$ der gegen Tris/NaCl-Puffer pH 7,5 dialysierten Fraktionen. Freie Bindungskapazitäten wurden 1,5 h mit $1 \%$ Ovalbumin in TBST abgesättigt. Der Nachweis von RubisCO erfolgte durch einen polyklonalen Antikörper gegen das Protein. 
Aus Abbildung 39 ist zu erkennen, daß die RubisCO sich vor allem in den Fraktionen 37 bis 43 befanden. Dieser Befund steht in Einklang mit dem Auftreten der 51 kDa Bande im SDSGel. Zusätzlich ist in Abbildung 39 eine Eichkurve dargestellt, die die Extinktion im ELISA in Abhängigkeit von der Konzentration der RubisCO (Sigma) zeigt. Es ist zu erkennen, daß die untere Detektionsgrenze für den Antikörper bei ungefähr $1 \mu \mathrm{g} / \mathrm{ml}$ liegt. Für diese Proteinmenge beträgt die Extinktion des Antikörpers 0,12 Einheiten. Extinktionen unterhalb von 0,1 Einheiten sind vermutlich auf unspezifische Bindung des primären oder sekundären Antikörpers zurückzuführen. Dieses Ergebnis zeigt, daß die RubisCO nicht in Fraktionen des DEAE-Säulenlaufs, welche eine hohe ABA-Konjugat-Bindung aufwiesen (Fraktion 2, 5 bis 8 , 15 bis 17 sowie 34 bis 36) (Kapitel 3.9.2) vorhanden war. Das heißt, eine ABA-Bindung in diesen Fraktionen beruht auf andere Proteine als die RubisCO.

\subsubsection{Aufreinigung ABA-bindender Proteine mittels ABA-Affinitätssäule}

Eine weitere Aufreinigung der Proteine des DEAE-Säulenlaufs erfolgte durch ABAAffinitäts-Chromatographie. Das Säulenmaterial wurde wie unter Kapitel 2.5.1 beschrieben hergestellt. Dazu wurde ABA an EAH-Sepharose 4 B gekoppelt. Die zweite Fraktion des in Abbildung 35 dargestellten DEAE-Säulenlauf war die Fraktion mit höchster ABA-BSAKonjugat-Bindung. Daher wurde diese Fraktion mittels ABA-Affinitäts-Säule weiter aufgereinigt. Die Durchführung der Affinitäts-Chromatographie erfolgte mit $500 \mu 1$ des Säulenmaterials in einem Eppendorf-Reaktiongefäß. Inkubations-, Wasch und Elutionschritte von Proteinen wurden durchgeführt, indem die entsprechenden Lösungen auf das Säulenmaterial pipettiert wurden. Die Inkubation mit dem Material erfolgte durch Schwenken des Eppendorf-Reaktiongefäßes für 0,5 Stunden. Im Anschluß daran wurde das Säulenmaterial durch Zentrifugation sedimentiert und der Überstand vorsichtig abgenommen.

Eine Bindung der Proteine an das ABA-Affinitätssäulenmaterial wurde bei einem pH-Wert von 7,5 durchgeführt. Dies ergab sich aus folgendem Zusammenhang. Der Nachweis ABAbindender Proteine erfolgte für cytosolische Fraktionen. Im Cytosol liegt ein neutraler pHWert vor. Da die Proteine des DEAE-Säulenlaufs sich in einem Puffer mit einem pH-Wert von 5,4 befanden, war es notwendig, die Probe mittels Vivaspin-Röhrchen umzupuffern. Aliquots der zweiten Fraktion des DEAE-Säulenlaufs wurden vor und nach Umpuffern im ELISA auf ABA-Bindung getestet sowie im SDS-Gel aufgetrennt. 
Zur Bindung der Proteine an das Affinitätssäulenmaterial wurden die umgepufferten Proben über Nacht mit dem Säulenmaterial inkubiert. Das Ablösen der Proteine erfolgte durch mehrere Wasch- und Elutionsschritte. Eine Bindung der eluierten Proteine an die Mikrotiterplatten erfolgte bei pH 5,4. Dazu wurden die Fraktionen der Affinitätssäule gegen MES/NaCl-Puffer pH 5,4 dialysiert. Der Nachweis ABA-bindender Proteine erfolgte durch ELISA. Die dabei gewonnenen Resultate sind in Abbildung 40 dargestellt. Die eluierten Proteine der Affinitätssäule wurden weiterhin im SDS-Gel aufgetrennt (Abbildung 41).

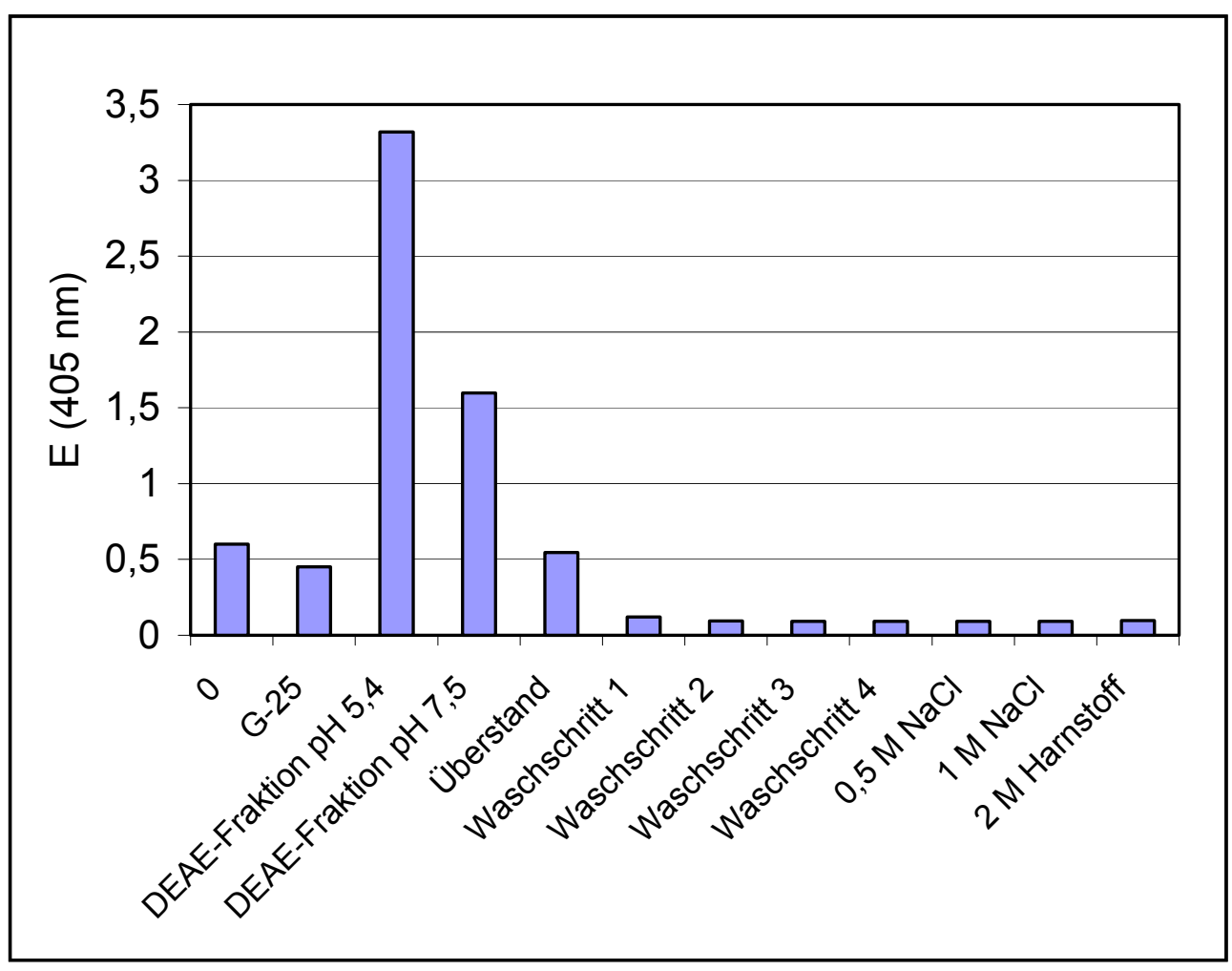

Abbildung 40: Nachweis ABA-bindender Proteine durch ELISA nach Aufreinigung der zweiten DEAE-Fraktion durch eine ABA-Affinitätssäule.

Die Mikrotiterplatten wurden mit $100 \mu \mathrm{l}$ der Extrakte oder Fraktionen beschichtet. ABAbindende Proteine wurden wie unter 2.8.4 beschrieben nachgewiesen.

$0=$ Arabidopsis-Extrakt nach Ammoniumsulfat-Fällung, G-25 = aufgereinigte Fraktion der Entsalzungssäule, DEAE-Fraktion pH 5,4 = zweite Fraktion des DEAE-Säulenlaufs vor dem Umpuffern, DEAE-Fraktion pH 7,5 = umgepufferte DEAE-Fraktion, Überstand $=$ Überstand der Lösung nach Inkubation mit den Säulenmaterial, Waschschritt $1-4=$ Waschschritte der Säule mit Puffer, $0,5 \mathrm{M} \mathrm{NaCl}$ sowie $1 \mathrm{M} \mathrm{NaCl}=$ Elutionsschritte mit verschiedenen NaClKonzentrationen, $2 \mathrm{M}$ Harnstoff = Elution der Proteine mit Harnstoff. 
In Abbildung 40 wird gezeigt, wie sich die nachgewiesenen Konzentrationen ABA-bindender Proteine während der verschiedenen Aufreinigungsschritte veränderten. In der zweiten Fraktion des DEAE-Säulenlaufs (DEAE-Fraktion pH 5,4) konnte im Vergleich zum Extrakt nach der Ammoiumsulfat-Fällung (0) und der mittels G-25 Sepharose aufgereinigten Proteine (G25) ein stärkeres Signal gemessen werden.

Für die Proteine der DEAE-Fraktion pH 7,5 wurde im Vergleich zur selben DEAE-Fraktion mit einem $\mathrm{pH}$-Wert von 5,4 eine geringere ABA-Bindung festgestellt. Die Proteine der DEAE-Fraktion pH 7,5 wurden zur Bindung an die Mikrotiterplatte nicht erneut umgepuffert, sondern bei diesem pH-Wert an die Mikrotiterplatte gebunden. Eine geringere Signalstärke kann auf eine veränderte Bindung der ABA-bindenden Proteine an die Mikrotiterplatte unter diesen Bedingungen zurückgeführt werden. Auf die Problematik der Bindung von Proteinen an die Mikrotiterplatten in Abhängigkeit vom pH-Wert wurde bereits im Kapitel 3.9.2 hingewiesen.

Nach Inkubation der Proteine mit dem ABA-Affinitätssäulenmaterial konnte im Überstand im Vergleich zu den DEAE-Fraktionen (sowohl bei pH 5,4 als auch bei pH 7,5) eine wesentlich geringere Mengen ABA-bindender Proteine detektiert werden. Dies läßt den Schluß zu, daß ein großer Teil ABA-bindender Proteine an die Matrix gebunden wurde. Beim Waschen und Eluieren der Proteine konnten keine ABA-bindenden Proteine gemessen werden. Nach der Elution mit Harnstoff lagen die Proteine denaturiert und biologisch nicht mehr aktiv vor. Daher konnte eine Detektion mittels mit Harnstoff eluierter Proteine nicht erfolgen.

Eine Auftrennung und Anfärbung der Proteine mittels SDS-Gelelektrophorese erfolgte für verschiedenen Aufreinigungsschritte der Arabidopsis-Extrakte, welche in Abbildung 41 dargestellt sind. Dazu gehören die Ammoniumsulfat-Fällung, die Entsalzung der Proteine, die DEAE-Säulen-Chromatographie und ABA-Affinitäts-Chromatographie. Um nochmals die Aufreinigung der Proteine von der RubisCO deutlich zu machen, wurden auf einer Spur des SDS-Gels $5 \mu$ g RubisCO (Sigma) aufgetragen. Aus Abbildung 41 läßt sich erkennen, daß die RubisCO (51 kDa) der Firma Sigma nur partiell aufgereinigt vorliegt. Dennoch ist deutlich zu sehen, daß die RubisCO nur in dem Extrakt vor der Ammoniumsulfat-Fällung (0) und in der Protein-Fraktion nach Aufreinigung mittels Entsalzungssäule (G-25) vorhanden sind. Keine RubisCO-Protein-Bande konnte für die nachfolgenden Fraktionen nachgewiesen werden. 


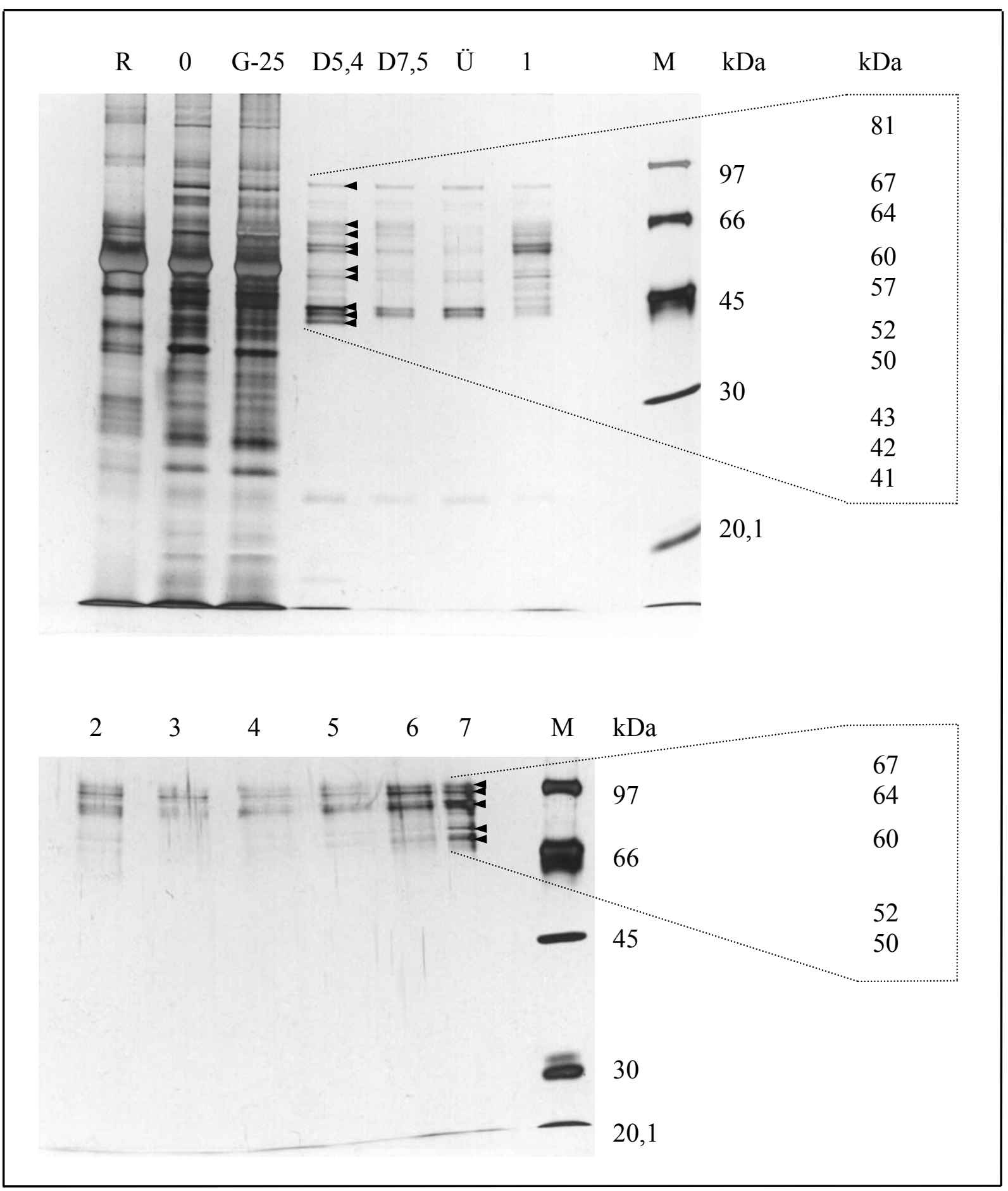

Abbildung 41: SDS-PAGE von Arabidopsis-Proteinen aus den Fraktionen verschiedener Aufreinigungsschritte.

Die hervorgehobene Skala rechts neben der Abbildung zeigt die durch lineare Regression ermittelten Molekulargewichte der mit Pfeilen markierten Proteine. $\mathrm{R}=5 \mu \mathrm{g}$ RubisCO (Sigma), $0=$ Extrakt vor der Ammoniumsulfat-Fällung, G-25 = Proteine nach Aufreinigung mittels Entsalzungssäule, D5,4 = Fraktion der DEAE-Säule vor dem Umpuffern, D7,5 = Fraktion der DEAE-Säule nach dem Umpuffern, $\ddot{U}=$ Überstand nach Inkubation mit der Affinitätsmatrix, 1 bis $4=$ Waschschritte mit Puffer, $5=$ Elution mit $0,5 \mathrm{M} \mathrm{NaCl}, 6=$ Elution mit $1 \mathrm{M} \mathrm{NaCl}, 7=$ Elution mit $2 \mathrm{M}$ Harnstoff, $\mathrm{M}=$ Molekulargewichtsstandard. 
Das SDS-Gel zeigt für die Fraktion aus der DEAE-Säule vor dem Umpuffern insgesamt 10 deutliche Proteinbanden, die in Abbildung 41 durch Pfeile markiert wurden. Die Molekulargewichte dieser Proteine wurden mittels linearer Regression bestimmt. Nach dem Umpuffern dieser Fraktion auf pH 7,5 (D7,5) ist die $41 \mathrm{kDa}$ Bande nicht mehr vorhanden. Vermutlich ist das Protein bei dem Umpuffern mittels Vivaspin-Röhrchen verloren gegangen. Die gemessene geringere Signalstärke im ELISA für diese Fraktion (siehe Abbildung 40) könnte somit auch auf den Verlust des 41 kDa Proteins zurückgeführt werden.

Im Überstand nach Inkubation mit dem Säulenmaterial (Ü) treten Proteinbanden bei 81, 43 und $42 \mathrm{kDa}$ auf. Während der Waschschritte $(1-4)$ wurden im geringen Umfang Proteine mit einem Molekulargewicht von 67, 64 und 60 kDa eluiert. Bei der Elution der Proteine von dem Affinitätssäulenmaterial mit verschiedenen $\mathrm{NaCl}-$ Konzentrationen (5 und 6) wurden diese Proteine stärker ausgewaschen. Erst bei Elution mit 2 M Harnstoff (7) konnten die Proteine mit einem Molekulargewicht von 52 und $50 \mathrm{kDa}$ eluiert werden. Da bei diesen Molekulargewichten sehr starke Banden auftraten, kann geschlossen werden, daß diese Proteine angereichert werden konnten. Es ist wahrscheinlich, daß diese Proteine spezifisch an die ABA-Affinitätssäule gebunden wurden. 


\section{Diskussion}

Das Ziel der vorliegenden Arbeit bestand darin herauszufinden, ob lösliche ABA-bindende Proteine im Cytosol von Blättern vorhanden sind. Die Notwendigkeit, ABA-bindende Proteine im Cytosol zu fordern, wurde aus folgenden Zusammenhängen geschlossen.

Slovik und Hartung (1992) berechneten die Verteilung von ABA in den subzellulären Kompartimenten von Mesophyll und Epidermis mit Hilfe einer computergestützten Verteilungsanalyse. Diese Studie ergab, daß etwa $50 \%$ der gesamten ABA der Mesophyllzellen im Stroma der Chloroplasten kompartimentiert ist. Grundlage der Analyse war die Annahme, daß die protonierte Form der schwachen Säure ABA (pKs 4,75) über Membranen diffundieren kann, die deprotonierte Form hingegen nicht (Kaiser und Hartung 1981). Dies führt zu einer pH-abhängigen Verteilung von ABA. Experimente mit isolierten Chloroplasten (Heilmann et al. 1980) und Protoplasten (Daeter und Hartung 1993) unterstützen diese Annahme, denn von außen zugesetzes ${ }^{3} \mathrm{H}$-ABA akkumulierte in dem alkalischen Kompartiment, dem Chloroplasten.

Büssis et al. (1998) untersuchten an Kartoffelblättern die subzelluläre Kompartimentierung von ABA mit Hilfe der nicht-wässrigen Fraktionierung. Dabei wurde eine Akkumulation von ABA nicht im Chloroplasten, sondern im Cytosol der Pflanzen gefunden. Diese Ergebnisse von Büssis et al. (1998) lassen sich nur erklären, wenn cytosolisches ABA an einen Rezeptor oder an ein Protein im Cytosol gebunden vorliegt. Diese Erklärung wird durch das folgende weiterführende Experiment unterstützt. Kauder (1998) konnte zeigen, daß bei Inkubation von Blattscheiben mit $20 \mu \mathrm{M}$ ABA die ABA-Konzentration im Chloroplasten und Cytosol anstieg. Dieses Ergebnis belegt, daß von außen zugegebene ABA auch in den Chloroplasten gelangen kann. Die unterschiedliche Verteilung zwischen ABA, die in den Pflanzen gebildet wurde, und der von außen zugegebenen ABA läßt sich am einfachsten erklären, wenn man annimmt, daß im Cytosol der Mesophyllzellen ABA-bindende Proteine existieren, die die freie Diffusion der ABA verhindern. Nach Absättigung dieser ABA-Bindungskapazität verteilt sich ABA zwischen den Kompartimenten entsprechend dem pH-Gradienten.

Diese Komponente fehlt in dem Modell von Solvik und Hartung (1992). Unterstützt wird die Hypothese zur Existenz ABA-bindender Proteine im Cytosol, durch den Einfluß der Expression eines scFv-Antikörpers gegen ABA im Endoplasmatischen Retikulum von 
Kartoffelpflanzen (Artsaenko et al. 1995). Mit Hilfe der nicht-wässrigen Fraktionierung wurde die subzelluläre Verteilung von ABA in diesen Pflanzen untersucht. Zwar stieg in diesen Pflanzen der Gesamt-ABA-Gehalt auf das 9-fache, aber die niedrige Konzentration im Stroma der Chloroplasten blieb unverändert (Strauß 1997). Der Antikörper, der durch seine hohe Affinität ABA dem Diffusionsgleichgewicht entzieht, verhinderte offensichtlich die Diffusion des Hormons in die Chloroplasten.

Die Lokalisation von ABA im Cytosol war insofern interessant, da bekannt ist, daß ABA die Genexpression beeinflußt (Skriver und Mundy 1990, Chandler und Robertson 1994). Büssis et al. (1998) zeigten an Kartoffelpflanzen, welche durch eine 14-tägige Behandlung mit PEG unter Wasserstreß gesetzt wurden, eine Entwicklung von zwei verschiedenen Blattypen. Ältere voll entwickelte Blätter wiesen eine 6-fache Erhöhung ihrer apoplastischen und eine 3fache Erhöhung ihrer cytosolischen ABA-Konzentration auf. Junge Blätter hingegen wiesen im Vergleich zu den Kontrollpflanzen nur einen geringen Anstieg ihrer cytosolischen und keine Veränderung ihrer apoplastischen ABA-Konzentrationen auf. In älteren Blättern wurde eine Abnahme der maximalen Aktivität von Photosynthese-Enzymen beobachtet. Möglich wäre, daß die Erhöhung der ABA-Konzentration im Cytosol unter Wasserstreß durch Änderung der Genexpression eine Adaptation der Blätter an den Wasserstreß bewirkte. Die Erkennung des ABA-Signals und der weiterführende Einfluß auf die Genexpression könnte durch ABA-bindende Rezeptoren oder Proteinen im Cytosol vermittelt werden.

\subsection{Direkte Hinweise auf cytosolische ABA-bindende Proteine}

Bislang sind nur wenige Veröffentlichungen bekannt, in denen eine ABA-Bindung an cytosolische Proteine beschrieben wurde. Veliev (1991) zeigte eine Bindung von ${ }^{3} \mathrm{H}-\mathrm{ABA}$ an Fraktionen löslicher cytosolischer Proteine, welche aus fünf Tage alten etiolierten WeizenSprößlingen präpariert wurden. Die Aufreinigung dieser Fraktionen erfolgte durch ABAAffinitäts-Chromatographie. Die Dissoziations-Konstante für Komplexe aus ${ }^{3} \mathrm{H}-\mathrm{ABA}$ und den eluierten Proteinen wurde mit $2 * 10^{-11} \mathrm{M}$ bestimmt. Eine weitere Auftrennung der eluierten Proteine mittels SDS-Gelelektrophorese führte allerdings $\mathrm{zu}$ keiner Anreicherung ABAbindender Proteine in einer der Banden. Weiterhin zeigte der Autor an der gleichen Fraktion, daß im stärkeren Maße als ABA das Phytohormon Gibberellin $\mathrm{A}_{1}$ gebunden wurde. 
Pédron et al. (1998) zeigten ABA-BSA-Konjugat-Bindung an mikrosomalen ProteinFraktionen aus sieben Tage alten Arabidopsis-Zellkulturen. Darüber hinaus konnten die Autoren auch eine geringe ABA-Konjugat-Bindung in der löslichen Protein-Fraktion beobachten. Zur Erklärung dieser Bindung nahmen die Autoren an, daß die Bindung auf eine andere Klasse ABA-bindender Proteine oder auf Kontaminationen von mikrosomalen Vesikeln zurückzuführen ist. Zhang et al. (2001) wiesen die ${ }^{3} \mathrm{H}-\mathrm{ABA}-$ Bindung an cytosolischen Fraktionen aus Äpfeln, welche sich noch in der Entwicklungsphase befanden, nach. Die Autoren fanden eine Abhängigkeit der ABA-Bindung vom $\mathrm{pH}-$ Wert, von der Temperatur und von der Inkubationszeit. Der Protein-Charakter der ABA-bindenden Substanzen wurde mittels Trypsin-Verdaus nachgewiesen. Es konnten zwei DissoziationsKonstanten für Komplexe aus ABA und Proteinen der cytosolischen Fraktionen ermittelt werden (2,3 nM und 58,8 nM). Dies deutet darauf hin, daß zwei verschiedene ABA-bindende Proteine in den Fraktionen vorlagen. Eine weitere Aufreinigung oder Isolierung dieser Proteine erfolgte allerdings nicht.

ABA-bindende Proteine im Cytosol könnten möglicherweise ABA-Rezeptoren darstellen, die an der Weiterleitung von ABA-Signalen beteiligt sind. Indizien dafür, daß lösliche Phytohormone an der Signaltransduktion beteiligt sind, wurden für Auxin gefunden. Das Auxin-bindende-Protein (ABP1) konnte bereits in vielen Pflanzen-Arten nachgewiesen werden. Seit längerer Zeit schon wurde vermutet, daß es sich bei ABP1 um einen AuxinRezeptor handelt (Venis und Napier, 1995). Das Protein (ABP1) ist überwiegend innerhalb des Lumens des Endoplasmatischen Retikulums lokalisiert. Aus dem Fehlen einer membrandurchspannenden Domäne wurde gefolgert, daß es sich bei ABP1 um ein lösliches Protein handeln müsse (Bauly et al. 2000). Gehring et al. (1998) konnten mit Hilfe eines ABP1-Antikörper zeigen, daß ABP1 den cytosolischen pH-Wert und die Stomata-Öffnung von Schließzellen aus Orchideen beeinflußt. Der von den Autoren verwendete Antikörper bindet wie Auxin an die Auxin-bindende Domäne von ABP1. Die Zugabe dieses Antikörpers bewirkte ein Öffnen der Stomata und eine Verringerung des cytosolischen pH-Werts innerhalb der Schließzellen.

Für die Beantwortung der Fragestellung dieser Arbeit, ob ABA-bindende Proteine im Cytosol von grünen Pflanzenteilen vorhanden sind, mußte zunächst ein geeignetes Nachweisverfahren entwickelt und etabliert werden. Durch Modifikation der in der Literatur beschriebenen ELISA-Verfahren (Enzym Linked Immunosorbent Assay) (Kemeny 1994, Pédron et al. 1998) 
wurde ein ELISA zum Nachweis ABA-bindender Proteine entwickelt. Weiterhin wurden Verfahren zum Nachweis und zur Aufreinigung von ABA-bindenden Proteinen im Cytosol etabliert. In den folgenden Kapiteln werden diese Schritte im Einzelnen betrachtet.

\subsection{ELISA zum Nachweis ABA-bindender Proteine}

Zum Nachweis ABA-bindender Proteine bieten sich zwei Verfahren an: Zum einen kann in Experimenten mit radioaktiv markierter ${ }^{3} \mathrm{H}-\mathrm{ABA}$ die Bindung von $\mathrm{ABA}$ an die Proteine ermittelt werden, und zum anderen ist es möglich, die ELISA-Technik einzusetzen. Der Vorteil des ELISAs besteht in seiner höheren Sensitivität und der Möglichkeit, eine große Menge an Proben gleichzeitig zu untersuchen. Ein Nachteil allerdings ist, daß zum Nachweis ABA-bindender Proteine das Phytohormon an eine Trägersubstanz gekoppelt werden muß. Die für die Kopplung verwendete funktionelle Gruppe steht somit nicht mehr als Epitop zur Erkennung durch das ABA-bindende Protein zur Verfügung.

Ein Nachweis von ABA-bindenden Proteinen mittels ELISA-Technik wurde erstmals von Wan und Hasenstein (1996) durchgeführt. Die Autoren reinigten mikrosomale Proteine aus Mais-Wurzelzellen über eine ABA-BSA-Affinitäts-Säule auf und wiesen ABA-bindende Proteine im kompetitiven ELISA-Blocktest nach. Dazu wurden ABA-Ovalbumin-Konjugate an Mikrotiterplatten gebunden und mit unterschiedlich verdünnten Fraktionen einer ABAAffinitätssäule mit einem anti-ABA-Antikörper inkubiert. Pédron et al. (1998) wanten zum Nachweis mikrosomaler ABA-bindender Proteine aus Arabidopsis-Zellkulturen einen direkten ELISA an. Dazu wurden unterschiedliche Konzentrationen in Lösung gebrachter mikrosomaler Proteine an Mikrotiterplatten gebunden und ABA-bindende Proteine mit ABAProtein-Konjugaten und anti-ABA-Antikörpern nachgewiesen. In der vorliegenden Arbeit wurde in Anlehnung an das Verfahren von Pédron et al. (1998) ein direkter ELISA zum Nachweis ABA-bindender Proteine entwickelt.

\subsubsection{Kopplung von $\mathrm{ABA}$ an ein Trägerprotein}

Die Kopplung von ABA an ein Trägerprotein kann über ihre Carboxylgruppe $\left(C_{1}\right)$ oder über ihre Ketogruppe $\left(\mathrm{C}_{4}\right)$ erfolgen. Weiler (1979) beschrieb als erster eine Kopplungsreaktion von ABA über die Carboxylgruppe an HSA nach der Carbodiimid-Methode unter Verwendung von EDC. Nachfolgende Arbeitsgruppen führten Reaktionen von ABA an ein Trägerprotein 
in erster Linie unter Modifikation dieser Methode durch (Wan und Hasenstein, 1996). Pédron et al. (1995) erweiterten die Carbodiimidreaktion mit EDC durch die zusätzliche Zugabe von NHSC. Der Reaktionsmechanismus ist noch nicht genau bekannt. NHSC wird zur Peptidsynthese über aktivierte Ester verwendet. In der vorliegenden Arbeit wurde die Kopplung in Anlehnung an die von Pédron et al. (1996) beschriebene Methode durchgeführt. Dabei wurde die Carboxylgruppe von $\mathrm{ABA}$ an eine der primären Aminogruppen von $\mathrm{BSA}$ gekoppelt. Theoretisch stehen $59 \varepsilon-\mathrm{NH}_{2}$-Gruppen des BSA-Moleküls für diese Reaktion zur Verfügung. Wie viele Gruppen davon tatsächlich eine Reaktion eingehen können, ist nicht genau bekannt. Es kann jedoch davon ausgegangen werden, daß die Anzahl reagierender Aminogruppen wesentlich geringer ist. Nach Dayhoff (1976) könnte die Anzahl reagierender Aminogruppen zwischen 30 - 35 liegen. Dies liegt darin begründet, daß durch die Faltung des Proteins nicht alle Aminogruppen zugänglich sind.

Um geeignete Bedingungen für die Durchführung dieser Kopplungsreaktion im Rahmen der vorliegenden Arbeit zu ermitteln, wurde zunächst das optimale Verhältnis von ABA zu BSA bestimmt. Die Reaktion wurde mit molaren Konzentrationen von BSA zu ABA von 1:10, 1:100 und 1:200 durchgeführt. Der Nachweis des Einbaus erfolgte mit ${ }^{3} \mathrm{H}-\mathrm{ABA}$ oder massenspektrometrisch. Bei einem Konzentrationsverhältnis von 1:10 wurde kein nennenswerter Einbau von ${ }^{3} \mathrm{H}-\mathrm{ABA}$ in BSA gefunden. Bei einem Verhältnis von 1:100 wurde mittels ${ }^{3} \mathrm{H}$-ABA ein Einbau von 10,4 \pm 4,6 und bei einem Verhältnis von 1:200 von $24,1 \pm 8,8$ ABA-Molekülen pro BSA-Molekül ermittelt (Tabelle 5). Die massenspektrometrische Analyse ergab bei der Kopplungsreaktion mit BSA:ABA von 1:100 im Vergleich zur Reaktion mit 1:200 einen Unterschied des Einbaus von etwa 10 ABA-Molekülen in BSA. Trotz des höheren Einbaus bei der Kopplungsreaktion bei einem Verhältnis BSA:ABA von 1:200 erfolgte die Konjugatherstellung für die Verwendung im ELISA bei einem Verhältnis von 1:100. Dies begründete sich darauf, daß am Ende der Kopplungsreaktion bei einem Verhältnis von 1:200 die Lösung ungewöhnlich trüb wurde. Eine Dialyse dieser Probe für 5 Tage gegen $\mathrm{H}_{2} \mathrm{O}_{\text {dest. }}$ konnte diese Trübung nicht beseitigen. $\mathrm{Da}$ während der Kopplungsreaktion die Konzentration an Kofaktoren im gleichen Umfang wie die ABAKonzentration erhöht wurde, wäre es denkbar, daß bei hohen Konzentrationen der Kofaktoren diese freie Carboxylgruppen der BSA-Moleküle mit Aminogruppen anderer BSA-Moleküle vernetzt haben. 
Zur Berechnung der gebundenen ABA-Moleküle an BSA mit Hilfe der Massenspektrometrie wurden mögliche Bindungen der Kofaktoren (EDC und NHSC) an BSA berücksichtigt. So konnte errechnet werden, daß bei einer Kopplungsreaktion mit BSA:ABA von 1:100 21 ABA-Moleküle pro BSA gebunden wurden. Im Unterschied dazu wurde mittels ${ }^{3} \mathrm{H}-\mathrm{ABA}$ ein Einbau von nur etwa 10 ABA-Molekülen pro BSA ermittelt. Zudem wurden bei der Meßmethode mit ${ }^{3} \mathrm{H}-\mathrm{ABA}$ große Schwankungen von fast fünf ABA-Molekülen gemessen (Tabelle 5).

Die Ursache für die unterschiedlichen Meßergebnisse der beiden Methoden und die starken Schwankungen der Ergebnisse mit ${ }^{3} \mathrm{H}$-ABA lassen sich aus folgendem Zusammenhang erklären. Bei der Berechnung der an BSA gekoppelten ABA-Moleküle war es bei der ${ }^{3} \mathrm{H}-$ ABA-Methode notwendig, die Konzentration von gekoppeltem BSA zu bestimmen. Eine genaue Proteinbestimmung der Konzentration von BSA-Molekülen, welche eine Bindung mit ABA-Molekülen eingegangen waren, konnte allerdings nicht erfolgen, da durch die KonjugatBildung die Anzahl primärer Aminogruppen stark reduziert war. Die Farbintensität ist jedoch abhängig vom Gehalt an basischen Aminosäureresten, insbesondere Arginin (Pingoud und Urbanke 1997). Daher wurde als Basis zur Berechnung der Anzahl gekoppelter ABAMoleküle pro BSA die während der Reaktion eingesetzte Menge an BSA zugrundegelegt. Ein weiterer Nachteil bei der Bestimmung von ABA unter Verwendung von ${ }^{3} \mathrm{H}-\mathrm{ABA}$ besteht darin, daß die Proteinfällung mit Ammoniumsulfat zum Entfernen nicht gebundener ${ }^{3} \mathrm{H}-\mathrm{ABA}$ nicht quantitativ erfolgte und somit ein Teil der Konjugate verloren ging. Dies läßt sich aus Abbildung 8 deutlich erkennen. Die Konjugate wurden im Experiment zur Bestimmung der Kopplungseffizienz bei 50 und $60 \%$ Ammoniumsulfat gefällt. Bei diesen Konzentration bleibt ein großer Teil der Radioaktivität im Überstand. Daraus resultiert, daß bei der ${ }^{3} \mathrm{H}-\mathrm{ABA}-$ Methode große Unterschiede in der Anzahl der gebundenen ABA-Moleküle pro BSAMolekül im Vergleich zur massenspektrometrischen Bestimmung auftraten. Ebenfalls läßt sich dadurch die große Schwankungsbreite der Ergebnisse des ${ }^{3} \mathrm{H}-\mathrm{ABA}-$ Einbaus erklären.

Mit Hilfe der Massenspektrometrie ließ sich die Anzahl an BSA gekoppelter ABA-Moleküle sehr zuverlässig bestimmen. Unter Berücksichtigung möglicher unspezifischer Bindung von Kofaktoren (NHSC und EDC) an BSA ergab sich, daß im Durchschnitt 21 ABA-Moleküle pro BSA gebunden wurden. Dieser Wert spiegelt nicht die tatsächliche maximale Kopplungsrate wieder, sondern wurde vielmehr aus einer Gaußschen Normalverteilung ermittelt. Allerdings muß beachtet werden, daß die Bindung der Kofaktoren an BSA ohne 
Zusatz von ABA durchgeführt wurde. Dieses Experiment war die Grundlage zur Berechnung von unspezifisch gebundenen Kofaktoren an BSA. Da nicht bekannt ist, ob derselbe Einbau von EDC und NHSC auch in Anwesenheit von ABA stattfindet, könnte der tatsächliche Wert von dem hier beschriebenen geringfügig abweichen.

Pédron et al. (1996) verwendeten zur Kopplung von ABA an BSA ein Verhältnis BSA:ABA von 1:1000 und erhielten unter Verwendung von ${ }^{3} \mathrm{H}-\mathrm{ABA}$ eine Bindung von etwa $17 \mathrm{ABA}$ Molekülen pro BSA-Molekül. Zwei Jahre später führten Pédron et al. (1998) die Reaktion mit ABA:BSA Konzentrationsverhältnissen von 1:250 bis 1:10 durch und erhielten ein Kopplungsprodukt, bei dem 36 ABA-Moleküle pro BSA-Molekül vorhanden waren. Aus ihrem Artikel geht allerdings nicht hervor, bei welchem molaren ABA:BSAKonzentrationsverhältnis dieser Wert erreicht wurde und welche Korrekturen durchgeführt wurden. Eine Kopplung von ABA an BSA nach Weiler (1980) ergab typischerweise Konjugate mit fünf ABA-Molekülen pro BSA-Molekül. Damit liegen die hier gefundenen Werte durchaus im Bereich der in der Literatur beschriebenen Ergebnisse. Der Einbau von möglichst vielen ABA-Molekülen pro BSA-Molekül begünstigt bei der Immunisierung von Tieren zur Herstellung von Antikörperen die Bildung von Antikörpern, welche gegen das Antigen gerichtet sind. Weiterhin wird durch einen höheren Einbau von ABA an BSA der Nachweis der ABA-Protein-Konjugate durch immunologische Analysen verbessert, da mehr Antigene zur Detektion zur Verfügung stehen.

\subsubsection{Herstellung und Charakterisierung von Anti-ABA-Antikörper}

Pflanzenhormone besitzen aufgrund ihres geringen Molekulargewichts keine Immunogenizität und können daher nicht direkt als Antigene zur Immunisierung eingesetzt werden. Um eine Antikörperreaktion auszulösen, ist es empfehlenswert, sie kovalent an eine Trägersubstanz zu koppeln und dann zu injizieren. Die gewonnenen Antikörper sind allerdings nicht in allen Fällen spezifisch für das Phytohormon. Entscheidend ist in vielen Fällen die richtige Wahl der Kopplungsstelle. Beispielsweise erkennen die gewonnenen Antikörper auch die in einer Pflanze vorkommenden ABA-Derivate, die über die Carboxyloder Ketogruppe substituiert sind (ABA-Methylester oder ABA-Glukose-Ester, etc.). Außerdem kann die Art der Kopplung die Affinität des Antikörpers in bezug auf stereochemische Unterschiede des Antigens beeinflussen. So erkennt ein Antikörper, der 
gegen ein racemisches Gemisch von (R,S)-ABA hergestellt wurde, vorzugsweise die R-Form und nicht die natürlich vorkommende S-Form (Walton et al. 1979).

Für die Detektion freier und gebundener ABA entwickelte E.W. Weiler (1979) einen Radioimmunoassay (RIA), mit dem mittels polyklonaler Antikörper gegen ABA-HSAKonjugate ABA-Gehalte im Pflanzenextrakt nachgewiesen werden konnten. Der Nachweis erfolgte über ${ }^{3} \mathrm{H}$-ABA, welche mit ABA um die Bindung am Antikörper konkurrierte. Die Firma Sigma bot bis 1999 kommerziell einen Antikörper gegen ABA an, der auf den Arbeiten von Weiler basierte.

Im Rahmen der vorliegenden Arbeit wurden ebenfalls Antikörper gegen ABA hergestellt. Durch die Firma BioScience wurden die hergestellten ABA-BSA-Konjugate in zwei Kaninchen (423 und 426) in mehreren Serien injiziert. Die Titerbestimmung zeigte, daß die Seren von Kaninchen 426 einen höheren Titer im ELISA aufwiesen als die von Kaninchen 423. Die Präimmunseren der beiden Kaninchen zeigten keine Reaktion mit ABA-BSAKonjugaten. Dies läßt den Schluß zu, daß die gewonnenen Antikörper gegen die ABA-BSAKonjugate als Folge der Injektion gebildet wurden. Weiterhin konnte gezeigt werden, daß die Präimmunseren keine Kreuzreaktion mit Proteinen aus Spinatextrakten zeigten.

Die Affinität des Antiserums gegenüber ABA wurde mittels RIA ermittelt und mit dem ABAHSA-Antikörper der Firma Sigma verglichen. Für den anti-ABA-BSA-Antikörper (BioScience) konnte ein $\mathrm{K}_{\mathrm{d}}$-Wert von $3,68 * 10^{-8} \mathrm{M}$ bestimmt werden, so daß dieser als affiner Antikörper klassifiziert werden kann. Für den anti-ABA-HSA-Antikörper (Sigma) wurde ein $\mathrm{K}_{\mathrm{d}}$-Wert von $4,2 * 10^{-9} \mathrm{M}$ bestimmt. Weiler konnte für den von ihm entwickelten anti-ABAHSA-Antikörper einen $\mathrm{K}_{\mathrm{d}}$-Wert von $7,7^{*} 10^{-10} \mathrm{~mol} / \mathrm{l}$ ermitteln. Zwischen dem von Weiler ermittelten $K_{d}$-Werts für seinen anti-ABA-HSA-Antikörper und dem gemessenen $K_{d}$-Wert des käuflichen anti-ABA-HSA-Antikörpers (Sigma) besteht eine große Differenz. Die Ursache dafür könnte einerseits in Unterschieden in den experimentellen Bedingungen liegen. Andererseits ist zu erwarten, daß die Affinität eines Antikörpers stark von dem jeweils immunisierten Kaninchen abhängt und damit bei dem von der Firma Sigma vertriebenen Antikörper variabel sein dürfte.

Weiler (1979) zeigte für den anti-ABA-HSA-Antikörpers eine Kreuzreaktivität von $103 \%$ für ABA-Glukose-Ester und von $182 \%$ für ABA-Methylester bezogen auf $100 \%$ Bindung von 
$\mathrm{ABA}$ an den Antikörper. Für ABA-Derivate, deren funktionelle Gruppen nicht die Carboxylgruppe veränderten, konnte nahezu keine Kreuzreaktion gefunden werden. Für den im Rahmen dieser Arbeit entwickelten anti-ABA-BSA-Antikörper konnten derartige Kreuzreaktionen nicht ermittelt werden, da ABA-Derivate oder ABA-Ester kommerziell nicht erhältlich waren. Da allerdings die zur Immunisierung verwendeten ABA-BSA-Konjugate ebenfalls über die Carboxylgruppe gekoppelt wurden, ist anzunehmen, daß ähnliche Kreuzreaktionen auftreten könnten.

Der anti-ABA-HSA-Antikörper (Sigma) und der anti-ABA-BSA-Antikörper (BioScience) wurden durch Bestimmung der ABA-Gehalte aus Gewebeextraken von Gerste miteinander verglichen. Die gefundenen Ergebnisse waren sehr ähnlich. Da durch Extraktionen aus pflanzlichen Geweben neben ABA auch ABA-Derivate und ABA-Ester isoliert werden, läßt dieses Ergebnis den Schluß zu, daß beide Antikörper ähnliche Kreuzreaktionen eingehen.

anti-ABA-BSA-Antikörper (Bioscience)

anti-ABA-HSA-Antikörper (Sigma)

$1,35 \pm 0,35 \mathrm{nmol}$ ABA/mg Chlorophyll $\quad 1,08 \pm 0,36 \mathrm{nmol}$ ABA/mg Chlorophyll

Abbildung 42: Vergleich der anti-ABA-Antikörper anhand von Gersteextrakten $(n=4)$ (Winkelmüller 2001).

Eine mögliche Kreuzreaktivität des ABA-BSA-Antikörpers gegenüber ABA-Derivaten hatte jedoch keinen Einfluß auf die in dieser Arbeit vorgestellten Experimente. Der Antikörper wurde als Affinitätssonde für den ELISA zum Nachweis ABA-bindender Proteine aus Pflanzenextrakten eingesetzt. Reaktionen des Antikörpers mit ABA-Derivaten und/oder ABA-Estern haben keinen Einfluß auf die Detektion ABA-bindender Proteine. Durch die Aufreinigung des Antikörpers über eine Protein A-Säule wurde sichergestellt, daß nur Immunglobuline signalgebend wirkten und unspezifische Bindungen von Serumproteinen keine Rolle spielten. 


\subsubsection{Etablierung eines nicht-kompetitiven ELISA}

Für die Entwicklung eines nicht-kompetitiven ELISAs wurden zunächst Mikrotiterplatten mit ABA-Protein-Konjugaten beschichtet. Der Nachweis des Antigens durch den ABA-BSAAntikörper und Protein A-HRP-Konjugat sollte anschließend in einer Reaktionskaskade erfolgen. Entscheidend für den Nachweis der spezifischen Bindung war unter anderem ein optimales Signal-/Hintergrundverhältnis bei der Detektion. Dieses konnte durch die Optimierung der einzelnen Schritte der Reaktionskaskade erreicht werden.

\subsubsection{Beschichtungs-Bedingungen der Mikrotiterplatten}

Eine Bindung von Proteinen oder ABA-Protein-Konjugaten an Mikrotiterplatten hängt stark von der Ladung und Hydrophobie des Proteins ab. Die Ladung eines Proteins kann durch die Wahl des Puffers beeinflußt werden. Die Kapazität von Mikrotiterplatten zur Bindung von Proteinen ist begrenzt. Kemeny (1994) und Morris (1996) empfehlen für eine optimale Detektion eine Beschichtung der Mikrotiterplatten mit 1 bis $10 \mu \mathrm{g} / \mathrm{ml}$ des Antigens. Bei hohen Konzentrationen treten nach der Sättigung der Bindungskapazität der Mikrotiterplatten Protein-Protein-Wechselwirkungen auf, die dazu führen können, daß an bereits an die Platte gebundene Proteine weitere Proteine angelagert werden. Solche Protein-ProteinWechselwirkungen sind im Allgemeinen schwächer als die zwischen Proteinen und der Oberfläche der Mikrotiterplatten. Binden in einem nachfolgenden Schritt der Reaktionskaskade Antikörper an Proteine, die an andere Proteine gebunden sind, können diese beim Waschen der Platte dissoziieren und dadurch die Signalintensität verringern (Kemeny 1994). Pédron et al. (1998) beschichteten zur Detektion von in Lösung gebrachten ABA-bindenden Proteinen aus Membranen von Arabidopsis thaliana die Mikrotiterplatten mit einer Protein-Konzentration von $5 \mathrm{mg} / \mathrm{ml}$.

Für die cytosolischen Spinatextrakte wurde erwartet, daß vor ihrer Aufreinigung maximal 1\% der vorhandenen Proteine ABA-Bindungen einzugehen vermochten. Unter Berücksichtigung der Ergebnisse von Kemeny (1994) und Pédron et al. (1998) wurden definierte Lösungen mit Gesamtproteingehalten von 0,16 bis $100 \mu \mathrm{g} / \mathrm{ml}$ aufgetragen, welche Untersuchungen über einen ausreichend großen Konzentrationsbereich erlaubten. 


\subsubsection{Auswahl der Blocksubstanz}

Eine spezifische Bindung war nur dann nachzuweisen, wenn der Hintergrund durch das Blockmittel das Signal der spezifischen Bindung nicht überdeckte. Das bedeutete, daß das Blockmittel kein Antigen des anti-ABA-BSA-Antikörpers oder des Protein A-HRP-Konjugats sein durfte. Zudem durften möglichst keine oder nur geringe Wechselwirkungen zwischen den Proteinen auftreten. Verschiedene Proteine wurden auf ihre Verwendbarkeit als Blockmittel hin untersucht: Fischhautgelantine, KLH und Ovalbumin. Von den verwendeten Blocksubstanzen zeigte Ovalbumin die geringste Bindung mit ABA-BSA-Konjugaten (Abbildung 16). Für keine der untersuchten Blocksubstanzen konnte eine unspezifische Bindung mit BSA, den anti-ABA-Antikörper und Protein A nachgewiesen werden. Für diesen Versuch zur Untersuchung der Wechselwirkungen zwischen verschiedenen Blocksubstanzen und BSA sowie den anti-ABA-Antikörper und Protein A wurden den Puffern 0,1 \% Tween 20 zugegeben. Wurde kein Tween verwendet, so traten bei allen verwendeten Blocksubstanzen unspezifische Wechselwirkungen auf (Daten nicht gezeigt). Darauf hin wurde die Wechselwirkung von BSA und Ovalbumin in Abhängigkeit von der Tween 20-Konzentration untersucht. Bereits bei Zugabe von 0,05 \% Tween konnte eine Wechselwirkung zwischen BSA und Ovalbumin deutlich reduziert werden. Wurde überhaupt kein Tween verwendet, trat eine Bindung von BSA an Ovalbumin auf. Diese hätten im ELISA ein spezifisches Signal überdecken können.

Weiterhin wurden die Blockmittel dahingehend untersucht, ob sie durch ihre Größe oder andere sterische Faktoren mögliche Bindungsstellen der ABA-BSA-Konjugate verdeckten. Dies diente stellvertretend zur Klärung der Frage, ob die Blockmittel die Bindung der ABABSA-Konjugate an die ABA-bindende Proteine be- oder verhindern könnte. Es zeigte sich für alle Blockproteine eine gleich gute Detektion der ABA-BSA-Konjugate (Abbildung 17).

\subsubsection{Untersuchungen zur Verwendbarkeit von ABA-Protein-Konjugaten im ELISA}

Verschiedene ABA-Protein-Konjugate wurden auf ihre Verwendbarkeit im ELISA getestet. Dazu wurde ABA über ihre Carboxylgruppe an BSA, KLH und Ovalbumin gekoppelt und im ELISA in Hinblick auf ihre Detektion durch anti-ABA-BSA-Antikörpern hin untersucht. Ein Vergleich der verschiedenen Konjugate zeigte, daß der Antikörper am besten ABA-BSAKonjugate und am schlechtesten ABA-Ovalbumin-Konjugate detektieren konnte. In diesem Experiment zeigte sich sogar eine Abnahme der gebundenen Antikörper bei höheren ABA- 
Ovalbumin-Konjugat-Konzentrationen. ABA-KLH-Konjugate konnten ähnlich gut wie ABAOvalbumin-Konjugate durch den Antikörper nachgewiesen werden. Bei KLH handelt es sich um ein Gemisch aus Proteinen der Napfschnecke mit einem Molekulargewicht von 3000 bis $7500 \mathrm{kDa}$. Aufgrund des hohen Molekulargewichts der Proteine von KLH und den daraus möglicherweise resultierenden höheren Anzahl unspezifischer Bindungen wurde auf eine Verwendung von ABA-KLH-Konjugaten zum Nachweis ABA-bindender Proteine verzichtet. Anhand dieser Untersuchungen erwiesen sich zum Nachweis ABA-bindender Proteine im ELISA die ABA-BSA-Konjugate als am besten geeignet. Unspezifische Bindungen des Trägerproteins BSA wurden mit demselben anti-ABA-BSA-Antikörper detektiert.

\subsubsection{Untersuchungen zur Anwendung von Anti-ABA-BSA-Antikörper im ELISA}

$\mathrm{Zu}$ Beginn der Experimente stand ein polyklonaler anti-ABA-Antikörper von der Firma Sigma zur Verfügung. Dieser Antikörper wurde etwa 1999 aus dem Angebot genommen. Da in unserer Arbeitsgruppe nur noch Restbestände vorhanden waren, war es notwendig, eigene anti-ABA-Antikörper zu produzieren. Dazu wurde das ABA-BSA-Konjugat verwendet, da es wegen seiner großen Anzahl gebundener ABA-Moleküle pro BSA-Molekül besonders geeignet war. Mit der Immunisierung von zwei Kaninchen mit diesen Konjugaten wurde die Firma BioScience in Göttingen beauftragt.

Eine Titerbestimmung der Kaninchenseren zeigte, daß das Serum des Kaninchens 426 besser geeignet war, da es eine höhere Bindung an ABA-BSA-Konjugate aufwies (Abbildung 19). Entscheidend für die Verwendung des Antikörpers im ELISA war, daß das Antiserum im Überschuß zu den ABA-BSA-Konjugaten vorhanden war. Dies war notwendig, damit die Bindung zwischen ABA-BSA-Antikörper und Antikörper für den Nachweis der ABAbindenden Proteine nicht limitierend war. Bei Verwendung von $10 \mu \mathrm{g} / \mathrm{ml}$ ABA-BSAKonjugat wurde eine Sättigung der Bindungskapazität durch den Antikörper von Kaninchen 426 bereits bei einer Verdünnung von 1:1000 erreicht. Hingegen erfolgte eine Sättigung durch das Antiserum vom Kaninchen 423 erst bei einer Verdünnung von 1:250. Hinzu kommt, daß im ELISA eine Verdünnung verwendet werden sollte, bei der das Signal/Hintergrundverhältnis optimal war. Dieses Verhältnis wurde aus den Differenzen der ELISASignale für die Bindung des Antikörpers an ABA-BSA-Konjugate und BSA bei unterschiedlicher Verdünnungen ermittelt (Tabelle 9). Möglichst hohe Differenzen spiegelten ein optimales Signal-/Hintergrundverhältnis wieder. Dies war für das Serum des Kaninchens 
426 bei einer Verdünnung von 1:1000 und 1:5000 der Fall. Für den ELISA wurde dieser Antikörper somit in einer Verdünnung von 1:3000 eingesetzt. Bei der Aufreinigung des Antikörpers über Protein A-Sepharose 4 B wurde der Antikörper etwa 1:10 bis 1:12 verdünnt. Daher wurde der aufgereinigte Antikörper im ELISA in einer Verdünnung von 1:200 eingesetzt.

Die optimale Inkubationszeit zur Bindung des Antikörpers an ABA-BSA-Konjugate wurde mittels ELISA ermittelt. Dabei zeigte sich, daß bei Einsatz von $10 \mu \mathrm{g} / \mathrm{ml}$ ABA-BSA-Konjugat eine Sättigung der normalen Bindungskapazität bereits nach einer zweistündigen Inkubation mit dem Antikörper eintrat. Bei einer Inkubationszeit von drei Stunden konnte keine höhere Bindung gemessen werden. Dadurch konnte gezeigt werden, daß die Bindung des Antikörpers an ABA-BSA-Konjugate für mindestens drei Stunden stabil war.

\subsection{Gewinnung cytosolischer Proteine}

Nachdem die immunologische Methode zum Nachweis ABA-bindender Proteine über ABABSA-Konjugate etabliert war, wurde diese zur Identifizierung cytosolischer ABA-bindender Proteine angewandt.

Dazu wurden 14 Tage alte Spinat- oder Arabidopsis-Pflanzen im Mörser auf Eis homogenisiert. Die dem Homogenisationspuffer zugegebenen Proteinase-Inhibitoren sollten einen Verdau der Proteine durch die bei der Präparation aus der Vakuole freiwerdenden Proteinasen verhindern. Zur Aufreinigung von cytosolischen Proteinen wurde eine Methode gewählt, bei der hauptsächlich lösliche cytosolische Proteine angereichert werden sollten. Dazu wurde das homogenisierte Blattmaterial mehreren Zentrifugationen unterzogen. Die erste Zentrifugation erfolgte bei einer relativ niedrigen Geschwindigkeit (650 x g), so daß zunächst nur größere Zelltrümmer und Stärkekörner sedimentiert wurden. Diese Abtrennung der Stärke von den Organellen sollte bewirken, daß ein höherer Anteil der Organellen intakt blieb. Die zweite Zentrifugation erfolgte bei 13.000 x g; dabei wurden Zellbruchstücke, Zellkerne, und intakte Chloroplasten und andere Organellen sedimentiert. Die anschließende Zentrifugation in der Ultrazentrifuge bei $150.000 \mathrm{x} \mathrm{g}$ diente der Sedimentation von Endomembranen. 
Durch das in dieser Arbeit angewandte Verfahren zur Aufreinigung cytosolischer Proteine, läßt sich nicht völlig ausschließen, daß auch andere als cytosolische Proteine isoliert wurden. Beim Aufschließen des Pflanzengewebes könnten Organellen, wie Mitochondrien oder Chloroplasten, zerstört worden und ein Teil ihrer Proteine in die Extrakte gelangt sein. Um derartige Störungen zu reduzieren, wurde in späteren Experimenten bei der Extraktion Sorbitol als Osmotikum hinzugefügt. Dadurch sollte erreicht werden, daß möglichst viele Organellen intakt sedimentieren. Ein Hinweis darauf, daß dies nicht vollständig erreicht werden konnte, zeigte sich darin, daß im Extrakt RubisCO nachgewiesen wurde.

Zur Volumenreduktion wurden die gewonnenen Proteine einer Ammoniumsulfat-Fällung unterzogen. Die im SDS-Gel untersuchten Überstände der gefällten Proteine zeigten, daß bis auf geringe Mengen an RubisCO alle Proteine sedimentiert werden konnten (Abbildung 32). Eine weitere Aufreinigung von Proteinen durch Variation der AmmoniumsulfatKonzentration könnte eine erste Anreicherung der ABA-bindenden Proteine erreichen.

\subsection{Aufreinigung von ABA-bindenden Proteinen aus Spinatextrakten}

Die Proteine der Spinatextrakte wurden zunächst mittels Gelfiltrations-Chromatographie ihrer Größe nach getrennt. Proteine ähnlicher Größe wurden zu einem Elutionsgipfel zusammengefaßt, indem die dazugehörigen Fraktionen vereinigt wurden. Anschließend wurden die vereinigten Fraktionen im ELISA auf ihre ABA-Bindung untersucht. Die im ELISA eingesetzten Protein-Mengen lagen zwischen 0,16 und $100 \mu \mathrm{g} / \mathrm{ml}$. Die Proteine der einzelnen Fraktionen zeigten eine unterschiedlich starke ABA-Bindung. Die höchste ABABindung konnte in der ersten und zweiten Fraktion bestimmt werden. Weiterführende Experimente zeigten jedoch, daß es sich bei der ABA-Konjugat-Bindung der Proteine der ersten Fraktion um vorwiegend unspezifische Bindungen zwischen den Trägerprotein BSA und dem Antikörper handelte. Hingegen wurde die in der zweiten Fraktion gefundene ABABindung vorwiegend der RubisCO dieser Fraktion zugeschrieben.

In engem Zusammenhang mit den hier vorgestellten Resultaten stehen die Ergebnisse von Winkelmüller (2001), der im Rahmen seiner Diplomarbeit cytosolische Proteine aus GersteProtoplasten aufreinigte. Eine Auftrennung dieser Proteine mittels GelfiltrationsChromatographie ergab ein ähnliches Protein-Profil, wie es in der vorliegenden Arbeit bei der Untersuchung von Spinatextrakten gefunden wurde. Die Anwendung der ELISA-Technik auf 
Proben aus der ersten Fraktion ergab ebenfalls keinen Hinweis auf ABA-bindende Proteine. In der zweiten Fraktion, in der sich RubisCO befand, konnte bei einer verwendeten Proteinmenge von 0,16 bis $100 \mu \mathrm{g} / \mathrm{ml}$ ein ähnlicher Verlauf der ABA-Bindung wie in der vorliegenden Arbeit gemessen werden.

Die hier mittels ELISA-Technik untersuchten ABA-bindenden Proteine wurden bei einem $\mathrm{pH}-$ Wert von 7,5 an die Mikrotiterplatten gebunden. Nicht ausgeschlossen werden kann, daß bei einem anderen pH-Wert ABA-bindende Proteine nachgewiesen werden könnten. Ein Wechsel des Puffers wurde nicht vorgenommen.

\subsection{RubisCO ein ABA-bindendes Protein?}

Anhand der Hinweise auf ABA-Konjugat-Bindung in Fraktionen mit hohen Gehalten an RubisCO, lag die Vermutung nahe, RubisCO könne ABA binden. Ein mit kommerziell erhältlicher RubisCO (Sigma) durchgeführter ELISA schien eine ABA-Bindung von RubisCO zu bestätigen (Abbildung 26). Bei der Interpretation dieses Resultats ist allerdings zu beachten, daß die RubisCO (Sigma) nur partiell aufgereinigt worden war. Eine Auftrennung im SDS-Gel zeigte, daß die RubisCO nur einen Anteil von schätzungsweise 70 bis $80 \%$ ausmachte (Abbildung 41). Um welche Proteine es sich bei den restlichen 20 bis $30 \%$ handelte, ist unklar. Daher kann auch nicht ausgeschlossen werden, daß ein Teil dieser Proteine ABA gebunden hat und somit zu dem Signal im ELISA führte.

Auffällig war die Abnahme der Extinktion im ELISA bei einer RubisCO-Menge (Sigma) von $100 \mu \mathrm{g} / \mathrm{ml}$. Diese Abnahme konnte bei den mit RubisCO angereicherten Fraktionen aus Pflanzenextrakten auch bei geringeren Konzentrationen beobachtet werden. Bei allen durchgeführten Aufreinigungen von Spinat-, Arabidopsis- und Gerste-Extrakten wurde eine Verringerung der Extinktion bei Protein-Gehalten ab $20 \mu \mathrm{g} / \mathrm{ml}$ gemessen. Ein analoges Verhalten konnte auch bei allen Messungen beobachtet werden, wenn ABA-OvalbuminKonjugate eingesetzt wurden (Daten nicht gezeigt). Untersuchungen zur Bindung von RubisCO (Sigma) an Mikrotiterplatten zeigten, daß bei Erhöhung der RubisCOKonzentrationen bis $100 \mu \mathrm{g} / \mathrm{ml}$ keine Abnahme der an die Platten gebundenen RubisCOMenge auftrat. Eine Abnahme der Bindungskapazität der Mikrotiterplatten bei hohen ProteinKonzentrationen konnte somit nicht als Grund für die beobachtete Abnahme der Extinktion herangezogen werden (Vergleich dazu Kapitel 4.2.3.1). Ein weiterer Grund für die 
Signalreduktion könnte sein, daß die Kapazitätsgrenze zur Detektion ABA-bindender Proteine im nicht-kompetitiven ELISA erreicht worden war. Dies erklärt aber nicht die kontinuierliche Abnahme der Extintion bei steigenden Protein-Gehalten aus Fraktionen der Gelfiltration. Vielmehr wäre dann eine Sättigungskurve zu erwarten gewesen.

Zur Bestimmung des $\mathrm{K}_{\mathrm{d}}$-Werts der $\mathrm{ABA}-$ Bindung an RubisCO, wurde ein kompetitiver ELISA durchgeführt werden. Dazu sollte die Bindung der ABA-BSA-Konjugate durch unterschiedliche Konzentrationen nicht an ein Trägerprotein gebundenes ABA verdrängt werden. Eine Bestimmung des $\mathrm{K}_{\mathrm{d}}$-Werts mit dieser Methode konnte allerdings nicht erfolgen, da entgegen den Erwartungen nicht an BSA gebundenes ABA ebenfalls vom anti-ABA-BSAAntikörper detektiert werden konnte. Auffällig war die hohe ABA-Konzentration von $5000 \mu \mathrm{g} / \mathrm{ml}$, die für die Bindung der anti-ABA-BSA-Antikörper zur Detektion der ABABindung an RubisCO notwendig war. Auch die Bestimmung des $\mathrm{K}_{\mathrm{d}}$-Werts durch die Bindung von ${ }^{3} \mathrm{H}-\mathrm{ABA}$ an RubisCO, mit RubisCO-Konzentrationen von 0,16 bis $100 \mu \mathrm{g} / \mathrm{ml}$ und einer ABA-Konzentration von $10 \mu \mathrm{g} / \mathrm{ml}$ sowie $0,1 \mu \mathrm{Ci}{ }^{3} \mathrm{H}$-ABA gelang nicht (Daten nicht gezeigt). Da hohe ABA-Konzentrationen zur Detektion einer ABA-Bindung an RubisCO notwendig waren, deuten diese Ergebnisse darauf hin, daß ABA unspezifisch an RubisCO gebunden wird. Für die Eigenschaft der RubisCO zur Bindung von Phytohormonen sind bisher keine Hinweise bekannt. Lediglich die RubisCO-Aktivase wurde als Gibberellin bindendes Protein identifiziert (Komatsu 1996).

Die Beobachtung einer ABA-Bindung durch die RubisCO stellt auf den ersten Blick die Arbeitshypothese in Frage, die von der Existenz cytosolischer ABA-bindender Proteine ausgeht (Büssis et al. 1998). Daher wurde in weiteren Experimenten die pH-WertAbhängigkeit der Bindung der ABA-BSA-Konjugate an RubisCO untersucht. Das Chloroplasten-Stroma weist einen alkalischen $\mathrm{pH}-$ Wert von etwa 8 auf. Bei diesem $\mathrm{pH}-$ Wert konnte nur eine sehr geringe Bindung von ABA-BSA-Konjugaten an die RubisCO gefunden werden (Abbildung 30). Dies zeigt, daß unter physiologischen Bedingungen die RubisCO als ABA-bindendes Protein keinen Einfluß auf eine Verteilung der Abscisinsäure über die Zellkompartimente nimmt. Damit widersprechen die hier gefundenen Ergebnisse nicht den Ergebnissen zur Verteilung der ABA über die Zellkompartimente (Büssis et al. 1998). 


\subsection{ABA-bindende Proteine aus Arabidopsis-Extrakten}

Wie in dem vorangegangenen Kapitel ausgeführt, konnten ABA-bindende Proteine aus Spinat- und Gersteextrakten allein durch Aufreinigung mittels Gelfiltrations-Chromatographie nicht ausreichend aufgereinigt werden. Es waren lediglich starke unspezifische Bindung der ABA-BSA-Konjugate an Proteine aus der ersten Fraktion und eine Bindung der ABA-BSAKonjugate an Proteine der zweiten Fraktion, in der überwiegend RubisCO angereichert wurde, zu beobachten. Eine weitere Aufreinigung dieser Extrakte schien aufgrund fehlender weiterer spezifischer Ergebnisse im ELISA nicht sinnvoll. Es ließ sich nicht klären, ob ABAbindende Proteine cytosolischer Natur durch die gewählten Aufreinigungsschritte verloren gingen oder ob der Nachweis durch die Bindung von ABA-BSA-Konjugaten an die RubisCO andere ABA-bindende Proteine überdeckte. Daher wurden in den folgenden Experimenten Proteine aus Extrakten einer anderen Pflanzenspezies auf eine Bindung von ABA untersucht. Dazu wurde Arabidopsis thaliana gewählt. Diese Pflanze bietet den Vorteil, daß ihr gesamtes Genom bereits sequenziert vorliegt und spätere Sequenzuntersuchungen von isolierten ABAbindenden Proteinen dadurch einfacher und genauer sind. Proteine aus Arabidopsis-Extrakten wurden zunächst wie bei den anderen Spezies mittels Gelfiltrations-Chromatographie, später aber durch Kationenaustauscher- und Affinitäts-Chromatographie aufgereinigt.

Nachdem die Arabidopsis-Protein-Extrakte mittels Gelfiltration aufgereinigt worden waren, wurden die erhaltenen Fraktionen auf das Vorhandensein ABA-bindender Proteine untersucht. Diese wurden wie bei den anderen Spezies in der ersten und zweiten Fraktion der Gelfiltration gefunden. Im Gegensatz zu Spinatextrakten lag eine unspezifische Bindung des Trägerproteins BSA nicht vor. Eine weitere Auftrennung und Anfärbung der Proteine durch SDS-Gelelektrophorese zeigte, daß sich RubisCO sowohl in der ersten als auch in der zweiten Fraktion befanden. Allerdings wies die erste Fraktion den für RubisCO typischen Kurvenverlauf, mit einer Abnahme der Extinktion bei höheren Protein-Konzentrationen, nicht auf. Dies wurde als ein Hinweis auf weitere ABA-bindende Proteine in dieser Fraktion gewertet. Um diese Vermutung zu überprüfen, wurde diese Fraktion mittels einer ABAAffinitätssäule weiter aufgereinigt. Dadurch konnten zwar Fraktionen mit hoher ABABindung gefunden werden, doch in diesen Fraktionen wurde mittels SDS-Gelelektrophorese überwiegend RubisCO nachgewiesen. Auch hier scheint, daß durch das Signal der RubisCO die Signale anderer ABA-bindender Proteine überdeckt wurden. Bedingt durch die hohen Gehalte an RubisCO schien somit eine Aufreinigung ABA-bindender Proteine mittels 
Gelfiltrations-Chromatographie nicht sinnvoll. Daher wurde als alternatives Trennverfahren die Kationenaustauscher-Chromatographie (DEAE-Säule) eingesetzt. Weiterhin wurde dem Extraktionspuffer als Osmotikum Sorbitol zugesetzt, damit möglichst viele Chloroplasten und andere Organellen während der Präparation intakt blieben und besser abgetrennt werden konnten. Dies sollte die RubisCO-Menge im Extrakt reduzieren.

Mit Hilfe der DEAE-Säule gelang es, RubisCO von anderen ABA-bindenden Proteinen abzutrennen. Dies konnte durch SDS-Gelektrophorese und durch Anwendung des ELISAVerfahrens zum Nachweis von RubisCO gezeigt werden. Die DEAE-Säulenläufe wurden bei einem pH-Wert von 5,4 durchgeführt. Unter diesen Bedingungen band der größte Teil der im Extrakt vorhandenen Proteine an das Säulenmaterial. Nur wenige Proteine wurden gleich zu Beginn des Säulenlaufs von der Säule gewaschen. Unter diesen Proteinen befanden sich allerdings einige, welche hochaffin ABA-BSA-Konjugate banden. Zwei Fraktionen zeigten im ELISA eine sehr hohe ABA-Bindung, während bei weiteren Fraktionen die ABA-Bindung etwas schwächer war. Um den Proteincharakter der ABA-Bindung nachzuweisen, wurde eine der Fraktionen des DEAE-Säulenlauf mit hoher ABA-BSA-Konjugat-Bindung im ELISA mit Trypsin behandelt. Nachdem die Proteine durch Trypsin verdaut worden waren, konnte im ELISA keine ABA-Bindung mehr nachgewiesen werden.

Aufgrund der Tatsache, daß unterschiedliche Proteine bei unterschiedlichen $\mathrm{pH}-\mathrm{Werten}$ an Mikrotiterplatten binden, wurde bei der Suche nach weiteren ABA-bindenden Proteinen der pH-Wert, bei dem die Bindung an die Mikrotiterplatten erfolgte, variiert. Die bisher gefundenen ABA-bindenden Proteine des DEAE-Säulenlaufs banden bei einem pH-Wert von 5,4 an die Mikrotiterplatten, dieser pH-Wert muß für andere im Extrakt vorhandene Proteine nicht optimal sein. So zeigte sich z.B., daß die RubisCO (Sigma) am stärksten bei einem pHWert von 9 an die Mikrotiterplatten gebunden wurde, während für sie zwischen $\mathrm{pH}$ 5,5 und 6,5 nur geringe Bindung nachweisbar war (Daten nicht gezeigt).

Bei einem pH-Wert von 7,5 konnten im ELISA weitere Proteine mit hoher Bindung von ABA-BSA-Konjugaten nachgewiesen werden. Weiterhin konnte gezeigt werden, daß in Fraktionen, in denen RubisCO nachgewiesen wurde, auch eine ABA-Bindung stattfand. Allerdings war die gemessene Extinktion im Vergleich zu den vorangegangenen Messungen der ABA-Bindung an RubisCO sehr niedrig. Die Ursache könnte der hohe Proteingehalt in diesen Fraktionen sein. Eine Beeinträchtigung der Detektion bei hohen RubisCO- 
Konzentrationen wurde unter Kapitel 4.5 diskutiert. Bei einer Verdünnung der DEAEFraktionen um einen Faktor von 5 konnten teilweise höhere Extinktionen als in den unverdünnten Fraktionen gemessen werden (Tabelle 11).

Im Folgenden wurde eine Fraktion des DEAE-Säulenlaufs mit hoher Affinität gegenüber ABA mittels ABA-Affinitäts-Chromatographie weiter aufgereinigt. Dazu mußte die Fraktion des DEAE-Säulenlaufs zunächst von $\mathrm{pH}$ 5,4 auf einem pH-Wert von 7,5 gebracht werden. Dies erfogte durch Zentrifugation mit Hilfe von Vivaspin-Röhrchen (Satorius). Im Anschluß daran wurden die Proteine der Fraktion mit dem ABA-Affinitätsmaterial inkubiert, das Affinitätsmaterial im Anschluß daran gewaschen und gebundene Proteine durch mehere Schritte eluiert. Die Proteine der über das ABA-Affinitätsmaterial aufgereinigten Fraktionen wurden mittels SDS-Gelelektrophorese aufgetrennt (Abbildung 41).

Zum direkten Vergleich wurde im SDS-Gel ebenfalls die RubisCO (Sigma) aufgetragenen. Dadurch konnte gezeigt werden, daß in keiner der über das ABA-Affinitätsmaterial aufgereinigten Fraktionen RubisCO vorhanden war.

In der DEAE-Fraktion, bevor diese mit dem ABA-Affinitätsmaterial inkubiert wurde, befanden sich 10 Proteine, die als potentielle Kandidaten für eine ABA-Bindung in betracht kamen. Beim Umpuffern der DEAE-Fraktion ( $\mathrm{pH}$ 5,4) mit Tris/NaCl-Puffer $\mathrm{pH}$ 7,5 ist ein 41 kDa-Protein verloren gegangen (Abbildung 41). Im ELISA wurde für die Probe, nachdem sie umgepuffert wurde, eine geringere ABA-Bindungs-Aktivität gemessen. Ein Grund dafür könnte sein, daß das verloren gegangene $41 \mathrm{kDa}$-Protein ABA-Bindung aufwies. Möglich ist allerdings auch, daß die Proteine bei einem pH-Wert von 7,5 ein anderes Bindungsverhalten an die Mikrotiterplatte aufwiesen als bei $\mathrm{pH}$ 5,4. Nach der Inkubation der umgepufferten Fraktion mit dem ABA-Affinitätsmaterial, zeigte sich im Überstand nur noch eine geringe ABA-Bindung. Daraus kann gefolgert werden, daß ABA-bindende Proteine an das Säulenmaterial gebunden wurden. Durch Inkubation des Säulenmaterials mit $1 \mathrm{M} \mathrm{NaCl}$ wurden Proteine mit einem Molekulargewicht von 67, 64 und 60 kDa eluiert. Für diese Proteine wurde im ELISA keine ABA-Bindung nachgewiesen. Nach einer Inkubation des Säulenmaterials mit 2 M Harnstoff wurden diese Proteine weiterhin eluiert. Darüber hinaus konnten zwei Proteine mit einem Molekulargewicht von 52 und 50 kDa eluiert werden. Für diese Fraktion konnte im ELISA ebenfalls keine ABA-Bindung nachgewiesen werden. Dies 
kann darauf zurückgeführt werden, daß Harnstoff die Proteine denaturierte, weshalb eine ABA-Bindungs-Aktivität nicht mehr nachzuweisen war.

Die Proteine mit einem Molekulargewicht von 52 und $50 \mathrm{kDa}$ gingen eine starke Bindung mit dem Säulenmaterial ein, so daß sie auch mit einer hohen $\mathrm{NaCl}-$ Konzentration von $1 \mathrm{M}$ nicht eluiert werden konnten. Erst durch ein stärkeres Elutionsmittel, dem Harnstoff, konnten diese Proteine eluiert werden. Bekannt ist, daß Proteine mit hoher Affinität zu ihrem Antigen nur schwer von diesem wieder getrennt werden können. Die starke Bindung dieser Proteine (50 und $52 \mathrm{kDa}$ ) an das ABA-Affinitäts-Säulenmaterial spricht somit für eine spezifische Bindung dieser Proteine an ABA.

Beachtet werden muß, daß die Methode zur Bestimmung der Molekulargewichte im SDS-Gel nur semi-quantitativ ist. Dazu wurden die Laufstrecken der Proteine des Molekulargewichtsmarkers und der Proteine der Extrakte ausgemessen und die Molekulargewichte der extrahierten Proteine durch lineare Regression bestimmt. Es konnten zur Linearisierung nur Markerproteine herangezogen werden, welche eine Gerade bildeten, aufgetragen wurde der Logarithmus der Masse gegen die Laufstrecke. In der Regel traf dies auf die Markerproteine mit einem Molekulargewicht von 66, 45 und $30 \mathrm{kDa} \mathrm{zu}$.

In der vorliegenden Arbeit konnte ABA-Bindung in löslichen Arabidopsis-Proteinextrakten nachgewiesen werden. Nach der Aufreinigung cytosolischer Proteinextrakte mittels DEAEKationenaustauscher-Chromatographie konnte in einzelnen Fraktionen eine starke ABABSA-Bindung gezeigt werden. Eine dieser Fraktionen wurde weiter über ABA-AffinitätsChromatographie weiter aufgereinigt. In den Eluat-Fraktionen der Affinitäts-Säule wurden zwei Proteine mit einem Molekulargewicht von 50 und $52 \mathrm{kDa}$ gefunden, die stark an die ABA-Affinitäts-Säule banden. 


\subsection{Ausblick}

In der vorliegenden Arbeit wurde ein nicht-kompetitiver ELISA zur Detektion ABAbindender Proteine entwickelt und erfolgreich angewendet. Es gelang, mindestens zwei ABAbindende Proteine (50 und $52 \mathrm{kDa}$ ) in cytosolischen Extrakten von Arabidopsis nachzuweisen. Das Ziel nachfolgender Forschungvorhaben sollte es sein, diese cytosolischen ABA-bindenden Proteine zu identifizieren und charakterisieren. Um dieses Ziel zu erreichen, muß die Aufreinigung der gefundenen ABA-Bindeproteine so weit optimiert werden, daß sie ohne störende Verunreinigungen vorliegen. Proteine, die durch eine Aufreinigung über ABAAffinitätssäulen gewonnenen wurden, sollen durch eine MALDI-TOF Analyse charakterisiert werden. Dafür muß das entsprechende Protein aus dem SDS-Gel herausgeschnitten und durch tryptischen Verdau in Peptide gespalten werden. Die Molekulargewichte (M) dieser Peptide werden mittels MALDI-TOF Analyse bestimmt. Die so erhaltenen Molekulargewichte der Fragmente werden mit den entsprechenden Daten aus der Datenbank für Arabidopsis verglichen. Daraus lassen sich anschließend Informationen über die cDNA des entsprechenden Ausgangsproteins erhalten. Aus der cDNA-Sequenz lassen sich geeignete Primer ableiten, die über PCR zur Klonierung der cDNA führen.

Ein weiteres Ziel zukünftiger Arbeiten sollte darin bestehen, weitere ABA-bindende Proteine durch Variation des $\mathrm{pH}-$ Werts bei der Bindung von Proteinen an die Mikrotiterplatten zu finden. Die hier über Affinitäts-Chromatographie aufgereinigte Fraktion wurde durch Bindung an die Mikrotiterplatte bei einem $\mathrm{pH}-$ Wert von 5,4 nachgewiesen. Dieser pH-Wert muß jedoch nicht für alle im Extrakt vorhandenen Proteine für eine Bindung an die Mikrotiterplatte optimal sein. In der vorliegenden Arbeit konnte bereits gezeigt werden, daß nach Dialyse der Proteine des DEAE-Sälenlaufs gegen Tris-Puffer pH 7,5 konnten ABAbindenden Proteinen in Fraktionen, in denen diese zuvor nicht nachgewiesen wurden, detektiert werden. Eine Dialyse der Proteinfraktionen gegen einen Puffer mit einem pH-Wert von 9 könnte zu einer Entdeckung von ABA-bindenden Proteinen in weiteren Fraktionen führen. 


\section{Zusammenfassung}

Ziel der vorliegenden Arbeit war es, cytosolische ABA-bindende Proteine aus Pflanzenextrakten zu isolieren und nachzuweisen. Dazu wurden Proteine aus Spinat- uns Arabidopsis-Pflanzen durch verschiedene proteinbiochemische Methoden wie Ammoniumsulfat-Fällung und Säulenchromatographie aufgereinigt. Für den Nachweis ABAbindender Proteine wurde als Detektionsverfahren ein nicht-kompetitiver ELISA etabliert.

Die Kopplung von ABA an BSA als Trägerprotein wurde in dieser Arbeit erfolgreich durchgeführt. Es konnte gezeigt werden, daß pro BSA-Molekül durchschnittlich 21 ABAMoleküle gebunden wurden. Die erhaltenen ABA-BSA-Konjugate wurden im ELISA als Sonden zum Nachweis ABA-bindender Proteine eingesetzt. Des Weiteren wurden die ABABSA-Konjugate zur Immunisierung von zwei Kaninchen verwendet. Die gewonnenen polyklonalen Antikörper erwiesen sich als affin gegenüber ABA. Aus Experimenten, bei denen die Konkurrenz von ${ }^{3} \mathrm{H}-\mathrm{ABA}$ und ABA um die Bindung an den Antikörper untersucht wurde, konnte ein $\mathrm{K}_{\mathrm{d}}$-Wert von 36,8 nM für den $\mathrm{ABA} /$ Antikörper-Komplex erhalten werden. Die Antikörper wurden im ELISA erfolgreich zum Nachweis gebundener ABA-BSAKonjugate oder BSA eingesetzt.

Mit Hilfe des ELISA-Verfahrens wurde nachgewiesen, daß ABA-BSA-Konjugate von RubisCO gebunden werden. ABA-BSA-Bindung an das Protein erfolgte bei einem pH-Wert von 7. Hingegen konnte bei alkalischen $\mathrm{pH}-$ Werten, wie sie im Chloroplasten vorliegen, nur eine sehr geringe Tendenz zur Bindung von ABA an RubisCO festgestellt werden.

Durch Aufreinigung von Proteinen aus Spinatpflanzen mittels Gelfiltrations-Chromatographie wurde ABA-Bindung in der ersten und zweiten Fraktion gemessen. Für die erste Fraktion wurde die Bindung der ABA-BSA-Konjugate als unspezifische Bindung des Trägerproteins BSA identifiziert. In der zweiten Fraktion wurde die RubisCO als ABA-bindendes Protein nachgewiesen. Von den durch Aufreinigung von Arabidopsis-Proteinen mittels Kationenaustauscher-Chromatographie erhaltenen Fraktionen zeigten mehrere eine hohe ABA-BSA-Konjugat-Bindung. Bei der weiteren Aufreinigung einer dieser Fraktionen durch ABA-Affinitäts-Chromatographie wurden zwei ABA-bindende Proteine mit einem Molekulargewicht von $50 \mathrm{kDa}$ und $52 \mathrm{kDa}$ wurden spezifisch an die Säule gebunden, diese mußten allerdings unter denaturierenden Bedingungen eluiert werden. 


\section{Verzeichnis der Abbildungen und Tabellen}

\subsection{Abbildungen}

Abbildung 1: Struktur von S(+)-Abscisinsäure. 2

Abbildung 2: Mögliche Synthesewege von Abscisinsäure (nach Taylor et al. 2000, Seo und Koshiba 2002).

Abbildung 3: Abbauprodukte zur Inaktivierung der von (+)-S-ABA. .5

Abbildung 4: Modell zur ABA-induzierten Signaltransduktionskette in Schließzellen zum Schließen der Stomata (modifiziert nach MacRobbie 1998).

Abbildung 5: Schematische Darstellung eines zweiteiligen Modells der ABA-

Signaltransduktionskette auf die Kontrolle des Pflanzenwachstums

(Himmelbach et al. 1998).

Abbildung 6: Schematische Darstellung der Bindungs-Reaktionskaskade zum Nachweis von ABA-bindenden Proteinen.

Abbildung 7: Beispiel einer logit-Transformation zur Linearisierung des Verhältnisses zwischen der prozentualen ABA-Bindung am Antikörper in Abhängigkeit von der ABA-Menge.

Abbildung 8: Ammoniumsulfat-Fällung der ABA-BSA-Konjugate bei unterschiedlichen Ammoniumsulfat-Konzentrationen. Gemessen wurde die Radioaktivität im Überstand und in den Sedimenten.

Abbildung 9: SDS-PAGE der Kopplungsprodukte von ABA an BSA, welche in An- oder Abwesenheit der Kofaktoren EDC bzw. NHSC gekoppelt wurden.

Abbildung 10: Bestimmung der Bindung der Präimmunseren und der polyklonalen Antikörperseren aus den Kaninchen 423 und 426 (jeweils 3 Blutabnahmen) an ABA-BSA-Konjugate durch ELISA

Abbildung 11: Untersuchung der spezifischen Bindung des anti-ABA-BSA-Antikörpers gegenüber ABA-BSA-Konjugat, BSA bzw. BSA-Kopplungsprodukten, die mit oder ohne Zusatz von ABA, EDC und/oder NHSC hergestellt wurden. .59

Abbildung 12: Prozentuale Bindung des anti-ABA-BSA-Antikörpers an ${ }^{3} \mathrm{H}-\mathrm{ABA}$ bei unterschiedlichen ABA-Konzentrationen $(n=4)$.

Abbildung 13: Logit-Transformation für die prozentuale Bindung des anti-ABA-BSAAntikörpers in Abhängigkeit von der ABA-Konzentrationen. 
Abbildung 14: Proteingehalte der Fraktionen des Protein A-Sepharose-Säulenlaufs für die Antikörper-Aufreinigung.

Abbildung 15: Analyse von Fraktionen der Antikörper-Aufreinigung über Protein A-

Sepharose durch SDS-PAGE.

Abbildung 16: Optimierung der Wahl des Blockmittels durch ELISA.

Abbildung 17: Untersuchung von unspezifischen Bindungen zwischen ABA-BSA-

Konjugaten, BSA, anti-ABA-Antikörper und Protein A an Ovalbumin (Ov),

KLH und Fischhautgelatine (FG).

Abbildung 18: Bestimmung der Konzentrationsabhängigkeit der Bindung des ABA-BSA-

Antikörpers an diverse ABA-Protein-Konjugate durch ELISA.

Abbildung 19: Untersuchung des polyklonalen anti-ABA-BSA-Serums aus der zweiten

Blutung auf Bindung an ABA-BSA-Konjugate und BSA im ELISA.

Abbildung 20: Bestimmung der optimalen Inkubationszeit zur Bindung des anti-ABA-BSAAntikörpers an unterschiedliche ABA-BSA-Konjugat-Konzentrationen durch

$\operatorname{ELISA}(\mathrm{n}=2)$. .73

Abbildung 21: ELISA zur Bestimmung der optimalen Reaktionszeit der Peroxidase-HRP-

Konjugat mit ABTS. 74

Abbildung 22: Dot-Blot-Analyse der Bindung eines anti-ABA-BSA-Antikörpers an ABA-

EAH-Sepharose 4 B-Säule zum Nachweis der Kopplungseffizienz von ABA an

EAH-Sepharose 4 B. .76

Abbildung 23: Schematische Darstellung der UV-Detektion des Protein-Elutionsprofils mittels Sephacryl S-300-HR. Die Elutionsgipfel (1) bis (4) stellen die zu einem Pool vereinigten Fraktionen dar. .78

Abbildung 24: Auftrennung der zu einem Pool vereinigten Elutionsgipfel der mittels

Gelfiltrations-Chromatographie aufgetrennten cytosolischen Spinat-Extrakte, des Extraktes vor und des Überstands nach Ammoniumsulfat-Fällung durch ein $10 \%$ iges SDS-Gel. .79

Abbildung 25, A): Nachweis ABA-bindender Proteine aus Spinatextrakten, welche mittels Gelfiltration aufgereinigt wurden, durch ELISA $(n=5)$. 80

Abbildung 25, B): Nachweis unspezifischer Bindungen des Trägerproteins BSA an Proteine aus Spinatextrakten, durch ELISA ( $\mathrm{n}=5)$.

Abbildung 25, C): Die gemessene Extinktion der Bindung von ABA-BSA-Konjugaten (Abbildung 25, A) wurde von der Extinktion, welche durch Bindung von BSA (Abbildung 25, B) detektiert wurde, subtrahiert. 
Abbildung 25, D): Nachweis von unspezifischer Bindung des ABA-Antikörpers und Protein A an Proteine aus Spinatextrakten, durch ELISA ( $\mathrm{n}=5)$.

Abbildung 26: Untersuchung der ABA-BSA-Konjugat-Bindung an RubisCO durch ELISA. 83 Abbildung 27: Bestimmung der Bindung von RubisCO (Sigma) an die Mikrotiterplatte durch ELISA. 84

Abbildung 28: Kompetitiver ELISA zur Bestimmung der ABA-Bindung an RubisCO. 85

Abbildung 29: Bestimmung der Bindung von freier, nicht an ein Trägerprotein gebundener, ABA an RubisCO durch ELISA.

Abbildung 30: Untersuchung der Bindung von ABA-BSA-Konjugaten an RubisCO in Abhängigkeit vom $\mathrm{pH}-$ Wert durch ELISA.

Abbildung 31, A): Nachweis von ABA-bindenden Proteinen aus Arabidopsis-Extrakten durch ELISA. Die Proteine wurden zuvor mittels Gelfiltration aufgereinigt. 89

Abbildung 31, B): Untersuchung der unspezifischen Bindung des Trägerproteins BSA an Proteine aus Arabidopsis-Extrakten.

Abbildung 32: SDS-PAGE von aus Gelfiltration resultierenden Fraktionen von Proteinen aus Arabidopsis-Extrakten, durch ein $10 \%$ iges SDS-Gel.

Abbildung 33: Optimierung des pH-Wertes für die Bindung von ABA-bindenden Proteinen aus Arabidopsis-Extrakten an einen DEAE-Sepharose-Kationenaustauscher (Pharmacia).

Abbildung 34: Proteinkonzentration und Ionenleitfähigkeit von Fraktionen einer Sephadex G25-Säule zum Entsalzen der Proteine aus Arabidopsis-Extrakten. 93

Abbildung 35: Elutionsprofil ABA-bindender Proteine aus Arabidopsis-Extrakten, welche mittels der DEAE-Sepharose fraktioniert wurden.

Abbildung 36: Elutionsprofil ABA-bindender Proteine aus Arabidopsis-Extrakten, welche mittels der DEAE-Sepharose fraktioniert wurden.

Abbildung 37: Untersuchung der Abhängigkeit vom $\mathrm{pH}-$ Wert bei der Bindung der Proteine an die Mikrotiterplatten durch ELISA. Die Ergebisse ABA-BSA-Bindung an Proteinfraktionen des DEAE-Säulenlaufs aus Abbildung 35 und Abbildung 36 wurden hier miteinander verglichen.

Abbildung 38: SDS-PAGE der Fraktionen des DEAE-Säulenlaufs durch 12,5 \% SDS-Gel. 100

Abbildung 39: Detektion der RubisCO in den Fraktionen des DEAE-Säulenlaufs. 101

Abbildung 40: Nachweis ABA-bindender Proteine durch ELISA nach Aufreinigung der zweiten DEAE-Fraktion durch eine ABA-Affinitätssäule. 
Abbildung 41: SDS-PAGE von Arabidopsis-Proteinen aus den Fraktionen verschiedener Aufreinigungsschritte.

Abbildung 42: Vergleich der anti-ABA-Antikörper anhand von Gersteextrakten $(n=4)$

(Winkelmüller 2001) 115

\subsection{Tabellen}

Tabelle 1: Übersicht über die wichtigsten Klassen pflanzlicher Phytohormone und deren charakteristische Wirkung.

Tabelle 2: Übersicht zur Immunisierung und Serengewinnung von zwei Kaninchen (423 und 426) nach Injektion von ABA-BSA-Konjugaten.

Tabelle 3: Übersicht zu den Versuchsbedingungen zur Aufreinigung von polyklonalen Antikörpern über Protein A-Säulen. 39

Tabelle 4: Benötigte Volumina zur Herstellung von zwei Minigelen zur Protein-Analyse.... 45

Tabelle 5: Kopplungseffizienz von ABA an BSA gemessen durch den Einbau von ${ }^{3} \mathrm{H}-\mathrm{ABA}$.

Tabelle 6: Massenspektrometrische Bestimmung des Molekulargewichts (g/mol) der ABABSA-Konjugate.

Tabelle 7: Massenspektrometrische Bestimmung des Molekulargewichts der Kopplungsprodukte von ABA an BSA in An- oder Abwesenheit von Kofaktoren (NHSC sowie EDC) und ABA.

Tabelle 8: Bestimmung von Kreuzreaktionen des Präimmunserums mit Proteinen aus Spinatextrakten, durch ELISA. 58

Tabelle 9: Differenz der gemessenen Extinktionen bei der Bindung zwischen ABA-BSAKonjugat und BSA der anti-ABA-BSA-Seren aus der zweiten Blutung aus Kaninchen 423 und 426.

Tabelle 10: Übersicht über die verwendeten Kopplungsmethoden von ABA über deren Ketound Carboxylgruppe an ein Säulenmaterial.

Tabelle 11: Bestimmung der ABA-BSA-Bindung an Proteine der Fraktionen 37 bis 40 des

DEAE-Säulenlaufs bei $\mathrm{pH} 7,5$.

Tabelle 12: Bestimmung der ABA-BSA-Konjugat Bindung an ABA-bindende Proteine des DEAE-Säulenlaufs, welche mit Trypsin behandelt wurden, durch ELISA. 


\section{Abkürzungsverzeichnis}

A

AA/BisAA Acryamid/Bisacryamid

ABA

ABTS

ADP

$\mathrm{AgNO}_{3}$

BSA

$\mathrm{Bq}$

bzw.

C

c

ca.

cADPR

$\mathrm{Ca}^{2+}$

$\mathrm{cab}$

$\mathrm{CaCl}_{2}$

$\mathrm{Chl}$

$\mathrm{Ci}$

$\mathrm{Cl}^{-}$

$\mathrm{CO}_{2}$

$\mathrm{Da}$

Dpm

DNA

DOC

DOXP

DPA

DTT

E

EDC

ELISA

g

$\mathrm{h}$

Abscisinsäure

Silbernitrat

Rinderserumalbumin

Becquerel

Beziehungsweise

Celsius

centi

circa

cyklische ADP Ribose

Calcium

Calciumchlorid

Chlorophyll

Chlorid

Kohlendioxid

Dalton

Zerfälle pro Minute

Desoxycholat

Dihydrophaseinsäure

Dithiotreitol

Einstein, Extinktion

N-Hydroxysuccinimid

Stunde
[2,2`-Azino-di(3-ethylbenzthiazolin)sulfonsäure-6]

Adenosin-5'-diphosphat

„,chlorophyll a/b binding Protein“, Gen

Curie $\left(1 \mathrm{Ci}=3,7 * 10^{10} \mathrm{~Bq}\right)$

Desoxyribonucleinsäure

1-Deoxy-D-Xylulose-5-Phosphat

„enzyme-linked immunosorbent assay“, Enzymimmuntest

Gramm, Erdbeschleunigung 


\begin{tabular}{|c|c|}
\hline${ }^{3} \mathrm{H}-\mathrm{ABA}$ & radioaktiv markierte Abscisinsäure \\
\hline $\mathrm{HCl}$ & Salzsäure \\
\hline Hepes & $\mathrm{N}$-(2-hydroxyethyl)-piperazin-N'-ethanosulfonsäure \\
\hline $\mathrm{H}_{2} \mathrm{O}_{2}$ & Wasserstoffperoxid \\
\hline HRP & Meerrettichperoxidase \\
\hline HSA & „human serum albumin“, Menschenserumalbumin \\
\hline $\mathrm{IP}_{3}$ & Inositol-1,4,5-Triphosphat \\
\hline $\mathrm{k}$ & Kilo \\
\hline $\mathrm{K}^{+}$ & Kalium \\
\hline $\mathrm{K}_{\mathrm{d}}$ & Dissoziations-Konstante \\
\hline KLH & „Keyhole limpet hemocyanin“ \\
\hline $\mathrm{KH}_{2} \mathrm{PO}_{4}$ & Kaliumdihydrogenphosphat \\
\hline 1 & Liter \\
\hline $\log$ & dekadischer Logarithmus \\
\hline M & Molekulargewicht (g/mol), Molar (mol/l) \\
\hline MALDI & „matrix-assisted laser-desorption ionization \\
\hline $\mathrm{m}$ & Meter, milli \\
\hline $\mathrm{m}^{2}$ & Quadratmeter \\
\hline MES & 2-(N-Morpholino-)ethansulfonsäure \\
\hline Min & Minute \\
\hline mRNA & „messenger“-RNA, Boten-Ribonukleinsäure \\
\hline$\mu$ & mikro \\
\hline $\mathrm{n}$ & nano $\left(1 * 10^{-9}\right)$, Anzahl der gemessenen Proben, Stoffmenge \\
\hline $\mathrm{N}$ & normal \\
\hline $\mathrm{Na}^{+}$ & Natrium \\
\hline $\mathrm{NaCl}$ & Natriumchlorid, Kochsalz \\
\hline $\mathrm{Na}_{2} \mathrm{CO}_{3}$ & Natriumcarbonat \\
\hline $\mathrm{Na}_{2}$ EDTA & Natrium-Ethylendiamintetraacetat \\
\hline $\mathrm{Na}_{2} \mathrm{HPO}_{4}$ & Natriumhydrogenphosphat \\
\hline $\mathrm{Na}_{2} \mathrm{~S}_{2} \mathrm{O}_{3}$ & Natriumthiosulfat \\
\hline NO & Stickstoffmonoxid \\
\hline $\mathrm{NaOH}$ & Natriumhydroxid, Natronlauge \\
\hline $\mathrm{Na}_{2} \mathrm{PO}_{4}$ & Natriumphosphat \\
\hline NHSC & N-(3-Dimethylaminopropyl)-N'-ethylcarbodiimidhydrochlor \\
\hline
\end{tabular}


$\left(\mathrm{NH}_{4}\right)_{2} \mathrm{SO}_{4} \quad$ Ammoniumsulfat

Ov Ovalbumin

$\mathrm{p} \quad$ pico

PA Phaseinsäure

PAGE Polyacryamid-Gelelektrophorese

PEG Polyethylenglykol

$\mathrm{pH} \quad$ negativ dekadischer Logarithmus der Wasserstoffionenkonzentration

PP Protein-Phosphatase

T Tween 20

TBST Tris gepufferte Kochsalzlösung mit Tween 20

TCA Trichloressigsäure

TEMED N,N, $\mathrm{N}^{\prime}, \mathrm{N}^{\prime}$-Tetramethylethylendiamin

Tween 20 Polyoxyethylensorbitanmonolaurat

PBS „phosphate-buffered-saline“, Phosphat gepufferte Kochsalzlösung

PBST PBS mit $0,1 \%$ Tween 20

RIA „radioimmunoassay“, radioaktiver Enzymtest

RT Raumtemperatur

RubisCO Ribulose-1,5-bisphosphat Carboxylase/Oxigenase

$\mathrm{scFv} \quad$ Einzelketten-Antikörperfragemt

Sec Sekunden

SD Standardabweichung

SDS „Sodium dodecyl sulfate“, Natriumdodecylsulfat

Tris Tris[Hydroxymethyl]aminoethan

UE Untereinheit

UV Ultraviolett

V Volt

$\%(\mathrm{v} / \mathrm{v}) \quad$ Volumenprozent

$\%(\mathrm{w} / \mathrm{v}) \quad$ Gewichtsprozent 


\section{Literaturverzeichnis}

Addicott F.T., Lyon J.L., Carns H.R., Smith O.E., Cornforth J.W., Milborrow B.V., Ryback G. und Wareing P.F. (1968) Abscisic acid: a new name for abscisin II (dormin). Science 159, 1493.

Alexandre J. und Lassalles J.P. (1991) Hydrostatic and osmotic pressure activated channel in plant vacuole. Biophys. J. 60, 1326-1336.

Allan A.C., Fricker M.D., Ward J.L., Beale M.H. und Trewavas A.J. (1994) Two transduction pathways mediate rapid effects of abscisic acid in Commelina guard cells. Plant Cell 6, 1319-1328.

Allen G.J., Muir S.R. und Sanders D. (1995) Release of $\mathrm{Ca}^{2+}$ from individual plant vacuolesby both $\mathrm{InsP}_{3}$ and cyclic ADP-ribose. Science 268, 735-737.

Anderson B.E., Ward J.M. und Schroeder J.I. (1994) Evidence for an extra-cellular reception site for abscisic acid in Commelina guard cells. Plant Physiol. 104, 1177-1183.

Artsaenko O., Peisker M., zur Nieden U., Fiedler U., Weiler E.W., Müntz K. und Conrad U. (1995) Expression of a single-chain Fv antibody against abscisic acid creates a wilty phenotype in transgenic tobacco. Plant J. 8, 745-750.

Bauly J.M., Sealy I.M., Macdonald H., Brearley J., Dröge S., Hillmer S., Robinson D.G.,Venis M.A., Blatt M.R., Lazarus C.M. und Napier R.M. (2000) Overexpression of auxin-binding protein enhances the sensitivity of guard cells to auxin. Plant Physiol. $124,1229-1238$.

Berridge M.J. (1993) Inositol triphosphate and calcium signalling. Nature 361, 315-325.

Blatt M.R., Thiel G. und Trentham D.R. (1990) Reversible inactivation of $\mathrm{K}^{+}$channels of Vicia stomatal guard cells following the photolysis of caged inositol 1,4,5trisphosphate. Nature 346, 766-769.

Blatt M.R. und Armstrong F. (1993) $\mathrm{K}^{+}$channels of stomatal guard cells: abscisic acidevoked control of the outward rectifier mediated by cytoplasmic pH. Planta 191, 330341.

Bradford M.M. (1976) Rapid and quantitative method for quantitation of microgram quantities of protein utilizing the principle of protein-dye binding. Anal. Biochem. 72, 248-252. 
Büssis D. (1995) Untersuchung zur Adaptation von Kartoffelpflanzen an milden Wasserstreß und zur Adaptation von transgenen Kartoffelpflanzen an die Expression einer heterologen Invertase im Apoplasten, der Vakuole und dem Cytosol. Cuvillier Verlag, Göttingen.

Büssis D., F. Kauder und D. Heineke (1998) Acclimation of potato plants to polyethylene glycol-induced water deficit. I. Photosynthesis and metabolism. J. Exp. Bot. 49, 13611370.

Chandler P.M. und M. Robertson (1994) Gene expression regulated by abscisic acid and its relation to stress tolerance. Annu. Rev. Plant Physiol. Plant Mol. Biol. 45, 113-141.

Davies W.J. und Zhang J. (1991) Root signals and the regulation of growth and development of plants in drying soil. Annu. Rev. Plant Physiol. Plant Mol. Biol. 42, 55-76.

Daeter W. und Hartung W. (1993) The permeability of the epidermal cell plasma membrane of barley leaves to abscisic acid. Planta 191, 41-47.

Gehring C.A., McConchie R.M., Venis M.A. und Parish R.W. (1997) Auxin-binding-protein antibodies and peptides influence stomatal opening and alter cytoplasmic pH. Planta 205, 581-586.

Gosti F., Beaudoin N., Serizet C., Webb A.A.R., Vartanian N. und Giraudat J. (1999) ABI1 protein phosphatase $2 \mathrm{C}$ is a negative regulator of abscisic acid signaling. Plant Cell 11, 1897-1909.

Hedrich R. und Neher E. (1987) Cytoplasmic calcium regulates voltage-dependent ion channels in plant vacuoles. Nature 329, 833-836.

Heilmann B., Hartung W. und Gimmler H. (1980) The distribution of abscisic acid between chloroplasts and cytoplasm of leaf cells and the permeability of the chloroplast envelope for abscisic acid. Z. Pflanzenphysiol. 97, 67-78.

Hetherington A.M. und Quatrano R.S. (1991) Mechanisms of action of abscisic acid at the cellular level. New Phytol. 119, 9-32.

Himmelbach C., Iten M. und Grill E. (1998) Signalling of abscisic acid to regulate plant growth. Phil. Trans. R. Soc. Lond. B. 353, 1439-1444.

Hocking J., Clapham J. und Catell K.J. (1978) Abscisic acid-binding to subcellular fractions from leaves of Vicia faba. Planta 138, 303-304.

Hornberg C. und Weiler E.W. (1984) High-affinity binding sites for abscisic acid on the plasmalemma of Vicia faba guard cells. Nature 310, 321-324.

Irving H.R., Gehring C.A. und Parish R.W. (1992) Changes in cytoplasmic pH and calcium of guard cells precede stomatal movements. Proc. Nat. Acad. Sci. USA 89, 1790-1794. 
Jarvis A.J. und Davies W.J. (1997) Whole-plant ABA flux and regulation of water loss in Cedrella odorata. Plant Cell Environ. 20, 521-527.

Kaiser W.M. und Hartung W. (1981) Uptake and release of abscisic acid by isolated photoautotrophic mesophyll cells, depending on pH gradients. Plant Physiol. 68, 202206.

Kauder F. (1998) Biochemische Reaktionen des pflanzlichen Stoffwechsels auf Abscisinsäure und Änderungen der atmosphärischen $\mathrm{CO}_{2}$-Konzentration. Cuvillier Verlag, Göttingen.

Kemeny D.M. (1994) Anwendung des Enzyme Linked Immunosorbent Assay im biologisch/medizinischen Labor. Gustav Fischer Verlag.

Komatsu S., Masuda T. und Hirano H. (1996) Rice gibberellin-binding phosphoprotein structurally related to ribulose-1,5-bisphosphate carboxylase/oxygenase activase. FEBS Letters 384, 167-171.

Laemmli U.K. (1979) Cleavage of structural proteins during the assembly of the head of bacteriophage T4. Nature 227, 680-685.

Lee Y., Choi Y.B., Suh S., Lee J., Assmann S.M., Joe C.O., Kelleher J.F. und Crain R.C. (1996) Abscisic acid-induced phosphoinositide turnover in guard cell protoplasts of Vicia faba. Plant Physiol. 110, 987-996.

Lehmann H. und Glund K. (1986) Abscisic acid metabolism - vacular/extravacular distribution of metabolites. Planta 168, 559-562.

Leung J. und Giraudat J. (1998) Abscisic acid signal transduction. Annu. Rev. Plant Physiol. Plant Mol. Biol. 49, 199-222.

Libbenga K.R. und Mennes A.M. (1995) Hormone binding and signal transduction. P.J.Davies, Plant Hormones, Kluwer Academic Publishers, 272-297.

Lichtenthaler H.K., Rohmer M. und Schwender J. (1997) two independent biochemical pathways for isopentenyl diphosphat and isoprenoid biosynthesis in higher plants. Physiol. Plant. 101, 643-652.

Lichtenthaler H.K. (1999) The 1-deoxy-D-xylulose-5-phosphate pathway of isoprenoid biosynthesis in plants Annu. Rev. Plant Physiol. Plant Mol. Biol. 50, 47-65.

MacRobbie E.A.C. (1998) Signal transduction and ion channels in guard cells. Phil. Trans. R. Soc. Lond. B. 353, 1475-1488.

McAinsh M.R., Brownlee C. und Hetherington A.M. (1990) Abscisic acid-induced elevation of guard cell cytosolic $\mathrm{Ca}^{2+}$ precedes stomatal closure. Nature 343 , 186-188. 
McAinsh M.R., Brownlee C. und Hetherington A.M. (1992) Visualizing changes in cytosolic free $\mathrm{Ca}^{2+}$ during the response of stomatal guard cells to abscisic acid. Plant Cell 4, 1113-1122.

Meskiene I., Bogre L., Glaser W., Balog J., Brandstötter M., Zwerger K., Ammerer G. und

Hirt H. (1998) MP2C, a plant protein phosphatase 2C, functions as a negative regulator of mitogen-activated protein kinase pathways in yeast and plants. Proc. Natn. Acad. Sci. USA 95, 1938-1943.

Morris G.E. (1996) Epitope mapping of protein antigens by competition ELISA. The Protein Protocols Handbook. Walker J.M. Humana Press Inc., Totowa, New Jersey, 595-600.

Muir S.R. und Sanders D. (1997) Inositol 1,4,5,-triphoshate-sensitive $\mathrm{Ca}^{2+}$ release across non vacuolar membranes in cauliflower. Plant Physiol. 14, 1511-1521.

Neill S.J., Desikan R., Clarke A. und Hancock J.T. (2002) Nitric Oxide Is a Novel Component of Abscisic acid Signaling in Stomatal Guard Cells. Plant Physiology 128, 13-16.

Pédron J., Brault M., Nake C. und Miginiac E. (1998) Detection of abscisic-acid-binding proteins in the microsomal protein fraction of Arabidopsis thaliana with abscisic-acidprotein conjugates used as affinity probes. Eur. J. Biochem. 252, 385-390.

Pédron J., Maldiney R., Brault M. und Miginiac E. (1996) Monitoring of hapten-protein coupling reactions by capillary zone electrophoresis: improvement of ABA-BSA coupling and determination of molar coupling ratios. J. Chromatogr. 723, 381-388.

Peterson G.L. (1977) A simplification of the protein assay method of LOWRY et al. which is more generally appicable. Anal. Biochem. 83, 346-356.

Pingoud A. und Urbanke C. (1997) Arbeitsmethoden der Biochemie. De Gruyter, Berlin. 152153.

Qin X. und Zeevaart J. (1999) The 9-cis-epoxycarotenoid cleavage reaction is the key regulatory step of abscisic acid biosynthesis in water-stressed bean. Proc. Nat. Acad. Sci., USA 96, 15354-15361.

Schmidt C., Schelle I., Liao Y.J. und Schroeder J.I. (1995) Strong regulation of slow anion channels and abscisic acid signaling in guard cells by phosphorylation and dephosphorylation events. Proc. Nat. Acad. Sci. USA 92, 9535-9539.

Schroder J.I. und Hagiwara S. (1990) Repetitive increases in cytosolic $\mathrm{Ca}^{2+}$ of guard cells by abscisic acid activation of non-selective $\mathrm{Ca}^{2+}$ permeable channels. Proc. Nat. Acad. Sci. USA 87, 9305-9309. 
Schwartz A., Wu W.H., Tucker E.B. und Assmann S.M. (1994) Inhibition of inward K channels and stomatal response by abscisic acid: An intercellular locus of phytohormone action. Proc. Natl. Acad. Sci. USA 91, 4019-4023.

Seo M., Koiwai H., Akaba S., Komano T., Oritani T., Kamiya Y. und Koshiba T. (2000) Abscisic aldehyd oxidase in leaves of Arabidopsis thaliana. Plant J. 23 (4), 481-488.

Seo M. und Koshiba T. (2002) Complex regulation of ABA biosynthesis in plants. Trends Plant Sci. 7, 41-48.

Shen W., Gómez-Cadenas A., Routly E.L., Ho T.-H.D., Simmonds J.A. und Gulick P.J. (2001) The salt stress-inducible protein kinase gene, Esi47, from the salt-tolerant wheatgrass Lophopyrum elongatum is involved in plant hormone signaling. Plant Physiol. 125, 1429-1441.

Skriver K.S. und Mundy J. (1990) Gene expression in response to abscisic acid and osmotic stress. Plant Cell 2, 503-512.

Slovik S. und Hartung W. (1992) Compartmental distribution and redistribution of abscisic acid in intact leaves III. Analysis of stress-signal chain. Planta 187, 37-47.

Strauß M. (1997) Physiologische und biochemische Charakterisierung von Kartoffelpflanzen mit Expression eines scFv-Antikörpers gegen Abscisinsäure. Diplomarbeit, GeorgAugust-Universität, Göttingen.

Strauß M., Kauder F., Peisker M., Sonnewald U., Conrad U. und Heineke D. (2001) Expression of an abscicic acid-binding single-chain antibody influences the subcellular distribution of abscisic acid and leads to developmental changes in transgenic potato plants. Planta 213, 361-369.

Taylor I.B., Burbidge A. und Thompson A.J. (2000) Control of abscisic acid synthesis. J. Exp. Bot. 51, 1563-1574.

Van Overbeek J., Loeffler J.E. und Mason M.I.R. (1967) Dormin (abscisin II), inhibitor of plant DNA synthesis. Science 156, 1497-1499.

Veliev S.N. (1991) Cytosolic high-affinity ABA-binding proteins from wheat shoots. Biokhimiya 56, 420-425.

Venis M.A. und Napier R.M. (1995) Auxin receptors and auxin binding proteins. Crit.Rev. Plant Sci. 14, 27-47.

Walton D., Dashek W. und Galson E. (1979) A radioimmunoassay for abscisic acid. Planta $146,139-145$.

Walton D.C. und Li Y. (1995) Abscisic acid biosynthesis and metabolism. P.J. Davies, Plant Hormones, Kluwer Academic Publishers, 140-157. 
Wan Y. und Hasenstein K.H. (1996) Purification and identification of ABA-binding proteins and antibody preparation. J. Mol. Recognit. 9, 722-727.

Ward J.M. und Schroeder J.I. (1994) Calcium-activated $\mathrm{K}^{+}$channels and calcium-induced release by slow vacuolar ion channels in guard cell vacuoles implicated in the control of stomatal closure. Plant Cell 6, 669-683.

Webb A.A.R., Larman M.G., Montgomery L.T., Taylor J.E. und Hetherington A.M. (2001) The role of calcium in ABA-induced gene expression and stomatal movements. Plant J. 26, 351-362.

Weiler E.W. (1979) Radioimmunoassay for the determination of free and conjugated abscisic acid. Planta 144, 255-263.

Weiler E.W. (1980) Plant hormone immunoassays based on monoclonal and polyclonal antibodies. Immunology in Plant Sciences, Linskens H.F. und Jackson J.F., Springer Verlag. 1-5.

Winkelmüller W. (2001) Untersuchungen zur Existenz Abscisinsäure-bindender Proteine in Gersteprotoplasten. Diplomarbeit, Georg-August-Universität, Göttingen.

Wu Y., Kuzma J., Maréchal E., Graeff R., Lee H.C., Forster R. und Chua N.-H. (1997) Abscisic acid signaling through cyclic ADP-ribose in plants. Science 278, 2126-2130.

Xiong L., Lee B.-H., Ishitani M., Lee H., Zhang G. und Zhu J.-K. (2001) FIERY1 Encoding an inositol polyphosphate-1-phosphatase is a negative regulator of abscisic acid and stress signaling in Arabidopsis. Genes Develo. 15, 1971-1984.

Zeevaart J.A.D. und Creelman R.A. (1988) Metabolism and physiology of abscisic acid. Annu. Rev. Plant Physiol. Plant Mol. Biol. 39, 439-473.

Zeevaart J.A.D. (1999) Abscisic acid metabolism and its regulation. Biochemistry and Molecular Biology of Plant Hormones, Hooykaas P.J.J. et al. Elsevier 189-207.

Zhang D.P., Zhang Z., Chen J. und Jia W. (1999) Specific abscisic acid-binding sites in mesocarp of grape berry: properties and subcellular localization. J. Plant Physiol. 155, 324-331.

Zhang D.P., Chen S.-W., Peng Y.-B. und Shen Y.-Y. (2001) Abscisic acid-specific binding sites in the flesh of developing apple fruit. J. Exp. Bot. 52, 2097-2103.

Zhang D.P., Wu Z.-Y., Li X.-Y. und Zhao Z.-X. (2002) Purification and identifikation of a 42-kilodalton abscisic acid-specific-binding protein from epidermis of broad bean leaves. Plant Physiol. 128, 714-725. 


\section{Danksagung:}

Priv.-Doz. Dr. Dieter Heineke danke ich für die Überlassung dieses vielversprechenden und interessanten Themas und die sehr guten Arbeitsbedingungen. Für sein großes Interesse und seine immer freundliche Diskussionsbereitschaft sowie für die Durchsicht des Manuskripts.

Herrn Prof. Dr. Hans-Walter Heldt danke ich für die Möglichkeit diese Arbeit an seinem Institut durchzuführen, die gewährte Unterstützung und sein Interesse am Fortschritt dieser Arbeit.

Für die wissenschaftlichen Anregungen, Hilfestellungen und ständige Diskussionsbereitschaft danke ich besonders Herrn Priv.-Doz. Dr. Giselbert Hinz sowie Frau Dr. Sigrun Reumann.

Herrn Dr. Bernhard Schmidt danke ich für die Messung der Protein-Konjugate durch MALDI-Analyse.

Ein riesengroßer Dank geht an Andrea Nickel für die immer freundliche Stimmung im Labor, für ihre stete Hilfe bei der Durchführung der Experimente und ihre Rücksichtnahme bei der Anfertigung der schriftlichen Fassung der Arbeit. Weiterhin bedanke ich mich bei Wulf Winkelmüller für die Unterstützung bei der Durchführung zahlreicher Experimente. Ganz herzlich danke ich Monika Raabe für ihre Hilfe und die angenehme Atmosphäre im Labor.

Bei Frau Dr. Sigrun Reumann und Jens Tilsner bedanke ich mich ganz herzlich für die Durchsicht und konstruktive Kritik des Manuskripts.

Gerd Mader danke ich für die wichtige Instandhaltung unserer Geräte sowie für die Hilfe bei allerlei Problemen mit dem Computer.

Herrn Wedemeyer für die sehr gute Betreuung und Versorgung meiner Pflanzen.

Frau Sibylle Hourticolon danke ich für die Fotografien meiner zahlreichen SDS-Gele.

Bei allen Mitarbeiterinnen und Mitarbeitern des Instituts möchte ich mich für die tolle Atmosphäre und ihr Interesse an meinen Experimenten bedanken.

Weiterhin bedanke ich mich bei meinen Eltern für die in jeder Hinsicht gewährte Unterstützung während meines Studiums.

Zum Schluß möchte ich mich bei Frank für seine Hilfe und das Korrekturlesen des Manuskripts bedanken sowie bei allen Freundinnen und Freunden, die mich während dieser Zeit begleitet haben. 


\section{Lebenslauf}

27.06.1971

Geboren in Stadtoldendorf

$1977-1982$

Besuch der Grundschule in Sievershausen

$1982-1984$

Orientierungsstufe Dassel

$1984-1987$

Hauptschule Dassel

$1987-1998$

Besuch der Berufsbildenden Schulen in Einbeck,

Abschluß: Erweiterter Sekundarabschluß I

$1998-1992$

Besuch des Fachgymnasiums Ernährung und Hauswirtschaft an der Berufsbildenden Schule in Einbeck, Abschluß: Abitur

Oktober 1992

Beginn des Studiums der Biologie an der Georg-August-Universität in Göttingen

Oktober 1996

Mündliche Diplomprüfung in den Fächern Biochemie, Botanik und Chemie

November 1996 Anfertigung der Diplomarbeit am Albrecht-von-Haller-Institut für Pflanzenwissenschaften in der Abteilung Biochemie der Pflanze von Prof. Dr. Heldt

Dezember 1997 Abgabe der Diplomarbeit mit dem Titel: „Physiologische und biochemische Charakterisierung von Kartoffelpflanzen mit Expression eines scFv-Antikörpers gegen Abscisinsäure““

Januar 1998

Durchführung der experimentellen Arbeiten zur vorliegenden

- Januar 2002

Dissertation am Albrecht-von-Haller-Institut für

Pflanzenwissenschaften in der Abteilung Biochemie der Pflanze von

Prof. Dr. Heldt 